University of Nebraska - Lincoln DigitalCommons@University of Nebraska - Lincoln

Sociology Theses, Dissertations, \& Student

Research

Sociology, Department of

$5-2018$

\title{
Disentangling the Roles of Modernization and Secularization on Fertility: the Case of Turkey
}

Dogan Hatun

University of Nebraska-Lincoln, doganhatun@gmail.com

Follow this and additional works at: https://digitalcommons.unl.edu/sociologydiss

Part of the Demography, Population, and Ecology Commons

Hatun, Dogan, "Disentangling the Roles of Modernization and Secularization on Fertility: the Case of Turkey" (2018). Sociology Theses, Dissertations, \& Student Research. 49.

https://digitalcommons.unl.edu/sociologydiss/49

This Article is brought to you for free and open access by the Sociology, Department of at DigitalCommons@University of Nebraska - Lincoln. It has been accepted for inclusion in Sociology Theses, Dissertations, \& Student Research by an authorized administrator of DigitalCommons@University of Nebraska - Lincoln. 


\title{
DISENTANGLING THE ROLES OF MODERNIZATION AND SECULARIZATION ON FERTILITY: THE CASE OF TURKEY
}

\author{
by \\ Dogan Hatun

\begin{abstract}
A DISSERTATION
Presented to the Faculty of

The Graduate College at the University of Nebraska

In Partial Fulfillment of Requirements

For the Degree of Doctor of Philosophy
\end{abstract}

Major: Sociology

Under the Supervision of Professors David F. Warner and Philip Schwadel

Lincoln, Nebraska

May, 2018 


\section{DISENTANGLING THE ROLES OF MODERNIZATION AND SECULARIZATION ON FERTILITY: THE CASE OF TURKEY \\ Dogan Hatun, Ph.D. \\ University of Nebraska, 2018}

Advisors: David F. Warner and Philip Schwadel

Second Demographic Transition (SDT) theory argues very low fertility results from the simultaneous processes of modernization and secularization. However, this theory has primarily only been examined in the Christian countries of Northern and Western Europe. The assumption that modernization and secularization are co-occurring processes may not apply in other non-European, non-Christian contexts. Notably absent are studies of Muslim-majority nations, where modernization has occurred separate from secularization because the primary interpretation of Islam views the pursuit of secular knowledge is as important as the pursuit of religious knowledge. Therefore, there is a critical need to examine the applicability of the SDT theory to fertility in a Muslimmajority country. Using data from the 2008 and 2013 Demographic and Health Surveys of Turkey, and a series of regression models, I examine the independent and joint effects of modernization and secularization on married women's parity, contraceptive use, and induced abortion receipt. Overall, I find mixed evidence concerning the effects of modernization and secularization on married women's fertility behaviors. Modernization and secularization are independently associated with married women's parity and abortion receipt. However, there modernization and secularization are jointly associated with married women's contraceptive use and methods. I conclude that the specification of the SDT theory, that modernization co-occurs with secularization to allow more contraceptive use and more abortion, does not follow—and therefore does not—explain low fertility in the Muslim-majority country of Turkey. 


\section{DEDICATION}

I dedicate this work to my loving wife, Hicret Hatun, who offered unconditional love and support. Thank you so much. 


\section{ACKNOWLEDGEMENTS}

I am so grateful for everyone that helped me write this dissertation. I begin by thanking my wife Hicret Hatun, who throughout my journey at the University of Nebraska-Lincoln has been my greatest supporter. She was always supportive of my endeavors, and no matter what happened in my life she was always by my side to help me. I am very thankful for your support.

My time at the University of Nebraska-Lincoln was one of tremendous intellectual growth and I have many people to thank for this. David F. Warner, Philip Schwadel, and Julia McQuillan helped me through conceptualizing and writing this dissertation. Thank you all for your thoughtful, and challenging, comments. I also thank Simon Wood, who served as my outside committee member. This dissertation is better thanks to you all. Without the support and challenge of my advisor David F. Warner, this dissertation would have remained as scattered thoughts. Also without the support and challenge of my co-advisor Philip Schwadel, this dissertation might have been missing some perspectives. You two kept me focused and motivated to discuss my thoughts in this dissertation. I am so grateful for my advisors' time and support, especially for their thoughtful and timely feedbacks. I cannot thank you two enough.

Lastly, I would also like to thank everyone that I came to know during my time in the United States. Their help and support influenced my life more than they will ever know. I am forever grateful to know you all. 


\section{TABLE OF CONTENTS}

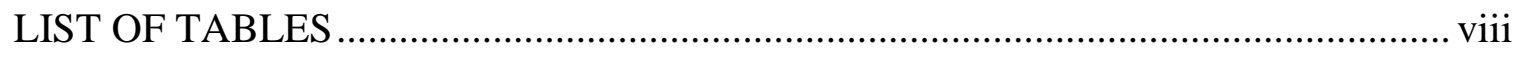

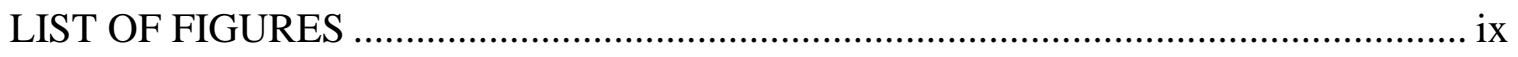

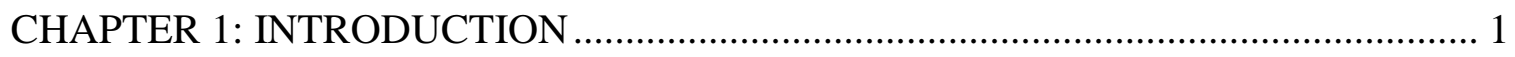

1.1 The Applicability of SDT Outside of Western Europe............................................... 1

1.2 Overview of the Dissertation Project.................................................................. 5

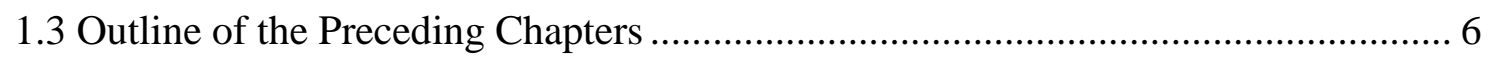

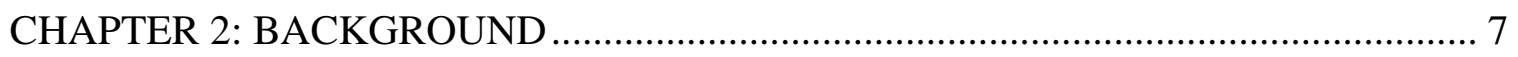

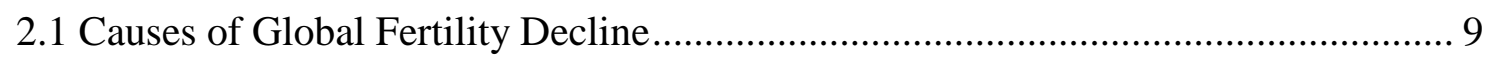

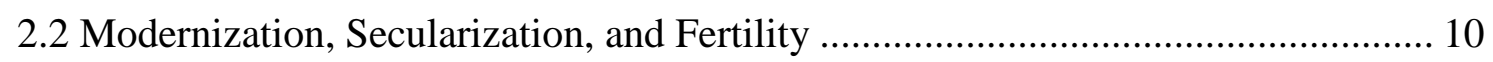

2.2.1 Modernization and Secularization ......................................................... 12

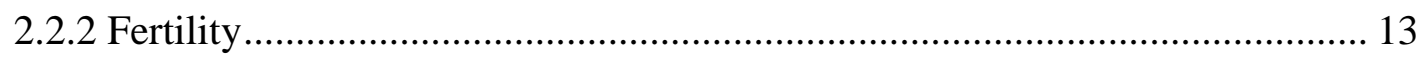

2.3 Modernization and the Movement toward Low Fertility ....................................... 14

2.3.1 Demographic Transition Theory ............................................................... 14

2.3.2 Second Demographic Transition Theory ………………………………...... 15

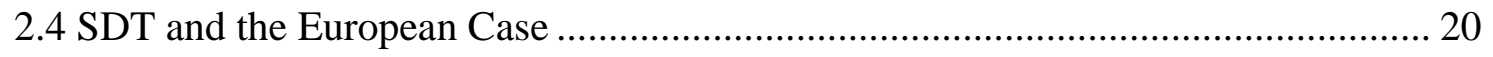

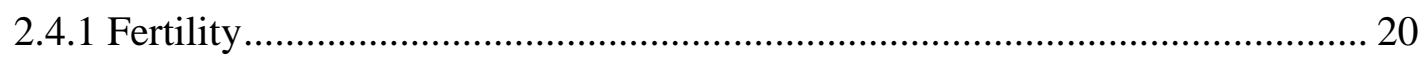

2.4.2 The Link between Modernization and Secularization .................................... 22

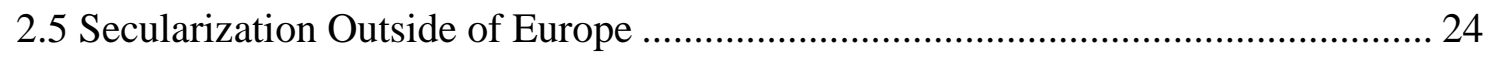

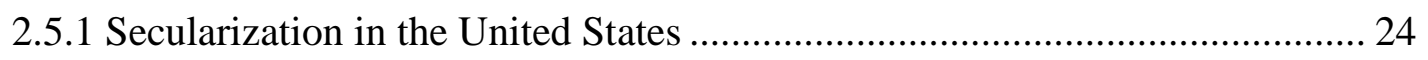

2.5.2 Secularization in Latin America …………................................................ 26

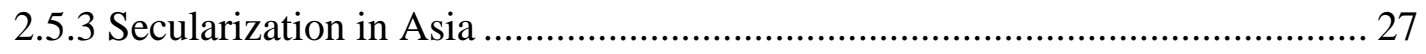

2.5.4 Secularization in Muslim-majority Nations................................................ 29

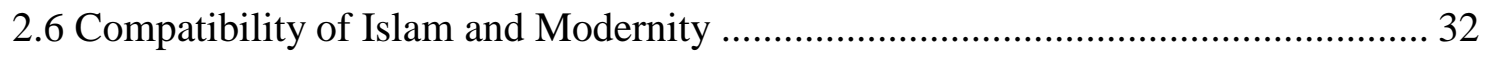

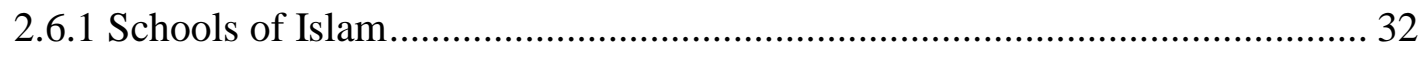

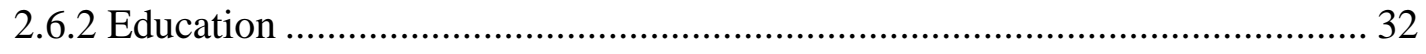

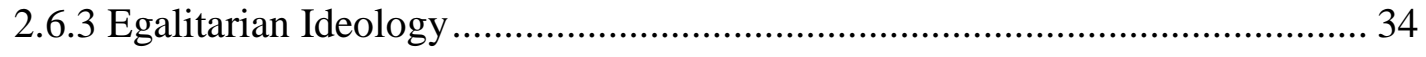

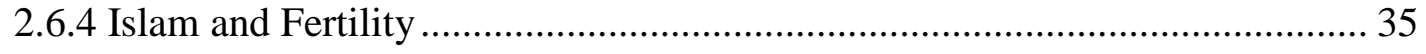

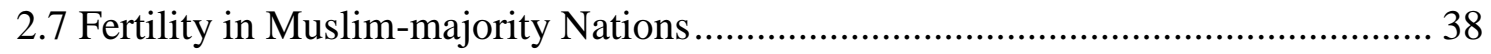

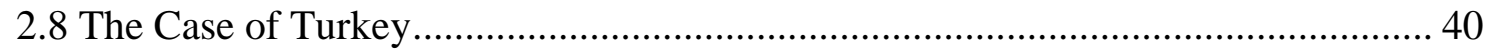

2.8.1 The Republic of Turkey .............................................................................. 41 


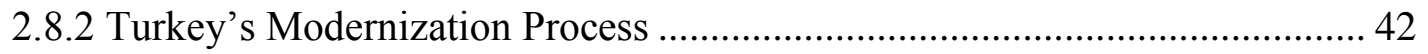

2.8.3 Demographic Statistics on Fertility Decline in Turkey .................................. 43

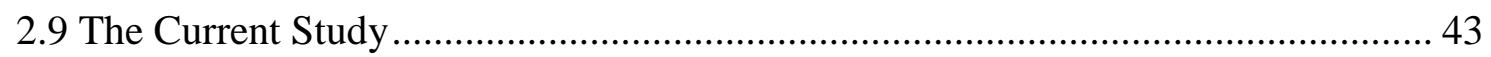

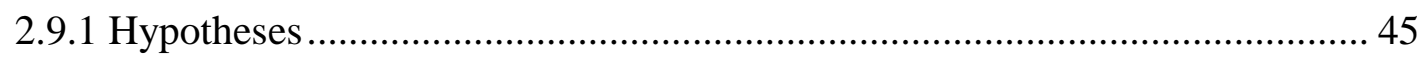

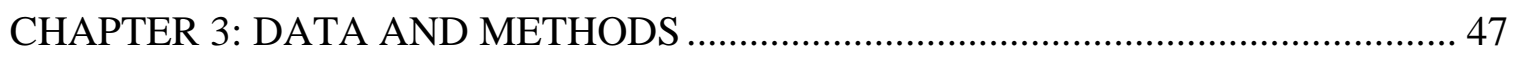

3.1 Turkey Demographic and Health Surveys (TDHS) ............................................... 47

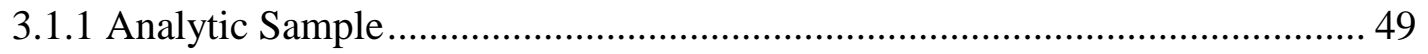

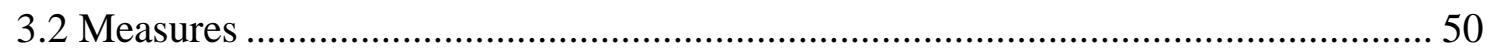

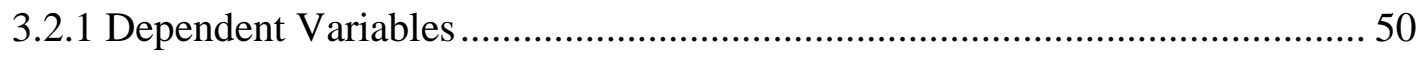

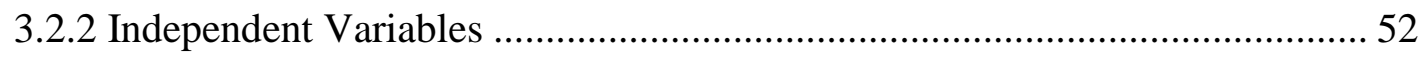

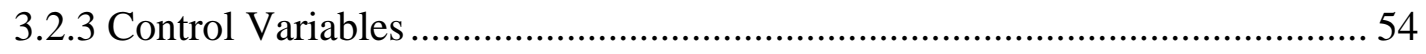

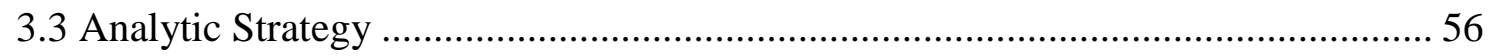

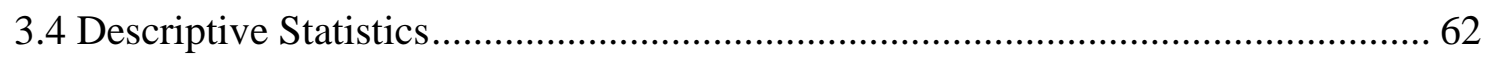

CHAPTER 4: ANALYSES OF NUMBER OF CHILDREN ............................................ 64

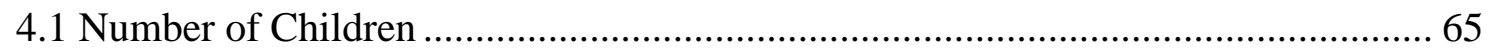

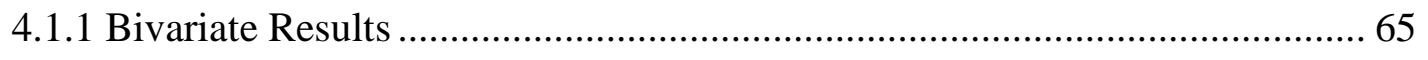

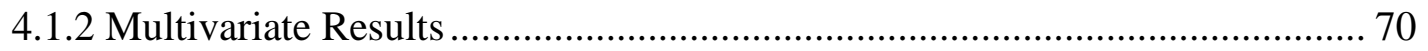

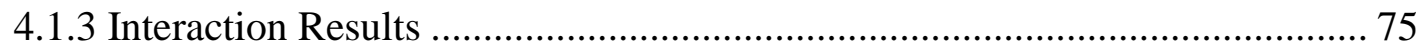

4.1.4 Supplemental Analyses of Binary Fertility Measure ……............................... 78

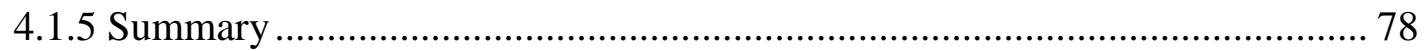

CHAPTER 5: ANALYSES OF CONTRACEPTIVE USE AND TYPE ......................... 81

5.1 Any Contraceptive Use ..................................................................................... 82

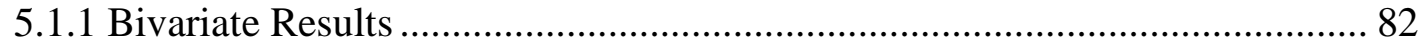

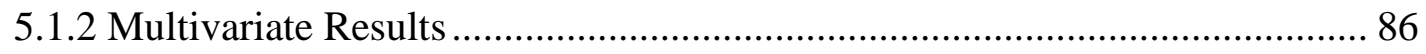

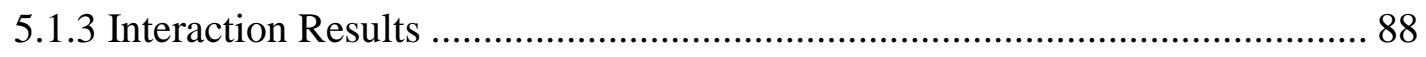

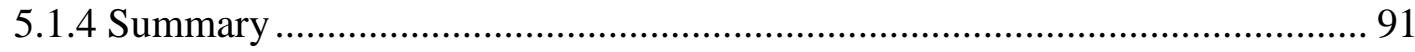

5.2 Types of Contraceptive Methods ......................................................................... 93

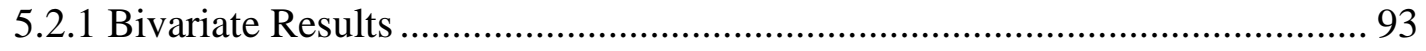

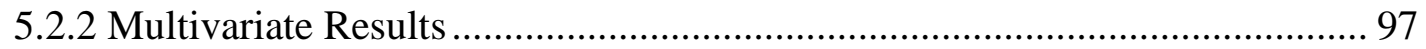

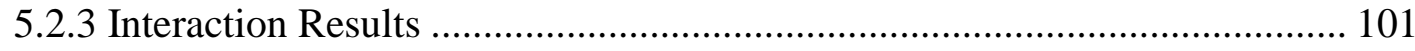

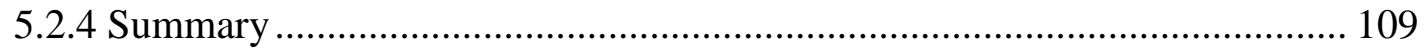

CHAPTER 6: ANALYSES OF ANY ABORTION USE AND FREQUENCY ............. 111

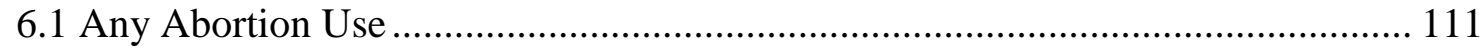

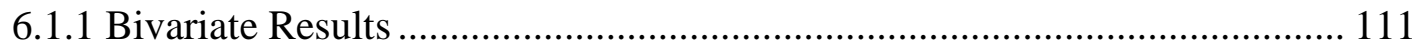




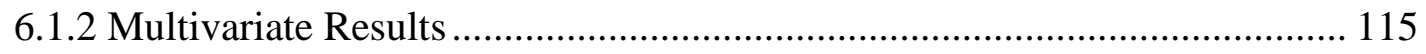

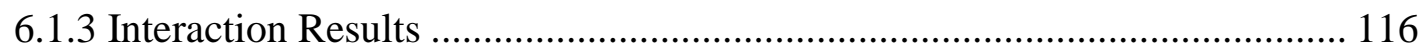

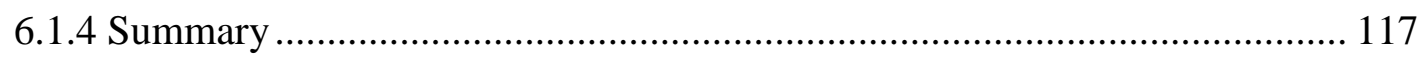

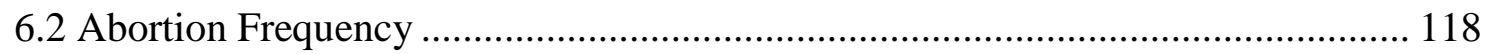

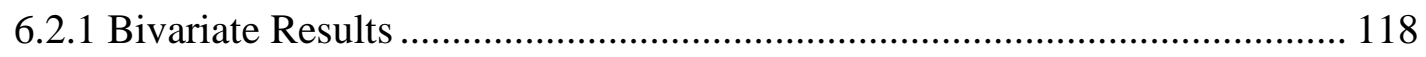

6.2.2 Multivariate Results ............................................................................ 119

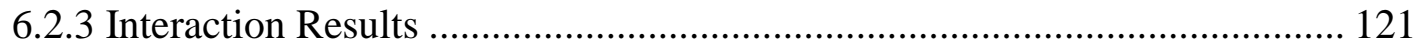

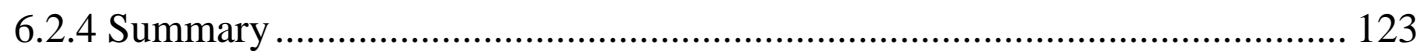

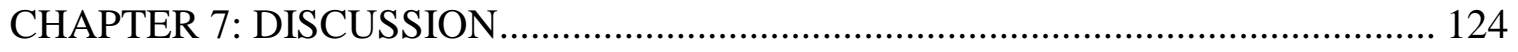

7.1 The Effects of Modernization and Secularization on Married Women's Parity ... 124

7.2 The Effects of Modernization and Secularization on Contraception Use.............. 125

7.2.1 Any Contraception Use...................................................................... 125

7.2.2 Types of Contraceptive Methods .............................................................. 127

7.3 The Effects of Modernization and Secularization on Abortion Use...................... 128

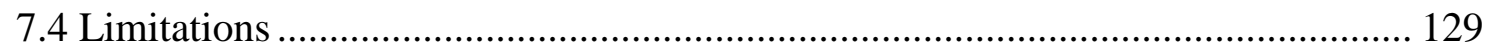

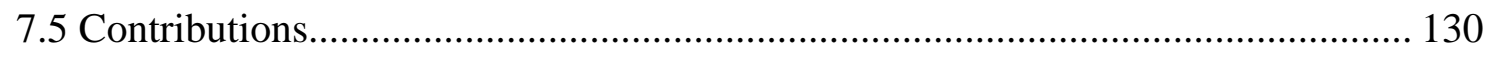

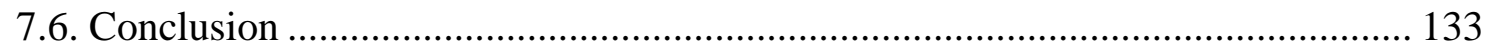

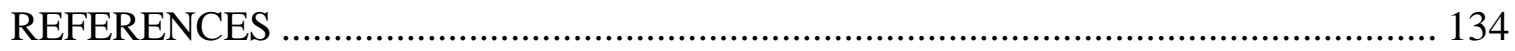

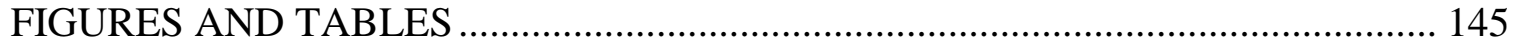

APPENDIX A: Supplemental Analyses Using the European Values Surveys .............. 207

APPENDIX B: Correlation Matrix for All Study Variables ............................................ 209 


\section{LIST OF TABLES}

Table 2.1. Hypotheses Table Comparing the Expected Association Derived from SDT

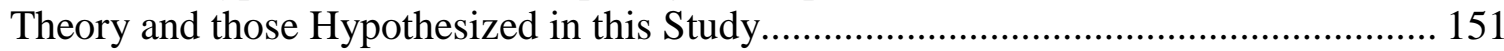

Table 3.1. Descriptive Statistics of Analytic Sample .............................................. 153

Table 3.2. Descriptive Statistics and Mean Differences Between 2008 and 2013 ........ 155

Table 4.1. Bivariate Poisson Regression Analyses between Number of Children and All

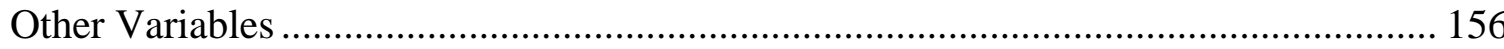

Table 4.2. Poisson Regression Results for Effect of Secularization and Modernization on Number of Children

Table 4.3. Poisson Regression Results for the Interactions between Secularization and Modernization on Number of Children................................................................. 161

Table 5.1. Bivariate Logistic Regression Analyses between Contraceptive Use and All Other Variables 165

Table 5.2. Logistic Regression Results for the Effect of Secularization and Modernization on the Contraceptive Use 166

Table 5.3. Logistic Regression Results for the Interactions between Secularization and Modernization on the Contraceptive Use 170

Table 5.4. Bivariate Logistic Regression Analyses between Contraceptive Method Types and All Other Variables

Table 5.5. Multinomial Logistic Regression Results for the Effect of Secularization and Modernization on Currently Used Contraceptive Methods 174

Table 5.6. Multinomial Logistic Regression Results for the Interactions between Secularization and Modernization on Currently Used Contraceptive Methods 181

Table 6.1. Bivariate Logistic Regression Analyses between Abortion Use and all Other Variables 195

Table 6.2. Logistic Regression Results for the Effect of Secularization and Modernization on Abortion Use

Table 6.3. Logistic Regression Results for the Interactions between Secularization and Modernization on Abortion Use

Table 6.4. Negative Binominal Regression Results for the Effect of Secularization and Modernization on Abortion Frequency 201

Table 6.5. Negative Binominal Regression Results for the Interactions between Secularization and Modernization on Abortion Frequency ...................................... 203

Table A.1. Poisson Regression Analysis for Number of Children, IRR ....................... 207

Table B.1.Correlation Matrix for All Study Variables 209 


\section{LIST OF FIGURES}

Figure 2.1. The Stages of Demographic Transition. 145

Figure 2.2. Percentage of Europeans Expressing a Belief in God, by Country. Results from the 2008 European Value Survey..... 146

Figure 2.3. Percentage of Europeans Indicating that Relgion is Important in their Lives, by Country. Results from the 2008. European Value Survey. 147

Figure 2.4. Percentage of Europeans AttendinG Religious Services at Least Once per Week, by Country. Results from the 2008 European Value Survey .............................. 148

Figure 2.5. Modernization and Secularization as Joint Processes according to SDT theory (Panel A) and as Separate Processes as Hypothesized Here (Panel B) .......................... 149

Figure 2.6. Observed and Projected Total Fertility Rate for Turkey .............................. 150

Figure 3.1. Distribution of the Number of Children Ever Born..................................... 152

Figure 4.1. The Effect of The Interaction Term between Religiosity and Urban on the Number of Children Born to A Married Woman.

Figure 4.2. The Effect of the Interaction Term between Respondent's Education and Urban on the Number of Children Born to A Married Woman. 160

Figure 4.3. The Effect of the Interaction Term between Egalitarian Ideology and Urban on the Number of Children Born to A Married Woman...

Figure 5.1. The Effect of the Interaction Term between Religiosity and Women's

Education on Contraceptive Use. 167

Figure 5.2. The Effect of the Interaction Term between Women's Education and Urban on Contraceptive Use. 168

Figure 5.3. The Effect of the Three-Way Interaction Term between Religiosity, Women's Education, and Urban on Contraceptive Use. 169

Figure 5.4. The Effect of the Interaction Term between Religiosity and Women's Education on Traditional Contraceptive Method. 177

Figure 5.5. The Effect of the Interaction Term between Religiosity and Women's Education on Modern Reversible Contraceptive Method. 178

Figure 5.6. The Effect of the Interaction Term between Religiosity and Women's Education on Permanent Contraceptive Method 179

Figure 5.7. The Effect of the Interaction Term between Religiosity and Egalitarian Ideology on Permanent Contraceptive Method

Figure 5.8. The Effect of the Interaction Term between Women's Education and Urban on Traditional Contraceptive Method. 188

Figure 5.9. The Effect of the Interaction Term between Women's Education and Urban on Modern Reversible Contraceptive Method 189 
Figure 5.10. The Effect of the Interaction Term between Women's Education and Urban on Permanent Contraceptive Method........................................................................ 190

Figure 5.11. The Effect of the Three-Way Interaction Term between Religiosity, Women's Education, and Urban on Traditional Contraceptive Method 191

Figure 6.1.The Effect of the Interaction Term between Woman's Education and Urban on Any Abortion Use. 192

Figure 6.2. The Effect of the Interaction Term between Religiosity and Egalitarian Ideology on Abortion Frequency

Figure 6.3. The Effect of the Interaction Term between Woman's Education and Urban on Abortion Frequency 194

Figure A.1. The Effect of The Interaction Term between woman's education and Religiosity on the Number of Children Born to An Ever Married Woman. 


\section{CHAPTER 1: INTRODUCTION}

For almost a century, scholars have been examining fertility in countries around the world. Understanding fertility has been the focus of some of the largest social science data collection efforts (e.g., the World Fertility Surveys, Demographic and Health Surveys [DHS]). The motivation for these surveys was initially to identify the correlates of excess fertility in developing countries. In the last few decades, however, following declines in fertility in the countries outside of sub-Saharan Africa, such studies have been increasingly focused on understanding low fertility and its consequences (Morgan and Hagewen 2005).

The most staggering examples of fertility decline are found in (Western) Europe. The simultaneous increase in modernization and secularization have been identified as having had a substantial role in the shift in Western European fertility behavior (Bruce 2011; Chaves 1994; Lesthaeghe 2010; Lesthaeghe and Wilson 1986; Martin 1978). Indeed, the Second Demographic Transition (SDT) theory was proposed to explain why fertility continues to decline in these nations and one chief component of this theory is that secularization (reinforced by modernization) leads to sustained very low fertility by disconnecting marriage and procreation (Lesthaeghe 2010).

\subsection{The Applicability of SDT Outside of Western Europe}

Although the experiences of Western Europe initially led to SDT being thought of as a global theory of fertility decline, there are several reasons to question its applicability outside of Western Europe. First, scholars have questioned whether secularization is inevitable and unfolds exactly as it did in Western Europe by pointing out different patterns in other regions (Berger 1999; Davie 2002; Rodney Stark and Iannaccone 1994). 
Second, although very low fertility has generally been accepted as the future of all populations, there is evidence that modernization does not necessarily lead to fertility decline or very low fertility (e.g. Sub-Sharan and Muslim countries) (Heaton 2011). Overall, studies examining the relationship between secularization argument of Second Demographic Transitions (SDT) theory and fertility have been conducted mostly in Christian-majority nations, where modernization and secularization have occurred relatively simultaneously. Such studies have largely neglected developing Muslimmajority nations, where modernization does not necessarily require secularization. Consequently, this study examined the applicability of the secularization component of SDT to fertility in a Muslim-majority nation, Turkey.

Continued trends show fertility has declined to very low levels within European, North American, and developed Asian nations. These trends have concerned national governments because of the wide-ranging consequences of fertility. At the population level, low fertility (below replacement level [2.1 children]) leads to unbalanced age structure for populations in the near future and will result in smaller cohorts of younger people supporting larger cohorts of older people. The root causes of low fertility, as Durkheim specified, can be seen in the changes of cultural, social, and moral elements within societies (such as individualization and secularization) characterized by the modernization process (Durkheim, Sutcliffe, and Simons 1992; Lamanna 2002). It has been argued for decades — and is the central tenant of SDT — that human development (modernization) has loosened the power of religion (secularization) and both modernization and secularization negatively affected fertility rates (Kane 2013; Kirk 
1996; Lesthaeghe 2010; Ron Lesthaeghe and Neels 2002; Norris and Inglehart 2004; Surkyn and Lesthaeghe 2004).

A large body of work has shown that both modernization and secularization have negatively affected fertility rates (Kane 2013; Kirk 1996; Lesthaeghe 2010; R Lesthaeghe and Neels 2002; Norris and Inglehart 2004; Surkyn and Lesthaeghe 2004). These studies of fertility decline have primarily drawn on the Classic (or First) and Second Demographic Transition theories (DT and SDT, respectively) for almost a century (Lesthaeghe 1983; Thompson 1929). The demographic transition refers to fertility and mortality declines occurring in Western countries (Lesthaeghe 2010). During the first DT, fertility decline was caused by greater survival rates of children in the event of increased agricultural production, decreased value of children's labor, due to technologically supported economic development, and increased parental investment in children, including education (Aries 1980). The motivation of the decline in fertility during the SDT included several ideational changes: self-actualization, individualization, and secularization (Lesthaeghe 2010). Because of those rapid changes in Western Europe, the trend of low fertility and the secularization of Europe was viewed as the future of human development globally (Durkheim 1902; Inglehart 1997; Weber 1973; Whimster and Lash 2014).

On the other hand, many scholars have argued that European secularization and the accompanying low fertility have not been an inevitable result of modernization everywhere (Berger, Davie, and Fokas 2008; Davie 2002; Finke and Stark 1998). Modernization has demonstrated evidence of the anticipated secularizing primarily in Europe and other English-speaking countries (Bickel 2017; Davie 2002). Many scholars 
argue that the secularization of Europe, specifically secularization because of modernization, has occurred in Western-Christian Nations, and cannot be generalized to all social contexts because of different historical backgrounds and cultural values (Berger 1999; Casanova 2011; Davie 2002). Similar to the secularization of Europe, in the 1990s scholars criticized the SDT theory as “an archetypical Western European feature," not even expected to spread to the United States or other parts of Europe, let alone Asia (Lesthaeghe 2010). Furthermore, studies support the counterargument that the United States and many other developed and developing nations, show different characteristics in regard to secularization and fertility (Finke and Stark 1998; Frejka and Westoff 2008; Sasaki and Suzuki 1987).

Both the SDT and secularization theories have been tested primarily in Christianmajority nations. Because of the evidence observed both historically and currently in parts of Europe, secularization has largely been viewed as an unescapable result of modernization (Inglehart 1997; Kaa 2002; Lesthaeghe 2010). This generally accepted phenomenon might not be applicable to Muslim-majority nations for two reasons. First, many scholars argue that Islam values scientific knowledge as much as religious knowledge; thus, Islam does not sacrifice religiosity for modernization (Ibn-Khaldūn 1969; Okumuş 2005; Sonn 2005). Second, because of the influences of historical colonization, many Muslim nations condemn secularity and view it, as well as modernity, as a device that destroys important Islamic values (Hoebink 1999). Therefore, examining Muslim nations might provide evidence that fertility change does not require the cooccurrence of secularization and modernization. 
Specifically, Turkey is an interesting Muslim-majority case for two reasons. First, it has not been colonized for more than 700 years, including the Ottoman era, meaning that the potential rejection of modernization due to its correspondence with colonialism does not apply. Second, Turkey has a secular state, where Westernized reforms were adopted, and the components of those reforms aiming to change traditional values were expelled. This historical preservation has allowed the Turkish people to retain most of their cultural and religious values. Thus, for Turkey modernization has not required secularization. Thus, in terms of testing the applicability of secularization component of the SDT theory to fertility in a Muslim-majority nation, Turkey is an ideal case study that advance the literatures.

\subsection{Overview of the Dissertation Project}

My overall goal in this project was to examine if the effects of different cultural and geographical social contexts create different levels of modernization, secularization, and thus fertility behaviors. Specifically, I sought to examine how Turkish context is influenced by both European and Eastern social contexts and how these other contexts affect demographic changes in the country. To do this, this dissertation investigated three indicators of fertility decline — specifically the number of children and the two proximate determinants of fertility, contraception and abortion (Bongaarts 1978) - by separating the primary components of modernization (education, egalitarianism, urbanization) and secularization. As I briefly reviewed above, and will elaborate on in the next chapter, modernization and secularization are jointly and negatively associated with fertility behaviors in modern Christian countries (Kane 2013; Lesthaeghe 2010), but I argue that this is not necessarily happening in Muslim nations in general, and specifically it is not 
happening in Turkey. My central hypothesis is that the interaction between modernization and religiosity will not be significantly associated with indicators of fertility behaviors. For instance, the effect of woman's religiosity on parity would not depend on her level of modernization including woman's education, egalitarianism, and urban residency. In order to test this hypothesis, I used data from the 2008 and 2013 Demographic and Health Surveys of Turkey (TDHS).

\subsection{Outline of the Proceeding Chapters}

This dissertation examines whether modernization and secularization are jointly or separately associated with the fertility behavior of married women in Turkey. In Chapter 2, I discuss the theoretical and empirical issues related with the secularization component of SDT theory on fertility, its implementation being largely limited to developed Christian nations, and why it is important to test its applicability in a different social context. Chapter 3 outlines the TDHS data and the methods used to whether secularization and modernization are jointly associated with fertility in Turkey. Modernization is specified as women's education, egalitarianism, and urban residency. Secularization is specified (inversely) by adherence to religious practices. Chapters 4, 5, and 6 present the results of analyses between modernization, secularization, and their interaction for three fertility behaviors - parity, contraception use, and abortion use, respectively. Finally, Chapter 7 discusses the implications of the findings from the three analytic chapters with an emphasis on the improvements to the literature, providing suggestions for government policies about low fertility in Turkey, and future research directions. 


\section{CHAPTER 2: BACKGROUND}

Low and declining fertility is a significant issue for nearly all developed and even many developing nations (United Nations 2011). Understanding demographic characteristics and trends remain critical for economic and population growth, yet they are the most difficult to forecast (Bongaarts and Bulatao 2000). Governments must make plans for schools, roads, and revenue, for future health care needs and pensions.

Businesses also need to forecast potential demands for goods and services (Hirschman and Tolnay 2005). Thus, low fertility — especially below replacement level— is a concern for most national governments because fertility rates are of vital importance for their socioeconomic development.

Low fertility is a source of social and economic problems of modern countries (Morgan and Hagewen 2005). The negative effects of low fertility are largely due to the resulting changes in age structure of the population. Low fertility causes slow population growth rates for developed countries and is the main cause of population aging (an increasing average age of the population). Several studies indicate that the recent financial crises in Japan, the Asian "Tigers" (i.e., Singapore, Taiwan, South Korea, and Hong Kong), and the United States were due to the shrinking young adult people (ages 15 to 24) in these populations (Macunovich 2007). Young adults use significant educational investments; thus, failure to predict the shrinkage of this group may result in inefficient resources use and ultimately costs for governments.

Population aging has implications for age-graded institutions, such as the labor force, social security programs, and even marriage. A decline in the proportion of working age adults relative to older adults increases the old-age dependency ratio, which means that the growing costs of public pensions and health care must be supported by a 
smaller tax base (Doepke 2004). The gradually shrinking working-age population also negatively influences the economic performance of countries in the global market. Low fertility may even have a critical effect on marriage in some countries because traditional son preferences lead to imbalanced sex ratios, which in turn limits the availability of potential marital partners (Choe, Kim, and Lee 1993). Therefore, many developed countries are investigating the reasons for low fertility and trying to increase their fertility through social policies (Chesnais 1996).

In the long term, if fertility continues to decline, as projected in some countries, population growth becomes negative and population decline starts. When the total fertility rates declines below the replacement rate of 2.1 , the population will begin to experience natural decrease. Even a small drop below replacement rate can be consequential. For example, a total fertility rate of 1.9 means that with each generation the size of the population will shrink by $5 \%$. These effects compound over time meaning that a negative growth rate can drastically reduce population size (assuming there is no immigration) in a relatively short time. For example, if today's fertility rates in Europe remain stable, the European population will decrease by 199 million — nearly $25 \%$ - by 2100 (United Nations 2013). Historically the concern with underpopulation has centered on its effects on international economic and political power. Today, many developed countries are afraid that their declining populations are undermining their power and that they will be economically, politically, and culturally eclipsed by developing or recently developed countries-given that the later are currently experiencing substantial population growth (Gerland et al. 2014; Teitelbaum and Winter 1985). However, recent statistics show that low fertility and underpopulation are not the problem of only developed 
countries, they have the potential to become a global issue (Bongaarts and Bulatao 2000; Morgan 2003; United Nations 2003).

\subsection{Causes of Global Fertility Decline}

For more than a century, in almost all developed countries, fertility decline followed moderation and was thought to be part of a universal demographic transition. The fertility effects of socioeconomic factors associated with modernization have been well documented (Inglehart 1997; Inglehart and Baker 2000). For instance, women's education is negatively associated with fertility. In early work seeking to understand the causes of fertility change, Bongaarts (1978) argued that in order to understand how socioeconomic development affected fertility behaviors, it was necessary to focus on the intervening behavioral and biological factors responsible for fertility Bongaarts (1978) designated these factors the Proximate Determinants of Fertility (PDF).

The PDF encompass 8 factors: 1) Proportion married, 2) Contraceptive Use, 3) Induced Abortion, 4) Frequency of intercourse, 5) Lactational infecundity. 6) Sterility and infecundity, 7) Spontaneous intrauterine mortality, and 8) Duration of the fertile period. The first four variables (proportion of married, contraceptive use, induced abortion, and frequency of intercourse) are the behavioral factors, while the remaining four variables are biological factors. Subsequent research has shown that the behavioral factors have the greatest potential to be affected by socioeconomic, cultural, and environmental processes (Bongaarts 1993), while the biological factors remain relatively constant across populations. Moreover, given the limited fertile period each month, subsequent studies have shown the frequency of sexual intercourse is only weakly 
associated with fertility, especially relative to the proportion married in developing countries or the proportion sexually active in develop countries (Stover 1998).

The three prime behavior factors that are associated with fertility are described as follows. The proportion married, limited to those of reproductive age, captures those who are risk of pregnancy due to regularly engaging in sexual intercourse (Bongaarts 1978). Although nonmarital sexual activity is of importance in many developed countries (and more so than marriage; Stover 1998), the focus of this study is Turkey where nearly all sexual activity and births happen within marriage (TDHS 2013). Contraceptive use includes "any deliberate parity-dependent practice_-including abstention and sterilization-undertaken to reduce the risk of conception" (Bongaarts 1978:107). Induced abortion includes any action that purposely ends the normal progress of pregnancy before its due date (Bongaarts 1978).

Although the original specifications of the PDF were for population-level indicators (e.g., proportion of pregnancies ending in induced abortion), they have parallels at the individual-level (e.g., use of abortion). In the current study, therefore, I investigate the association between individual-level indicators of modernization and secularization and behaviorally indicators of fertility: parity, contraceptive use, and induced abortion use. Given that most sexual behavior and nearly all fertility in Turkey is marital (TDHS 2013), this study examines these factors only among married women.

\subsection{Modernization, Secularization, and Fertility}

The classic theory of secularization claims that the modernization process including developments in technology, economy, and education-decreases the importance of religion until it no longer has any influence on private and social life 
(Bruce 2011; Wilson 2003). Many scholars have consequently assumed that the decline in religious practice changes family behaviors by increasing the influence of the desire for self-fulfillment, which guides union formation and reproductive choices (Van de Kaa 1987; Lesthaeghe 2010; Lesthaeghe and Surkyn 1988).

Reproductive behaviors are often investigated under the guidance of classic Demographic Transition (DT) theory. DT theory was derived from the observed historical fertility and mortality changes shaped by modernization as they occurred in Western and Northern Europe (Notestein 1953). The DT refers to the process of fertility and mortality decline (Lesthaeghe 2010). During the early stages of DT, fertility and mortality are high until agricultural production causes mortality decline. As soon as humans could produce surplus food, we had the caloric reserves to fight off routine infection, which drastically reduced the infant mortality rate; thus, fertility declined because not as many children were needed on the whole to ensure that some would survive to adulthood.

During the later and post-transition stages of the DT, fertility decline was caused by industrialization, urbanization, and technologically supported economic development. Fertility rates declined to at or below the replacement level (2.1 children) because of the decreased the value of children's labor and increased parental investment in children's education (Aries 1980). These changes not only caused very low fertility (VLF), but also resulted in ideational changes, the focus of the Second Demographic Transition (SDT) (Lesthaeghe 1983, 2014). SDT theory argues that the cause behind VLF is individual self-fulfillment, individualization, and secularization (Lesthaeghe 2010). Thus, critical changes in Western Europe precipitated the trend of VLF and modernization, with 
secularization in Western Europe accepted as a by-product of future global human development (Durkheim 1902; Inglehart 1997; Weber 1973).

\subsubsection{Modernization and Secularization}

Berger, Berger, and Kellner (1973) define modernization as a group of social processes occurring in the recent history to adapt all elements of society to technological and economic growth. There are various processes accepted as components of modernization, but education, egalitarianism, and urbanization are generally viewed as key components of modernization (e.g., Inglehart 1997; Inglehart and Baker 2000; White et al. 2008). Those social processes_-including changes in economic, political, and social institutions - highlight the interrelatedness of institutions; during modernization the changes in one institution reciprocally influence other key institutions (Black 1976). For example, the modernization of economic and political institutions of Europe during industrialization triggered the decline of the social importance of religion (Berger 1999; Martin 1991). Therefore, many scholars emphasize European modernization and secularization — the latter as a result of modernization — as reciprocal and co-occurring worldwide (e.g., Inglehart 1997).

Secularization refers to a social process in which the social significance of religion declines (Chaves 1994; Wilson 1985). Although definitions vary across studies and scholars, there is a fair degree of consensus on multidimensionality of secularization (Dobbelaere 1981, 1985, 1987). In this study, secularization will be defined in two overlapping ways. First, I will use secularism as defined as an institutional-level process by which religion loses its authority over other institutions (Wilson 1985). This process is also accepted as the differentiation of institutions, which is at the macro level 
(Tschannent 1991). Second, I use secularization to mean the individual- or micro-level process by which church, mosque, or temple attendance and religious beliefs of individuals decline and lose their value in daily life (Tschannent 1991). This distinction is important to this proposed study, which tests the effects of secularization, as a result of modernization.

Scholars have viewed modernization and secularization as inextricably linked social phenomena in the Western Christian world (Bruce 2002; Casanova 2011; Lamanna 2002). They have commonly argued modernization and secularization as having a reciprocal relationship, but secularization is seen as the result of modernization in secularization theory — where "modernization necessarily leads to a decline of religion, both in society and in the minds of individuals" (Berger 1999:2, 2012). McLeod and Ustorf (2003) define secularization theory as "the decline in the social significance of religion [at social and individual-levels] as a long-term and inevitable historical process, with short-term accelerants (such as enlightenment... industrialization and urbanization) ..." (p. 37). More specifically, the secularization process among all other things has been accepted as an inescapable consequence of modernity in Christian, Western nations: "to be secular means to be modern, and therefore by implication, to be religious means not yet fully modern" (Casanova 2011:59). This understanding of modernity with secularization in Western Christian nations, as an applicable paradigm to all nations, takes for granted a universal transition of human development (Wilson 1966, 2016).

\subsubsection{Fertility}

Many scholars have argued that modernization has loosened the power of religion (secularity) for individual behavior, thus both modernization and secularization are key 
factors for declining fertility (Kane 2013; Kirk 1996; Norris and Inglehart 2004).

Durkheim specified that the root cause of low fertility is demonstrated in the changes of cultural, social, and moral elements (such as individualization and decline of religious authority) of societies affected by the modernization process (Durkheim 1902; Lamanna 2002). Various aspects of modernization—including industrialization, urbanization, greater education attainment, female employment, egalitarian ideology, and secularization - are used to explain low fertility, all of which co-occur with technologically enhanced economic growth (Berger et al. 1973; Notestein 1945).

\subsection{Modernization and the Movement toward Low Fertility}

\subsubsection{Demographic Transition Theory}

Even though Notestein $(1945,1953)$ is generally known as the founder of the concept of the demographic transition, Thompson (1929) offered the three-stage explanation of demographic transition before Notestein. The beginning of the DT starts with high birth and mortality rates where both are unstable. As shown in Figure 2.1, this period of time is called pre-transition stage 1 (Thompson 1929). The second stage started with the decline of the mortality rates (see Figure 2.1) and rapid population growth—first with increased agricultural production and then later with improvements in health and sanitation (Notestein 1945; Thompson 1929). Because of this development in agriculture and medicine, the proportion of the population who survived to reproductive age increased, along with their life expectancy. In the third stage, fertility begin to decline from very high levels to replacement level given the increased probability of survival and the increasing socioeconomic costs for rearing children that accompany economic development (Notestein 1945, 1953; Thompson 1929). In the fourth stage, both the 
fertility and mortality rates have declines to low levels and the size of the population is stable.

The fourth stage of DT theory illustrates the effects of modernization on fertility rates and the potential for fertility to decline below replacement level. Today's typical small families were shaped by industrialization and urbanization of European societies. As Notestein (1953) argued, urbanization pushed the family into new roles in industrializing society. Employment in factories allowed individuals to stand on their own accomplishments (Coale and Hoover 1958). The anonymity of urban life also increased the individualization through reducing family and community pressures to practice traditional behaviors.

In addition, rapid changes in technology required new skills and provided new opportunities for individuals to advance their education and to discover rational thought around human existence (Notestein 1953). As a consequence of changes brought about by urbanization and secularization, the cost of rearing children increased; developments in hygiene and medicine kept mortality decline very low, and decreased the incentives of having many children (Notestein 1953). Because of these changes in modernization process including the development of modern contraceptive methods and induced abortion, women had new opportunities, such as participating in work life and education, both less compatible with childbearing (Notestein 1953).

\subsubsection{Second Demographic Transition Theory}

Classic DT Theory specified that fertility would stabilize at replacement-level. By the 1960s, however, there was growing evidence that fertility was continuing to decline in many developed counties. Lesthaeghe (Lesthaeghe 2014) positied that a Second 
Demographic Transion (SDT) — denoted by below replacement level fertility and a wider range of union formation behaviors - has been triggered by series of "revolutions": (1), the development of modern contraceptive methods, including hormonal regulation and more efficient IUDs; (2) the questioning of traditional gender roles; and (3) the rejection of authority, specifically religion. The overall outcome of these revolutions- the postponement of marriage and having the first child, increased cohabitation and divorce rates, and the rarity of higher parity births (four or more) - was the emergence of fertility far below replacement level or Very Low Fertility. Although a combination of many factors lead to low and VLF, SDT theory typically focuses on women's education, gender ideology, urbanization (as components of modernization), and secularization to explain VLF rates.

\subsubsection{Women's Education}

A number of studies have shown that women's education is negatively associated with their number of children (Basu 2002; Colclough 1982; Kazembe 2009; Lutz and Kc 2011; Strauss and Thomas 1995). Better educated women have greater decision-making power over reproduction (in part because they tend to marry highly educated men who have similar fertility preferences) and possess more knowledge about how to access and effectively use contraception (Basu 2002; Cleland and Rodriguez 1988). Better educated women also face higher opportunity costs from the resulting disruption to employment that comes with childbearing (Becker 1981). In developing countries, more educated women have greater confidence that their children will survive and this is negatively associated with parity (Basu 2002; Cohen 2008; Lutz and Kc 2011). The negative association between a woman's level of education and the overall birth rate accounts in 
part for the decline in the total fertility rate of societies with greater levels of female higher education (Cohen 2008; Martin 1995).

Lutz and KC (2011) show that women's education (specifically secondary education) is negatively associated with child mortality and birth rates, but the effect of women's education on fertility rates might vary by countries. Education and religion are inversely related (Berger 2011; Sherkat 1998), although this varies across countries. Directly relevant to the current study is the fact that the effect of education on fertility is lower in Muslim-majority countries than it is in Christian-majority countries (Heaton 2011).

\subsubsection{Egalitarian Ideology}

Changing economic structure, increasing education, and greater employment opportunities for women with modernization are associated with changes in both gender role ideology (Lesthaeghe 2010; Notestein 1953). Specifically, increasing egalitarian ideology is associated with declines in fertility (McDonald 1992, 1994) It is well documented that a traditional, less egalitarian, ideology supports having children at earlier ages, which leads to higher rates of fertility (Bongaarts 1978; Stewart 2003), while an egalitarian gender ideology is associated with postponing marriage and consequently postponing first birth (Cunningham et al. 2005). Moreover, Kaufman (2000) found that women with egalitarian attitudes toward gender roles are less likely to actualize their intention to have children than are women with a more traditional ideology.

Generally, consistent with the premises of SDT theory, studies reveal a negative association between egalitarian gender ideology and religiosity (Abouchedid and Nasser 2007; Hertel and Hughes 1987; Peek, Lowe, and Williams 1991). However, again the 
strength of this association varies across countries. Limited prior research has demonstrated, for example, the effect of ideational changes on fertility in some Muslimmajority countries even though there are high levels of religiosity. Specifically, increasing egalitarian ideology in Iran provided greater decision-making power for women within the family and decreased their fertility from 6.5 children to below replacement level in a short period of time (Abbasi-Shavazi, McDonald, and HosseiniChavoshi 2009).

\subsubsection{Urbanization}

Urbanization has been one of the commonly used indicators of modernization because of its wide availability and easy comparability (e.g., Acemoglu, Johnson, and Robinson 2002). The pattern of lower fertility in urban areas than in rural areas has been observed for all developing and developed countries (Heaton, Lichter, and Amoateng 1989; Kulu 2005, 2006; Tromans, Natamba, and Jefferie 2009). The urbanization effect is particularly pronounced for higher parity births (Kulu 2013). White and colleagues (White et al. 2008) argue that the high opportunity costs and price of housing in urban areas are main factors discouraging high fertility, as well as the easier access to contraceptive methods in urban areas that encourage the postponement of parenthood.

Cities (urban areas) are a monument of modern (secular) values (Ron Lesthaeghe and Neels 2002). As Tönnies emphasized, societies, in this case urban life style, promote secularization, individualization and self-actualization that all favor childlessness or fewer children. (Wilson 1998) also argued that secularization is an inevitable thrust as a consequence of other changes in a social structure in modern societies. A number of 
studies show that urbanization is negatively associated with both religiosity and fertility

(Gries and Grundmann 2015; Hay 2014; Ruiter and van Tubergen 2009; Steinhoff 2011).

\subsubsection{Secularization}

In addition to modernization, which is negatively associated with religiosity, SDT theory also considers secularization as an important factor accounting for VLF rates (Lesthaeghe 2014; Surkyn and Lesthaeghe 2004). Secularization was observed during modernization of Europe and accelerated fertility decline to VLF (Lesthaeghe 2010). There is a general agreement on the role of religion in affecting behaviors of marriage and fertility through traditional family values, importance of parenthood, and gender roles (Goldscheider and Kaufman 2006; Hayford and Morgan 2008). The modernization process of Western Europe, for instance, reduced the pressure of community toward traditional values and gave a way to individualistic and self-fulfilling behaviors that proceeded in parallel with the fertility decline (Kirk 1996). Secularization is clearly connected with modernization and also associated with declining fertility (Coale and Watkins 1986).

More than most other social institutions, religion creates moral codes to guide individual behaviors, including sexual behaviors, roles of men and women, and the importance of the family in society (McQuillan 2004; Wallwork 1985). There are religious rules and norms that directly regulate fertility behaviors through the PDF. Additionally, broader values indirectly influence fertility behaviors through conservative family ideology, such as the importance of marriage and parenthood (Hayford and Morgan 2008). Religious values, however, have been losing their power on individual behaviors, specifically fertility behaviors, because of self-actualization and 
individualization, both observed in modernizing and modern societies since industrialization (Lesthaeghe and Surkyn 1988; Wallwork 1985).

There is widespread agreement among scholars that rising secularization head led to declines in fertility and population growth (Frejka and Westoff 2008; Lesthaeghe 2010; Lesthaeghe and Van de Kaa 1986; Norris and Inglehart 2004). The association between secularization and individual fertility behaviors at the individual-level is quite clear with, for example, Kane (2013) finding that increase in secularization was associated with decreased final parity. Indeed, a number of studies have shownconsistent with SDT theory — that secularization and the decline of religious authority are a substantial cause of very low fertility in developed societies (Kane 2013), especially in Europe (Lesthaeghe 2010; Ron Lesthaeghe and Neels 2002; Mcdonald 2006; Moors 2008; Ogden and Hall 2004).

\subsection{SDT and the European Case}

\subsubsection{Fertility}

The transition from high to low fertility is not only "the result of cost-benefit structure of each additional child... but a strong correlate of other indicators of a shift in the ideational system" in Western Europe (Lesthaeghe 1983:412). Many scholars argue that the relationship between fertility and religion has been changing because of increasing secularization from one generation to the next (Van de Kaa 1987; Lesthaeghe 1983; Nitzan 2016). Nitzan (2016) examined religious structures in France, the Netherlands, and Britain between 1930 and 1965, and the effect of these (including religion and practice variable) on completed (or near completed) family size across cohorts of women. This study found that, the proportion of regular (church) attendees 
declined from older to younger cohorts in both Britain and France. Among later-born cohorts in France, non-practicing women have lower fertility than practicing Catholic women. Fertility levels for both nominal Catholic and non-affiliated women also continued to decline to below-replacement levels, 1.9 and 1.7, respectively. Fertility levels among nominal Catholic women in the Netherlands showed a decline from 2.6 to 1.8 children on average. In Britain, the role of religion on explaining fertility differences among new generations is diminishing, although Nitzan argues this is a temporary situation.

Modernization and secularization, the two primary components of SDT, have had a strong influence on the VLF rates observed in Europe. Indeed, this strong correspondence is exhibited by my own analyses using the European Value Surveys (EVS) 2008 (see Appendix A). The mean number of children born in all European countries was 1.69 in the 2008 EVS, well below the replacement level. Among female respondents who are age between 16 and 49 in the EVS $(N=15,049)$, religiosityincluding religious service attendance, belief in God, prayer outside of religious services, and the importance of religion in respondent's life-were all positively associated with number of children (Model 1 in Table A.1 in Appendix A), whereas education was negatively associated with parity both all women and married women's parity (see Model 2 in Table A.1 in Appendix A). In these analyses, I included control variables for women' employment, income level, and age. Furthermore, the interaction between a summated scale of these religiosity variables and education showed a statistically significant and negative association with the number of children, in both the full sample of women (Model 3, $\mathrm{p}<0.050$ ) and in a sample limited to ever married women (Model 4, $\mathrm{p}<$ 
0.050) (see Figure A.1 in Appendix). These findings support the secularization component of SDT theory and the argument of Lesthaeghe $(2010,2014)$ that modernization and secularization have an interdependent relationship and joint effects on fertility.

\subsubsection{The Link between Modernization and Secularization}

The secularization model is supported by much empirical evidence because secularization and modernization have progressed simultaneously in Western and Central European countries (Casanova 2011; Davie 2002, 2000), as well as some Englishspeaking countries. As the economic and political modernization of Europe accelerated, religion lost its significance in the public sphere, and religious behaviors were pushed to private life (Berger 1992; Martin 1991).

For years, scholars have argued that many nations in Europe are experiencing secularization at both institutional and individual levels, including decline in church attendance, in belief, and in significance of religion in public life (Berger 1967; Wallace 1966). Wilson (1982) argues that Europe has lost the social significance of religious consciousness, actions, and institutions. The spread of modernity and rationalization eclipsed religion (Wallace 1966). More specifically, the demise of religion and its loss of influence was predicted (Wilson 2016, 1985). Even though key secularization theorists remain cautious about claiming the disappearance of individual practices and beliefs, they view secularization as an inevitable change of modernization (Bruce 2011; Wilson 2016).

For example, a study of 30 European countries revealed that secularization theory remains applicable to many European countries (Halman and Draulans 2006). The authors used religious belief and religious practices as dependent variables to measure the 
effects of both individual and aggregate level variables. Findings show that modernization (level of education, women in paid employment, globalization, and GDP) has changed the role of the church and of religion generally in Europe (Halman and Draulans 2006). In particular, Halman and Draulans (2006) found that women in paid employment were less religious than their unemployed counterparts. Moreover, both globalization and the wealth of societies were negatively associated with their religiosity. Even though a secularization process can be observed throughout Europe, the speed of the process varies from one society to another. For instance, Halman and Draulans (2006) also found that "believing without belonging" to a denomination was common in the Netherlands, Estonia, and Latvia, but that the Czech Republic and Estonia were the most secular societies, according to the percentages of non-religious and non-churchgoers.

Data from the 1999 to 2004 and 2008 European Value Surveys show that people in Western Europe and some central European countries are less likely to find religion important in their lives, believe in God, and attend religious services. Specifically, Figure 2.2 shows that the percentage of people who believe in God higher in the Eastern and Southern European countries, while it is lower in the Western and Northern European countries (except Ireland). Figure 2.3 shows a decrease in percentage of people who find religion important in their lives in almost all European countries, but especially so in the Western and Northern countries. Lastly, Figure 2.4 shows that religious service attendance is quite low, mostly varies between $5 \%$ and $20 \%$ (exceptions being Italy, Poland, and Turkey). Overall, the EVS indicate that religiosity in Western and Northern Europe (which are the most developed countries) is considerably lower than in the rest of European. 
These maps from the 2008 European Values Survey support the idea that secularization and modernization are intertwined in Europe, although there is some variation across countries. The fact that modernization and secularization co-occurred lead to an assumption that Europe's modernization would be replicated in other regions (Martin 1991). This European view of the modernization process specifies secularization as a necessary and automatic result of modernization (Bruce 2002; Dobbelaere 1981).

\subsection{Secularization Outside of Europe}

Although scholars have traditionally argued that modernization and secularization are inevitably connected, this idea is now losing support from many sociologists and historians (Berger 1999; Cox and Swyngedouw 2000; Iannaccone, Stark, and Finke 1998; McLeod and Ustorf 2003). Therefore, we might study other social contexts to understand whether the European modernization and secularization dynamics are applicable elsewhere. North America, Latin America, and Islamic Middle East are distinct areas worth examining (Martin 1991:470). Empirical research has shown that secularization in North America and Asia differ considerably from Europe (Davie 2002; Finke, Guest, and Stark 1996; Sasaki and Suzuki 1987). The Islamic Middle East, however, has been left largely unexplored by sociologists of religion (partially because of limited data on religion and religious practices; Colonna and Macey 1995).

\subsubsection{Secularization in the United States}

Secularization in the United States is quite different than in Europe (Berger et al. 2008; Stark and Finke 2000). There—at least nominally — the separation of church and state in the United States. The separation in this sense differs from most European nations; for instance, U.S. presidents and legislators swear an oath on the Bible or other 
religious text. Moreover, at an individual level, even though the secularization argument remains an unsettled issue, Finke and Stark (1998) argue that pluralism is key to the higher church attendance in the United States than in Europe. One could argue that pluralism leads to secularization (Bruce 2002; Quinn et al. 1982), though Stark, Iannaccone, and Finke (1996) make the opposite argument, claiming that secularization in this sense is replaced by the pluralism of American religion, which includes many religious organizations available in a free market.

On the other hand, Bruce (Bruce 2002) argues that decline of religion is happening in most Western countries including the United States. Bruce (2002) connects the secularization with modernization. Specifically, Bruce (2002) claims that the weakening of religious power in public relationships also affects individuals' thoughts and behaviors, specifically less belief in God, lower church attendance, and less use of prayer, which is exhibited in many Western nations (e.g., the United States, Quinn et al. 1982). Contrary to Finke and Stark (1989), Quinn and his colleagues (1982) found a negative association between religious pluralism and church attendance. The debate on secularization is still an ongoing process, but Bruce argues that increasing secularization does not mean that religion will eventually disappear but points out that when religion loses its influence on individuals, it will be a lot harder to regain its power back. Furthermore, Bruce (2002) agrees with Finke and Stark (1989) that religion in the United States is stronger than in most other Western countries because it is deregulated.

These arguments above show that secularization in the United States varies somewhat form the European case. For example, negatively correlation of pluralism with religiosity is mostly accepted in European countries, whereas the effect pluralism in 
North America on religious practices has still being debated because of high religiosity in most North America countries (Finke et al. 1996; Finke and Stark 1989; Halman and Draulans 2006; Johnson and Ross 2009; Olson 1998). Secularism in the United States allows the co-existence of different religious institutions (pluralism), and the coexistence of both religious and secular discourses; thus, the North American case shows religion and modernity as compatible, contrary to Western and Northern Europe.

\subsubsection{Secularization in Latin America}

Latin America provides a quite different case, with a large and growing Christian population (Johnson and Ross 2009). At first glance, it appears as if religion and modernity are absolutely disconnected, as they are in much of Southern Europe (Berger 1999, 2014; Martin 1991). However, although a few Latin American societies have "an explicit secularization of everyday consciousness," the Christianity has maintained its hold in the majority of Latin American societies (Martin 1990, 1991:8).

The Latin American case entails a combination of European and North American patterns, with some variations across counties On the one hand, Uruguay clearly resembles European cases where a huge part of society has distanced itself from the Church (Martin 1991). On the other hand, many Latin American societies have enjoyed the religious competition because of the explosion of some religious movements, such as Protestantism (Berger 2014). The majority of Latin American countries, especially Brazil and Chile, make good examples of the free religion market. Modernizing Latin America demonstrates "modernity lead[ing] to pluralism," rather than to secularization (Berger 2014:20). As in the United States case, the Latin America case shows that the relationship between modernization and secularization in Europe is not a universal phenomenon. 


\subsubsection{Secularization in Asia}

Asia also fits uneasily into the Western European conceptualization of secularization, in part due to the a large regional gap between South and East Asia concerning the percentage of non-affiliated people (Reed 2007). Most South Asian respondents profess to have a religious identity, while East Asian respondents with no religious identity ranged from $18.6 \%$ to over $70 \%$ (Reed 2007). These findings could be interpreted to mean that East Asia (which includes most developed nations of Asia) is following the same track as Europeans with modernization and secularization. Reed (2007), however, found that affirmative answers to a belief in a spiritual world ranged from $49.3 \%$ in China to $72.3 \%$ Taiwan, and high levels of support for the involvement in weddings and funerals of religious professionals (such as imam, priest, and monk) and institutions (such as the mosque, church, temple, and shrine).

Again, these findings suggest that high levels of modernization are compatible with high levels of religiosity; they also support the argument in Asia that Western modernity should not simply be accepted as a whole, but instead it is possible for countries to adopt the parts of modernity that work for them and to reject the others (Berger 2014). For example, Japan, one of the most developed countries still has retained key elements of traditional Japanese culture (Berger 2014). Shintoism not only persists, but it has been revitalized in Japan, helping people to cope with the transitions that modernity has brought (Cox and Swyngedouw 2000). Even though Japan is generally considered as a very secular nation, the evidence above shows that religiosity and modernization can coexist together. 
South Korea provides a similar case. Contrary to most other industrialized societies, the social power of religion there has reflected the growth of the religious organizations in South Korea (Kim 2002). Modernization has not weakened the power of religious organizations. Even though almost half (46\%) of the Korean people have no official religious affiliation, church attendance among Catholics and Protestants in South Korea is higher than among their counterparts in the United States (Gallup-Korea 1998). South Korea, similar to other East Asian nations, is a secular society with a high demand for religious services (Reed 2007). These findings also show that the association between modernization and secularization can vary from country to country, indicating that secularization is not inevitable in all nations.

To summarize, studies conducted in North and South America, Asia, and many other modern societies suggest that the model of European secularization need not describe the future for all modernizing and modern countries (Finke et al. 1996; Kim 2002; Sasaki and Suzuki 1987). Different cultural and political backgrounds provide different meanings to the concepts of secular, secularism, and secularity; thus, multiple secularities occur depending on structural conditions and cultural frameworks (WohlrabSahr and Burchardt 2012). As Stark (1999) argues, it would be wishful thinking to view the European secularization model as a global certainty. As the evidence above shows, it is important to test the applicability of secularization arguments in different and unexplored contexts because the association between modernization and secularization varies from country to country. 


\subsubsection{Secularization in Muslim-majority Nations}

Given the variation across regions, it is worth considering whether secularization and VLF are unique to Europe. Secularism and secularization were clearly an important result of European modernization, which negatively affects fertility. Despite the general claim that the secularization of Europe is the inevitable fate of all religions, many scholars argue that religiosity is increasing worldwide, except in Western and Northern Europe (Berger 1999; Davie 2002, 2000). Further, the secularization of Western and Northern Europe has been considered as a primary reason for low fertility (Lesthaeghe 1983, 2010). Based on the arguments above, secularization and VLF might be viewed as characteristic of Christian Europe but not elsewhere.

The Western model of modernization was generally accepted as a global process that leads to the secularization of societies (Lerner 1958; Wilson 1985, 2016). Muslimmajority counties provide a different context—on that has been largely unexplored— where we might also expect modernization only to be weakly associated with secularization. Even though the primary interpretation of Islam has nothing against modernization or development, many colonized Muslim countries rejected European modernization (Martin 1991), not because of modernizing per se, but because of its European roots; Europeans had invaded their countries and attacked their traditional values (Saeed 1994). On the other hand, many elites from Muslim-majority countries have viewed European modernization as a salvation for their countries and implemented reforms, including secularization, to achieve European modernization without any desire or commitment from major elements of society (Göle 1997; Hoebink 1999). It is 
important to elucidate these as two approaches to modernization, to understand better the modernization progress of Muslim-majority nations.

The first approach, mostly a reaction to colonization experiences, rejects the modernization of the Muslim-majority society. European modernization has had important effects on developed and developing Middle Eastern countries; nonetheless, European modernization is unwelcome to many Middle Eastern countries given the history of colonization (Saeed 1994). The colonization period left many negative impressions about European modernization on colonized peoples. For example, colonial powers oppressed Muslim populations in colonized Muslim countries by imposing Western values as a central to conditions of modernization, while also labeling Islamic and traditional values as a burden to modernization. During the colonization period, European powers also portrayed Islam as a major obstacle to achieving modernization (Hoebink 1999). Even though the primary interpretation of Islam has never excluded modernity and rationality (Abduh 1966; Okumus 2008), European modernization has been understood as a threat to traditional Islamic values and was thus excluded as foreign in many Muslim countries (Martin 1991), including Sudan and some other North African Muslim majority countries. These experiences slowed down the modernization process for such Muslim countries because they explicitly rejected the inevitability of secularization that is embedded in European modernization model.

By contrast, the second approach embraces the European modernization model that includes secularization. In some Muslim countries—such as Turkey, Tunisia, and Egypt, European modernization had been accepted as necessary for development (Martin 1991). As it had in Europe, this view included secularization as a precondition for 
Muslim modernization (Hoebink 1999). The main strategy of these developing countries was to simply imitate Western countries without attention to the processes that those countries underwent as they achieved modernization (Saeed 1994). Contrary to Medieval European conditions, where secularization involved a desire for change among the general population (Patrick 2007), most people in Muslim countries—where European modernization with secularization was implemented — had no disputes with their religion or religious authorities (Saeed 1994). They simply implemented the European modernization with secularization to quickly modernize their societies by disregarding Islamic thought, practice, and values (Mardin 1983, 2006; Saeed 1994).

Turkey is a prime example of successful voluntarily implementation of European modernity, including both secularism and secularization, through social, political, and cultural reforms. Since reforms rarely work when initiated by social and economic elites, the government was confronted by a strong resistance among the general population (Mardin 2006). As with Japan, Turkey adopted many successful parts of European modernization (including secularism, the removal of religious authority from the state) and mostly rejected the parts—secularization—attempting to change key elements of traditional Turkish culture (Saeed 1994). Since the understanding of secularization as an inevitable condition for modernization is irrelevant to Islam, it can be argued that Turkish society created a third approach, modernization without secularization. Therefore, Turkey as a Muslim-majority country forms an interesting case for examining the effects of modernization — as separated from secularization—on fertility. 


\subsection{Compatibility of Islam and Modernity}

\subsubsection{Schools of Islam}

No religion is monolithic. As with Christianity, Islamic practices vary from region to region due to different traditions, cultures, and political histories. These differences are quite important in Islam because there are legal schools that interpret laws and the variation in their interpretations generally reflect such regional differences (Melchert 1997). There are many schools of law from the four different branches of Islam (Ahmadiyya, Sunni, Shi'ah and Khawarij), but a majority of Muslims follow one of five main schools of law: 1) Ja 'fari (from the Shi'ah branch) includes $23 \%$ of Muslims; 2) the Hanafi (from the Sunni branch) includes 31\% of Muslims; 3) the Maliki (from the Sunni branch) includes of $25 \%$ of Muslims; 4) the Shafi'i (from the Sunni branch) includes $16 \%$ of Muslims; and 5) the Hanbali (from the Sunni branch) includes $4 \%$ of Muslims. The remained of Muslims follow other schools of laws (Al-islam.org 2018). As is clear from these percentages, the Sunni schools are the primary schools of law followed by majority of Muslims worldwide. It is important to that that although these school are all in the same branch of Islam, their interpretations vary by their conservativeness.

\subsubsection{Education}

Islamic thinkers, like the most popular medieval theologian Al-Ghazali, the fourteenth century legal scholar Ibn Khaldun, and many others, view knowledge as sacred and suggest that people value it as they value religious teachings. Even though the idea of secularization is contrary to Islam (Saeed 1994), reason and secular thoughts are, however, dominant values in Islam because a balanced human life can be achieved with both faith and reason (Ibn Khaldun 1974). According to the Quran and Hadiths, secular 
knowledge is as important as religious knowledge; secular knowledge is for dwelling on earth and religious knowledge is for having a smooth life in both this life and in the afterlife (Quran 58:11). Similar to Christianity (Gould 1999), Ibn Khaldun (1974) argued that the separation of reason and faith could not be acceptable because there are some things that reason cannot explain. Thus, people should not focus on finding broad explanations for all parts of existence (Ibn Khaldun 1974). Rather, for example, people should focus on things, such as empirical science, where they can examine the empirical parts of existence by observing and reasoning. Concentrating on this kind of work would promote practical materials that aid human well-being (Ibn Khaldun 1974).

Thus, modernization and Islam are compatible. Muslims have a common understanding that all knowledge comes from God (Al-attas 1980), and knowledge is for both men and women and should aid human well-being (Ibn Khaldun 1974). According to (Al-Ghazali 1939), "Knowledge exists potentially in the human soul, like a seed in the soil, through learning, that potential turns into reality" (Al-Ghazali 1939). Secular education and knowledge, consequently, are accepted as a religious duty for all Muslims.

The Prophet Mohammed said, "Acquisition of knowledge is binding on all Muslims [both men and women without any discrimination]" (Ibn Maja in al-Sunan 1:81 p.224, as cited in sunnah.com). Thus, in Islam obtaining knowledge is as obligatory for women as it is for men. Women's increasing education and employment across most of the Islamic world (Abbasi-Shavazi, Mohammad Jalal and Torabi 2012; Kuhn 2012; Turkstat 2016) requires critical examination as to whether Islam creates barriers for modernization, including egalitarianism. 


\subsubsection{Egalitarian Ideology}

Equality (musawat) is one of the most important teachings of Islam. The Prophet Muhammad suggested all Muslim men provide equality in their household for each family member, and he became the first example by helping his wife on household tasks (Al-Bukhari 1976). Although men are expected to be the provider and the protector of their family (Quran 4:34), the prophet suggested that believers provide the same opportunities, such as love, education, and financial support, to both their sons and their daughters.

The Quran does not discriminate against men or women. Many people might have falsely assumed that the Quran chooses men as the head of their household to behave obstinately towards their wife, subject women to men's will, compel women, destroy women's individuality, and thus deny women's identity. Quran (4:19) states that "Live with your wife on a footing of kindness and equity." The responsibility of being the head of the household is given to men because biologically women bear and nurture children. In addition to the Prophet Mohammed's suggestion, many Islamic scholars argue that marriage does not allow men to confine their wives' activities to housework and make them serve their husbands (e.g., Abu Hanifa 2007; Al-Shafi'i 2008). The suggestions and arguments above show that Islamic teachings value egalitarian understanding as well as education — which are key components of modernization (Inglehart 1997; Inglehart and Baker 2000). Based on the arguments above, it can be argued that primary teachings of Islam show that Islam and modernization can work together in the process of human development (Al-Ghazali 1939; Ibn-Khaldun 1974). 


\subsubsection{Islam and Fertility}

Studies of Muslim countries are notably lacking. Prior studies of the association between fertility and religion have been conducted mostly in Christian societies. The findings of numerous studies show that religious traditions may affect individuals' fertility in many ways (Mosher, Williams, and Johnson 1992; Sarah R. Hayford and Morgan 2008; Zhang 2008). For example, religions with pro-natalist values emphasizing the importance of family and parenthood are positively associated with parity (McQuillan 2004), as is religious service attendance. Similarly, religiosity and fertility are positively associated in Muslim countries (Kaufmann 2009; Yavuz 2008). Despite high levels of religiosity, however, the fertility rates in most Muslim countries have been gradually decreasing (World Bank 2015; TSI 2016). The reason for this decline has not been systematically examined.

\subsubsection{Islam and Parity}

Islam, like other Abrahamic religions, has pro-natalist norms and values that influence fertility behaviors through the PDF (McQuillan 2004), most specifically marriage, contraceptive use, and abortion. Islam encourages adherents to marry and have children and teaches its believers not to worry about the financial burden of having children because Allah (God) will always provide for children and their parents (Quran 6:151, 17:31). Islamic legislation does not limit the number of children that one can have and suggests that believers should not limit themselves to a specific number.

Islam also encourages having as many children as one can because this is filling the Earth with obedience to Allah and His worship, and increasing the progeny. It is also accepted that increasing progeny is a provision for the person in both this life and in the 
hereafter, especially when they raise their children according to Islamic. A hadith also states that "When a man dies, his deeds come to an end, except for three: a continuous charity, knowledge that benefits people, and a pious child who supplicates for him." Islamic teachings place important value on having children, thus it would not be surprising to see a positive relationship between religiosity and number of children.

\subsubsection{Contraceptive Use}

Although the Quran does not talk about contraceptive use, some hadiths allow using traditional contraceptive methods (e.g., Al-Bukhari 1999 v7:b62:h135, h136) and the interpretation of those hadiths also include reversible contraceptive methods (AlGhazali 1939; Karaman 2018). For example, the only contraceptive method (e.g., coitus interruptus) used during the lifetime of the Prophet Muhammad, and he did not express disapproval of its use (al-Bukhari 1999) to postpone pregnancy for a certain period.

The opinions of Islamic scholars vary on contraceptive use (Obermeyer 1992). Some scholars claim that is not allowed because it is like killing your child and based their arguments on Quran verses (81:8-9; 1731) (Musallam 1983). The verses specifically refer to the pre-Islamic period when some people killed their female children out of the fear of feeding and the unfortunate conditions of women during war and plunder times(see Yusuf 2014).

However, many others allow contraceptive use for the mother's health and when it is the decision of both husband and wife (Iyer 2002; Karaman 2018). Al-Ghazali (AlGhazali 1939) argues (in his Ihya' 'Ulum-ud-Din) that male sperm alone cannot be accepted as human beings unless they are united with female egg in the uterus. AlGhazali (1939) also adds that no one can guarantee that contraceptive will block a female 
egg from fertilization with sperm. In his work, Al-Ghazali (1939) also talks about five reasons for contraceptive use: 1) to prevent transmission of disease from partners; 2) to space pregnancies, which can also be supported by a Quran verse (Al-Bakara 2/233) "Mothers may breastfeed their children two complete years for whoever wishes to complete the nursing [period];" 3) for the health of wife; 4) when husbands have no or little money (unless they want to have children); 5) for women's beauty.

Some hadiths tolerate and legitimize both traditional and modern contraceptive methods when it is the mutual decision of husband and wife; permanent contraceptive methods are prohibited, however (Atighetchi 1994). Several hadiths state that some believers went to the Prophet Mohammed and asked him “... Shall we get castrated?” and the Prophet forbade them to castrate themselves (Sahih al-Bukhari 1999: v7:b62: h9, h11, h12). Turkish Islamic scholar Hayrettin Karaman (2018) also argues that “continuous and irreversible contraceptive methods" are not allowed. Irreversible contraceptive methods (e.g. vasectomy, tubal ligation, and hysterectomy) are forbidden, unless for medical reasons. Thus, in general, Islam allows for reversible forms of contraception when their use is the joint decision of the husband and wife.

\subsubsection{Abortion Use}

Abortion without just cause is prohibited in Islamic teachings. Some Islamic scholars suggest that abortion is permissible if the pregnancy is ended before the ensoulment of the fetus — defined as occurring between 40, 90, and 120 days after conception, depending on the school of thought-however, most schools of thought suggest that abortion requires a justifiable reason such as the mother's health or in the case of rape (Asman 2004; Hessini 2007). Therefore, in most of today’s Muslim 
countries, Islamic scholars do not allow abortion as a contraceptive method even though the legislation of abortion in some Muslim majority countries (e.g. Turkey and Tunisia) would seem to indicate otherwise (Aramesh 2006).

\subsection{Fertility in Muslim-majority Nations}

Even as fertility has declined worldwide, the demographic transition has proceeded at a considerably slower pace in many Muslim nations. Sub-Saharan Africa, which includes many Muslim-majority nations, is one of the areas where fertility decline has been quite slow despite concerted efforts by international aid organizations (Bongaarts 2011). Although most Muslim-majority nations have large young populations, some Muslim nations (such as Iran and Turkey) do have fertility rates around the replacement level or even lower (United Nations 2016). It is well documented that components of modernization are negatively associated with low fertility; however, Caldwell (1980) argues that education specifically has important effects on fertility decline. The effect of education, however, may vary across religious groups. Indeed, a study examining 30 developing countries found that education had a greater impact on fertility in non-Muslim nations than in Muslim nations (Heaton 2011).

The weaker association between education and fertility decline in Muslimmajority nations may reflect the co-existence of religious and secular knowledge in these nations. For example, a study conducted in Egypt found that education strengthened traditional pro-natalist familial norms, those associated with higher fertility (Faust, Bach, and Alla 1991). This likely reflects the fact that public school systems in Egypt have an Islamic curriculum, teaching religion in all grades from elementary to high school (Almonitor 2016). Indeed, Faust and colleagues (1991:340) note that the Egyptian education 
curriculum includes non-Western components that promote "traditional Islamic family morality rather than Western middle-class secularization.” These findings from Egypt show that education, and therefore modernization more broadly, need not promote Western secular values that have been identified as critical to low fertility in Europe and other regions. This points to the need to examine declining fertility in Muslim-majority nations in ways that do not simply replicate the assumed joint effects of secularization and modernization presumed by the SDT theory.

The need to consider modernization as separate from secularization is necessary because, despite the fact that Muslim-majority nations remain highly religious and Islamic teachings have a pro-natalist ideology, some Muslim countries have in fact been experiencing (sometimes rapid) fertility decline (Abbasi-Shavazi, Mohammad Jalal and Torabi 2012; Kaufmann 2009; Yavuz 2008). For instance, Iran's fertility rate declined by more than $50 \%$ in a single decade after the government implemented a family planning policy (Ministry of Health and medical education 1998). Iran's fertility rate (1.69) today is well-below the replacement level (World Bank 2015). Abbasi-Shavazi and Torabi argue that in addition to the government's policy change about family planning, religious leaders' support for family planning had an important influence on the fertility decline in Iran (2012). Similarly, Turkey has been experiencing fertility decline since the 1960s, with the TFR declining from 6.30 to 2.05 (World Bank 2015). As in other countries, traditional beliefs are associated with higher fertility in Turkey (Yavuz 2003) because Islam encourages believers to marry and have children, and yet the fertility rate in Turkey (and many other Muslim countries) is declining (World Bank 2015). Therefore, it is necessary to examine the how modernization and religiosity separately affect fertility 
in Muslim societies to better understand the reason for this fertility decline. Turkey is an ideal country in which to undertake such an examination.

\subsection{The Case of Turkey}

Turkey became a unitary secular state as a key condition for modernization (Kuru 2009). Though Westernization reforms in Turkey encountered some resistance, reforms that were not threat to Turkey's traditional religious values accelerated the modernization process (Çinar 2005). Westernization differs from modernization because it includes Western cultural values. In recent history Muslims have looked for ways to modernize without being forced to Westernize (e.g. secularize) (Hoebink 1999). Turkey differs in important ways from other Muslim-majority countries, such as a close and non-colonial relationship with Europe and a longstanding secular state ideology that facilitated such a non-Westernized modernization process. These characteristics make it a unique case in the Muslim world.

Turkey's case becomes most interesting and relevant when compared to other modern Muslim nations, particularly because it has had the longest period of independence (Saeed 1994) — with the current republic now independent for almost 100 years. If we include the period of the Ottoman Empire (founded in 1299), the Turkish people have protected most of their cultural and religious values for 700 years.

In contrast to Turkey, colonized Muslim-majority nations experience a repression of traditional and Islamic cultural values. Islam was totally disregarded and made a private matter, restricted to the observance of rituals, because Western elites saw Islam as a major hindrance to social and political change (Esposito 1999; Saeed 1994). For example, Lord Cromer, the British counsel in Cairo from 1883-1907, argued “. . . as a 
social system, Islam has been a complete failure. Islam keeps women in a position of inferiority ... it permits slavery ... its general tendency is intolerance towards other faiths...." Because "the West was trying to subject Muslim society by weakening its cultural foundations," modernity and secularization were interpreted as a device to undermine traditional Muslim values and therefore create Muslim dependency on the West (Cromer 1908; Hoebink 1999). The colonization process was condemned by colonized countries; thus, it is not surprising to hear denunciations of modernity from twentieth-century Islamists and to see Muslim societies avoiding European dynamics, including in modernity and secularity (Martin 1991; Sonn 2005).

\subsubsection{The Republic of Turkey}

To better contextualize the aims of this dissertation, it is necessary to briefly review the geographical and political characteristics of the Republic of Turkey. Because of its location straddling two continents, Turkey is referred to as a bridge between Europe and Asia. It shares borders with eight European and West Asian countries: Bulgaria to the northwest; Greece and the Aegean Sea to the west; Georgia to the northeast, with the Black Sea to the north; Armenia and Azerbaijan to the east; Iran to the southeast; and Iraq, Syria, and the Mediterranean Sea to the south (National Geographic 2012). The "Turkification" of Anatolia started with the Seljuk Turks winning the battle of Manzikert in 1071 (Yardumian and Schurr 2011). After the foundation of the Ottoman Empire in 1299, Anatolia (Turkey) became the center of the Ottoman Empire for more than six centuries. The end of the Ottoman Empire led to Mustafa Kemal Ataturk's founding of the Republic of Turkey, becoming the first president of the state in 1923. 


\subsubsection{Turkey's Modernization Process}

The Republic of Turkey was founded as a secular state. The secular ideology of the new state and government of Turkey meant that many reforms incorporated secular Western ideologies. These reforms met resistance among the Turkish people to the extent that they were viewed as incompatible with Islamic values (Saeed 1994). Islam is not inherently opposed to modernization processes, but the Turkish people opposed the initial reforms imposed by the new Turkish government—particularly assertive secularization, the idea of limiting religion in both governmental and public places (Kuru 2009; Mardin 2006). These limitations included banning headscarves in all educational institutions, closing courses on the Quran, and terminating secondary schools with predominantly religious classes (Kuru 2009). This Westernization process, that included both European values and modernization, changed individuals' perspective about modernization because it was viewed as an attack on both individual and religious values (Saeed 1994). This resistance to Western-style modernization has also been observed in other Muslim countries such as Egypt, Tunisia, and Pakistan. This resistance slowed the modernization process in Turkey.

Nevertheless, Turkey did modernize. Modernization efforts in both the Ottoman Empire and the Republic of Turkey played a key role in the socio-economic and political conditions of Turkey today (Çinar 2005). The objections to the secularism of Westernization policies, however, preserved the unique culture of Turkey. If Westernization was taken to its extreme and accepted without resistance by the public, Turkey would have lost its cultural distinctiveness. On the other hand, if the modernization efforts had not started during the Empire, Turkey would likely have 
achieved much less in its modernization progress (Çinar 2005).

\subsubsection{Demographic Statistics on Fertility Decline in Turkey}

Turkey has experienced a significant decline in its total fertility rate beginning around 1960, from 6.50 to 2.10 (World Bank 2015; TSI 2017) and is approaching VLF (see Figure 2.6). Compulsory education reforms (requiring 8 years in 1997 and then 12 years in 2012) have had an important influence on fertility decline observed in Turkey. Women's age at first birth rose as a result of compulsory education reforms, which in 2002 led to an increase in the legal age of marriage from 15 to 17 years (Dayioglu and Kirdar 2010; Ince 2010). Education reforms and legal changes to marriage age negatively affected the number of children ever born to married women age 15-49, because almost all births occur within a marital bond in Turkey (TDHS 2013). Beginning in the 1970s, the use of modern contraceptive methods began to increase in Turkey (Senlet et al. 2001). Increased use of modern contraceptive methods constitutes another factor that negatively affected the number of children ever born to ever-married women (TDHS 2013). The greater use of modern contraceptive methods also contributed to a decline in the rate of induced abortions (which were legalized in 1983) because modern reversible methods have a much lower failure rate than traditional (e.g., coitus interruptus) methods (Senlet et al. 2001).

\subsection{The Current Study}

The application of the secularization model for understanding Turkish fertility decline is unclear, given that prior research has examined SDT theory in largely Christian countries where modernization processes (including increasing education and egalitarian ideology) have occurred simultaneously with declining frequency of religious behaviors 
(e.g., Kane 2013) — a condition not observed in Turkey. Contrary to common Western belief, Islamic teachings do not view the pursuit of rational and secular thoughts- key components of modernization — as incompatible with religious teachings (Munir 2003; Okumuş 2008; Sonn 2005). Thus, there remains a critical need to examine whether the European secularization model applies to Turkey, or whether a refinement of this perspective to focus on modernization as separate from declining frequency of religious behaviors is needed to understand Turkish fertility change. Failure to understand the Islamic context of Turkey may result in ineffective government policies aimed at improving Turkey`s fertility rate so as to preserve its position in the global market.

My overall goal is to understand how the unique cultural and geographical context of Turkey, one influenced by both Western and Eastern cultural traditions, shapes the nature and the speed of demographic changes in the country (Bongaarts and Bulatao 1999). The immediate goal of the current study is to investigate the indicators of fertility — specifically the number of children and the two proximate determinants of fertility, contraceptive use and induced abortion receipt (Bongaarts 1978) — by separately examining modernization (education, egalitarianism, urbanization) and secularization (measured in this study by its opposite, individual level religiosity). It is well established that modernization and secularization are negatively associated with fertility behaviors in modern Christian nations (Kane 2013; Lesthaeghe 2010), but I expect to find that it is not in Muslim nations, specifically in Turkey. Thus, my central hypothesis is that the interaction between modernization and religiosity will not be significantly associated with indicators of fertility behaviors. That is, for example, the effect of women's 
religiosity on her number of children will not depend on her level of modernization (education, egalitarianism, and urban residence).

The general literature argues that modernization and secularization co-occur and do not have independent effects on fertility (Lesthaeghe 2010). Indeed, as I showed above in section 2.4.1 on European fertility, there is a statically significant and negative interaction between modernization (women's education) and religiosity on women's parity in Europe. Thus, there is empirical support for the theoretical proposition of the secularization argument of SDT theory, as depicted in panel A of Figure 2.5. In contrast, I argue that modernization and religiosity in Turkey are separate process and independently affect fertility behaviors, as depicted in panel B of Figure 2.5.

\subsubsection{Hypotheses}

I test three hypotheses as to whether modernization and secularization are separately and independently associated with fertility in Turkey. These hypotheses are described below and also in Table 2.1, which shows how my expectations contract with those derived from the secularization argument of SDT theory:

H1: I hypothesize that modernization will be negatively associated with the number of children born to a woman, and a positive association between religious behaviors and the total number of children born to a woman, but that the interaction effects of modernization (education, egalitarianism, and urban residence) and religiosity variables will not yield a significant association with the number of children.

H2: I hypothesize that modernization will be positively associated with contraceptive use, but that there will be no association between religious behaviors and contraceptive use, as contraceptive use in Islam is generally permissible. The interaction 
terms between modernization (education, egalitarianism, and urban residence) and religiosity will also demonstrate no significant association with contraceptive use.

H3: I hypothesize that modernization will be positively associated and that religious behaviors will be negatively associated with abortion, given Islamic prohibition against the practice, but that the interaction terms between modernization (education, egalitarianism, and urban residence) and religiosity will demonstrate no significant association with abortion use because primary interpretation of Islam generally prohibits abortion use but it also allows it in some conditions. 


\section{CHAPTER 3: DATA AND METHODS}

\subsection{Turkey Demographic and Health Surveys (TDHS)}

This study uses data from Demographic and Health Surveys (DHS) for Turkey. DHS programs provide technical assistance to more than 300 surveys in approximately 100 countries to advance global knowledge on the trends of health and population in developing countries. The DHS program is funded by the U.S. Agency for International Development (USAID) and participating countries. The surveys include basic household characteristics and a detailed interview with women age 15-49, who are in the childbearing ages. In some countries, data collected from only women who have been in a union but in others, include all women who are in the childbearing age.

The Turkey Demographic and Health Surveys (TDHS) are face-to-face, nationally representative household surveys conducted in rural and urban areas in five regions of Turkey in 1993, 1998, 2003, 2008 and 2013. TDHS use a weighted, multistage, stratified cluster sampling approach in selection of all samples to provide estimates for a variety of characteristics for various domains (Turkey as a whole, Urban and rural areas, five major regions of the country, the 12 Nomenclature of territorial units, seven largest metropolitan cities (each with populations above one million). The purpose of the TDHS is to provide updated information about a number of factors, including demographic and health indicators, fertility, contraceptive knowledge and use, abortion practices, maternal and child health, nutritional status of mothers and children, and socioeconomic characteristics of households for policymakers and researchers (TDHS-2008, 2013). I use only TDHS-2008 and 2013 because they are only surveys that have religiosity measures including performing namaz (praying five times in a day), fast (fasting during Ramadan 
month) and wearing a headscarf. Thus, these surveys are used to test the hypotheses of this present study.

The TDHS-2008 was implemented by Hacettepe University Institute of Population Studies (HUIPS) in collaboration with the General Directorate of Mother and Child Health and Family Planning, Ministry of Health and the Undersecretary of State Planning Organization. The TDHS-2013 was carried out by HUIPS in collaboration with The Ministry of Development and the Ministry of Health, Public Health Institution. Both surveys were entirely funded by the Government of Turkey through the Scientific and Technological Research Council of Turkey (TÜBİTAK) within the scope of the Support Programme for Research and Development Projects of Public Institutions (KAMAG) (TDHS-2008, 2013). Fieldwork for the surveys was completed in 3 months (from October to December) for TDHS-2008 and in 5 months (from September to January) for TDHS-2013.

Two different questionnaires (household and individual) were used to collect the data of TDHS-2008 and TDHS-2013. These questionnaires were formed by using the international DHS program survey project model questionnaires and the questionnaires that have been used in previous Turkish population and health surveys to ensure that the results of TDHS-2008 and 2013 would be comparable with previous TDHS. First, the Household Questionnaire was used to gather information for each household member regarding their sex, age, education, marital status, employment status, and relationship to the household head. The household questionnaire also collected data on households' socio-economic levels and wellbeing of the elderly, if any resided in the households. For example, the wealth was measured by households' socioeconomic characteristics. 
Second, the Individual Questionnaire for TDHS 2008 includes only ever-married women who are reproductive age while TDHS-2013 includes all women who are in the reproductive age. For both questionnaires, reproductive age ranges from 15 to 49, and questionnaires include all women who usually live and/or were present in the selected household on the night before the interview. The individual questionnaire includes information on women's background characteristics, migration history, marriage history and information on marriage, pregnancy, birth history, fertility preferences, assisted reproductive techniques, knowledge and use of contraceptive methods, antenatal and postnatal care, breastfeeding, nutrition, diarrhea and immunization of children under age five, work history and status, husband's background characteristics, anthropometric measurements of women and their children under five (TDHS-2008:13, 2013:14).

More than $90 \%$ of women who were identified as eligible on the night before the interview completed the interviews. TDHS-2008 identified 8003 women as eligible for individual interviews and 7405 (92.5\%) of these interviews were finished. TDHS-2013 sampled 10840 women as eligible and successfully completed 9746 (90.0\%) individual interviews. Questionnaires were completed in Turkish by $95.6 \%$ and $96.8 \%$ of respondents in TDHS 2008 and TDHS 2013, respectively. Less than 5 percent of the respondents preferred another language (e.g., Kurdish, Arabic). The primary reason for non-response among eligible women was that they were not present in the household during the extended time-period of the surveys.

\subsubsection{Analytic Sample}

For the present study, I limited my sample to the TDHS-2008 and 2013 respondents who were currently married (by excluding women who were "never in a 
union [available only in TDHS-2013]," "divorced," "widowed," and "no longer living together") because almost all births are marital in Turkey_-based on 2013 statistics all births happen in a marriage- (TDHS 2008, 2013). In 2008, 363 women-146 of them are widowed, 156 divorced, and 61 no longer living together-were excluded. In 2013, $2911(29.9 \%)$ women -2527 of them are never in a union, 120 widowed, 194 divorced, and 70 no longer living together-were excluded. I pooled the data across both survey years to increase statistical power; preliminary analyses show that there were not statistically significant differences between models in 2008 and 2013.

Missing data among married respondents were minimal: respondent's mother tongue group (Turkish) $(0.01 \%)$, contraceptive use $(0.01 \%)$, use of induced abortion $(0.06 \%)$, frequency of wearing a head-scarf $(0.16 \%)$, frequency of performing namaz $(0.25 \%)$, husband's education $(0.34 \%)$, opinion on "husband should help household chore" $(0.36 \%)$, opinion on "better to educate son rather than daughter" $(0.39 \%)$, opinion on "family decisions should be made by men" $(0.63 \%)$, frequency of fast $(0.69 \%)$. I excluded the total of 302 cases (2.15\% of total cases) through listwise deletion. My analytic sample was 13575 ever-married women (6888 from TDHS-2008 and 6687 from TDHS-2013).

\subsection{Measures}

\subsubsection{Dependent Variables}

Three dependent variables are used as indicators of fertility behaviors: the number of children born, contraceptive use, and abortion use.

The first variable measures the number of children ever born to a currently married woman. Descriptive statistics of this count variable show that women had an 
average of 2.51 children. The modal number was two children $(31.82 \%)$, but it is also apparent that higher parities were not uncommon. For example, $9.50 \%$ of married women had 4 children, $4.87 \%$ had 5 children, and $2.85 \%$ had 6 children. Only a very small number of women had 7 or more children. Therefore, I coded this variable into 8 categories from $0=$ No child to $7=7+$ children. In preliminary analyses, I tested alternative specifications of the number of children and findings show that Wald ChiSquare improved up until 8+ children (10971.56 for categories from 0 to 5+ children, 12071.61 for categories from 0 to $6+$ children, 12447.96 for categories from 0 to $7+$ children, and 12450.71 for categories from 0 to $8+$ children). These preliminary results indicate that making the highest category $7+$ children had the best model fit, and that including categories above 7 children was therefore not necessary.

The second set of dependent variables measure contraceptive use, and asks if the respondent ever used a contraceptive method and what is the currently used contraceptive method. From the questions about contraceptive use I created two variables. First, I created a simple binary variable (none $=0$ and any contraceptive use $=1$ ). Second, I created a multinomial variable. Contraceptive methods being used is coded as $0=$ No Method (omitted reference in multinomial model), $1=$ Traditional Methods (Periodic Abstinence, Withdrawal, and Lactational Amenorrhea), 2 = Modern Reversible Methods (Pill, Intrauterine Device, Injections, Diaphragm/Foam/Jelly, Condom, Norplant, Female Condom, and Other), and 3 = Permanent Methods (Female and Male Sterilization).

The third dependent variable measures abortion use and asks if respondents have had any "pregnancies [end] in induced abortion" and the number of such pregnancies. 
This variable is coded as both a binary variable (none $=0$ and any abortion use $=1$ ) and as a count variable, number of abortion ( 0 to $3+)$.

\subsubsection{Independent Variables}

The present study has four focal independent variables. Three variables are primary components of modernization that are measured through education, egalitarianism scale, and urbanization. The last variable measures religiosity.

\subsubsection{Modernization}

The first independent variable measures highest education level in four categories: $0=$ No Education, $1=$ Primary and Middle school, $2=$ Secondary and $3=$ Higher. The primary category includes the first eight years of education from general and vocational schools. The secondary category includes high school education from both general and vocational high schools. The higher category includes Bachelor's, Master, and PhD.

The second variable measures egalitarianism with a scale using three variables that asked respondents whether they agreed or disagreed with the following questions: (1) "the important decisions in the family should be made only by men of the family," (2) "it is better to educate a son than a daughter," (3) "men should also do the housework like cooking, washing, ironing, and cleaning." The choice categories of variables measuring women's opinion on "the important decisions in the family should be made by men of the family" and "it is better to educate a son than a daughter" are coded as $0=$ Agree and $1=$ Disagree. The choice categories of the variable measuring women's opinion on "men should also do the housework like cooking washing, ironing, and cleaning" is recoded 0 $=$ Disagree and $1=$ Agree to create a scale in which higher values indicate more egalitarian attitudes of women. 
Nunnally (1978) argues that reliabilities that exceed 0.700 are considered acceptable. The three variables measuring egalitarian attitudes have an alpha score of 0.440 - below the recommended cut-off value of $(0.700)$ - but this score is acceptable for a three item-scale because Cronbach's alpha calculation depends both on the correlation between the items in a scale and the number of items in the scale (Ladhari 2010). Therefore, a small number of items in a scale makes them more unstable and decreases their alpha score (Moss et al. 1998). In addition, preliminary factor analysis also indicated that these three items are loaded on a one-factor (they are unidimensional). The egalitarianism scale was calculated through the summation of the items described above to range from low (0) to high (3) egalitarian gender ideology.

The third independent variable is urban, measured as a binary variable measuring if respondent's residence is $0=$ Rural and $1=$ Urban. Residence areas with a population of less than 10000 were defined by TDHS as rural, while residence areas with populations 10000 and more were considered urban.

\subsubsection{Secularization}

The fourth focal independent variable is religiosity, measured with three variables that asked respondents: (1) "Do you perform the namaz?" (2) "Do you fast?" and (3) "Do you wear a headscarf when you go outside?" All three variables are codes as follows: $0=$ No, $1=$ Regular, and $2=$ Irregular. I recoded these variables into binaries where $0=$ No and Irregular, and $1=$ Regular. Therefore, the scale ranges from low religiosity $(0$, or no religious actions) to high religiosity ( 3 , or regularly performing all three religious actions). 
In preliminary analyses, I tested alternative specifications of the religiosity variables. I generated two different versions of these variables. First, I recoded variables as ordinal where $0=$ No, $1=$ Irregular, and $2=$ Regular. Second, I created binary variables having categories where $0=$ No and $1=$ Irregular and Regular. I computed Wald tests after regression analyses for each versions of each variable stated above. Preliminary results showed that the versions of religiosity variables that I use provide, respectively, more meaningful results and better fit statistics (e.g., larger Wald ChiSquared scores [8926.05]) than other versions (8925.52, and 8920.05). Therefore, I use the first version of religiosity variables, and they have 0.624 alpha score, which is acceptable for three-item scale and quite close to the cut-off point $(0.700)$ recommended by Nunnally (1978). The scale score is computed by simple summation of items, and the scale has ranges from 0 to 3; the higher the category, the higher religiosity respondents have.

\subsubsection{Control Variables}

All analyses control for several factors associated with modernization, religiosity, and fertility behaviors: Proximate Determinants of Fertility (PDF), women's characteristics, household characteristics, region, and survey year.

The variables that control for PDF includes: Age at first sex (measured through "age at first marriage" in 2008 and "age at first cohabitation" in 2013, given the strong norms against premarital sex in Turkey). This is a continuous variable and is centered to zero to avoid multi-collinearity. All dependent variables (The Number of Children, Contraception Methods, and Abortion Use) are also PDF and are used as control variables in the analyses where they are not dependent variables because they are all 
highly related to each other, thus, controlling for these variables will provide more meaningful results.

The following variables measure women's sociodemographic characteristics: respondent's employment asking respondent "Are you currently working?" $0=$ No, $1=$ Yes. Respondent's age is a continuous variable and is centered at age $15(=0)$ to avoid collinearity issues and to make a more interpretable constant. Husband's education is coded as: $0=$ No Education, $1=$ Primary, $2=$ Secondary, and $3=$ Higher. Mother tongue variable is used to indicate ethnicity but because classifying ethnic groups requires a more complex procedure I use the term mother tongue groups as Yavuz (Yavuz 2008) did. This measurement is a dummy variable coded as $0=$ Others and $1=$ Turkish. A woman's economic status is measured through household wealth. DHS created this variable by following the procedures for a wealth index. The index was created by using household asset data that includes almost all household belongings (ranging from a television to a car), utility services (telephone, internet, and so on), and dwelling characteristics (e.g., source of drinking water, and type of flooring material) that reflect economic status: $1=$ poorest, $2=$ poorer, $3=$ middle, $4=$ richer, and $5=$ richest, which is also recoded so that zero (0) is the lowest category to make for a meaningful constant. More specifically, DHS created the wealth index as explained in the following paragraph:

Each asset was assigned a weight (factor score) generated through principal component analysis, and the resulting asset scores were standardized in relation to a standard normal distribution with a mean of zero and standard deviation of one (Gwatkin et al. 2000). Each household was then assigned a score for each asset, and the scores were summed for each household. Individuals were ranked according to the total score of the household in which they reside and divided into population quintiles (five groups with the same number of individuals in each category). (TDHS 2008, 2013:39). 
As described in the literature review there are differences in birth rates by region; therefore, I also control for regional differences. Region is captured with four dummy variables (Center, North, South, and East). West is the reference category because it is the most developed and Europeanized part of Turkey.

Finally, Year of the survey is included as a binary control variable as $0=2008$ and $1=2013$.

\subsection{Analytic Strategy}

This study has three empirical sections following the given approach above for each dependent variable: number of children ever born to a currently married woman, contraceptive use, currently used contraceptive method, ever-used induced abortion, and the frequency of induced abortion use. In order to examine the effects of interactions terms between modernization and religiosity on these indicators of fertility behaviors, appropriate regression analyses (Poisson, Binary Logistic, Multinomial Logistic, and Negative Binomial Regressions) are respectively estimated for each dependent variable.

First, to address the effects of modernization and religiosity on the number of children ever born to currently married woman, Poisson regression models (PRM) are estimated because the dependent variable, as can be seen in Figure 3.1, does not have excessive zeroes, and descriptive statistics also show that variance and mean scores are almost equal, (2.81 and 2.49, respectively). One assumption of PRM is that the variance and mean are equal (equidispersion), whereas this assumption is generally violated and over-dispersion or under-dispersion happens. In this case, over-dispersion happens. In rare cases like this, to decide whether this over-dispersion suggests PRM or Negative Binomial Regression Model (NBRM), the appropriate test ("countfit" code in Stata) was 
conducted. This test shows that PRM has better fit than NBRM. More specifically, statistics show that PRM has smaller Bayesian Information Criterion (BIC) and Akaike Information Criterion $(\mathrm{AIC})$ scores $(\mathrm{BIC}=42113.731, \mathrm{AIC}=41963.411)$ than NBRM does $(\mathrm{BIC}=42123.243$ and $\mathrm{AIC}=41965.408)($ Long and Freese 2014).

These results indicate that Poisson distribution (not excessive zeroes- the distribution does not suggest that I need to use a Negative Binomial or Zero-Inflated Poisson (ZIP) model-) is good, and the Poisson model is appropriate. In preliminary analyses, I also ran deviance goodness of fit (gof) tests that measure whether the model's predictions are close to the observed outcomes. The findings show that there is a small value for chi-square, and the findings from the gof test are not statistically significant $(p>0.100)$. The results of these goodness of fit tests also indicate that the model is correctly specified.

The structural model of a Poisson regression is:

$\mu_{i}=E\left(\gamma_{i} \mid x_{i}\right)=\exp \left(x_{i} \beta\right)$

where $y$ is the number of children ever born to currently married woman $i$, with a conditional mean dependent on $x_{\mathrm{i}}$, a vector of individual characteristics. $\beta$ is a vector of regression coefficients. A necessary condition of a Poisson distribution is to exponentiate the product of $x_{i}$ and $\beta$ results in an expected count, $\mu_{i}$ that is positive. The probability of a count given $x_{i}$ is:

$\operatorname{Pr}\left(\gamma_{i} \mid x_{i}\right)=\frac{\exp \left(-\mu_{i}\right)\left(\mu_{i}^{\gamma_{i}}\right)}{\gamma_{i} !}$

and the measurement model is:

$$
\begin{aligned}
& \log _{e}\left(\gamma_{i}\right)=\beta_{0}+\beta_{1} x_{1}+\beta_{2} x_{2}+\beta_{3} x_{3}+\beta_{4}\left(x_{1} * x_{2}\right)+\beta_{5}\left(x_{1} * x_{3}\right)+\beta_{6}\left(x_{2} *\right. \\
& \left.x_{3}\right)+\beta_{7}\left(x_{1} * x_{2} * x_{3}\right)+\beta_{n} \boldsymbol{V}_{n}
\end{aligned}
$$


where $\log _{e}\left(\gamma_{i}\right)=\mu_{i}$ is the expected number of children born to a respondent based on a respondent's level of religiosity, modernization, and so forth. $x_{1}$ is the religiosity scale, $x_{2}$ is woman's education, and $x_{3}$ women's egalitarian ideology.

To test my hypotheses with interaction terms, first, I examine how indicators of the SDT (women's education, gender ideology, urbanization, and the level of religiosity) shape married women's fertility. In addition to the main independent variables, I created two-way cross-product terms between components of modernization and level of religiosity to test if effects of religiosity on fertility behaviors vary by modernization factors. Finally, I include two three-way cross-product terms (religiosity*education*urban and religiosity*gender ideology*urban) to examine how the effects of religiosity on fertility behaviors vary by more components of modernization.

$\beta_{4}, \beta_{5}$, and $\beta_{6}$ are the coefficients of two-way interactions between religiosity and education, religiosity and urban, and education and urban. $\beta_{7}$ is the regression coefficient of the three-way interaction term between religiosity, education, and urban variables. $\boldsymbol{V}$ is the vector of $n$ control variables.

Second, to predict the probability of contraception use of currently married woman, I employed Binary Logistic regression models. The dependent variable (contraception use) is dichotomous and has values $1=$ Yes (Contraception used) and $0=$ No (Contraception never used) and thus, violates some assumptions of ordinary least square regression (e.g., homoscedasticity of the residual and normality of the responses), thus, using Binary Logistic regression models is more appropriate. The equation for Logistic model is: 


$$
\begin{aligned}
& \ln \left\{\frac{\operatorname{Pr}(y=1 \mid x)}{\operatorname{Pr}(y=0 \mid x)}\right\}=\beta_{0}+\beta_{1} x_{1}+\beta_{2} x_{2}+\beta_{3} x_{3}+\beta_{4}\left(x_{1} * x_{2}\right)+\beta_{5}\left(x_{1} * x_{3}\right)+ \\
& \beta_{6}\left(x_{2} * x_{3}\right)+\beta_{7}\left(x_{1} * x_{2} * x_{3}\right)+\beta_{n} \boldsymbol{V}_{n}
\end{aligned}
$$

To make the interpretations more meaningful, we can change the log odds to the odds by reformulating the equation and taking the exponential for both sides of the eq. (4) (Long and Freese 2014) for all equations with binary dependent variables including any contraceptive use, and abortion use. This process provides a multiplicative model instead of a linear model, and the outcome can be interpreted as the odds. The basic formula to estimate contraception use $(\mathrm{Y})=1$ in logit model:

$$
\begin{aligned}
& \operatorname{Pr}(y=1 \mid x)= \\
& \frac{\exp \left(\beta_{0}+\beta_{1} x_{1}+\beta_{2} x_{2}+\beta_{3} x_{3}+\beta_{4}\left(x_{1} * x_{2}\right)+\beta_{5}\left(x_{1} * x_{3}\right)+\beta_{6}\left(x_{2} * x_{3}\right)+\beta_{7}\left(x_{1} * x_{2} * x_{3}\right)+\beta_{n} V_{n}\right)}{1+\exp \left(\beta_{0}+\beta_{1} x_{1}+\beta_{2} x_{2}+\beta_{3} x_{3}+\beta_{4}\left(x_{1} * x_{2}\right)+\beta_{5}\left(x_{1} * x_{3}\right)+\beta_{6}\left(x_{2} * x_{3}\right)+\beta_{7}\left(x_{1} * x_{2} * x_{3}\right)+\beta_{n} V_{n}\right)}
\end{aligned}
$$

After exponentiation of equation, the interpretation of results changes and requires some basic calculations. These calculations depend on the magnitude of $\exp (\mathrm{b})$ score. When $\exp (b)>1$, we can calculate the percent increase with this equation:

$\%$ increase $=(\exp (b)-1) * 100$

When $\exp (b)<1$, we can calculate the percent decrease with this equation:

$\%$ decrease $=(1-\exp (b)) * 100$

Third, to predict the odds of currently using a contraception method by married woman, Multinomial Logistic Regression models are used. The dependent variable, contraception methods, has None, Traditional, Modern Reversible, and Irreversible categories. Because there are 4 categories (with the first category as reference), multinomial regression estimates $3(\mathrm{k}-1=4-1)$ multiple linear regression functions defined as: 


$$
\begin{aligned}
& \ln \left(\frac{\operatorname{Pr}(y=1)}{\operatorname{Pr}(y=0)}\right)=\beta_{0}+\beta_{1} x_{1}+\beta_{2} x_{2}+\beta_{3} x_{3}+\beta_{4}\left(x_{1} * x_{2}\right)+\beta_{5}\left(x_{1} * x_{3}\right)+ \\
& \beta_{6}\left(x_{2} * x_{3}\right)+\beta_{7}\left(x_{1} * x_{2} * x_{3}\right)+\beta_{n} \boldsymbol{V}_{n} \\
& \ln \left(\frac{\operatorname{Pr}(y=2)}{\operatorname{Pr}(y=0)}\right)=\beta_{0}+\beta_{1} x_{1}+\beta_{2} x_{2}+\beta_{3} x_{3}+\beta_{4}\left(x_{1} * x_{2}\right)+\beta_{5}\left(x_{1} * x_{3}\right)+ \\
& \beta_{6}\left(x_{2} * x_{3}\right)+\beta_{7}\left(x_{1} * x_{2} * x_{3}\right)+\beta_{n} \boldsymbol{V}_{n} \\
& \ln \left(\frac{\operatorname{Pr}(y=3)}{\operatorname{Pr}(y=0)}\right)=\beta_{0}+\beta_{1} x_{1}+\beta_{2} x_{2}+\beta_{3} x_{3}+\beta_{4}\left(x_{1} * x_{2}\right)+\beta_{5}\left(x_{1} * x_{3}\right)+ \\
& \beta_{6}\left(x_{2} * x_{3}\right)+\beta_{7}\left(x_{1} * x_{2} * x_{3}\right)+\beta_{n} \boldsymbol{V}_{n}
\end{aligned}
$$

Fourth, to test the effect of modernization and religiosity on ever-used abortion and number of induced abortions used by currently married woman, Logistic regression and Negative Binominal regression models are constructed, respectively. The formula to estimate induced abortion use in logit is the same formula used in equation (5):

$$
\begin{aligned}
& \operatorname{Pr}(y=1 \mid x)= \\
& \frac{\exp \left(\beta_{0}+\beta_{1} x_{1}+\beta_{2} x_{2}+\beta_{3} x_{3}+\beta_{4}\left(x_{1} * x_{2}\right)+\beta_{5}\left(x_{1} * x_{3}\right)+\beta_{6}\left(x_{2} * x_{3}\right)+\beta_{7}\left(x_{1} * x_{2} * x_{3}\right)+\beta_{n} V_{n}\right)}{1+\exp \left(\beta_{0}+\beta_{1} x_{1}+\beta_{2} x_{2}+\beta_{3} x_{3}+\beta_{4}\left(x_{1} * x_{2}\right)+\beta_{5}\left(x_{1} * x_{3}\right)+\beta_{6}\left(x_{2} * x_{3}\right)+\beta_{7}\left(x_{1} * x_{2} * x_{3}\right)+\beta_{n} V_{n}\right)}
\end{aligned}
$$

Lastly, for the number of induced abortions, even though descriptive statistics do not show greater variance than the mean, the dependent variable has excessive zeroes, which does not meet the assumptions of Poisson regression. The test ("countfit" code in Stata) that compares fit of alternative count models also suggests that Negative Binominal regression model fits better than Poisson model for this dependent variable. Specifically, test results show that NBRM has smaller BIC and AIC scores (14349.5 and 14206.7, respectively) than PRM scores (14777.7 and 14642.4, respectively). The equation for Negative Binomial regression is the same as the equation of Poisson Regression: 
$\log _{e}\left(\gamma_{i}\right)=\beta_{0}+\beta_{1} x_{1}+\beta_{2} x_{2}+\beta_{3} x_{3}+\beta_{4}\left(x_{1} * x_{2}\right)+\beta_{5}\left(x_{1} * x_{3}\right)+\beta_{6}\left(x_{2} *\right.$

$\left.x_{3}\right)+\beta_{7}\left(x_{1} * x_{2} * x_{3}\right)+\beta_{n} \boldsymbol{V}_{n}$

Because researchers do not usually like to interpret in terms of logarithms, we can reformulate the equation (2) by taking its antilogarithm for both sides (Moksony and Hegedus 2015):

$\gamma_{i}=\exp \left(\beta_{0}\right) * \exp \left(\beta_{1} x_{1}\right) * \exp \left(\beta_{2} x_{2}\right) * \exp \left(\beta_{3} x_{3}\right) * \exp \left(\beta_{4}\left(x_{1} * x_{2}\right)\right) *$

$\exp \left(\beta_{5}\left(x_{1} * x_{3}\right)\right) * \exp \left(\beta_{6}\left(x_{2} * x_{3}\right)\right) * \exp \left(\beta_{7}\left(x_{1} * x_{2} * x_{3}\right)\right) * \exp \left(\beta_{n} \boldsymbol{V}_{n}\right)$

The coefficient $\beta_{1}$ has an additive effect of the explanatory variable on the $\log (\gamma)$ scale, $\exp \left(\beta_{1}\right)$ represents incidence-rate ratios (IRR), which have a multiplicative effect in the $\gamma$ scale, indicating "how many times larger (or smaller) the mean frequency of the phenomenon under study becomes as the independent variable increases by one unit" (Long and Freese 2014; Moksony and Hegedus 2015:101).

DHS recommends sample weights for all analyses to adjust for non-response. The weights that are used for all units of analyses in DHS are to make the sample data representative of the population. DHS sample weights are computed with six decimals, but they are presented without decimal points in the standard data files. For example, for women dataset, DHS provides a weight variable (v005) that does not include decimal points; thus, analysts need to divide that variable by 1000000 and create a new variable. I created this variable for sample weight and used that sampling weight variable in all analyses. I use the Stata/MP 14.0 software package to perform all statistical analyses stated above. 


\subsection{Descriptive Statistics}

Tables 3.1 and 3.2 present descriptive statistics for the analytic sample. I also presented a correlation matrix for all study variables in Appendix B. As expected, women in the sample are quite religious with a mean score of 2.154 (out of three) on the religiosity scale. Although not shown in the table, in fact, almost half (47.3\%) of married women regularly practice all three religious behaviors (praying, fasting, and wearing a headscarf). Variables measuring the level of modernization of women show that a majority of women completed primary education $(60.4 \%)$. In addition, there is a statistically significant $(p<0.001)$ increase in women's education from 2008 to 2013 . A majority of women have egalitarian ideology in their households (mean=2.384) and this again significantly $(\mathrm{p}<0.001)$ increased between 2008 and 2013. More than four out of five women $(84.0 \%)$ chose answers supporting egalitarian ideology for at least two statements measuring gender ideology in households (not shown). A majority of respondents $(73.0 \%)$ were living in urban areas. Although urbanization is generally increasing in Turkey, though data do not show a statistically significant increase from 2008 to 2013.

The four proximate determinants of fertility measures generally show early marriage but also fairly high engagement with methods to avoid pregnancy. The mean age at first sex, which usually indicates the age at marriage in Turkey, is 20 (ranging from 10 to 48$)$. Almost all of married women (90.3\%) have used a contraception method at least once. Almost half of respondents (45.2\%) uses modern methods. Few women use irreversible contraceptive methods $(9.1 \%)$. However, use of irreversible contraception methods significantly increases $(\mathrm{p}<0.050)$ from $8.5 \%$ in 2008 to $9.7 \%$ in 2013 . About 
$16 \%$ of married women ended their pregnancies in induced abortion at least once, although the abortion rate declined over time (from $19.0 \%$ in 2008 to $12.9 \%$ in 2013 ; $\mathrm{p}<0.001)$. The frequency of induced abortion use shows that $10.9 \%$ of married women used induced abortion one time, $3.3 \%$ two times, and $1.7 \%$ three times. The number of children born to a married woman show that the mean children born to a married woman is 2.5 . There is a statistically significant $(\mathrm{p}<0.001)$ drop from the mean of 2.6 children in 2008 to 2.4 children in 2013 .

About $43 \%$ of married women are employed. There is a large and significant increase in the percent of married women's employment from $29.2 \%$ in 2008 to $31.5 \%$ in 2013. Since DHS examines the reproductive period of women from puberty through menopause, women's age ranges from 15 to 49 and the mean age is 34.2 . A majority of husbands completed primary education $(42.7 \%)$ or secondary school $(30.0 \%)$. The mean wealth (2.91) in the sample indicates that a majority of married women are living in at least middle economic status.

A majority of respondents are Turkish $(77.1 \%)$ and about $22.9 \%$ are nonTurkish — primarily Kurdish (19.5\%), with very small percentages of Arabic (around $2.5 \%)$ and others $(0.9 \%)$. A quarter $(25.2 \%)$ of respondents reside in the West region, with $13.7 \%$ from the South, $19.8 \%$ from the Central, $13.2 \%$ from the North, and $28.1 \%$ from the East regions. Lastly, survey year variable shows that the ratio of respondents from 2008 and 2013 surveys is about equal (51.2\% and 48.8\%, respectively). 


\section{CHAPTER 4: ANALYSES OF NUMBER OF CHILDREN}

This chapter presents the results of bivariate and multivariate analyses of modernization and secularization on the number of children born to ever-married women in Turkey. I hypothesized that (H1) modernization would be negatively associated with the number of children, and a positive association between religiosity and number of children, but also that the interaction effects of modernization (education, egalitarianism, and urbanization) and religiosity variables would not provide a significant association with number of children (see Table 2.1).

I expected to find a negative association between modernization and parity rates, because of increasing opportunity cost and changing ideologies, along with modernization and decreased fertility rates (Becker 1981; Lesthaeghe 2014). I also expected to find a positive association between religiosity and parity rates, because most religions encourage their believers to have many children. Religion has quite strong and important effects on fertility rates, so might balance the negative effect of modernization and prevent population growth from going into negative values. Therefore, I expected to find non-significant effects of interaction terms between religiosity and modernization factors.

I used Poisson regression models to examine the interaction effects between women's education, egalitarian gender ideology, urban residence, and level of religiosity on the number of children. Parity is a count of the number of children born and preliminary analyses showed that this count did not have excessive zeroes, and was not over-dispersed as the variance and mean scores were almost equal (2.81 and 2.49, respectively), indicating that the Poisson distribution is appropriate. 


\subsection{Number of Children}

\subsubsection{Bivariate Results}

Table 4.1 shows the exponentiated Poisson regression coefficients (exp[b]) for bivariate analyses between the total number of children born to a married woman and all other variables included in analyses. I used exponentiated coefficients (Incidence Rates Ratio [IRR], in this case) to allow for more meaningful interpretations. IRR scores are interpreted in multiplicative terms; for instance, in calculating "how many times larger (or smaller) the mean frequency of the phenomenon under study becomes as the independent variable increases by one-unit" (Long and Freese 2014; Moksony and Hegedüs 2014).

Consistent with my expectations, religiosity showed a statistically significant $(\mathrm{p}<$ $0.001)$ and positive association ( $I R R=1.237)$. These results indicate that religious women had more children than their counterparts. All modernization factors (women's education, egalitarian ideology, and urban residence) were negative associated with parity $(\mathrm{IRR}=0.658, \mathrm{IRR}=0.840$, and $\mathrm{IRR}=0.794$, respectively $)$ and highly significant $(\mathrm{p}<$ 0.001). All these findings were consistent with my expectations and support the first and second part of my first hypothesis (H1), stating that modernization would be negatively associated with number of children, and projecting a positive association between religiosity and number of children.

These four main variables were highly significant $(\mathrm{p}<0.001)$ and had quite large effect sizes. First, religiosity had IRR $=1.237$ on number of children born to a married woman. Specifically, for a one-unit increase in religiosity, the incidence rates of higher parity is multiplied by a factor of 1.237. An alternative way to interpret this effect is in 
the percentage change, mostly preferred by social scientists, and calculated using the equations (6 and 7) in Chapter 3. For example, the interpretation of religiosity in percentage can be calculated by placing given statistics to the first equation 6 , because IRR is larger than one. $(1.237-1) * 100=23.7 \%$ the change can be interpreted as: the incidence rates of higher parity were $23.7 \%$ larger with each one-unit increase in religiosity.

The constant of this Poisson model had the value of 1.49, indicating the average number of children when all other variables are zero. With the given statistics, I calculated the estimated number of children born for any variable by using this equation (_cons* $(\exp (b) / 1))$, where _cons shows the expected mean value of a dependent variable. $\operatorname{Exp}(b)$, in this case, indicates the exponentiated Poisson coefficient, or IRR, and " 1 " indicates the $100 \%$ incidence rate. The constant must be multiplied with the IRR values because, after exponentiation of a coefficient, the new value becomes a multiplicative value.

For example, we can estimate the average number of children born to a married woman who practices only one religious behavior by placing given statistics into the equation $(1.49 *(1.237 / 1))=1.84$. This finding shows that a married woman who practices only one religious behavior has an average of 1.84 children, after holding all other factors constant. By using the equation above, we can also estimate the average number of children born to married women who practice two and all three religious behaviors $[(1.84 *(1.237 / 1))=2.27$ and $(2.27 *(1.237 / 1))=2.82$, respectively $]$. These results showed that religiosity has the third largest effect size $(2.82-1.84=0.98)$ among 
focal independent variables. Overall, these findings show that married women's religiosity is positively associated with their parity, holding all other factors constant.

Second, women's education is negatively associated $(I R R=0.658)$ with number of children born. This result indicates that for a one-unit increase in women's education, the incidence rates of higher parity multiplied by a factor of 0.658 . We can also calculate the number of children ever born to a married woman for each category of their education.

The constant of this Poisson analyses was 3.81, which indicates the average number of children born to married women with no education. By using these statistical values, we can estimate the average number of children born to married women for each category of their education. For example, the estimated number of children born to a married woman with a primary education can be calculated with the formulation $(3.81 *(0.658 / 1))=2.51$. The estimated number of children born to a married woman with a secondary or higher education can be calculated with the same equation, just by using the estimated number of children from the prior category $[(2.51 *(0.658 / 1))=1.64$ and $(1.64 *(0.658 / 1))=1.08$, respectively]. These findings showed that women's education has the largest effect size $(3.81-1.08=2.73)$ among focal independent variables. Overall, findings showed that married women's education had an inverse effect on the number of children ever born.

Third, egalitarian ideology is negatively associated $(I R R=0.840)$ with number of children born. This finding indicates that a one-unit increase in egalitarian ideology multiplied the incidence rates of higher parity for a married woman by a factor of 0.840 , net of all other factors. The constant of this model was 3.57, which shows the average 
number of children born to married women. One can estimate the number of children born to married women for each category of egalitarian ideology by using the equation given above (_cons*(IRR/1)). When we simply added the given statistics $(3.57 *(0.840 / 1))$, we found that married women who supported only one egalitarian ideology statement had the average of 3.00 children. The estimated number of children born to married women who supported two and three egalitarian ideology statements was calculated with the same equation, using the estimated number of children for the prior category $[(3.00 *(0.840 / 1))=2.51$ and $(2.51 *(0.840 / 1))=2.11]$. These results showed that egalitarian ideology has the second largest effect size $(3.57-2.11=1.46)$ among focal independent variables. Overall, egalitarian ideology had an inverse relationship with number of children born to married women.

Lastly, urban residence had IRR $=0.794$ on number of children born. This finding shows that the incidence rates of higher parity for a married woman living in urban areas were $20.6 \%$ smaller than their rural counterparts, holding all other variables constant. The intercept of this analysis was 2.80 , meaning the average number of children born to rural married women. The parity rate of urban women can be estimated by using the same equation used for the estimations above $(2.80 *(0.794 / 1))=2.23$. This finding indicates that the estimated number of children born to urban women was 2.23 children. These results showed that urban residence has the smallest effect size $(2.80-2.23=0.57)$ among focal independent variables. Overall, results showed living in urban areas as negatively associated with number of children born to married women.

To summarize the effects of the main independent variables on number of children born, I found women's education as the largest effect size. Women with no 
education had 3.81 children on average but women with highest level of education had 1.08 children on average. In addition, egalitarian ideology has the second largest effect and had 2.11 children on average for highest egalitarian ideology (which dropped from 3.57 children on average for women with traditional ideology). Urban residence had 2.22 children on average and rural had 2.80 . On the other hand, religiosity showed that married women with lowest religiosity had 1.84 children on average, but married women with highest religiosity had 2.82 children on average. Based on these statistics, women's education has the largest, egalitarian ideology is second largest, religiosity is third largest, and urban has the smallest effect size.

The variables that measure the Proximate Determinants of Fertility (PDF) showed that age at first marriage had a statistically significant and negative association $(\mathrm{OR}=$ 0.933, $\mathrm{p}<0.001)$ with number of children. Contraceptive use had a statistically significant and positive association $(\mathrm{OR}=1.712, \mathrm{p}<0.001)$ with number of children. Thus, married women who use contraceptives had more children on average. Married women not using any contraceptive methods had fewer $(\mathrm{OR}=0.768, \mathrm{p}<0.001)$ children than other women using any methods. Use of traditional and modern methods had no statistically significant associations. Permanent contraceptive method was positively associated $(\mathrm{OR}=1.638, \mathrm{p}<0.001)$ with number of children born to a married woman. Similarly, abortion use and frequency were statistically significant and positively associated $(\mathrm{OR}=1.261, \mathrm{p}<0.001$ and $\mathrm{OR}=1.153, \mathrm{p}<0.001$, respectively $)$ with number of children. These findings are not surprising given the cross-sectional nature of the data-women with more children are more apt to have completed their family size and thus be actively trying to avoid pregnancy/ birth. 
The variables measuring women's and household characteristics showed women's employment was statistically significant and negatively associated $(\mathrm{OR}=0.888, \mathrm{p}<$ 0.001) with number of children. As expected, women's age was positively associated $(\mathrm{OR}=1.039, \mathrm{p}<0.001)$ with number of children. Husband's education, wealth, and Turkish ethnicity had negative associations $(\mathrm{OR}=0.750, \mathrm{p}<0.001 ; \mathrm{OR}=0.863, \mathrm{p}<$ 0.001; OR $=0.627, \mathrm{p}<0.001)$ with number of children.

Among the region variables west and central had statistically significant and negative associations $(\mathrm{OR}=0.793, \mathrm{p}<0.001$, and $\mathrm{OR}=0.976, \mathrm{p}<0.001)$ with number of children. The negative association for the central region might stem from the fact that the capital city is located there. The west region is the most developed and Europeanized in Turkey. The south and east regions had statistically significant and positive associations $(\mathrm{OR}=1.069, \mathrm{p}<0.001$ and $\mathrm{OR}=1.504, \mathrm{p}<0.001)$ with number of children, and the north region was not significantly associated with parity.

Lastly, the regression coefficients of survey year showed total number of children born to a married woman as declining $(\mathrm{OR}=0.944, \mathrm{p}<0.001)$ from 2008 to 2013. This finding is consistent with declining birth rates in Turkey across this time period (World Bank 2015).

\subsubsection{Multivariate Results}

Table 4.2 presents the Poisson regression of the number of children on key independent variables, religiosity, women's education, egalitarian ideology, and urban residence. The IRR are presented in the tables for all Poisson regression analyses.

The results in Model 1 indicate that a one-unit increase in religiosity multiplied the incidence rates of a married woman having had another child by an additional 1.069 
(or $(1.069-1) * 100=6.9 \%$ ), holding the other variables constant. A one-unit change in religiosity indicates the difference, for example, between a respondent who never practices any religious behaviors and one who practices one of three religious behaviors (fasting during Ramadan, prays five times in a day, or wears a headscarf). All else being equal, the estimated parity for a married woman who practices none of the religious activities is 2.44 . The estimated parity was calculated for other categories by using this equation: $(2.44 *(1.069 / 1)=2.61$ children for a married woman who practices only one religious behavior, $(2.61 *(1.069 / 1)=2.79$ children for a married woman who practices two religious behaviors, $(2.79 *(1.069 / 1)=2.98$ children for married women who practice all three religious behaviors, while holding all other factors constant.

The findings of control variables were generally consistent with the prior literature, and their effects were similar across all models shown in Table 4.1 and Table 4.2. The variables measuring (PDF) showed the expected results. Age at first marriage was statistically significant $(\mathrm{p}<0.001)$ and negatively associated $(\mathrm{IRR}=954)$ with the parity level of married women; thus, a later age at first marriage reduces the incidence rates of higher parity, net of other factors. The variables measuring contraceptive methods showed using any kind of contraceptive methods (traditional, modern reversible, and permanent vs. none) was statistically significant (all has $p<0.001)$ and positively associated ( $I R R=1.310, I R R=1.394$, and $I R R=1.596$, respectively) with higher parity level. In addition, the number of induced abortions used by a married woman was also significantly $(\mathrm{p}<0.010)$ and associated with (IRR $=1.021)$ a higher number of children born to that woman. 
This finding indicates that induced abortion is used either for purposes of limiting or spacing births. Prior studies suggest that even though distribution of abortion use by parity varies across countries (Henshaw 1986), the abortion use for limiting or spacing births is common among older women in some Eastern nations (Westoff et al. 1998). The abortion rates among younger people (age group 20-24) tend to peak in English-speaking countries. Thus, in developed countries induced abortion is used to prevent having any child, while in developing and some recently developed countries induced abortion is generally used following initiation of childbearing to spacing or limit subsequent births.

Variables controlling for women's individual and household characteristics also showed generally expected findings. Women's employment was negatively associated $(\mathrm{IRR}=0.952, \mathrm{p}<0.001)$ with the parity level. Women's age was positively associated $(\mathrm{IRR}=1.040, \mathrm{p}<0.001)$ with the parity level of a married woman. However, husband's education, household wealth, and Turkish ethnicity were negatively associated (all $\mathrm{p}<$ 0.001 , and respectively $I R R=0.929, I R R=0.937$, and $I R R=0.768)$ with parity.

Variables for region showed all regions (south with IRR $=1.091$, central with IRR $=1.047$, north with IRR $=1.062$, and east with $I R R=1.240)$ had higher parity rates than the west region. Again, the western part of Turkey is the most developed and Europeanized. In addition, the variable controlling for survey year continued to show lower parity for married women in 2013, compared to 2008.

Model 2 presents the results incorporating both religiosity and components of modernization. A one-unit increase in religiosity multiplied the incidence rates of higher parity of a married woman by an additional 1.057 (IRR), holding all modernization variables and other control variables constant. Adding modernization factors resulted in a 
slight decrease in the effect of religiosity between Models 1 and 2 (from IRR $=1.069$ to IRR $=1.057)$. Post-estimation Wald $\mathrm{X}^{2}$ indicated this was a statistically significant change $(\mathrm{p}<0.001)$. The strength of the religiosity effect between Models 1 and 2 remained robust. However, this finding also showed the effect of religiosity on married women's parity as minimally mediated by these modernization factors. This indicates that religion had a quite strong association with the number of children born to a married woman.

Except for urban residence, the components of modernization were negatively associated with number of children born to a married woman. For example, a one-unit increase in woman's education multiplied the incidence rates of the woman would have had another child by a factor of 0.921 (IRR), net of all other control variables. I calculated the estimated parity at different levels of education. The constant value of this analysis was 2.44 , showing the average parity while holding all factors constant. This means 2.44 children for women with no education, $(2.44 *(0.921 / 1))=2.25$ children for women with primary education, $(2.25 *(0.921 / 1))=2.07$ children for women with secondary education, and $(2.07 *(0.921 / 1))=1.91$ children for women with higher education. These results indicated women's education as a statistically significant and quite large association with the number of children born to married women in Turkey.

Similarly, a one-unit increase in egalitarian ideology multiplied the incidence rates of a married woman having had another child by a factor of 0.971 , holding all other factors constant. A one-unit increase in egalitarian ideology indicates, for example, the difference between a respondent who favored statements measuring egalitarian gender ideology and one who supported one of the statements. By using the same equation 
above, I calculated the estimated parity at different levels of egalitarian ideology. The intercept was 2.44 , the average parity, after holding all factors constant in the model. This means women with no egalitarian ideology had 2.44 children. For women who supported one statement measuring egalitarian ideology, the estimated number of children was $\left(2.44^{*}(0.971 / 1)\right)=2.36$. For women who supported two statements measuring egalitarian ideology, the estimated parity was $(2.36 *(0.971 / 1))=2.29$. For women with egalitarian ideology, the estimated parity was $(2.29 *(0.971 / 1))=2.22$. These findings show that egalitarian ideology has a very small but statistically significant association with the number of children of married Turkish women, all else being equal.

Unexpectedly, urban residence was positively association with number of children born to a married woman. More specifically, the incidence rates for higher parity of a married woman living in an urban area were $2.3 \%$ larger than for a married woman living in a rural area, net of all other factors. Preliminary analyses showed that the magnitude and direction of urban variable changed (from 0.967 IRR to 1.022 IRR) after controlling for wealth, suggesting wealth was acting as a "distorter" variable. According to Rosenberg (1968: 94), "a distorter variable reveals that the correct interpretation is precisely the reverse of that suggested by the original data."

In the present case, the inclusion of wealth in the model reversed the negative association between urban residence and number of children into a positive one. There is an inverse association between wealth and parity for several reasons: 1) Time is more expensive for wealthy people (opportunity cost); thus, they generally have two or fewer children (Becker 1981; Kaplan 1996; Kaplan et al. 1995). 2) Wealthy people prefer quality over quantity and raise quality children because of human capital they have; thus, 
they generally have fewer children than lower income people (Becker and Lewis 1973; Moav 2005). 3) Aging parents are usually taken care of by their children, but such an oldage security motive is less necessary for wealthy parents (Rendall and Bahchieva 1998). Yet. wealth is positively associated with urban because urban life is more expensive than rural life and wealthy persons are able to afford to support more children. Thus, once I controlled for wealth I found that urban was associated with a higher parity.

\subsubsection{Interaction Results}

Table 4.3 presents the key tests for my first hypothesis (H1). The table shows the results of interactions between religiosity and components of modernization on the number of children born to a married woman. Model 1 shows the interaction between religiosity and women's education as not statistically associated with married women's parity. Similarly, Model 2 shows the interaction term between religiosity and egalitarian gender ideology as not statistically significant with number of children ever born to a married woman. Model 3, however, presents a marginally significant $(\mathrm{p}=0.050)$ and positive association between the interaction between religiosity and urban, and number of children ever born to a married woman. The control variables interpreted above in previous table (4.2) remain significant and are quite similar in magnitude in Model 1 across Model 7 in Table 4.3.

This statistically significant interaction between religiosity and urban residence (model 3) shows that for a married woman living in urban areas, a one-unit increase in the religiosity multiplied the incidence rates of higher parity by an additional 1.023 (IRR), holding other factors in the model constant. Figure 4.1 graphically presents the interaction between religiosity and urban residence on parity and shows almost perfectly 
parallel lines, probably because the significance level of this interaction is the cut-off point $(\mathrm{p}=0.050)$. This interaction effect indicates that the effect of religiosity on a married woman's parity slightly depends on her residence area (urban vs. rural). This positive association between the interaction variable and married women's parity nevertheless supports my argument that the effect of religiosity and modernization factors (in this case, urban) can coexist because SDT theory would predict a negative association (see Table 2.1).

In order to make sure these unexpected results were not caused by the effect of distorter variable (wealth) on urban residence, in the supplementary analysis I excluded the wealth variable from the analysis of Model 3, and neither the magnitude nor significance level of the interaction variable changed; however, the $\mathrm{p}$ value dropped from 0.050 to 0.016 , indicating a more significant effect. These supplementary findings indicate that this unexpected finding was not caused by the distorter variable wealth.

Overall, the findings were consistent with my first hypothesis (H1). Models 1 and 2 (Table 4.3) show that the effect of religiosity on parity did not vary by modernization components. Model 3 also shows that the effect of urban on parity depends on the effect of religiosity, which still supports my argument that secularization is not an inevitable result of modernization.

Models 4 and 5, however, unexpectedly showed statistically significant ( $\mathrm{p}<$ 0.001 ) and positive interactions between women's education and urban residence, and between women's egalitarian ideology and urban residence. This significant and positive association of the interaction in Model 4 demonstrates the negative effect of women's education on the incidence rates of higher parity was $6.3 \%$ larger in urban areas than rural 
areas, after controlling for other factors in the model. The interaction plot in Figure 4.2 presents the interaction between women's education and urban residence on parity; the lines are not parallel. The lines in the plot demonstrate that urban women (especially women with higher education) having had more children than their rural counterparts. This interaction effect indicates that the association between women's education and married women's parity varies by residential area (urban vs. rural).

Similarly, the association in Model 5 (Table 4.3) shows that the negative effect of egalitarian ideology on the incidence rates of higher parity was $3.1 \%$ larger in urban areas than rural areas, net of other factors in the model. Similarly, as in Model 3, supplementary analyses indicated that the results of these interaction variables in Model 4 and 5 were not affected by wealth. Figure 4.3 presents the interaction between egalitarian ideology and urban residence on the number of children ever born; the lines as not parallel. This interaction effect indicates that the effect of egalitarian ideology on married women's parity depended on residence area (urban vs. rural). Both Figures 4.2 and 4.3 reveal that urban married women with higher education and higher egalitarian ideology had more children than their rural counterparts.

Models 6 and 7 (Table 4.3) present the results of three-way interactions between religiosity and components of modernization. Model 6 shows a non-significant association between the first three-way interaction term between religiosity, woman's education, and urban residence and number of children born to a married woman. Similarly, Model 7 shows the association between number of children born to a married woman and the second three-way interaction between religiosity, egalitarian gender ideology, and urban residence as not statistically significant. 


\subsubsection{Supplemental Analyses of Binary Fertility Measure}

I ran supplementary analyses to test the effects of modernization and secularization on a dichotomous fertility variable, where $0=$ childless and $1=$ having at least one child. These results showed that contraceptive use and methods have unexpectedly large effect sizes due to multicollinearity. When I further checked the descriptive statistics of contraceptive use, I found out that the number of married women with no children and who also use no contraceptive methods was quite small, 400 respondents (3.3\% of total sample). Because of the multicollinearity issue, in further analyses, I ran my models without controlling for contraceptive use; these findings showed almost all my indicators (including main independent variables) were not statistically significant. When I exclude married women's age—which I suspected explained married women's childlessness - the results showed some statistically significant associations. These supplementary analyses indicated that married Turkish women in the reproductive years are childless because of their age; that is, they are young and have not yet initiated childbearing. I did not further pursue these analyses due to this finding.

\subsubsection{Summary}

To summarize the findings, the main independent variables showed findings consistent with the literature: 1) a married woman's religiosity was associated with the higher parity, and 2) components of modernization were negatively associated with parity. The exception to this latter point was that urban residence was influenced by the distorter variable wealth. 
On the other hand, interaction terms provide quite interesting findings. The twoway interaction terms between religiosity and two components of modernization (women's education and egalitarian ideology) had statistically non-significant associations, but the interaction term between religiosity and urban residence provided a statistically significant and positive association with number of children born to a married woman. These statistically non-significant findings support my hypothesis (H1) and my argument that the effects of religiosity on parity do not depend on modernization in Turkey. These results contradict the general literature-where modernization and secularization are generally accepted as hand-in-hand processes, which exert a joint negative affect on fertility behaviors (Lesthaeghe 2010, 2014).

Furthermore, the interaction term between religiosity and urban residence was statistically significant and positively associated with married women's parity. This finding also supports the first hypothesis (H1); this positive association shows that both modernization factor (urban residency) and religiosity can coexist. This positive association also forms a key divergence because the Second Demographic Transition (SDT) theory would suggest a negative association. Hence, contrary to the SDT theory, urbanization does not diminish the positive effects of religiosity of married women on parity in Turkish society.

The interaction terms between women's education and urban residence, and between egalitarian ideology and urban residence were statistically significant and positively associated with married women's parity. These findings indicate that the effects of women's education and egalitarian ideology on married women's parity vary by residential area (urban vs. rural). 
Lastly, the three-way interaction terms had no statistically significant associations. These results show that the effect of religiosity on married women's parity does not depend on women's education, egalitarian ideology, or residential area.

Overall, the results from this chapter suggest that even though the components of modernization (except urban residence) were negatively related to women's parity, the effect of religiosity on women's parity does not depend on components of modernization (except urban residence). However, both statistically significant and non-significant findings support my hypothesis (H1) as they reveal that, contrary to general literature, the effect of religiosity and modernization on women's parity coexists together in Turkish society. 


\section{CHAPTER 5: ANALYSES OF CONTRACEPTIVE USE AND TYPE}

This chapter presents the results of bivariate and multivariate analyses of modernization and secularization on any contraceptive use, as well as the type of contraceptive method uses, by married women in Turkey. I hypothesized that $(\mathrm{H} 2)$ modernization would be positively associated with contraceptive use, but there would be no association between religious behaviors and contraception use, as contraceptive use in Islamic teachings, based on many hadiths, is generally permissible. Also, $\mathrm{H} 2$ stated that the interaction terms between religiosity and modernization factors (education, egalitarianism, and urbanization) would have non-significant associations with contraceptive use (see Table 2.1).

I expected to find such results because modernization, and the opportunity cost of having children that comes with modernization, increases individuals' contraceptive use. In developed countries this social change is accompanied by secularization, which is also positively associated with contraceptive use. In Turkey's case, however, I expected to find no relationship between contraceptive use and religion, because the primary interpretations of Islamic teachings permit contraceptive use-except for permanent contraceptive methods (Al-Bukhari 1999: v7: b62:h9, h11, h12, h135; e.g., Al-Ghazali 1939; Karaman 2018). I also expected to find a statistically non-significant association between contraceptive use and the interaction term between religiosity and modernization factors, because Islamic teachings based on hadiths permit all reversible contraceptive methods.

There were two dependent variables used to test this hypothesis: any contraceptive use (a dichotomous variable) and a categorically indicator of specific contraceptive methods used. Thus, I used binary logistic regression models for analyses 
of any contraceptive use and multinomial logistic regression for the analyses of contraceptive type.

\subsection{Any Contraceptive Use}

\subsubsection{Bivariate Results}

Table 5.1 shows the binary logistic regression coefficients of bivariate analyses between any contraceptive use and all other variables included in the analyses in terms of Odds Ratios (OR). As with IRR, I used exponentiated binary logistic regression coefficients (OR) for more meaningful interpretations. The exponentiated coefficients allow researchers to calculate percentage change by using the equations ( 5 and 6 ) in chapter 3 .

Religiosity was statistically significant and negatively associated with contraceptive use. More specifically, for a one-unit increase in religiosity, the odds of using any contraceptive method multiplied by a factor of $0.852(\mathrm{OR})$, net of all other factors in the analysis. Alternatively, by using Equation 6 from chapter 3, we can calculate and interpret this result in percentages: a one-unit increase in religiosity decreased the odds of contraceptive use by $14.8 \%(=(1-0.852) * 100)$ net of all other factors in the analysis. The negative association between religiosity and contraceptive use was unexpected and suggests that some religious women in Turkey may believe using contraception goes against the general teachings of Islam.

All components of modernization had statistically significant (all $p<0.001$ ) and positive bivariate associations with contraceptive use. More specifically, women's education, egalitarian ideology, and urban had positive associations $(\mathrm{OR}=1.506, \mathrm{OR}=$ 1.479, and 1.706, respectively). The effect sizes of women's education, egalitarian 
ideology, and urban on contraceptive use were quite large (in percentage change in odds, $50.6 \%, 47.9 \%$, and $70.6 \%)$.

Women's education had OR $=1.506$, which indicated that for each unit increase in women's education, the odds of using any contraceptive methods multiplied by 1.506 . Woman's education included three categories, and the analysis between women's education and any contraceptive use show a 6.82 constant score. I simply calculated the effect sizes by using the equation (_cons* $(\exp (b) / 1))$ for all bivariate analyses.

Specifically, for women with no education, the odds ratio of using any method was 6.82; for women with primary education; the odds ratio was $(6.82 *(1.506 / 1))=10.27$; for women with secondary education, the odds ratio was $(10.27 *(1.506 / 1))=15.47$; and for women with higher education, the odds ratio was $(15.47 *(1.506 / 1))=23.30$. When I calculated their effect sizes, I found the second highest change $(23.30-6.82=16.48)$ in OR of using any contraceptive method for women's education.

Egalitarian ideology had $\mathrm{OR}=1.479$, which indicated that for a one-unit increase in egalitarian ideology, the odds of using any contraceptive method multiplies by 1.479 . Egalitarian ideology also had three categories and a larger constant (11.24) than the (6.82) constant for woman's education. I calculated the effect size for this variable with the same equation used for the effect size of woman's education. Calculations showed that the OR of using any contraceptive method varied, from 11.24, for women with traditional ideology, to 36.35 , for women with egalitarian ideology. The calculations revealed egalitarian ideology as having the largest effect size $(36.35-11.24=25.11)$ on contraceptive use. 
Lastly, urban residence had $\mathrm{OR}=1.706$, thus the odds of using a contraceptive method for urban married women was $70.6 \%$ larger than their rural counterparts. Urban was a dichotomous variable, with a 7.43 constant. I calculated the effect size with the same equations used above (_cons*(exp(b)/1)). Specifically, calculations showed the OR for women living in rural areas as 7.43, and for women living in urban areas as $(7.43 *(1.706 / 1))=12.66$. The calculations showed that the OR of using any contraceptive method in urban areas had the smallest effect size $(12.66-7.43=5.23)$ among modernization factors.

The Proximate Determinants of Fertility (PDF) showed the expected associations. Age at first marriage (as a proxy for age at first sex) was statistically significant and negatively associated $(\mathrm{OR}=0.952$ at $\mathrm{p}<0.001)$ with contraceptive use. As age at marriage (or first sex) increases, the use of any contraceptive methods likely decreases because couples might want to have children before the end of reproductive years. The use of induced abortion was statistically significant and positively associated $(\mathrm{OR}=$ 4.488 at $\mathrm{p}<0.001)$ with contraceptive use. This result was expected because people who ended their pregnancy with induced abortion probably want to stop becoming pregnant again. Similarly, abortion frequency showed a highly significant and positive association $(2.588$ at $\mathrm{p}<0.001)$. The number of children born to a married woman was also statistically significant and positively associated $(\mathrm{OR}=1.775$ at $\mathrm{p}<0.001)$ with any contraceptive use. This result indicated that the number of children a married woman has increases the odds of using any contraceptive methods. This result could have occurred because, once the desired family size has been, reached, married women want to limit further pregnancies or to space their births (Westoff et al. 2008). 
The variables measuring women's and household characteristics showed women's employment was statistically significant $(\mathrm{p}<0.001)$ and positively associated $(\mathrm{OR}=$ 1.433) with contraceptive use. The odds of using any contraceptive methods were $43.3 \%$ higher for employed married women than their unemployed counterparts. Woman's age was statistically significant $(\mathrm{p}<0.001)$ and positively associated $(\mathrm{OR}=1.050)$ with contraceptive use. Her husband's education, wealth, and Turkish ethnicity were statistically significant $(\mathrm{p}<0.001)$ and positively associated $(\mathrm{OR}=1.375$, $\mathrm{OR}=1.423$, and $\mathrm{OR}=2.772$, respectively) with a married women's contraceptive use.

The region variables showed that, compared to other regions, the south $(\mathrm{OR}=$ $0.757, \mathrm{p}<0.010)$ and east $(0.358, \mathrm{p}<0.001)$ regions had statistically significant and negative associations with contraceptive use. Other regions showed positive associations, but only the west and central regions were statistically significant. The west and central regions showed statistically significant $(\mathrm{p}<0.001)$ associations $(\mathrm{OR}=1.802$ and $\mathrm{OR}=$ 1.479). As can be seen from results given above, the west and east, respectively, represent the areas of highest and lowest contraceptive use in Turkey.

These contraception statistics correspond to the birth rates in these regions. The eastern part of Turkey has higher fertility rates than other regions, which might be briefly explained by the fact that, although Kurdish people live throughout the country, $71.0 \%$ of those who speak Kurdish as a mother tongue live in eastern parts of Turkey (TDHS 2008-2013). Among the Kurdish people, girls generally marry earlier than Turkish girls and earlier age at marriage is associated with higher fertility (Gönder 2017). In contrast, the western part of Turkey has the lowest fertility rates primarily because these areas are more developed and Europeanized. 
Finally, the survey year variable showed a positive but statistically non-significant association, indicating that the use of any contraceptive methods among married women experienced little change from 2008 to 2013.

\subsubsection{Multivariate Results}

Table 5.2 provides the results of logistic regressions of any contraceptive use with key independent variables in odds (exponentiated coefficients $[\exp (b)])$. Model 1 shows that a one-unit increase in the religiosity multiplied the odds of using any contraceptive method by $0.880(\mathrm{OR})$, net of other factors in the model. This result indicated that religious people are reluctant to use contraceptive methods, even though Islamic teachings permit reversible contraceptive use (Sahih al-Bukhari 1997: v7: b62:h9, h11, h12, h135).

I ran all models in Table 5.2 with a series of control variables. The results of almost all control variables (except respondent's employment) were quite similar across Models 1 and 2. I used three variables to control for the PDF in these analyses. Age at first marriage had no statistically significant association with contraceptive use. Age at first marriage variable had a statistically significant and negative association in the bivariate analysis, but in the multivariate models it was no longer significant. The results of abortion frequency showed that, for a one-unit increase in induced abortion, the odds of using any contraceptive method were multiplied by 1.836 , after controlling for other factors in the model. Similarly, for each additional child in married women's parity, the odds of using a contraceptive method were multiplied by 2.386 , net of other factors. In addition, I controlled for women's and household characteristics with five variables. Women's employment showed a positive association with contraceptive use 
(but when I included modernization factors into the analysis the association disappeared). Respondent's age showed a negative association with contraceptive use. A woman's husband's education, her household wealth, and Turkish ethnicity presented positive associations with contraceptive use. Compared to the west of Turkey, only the south and east were statistically significant, showing negative associations with contraceptive use. Survey year showed no statistically significant association with contraception use.

Model 2 provides the results of both religiosity and components of modernization. Religiosity, as anticipated, was no longer statistically significant after including modernization factors into the analysis. I expected this result based on the assumption that educated people are more likely to search for and find information about their behaviors, and Islamic teachings have fewer strong restrictions on contraceptive use than on abortion use (The Pew Reserch Center (2010) also found education associated with greater religious knowledge in the United States.) This finding might be related with the available sources (books, the internet, and online forums for religious questions) that educated people can reach; thus they can advance their knowledge about their religion. Therefore, common view that Islam prohibits contraceptive use is mostly challenged by educated people.

In preliminary analyses, I tested the effects of modernization factors individually. Each component of modernization, except urban, showed statistically significant and positive associations with contraceptive use when entered into the model separately. For example, for a one-unit increase in women's education, the expected odds of using a contraceptive method multiplied by 1.403 , holding all other factors constant. Similarly, for a one-unit increase in egalitarian gender ideology, the odds of using a contraceptive 
method multiplied by 1.358 , net of all other factors. Only women's education mediated the effect of religiosity, however. This indicated that women's education has a strong effect on contraceptive use. The Wald test showed the change in coefficients was statistically significant $(\mathrm{p}<0.001)$.

Urban, was not statistically associated with contraceptive use. Preliminary analyses showed that wealth, again, influenced the effect of the urban variable. In this case, this non-correlation could be spurious, because of the presence of the third variable, wealth (Rosenberg 1968).

\subsubsection{Interaction Results}

Table 5.3 presents the results of interactions between religiosity and modernization factors (women's education, egalitarian ideology, urban) on contraceptive use. Model 1 shows a statistically significant $(\mathrm{p}<0.050)$ and positive association $(\mathrm{OR}=$ 1.128 ) between the interaction term between religiosity and women's education and contraceptive use. Specifically, for a one-unit increase in religiosity the positive effect of woman's education on the odds of using any contraceptive methods multiplied by 1.280 , holding other factors in the model constant.

The interaction plot in Figure 5.1 presents the interaction term between religiosity and women's education on any contraceptive use. The non-parallel lines show that the effect of religiosity on contraceptive use varies by each unit increase in education.

Specifically, at higher level of education the effect of education increases very little from no religiosity to high religiosity. However, the secondary education line shows a decline when religiosity increased, but the odds of contraceptive use was higher than the no education line and mostly higher than the primary education line. The primary education 
line also shows a quite small decline as religiosity increased. The no education line shows that religiosity has a stronger association with any contraceptive use. However, the effect of religiosity became smaller with the increase of women's education. This interaction effect indicated that the effect of religiosity on any contraceptive use depends on women's education. Therefore, this result failed to support my hypothesis (H2). However, the result must be ascertained by further investigation using permanent contraceptive methods, discussed in the second part of this chapter. Finally, control variables in Table 5.3 present findings similar to those from Table 5.2.

The interaction term between religiosity and egalitarian ideology in Model 2 showed no statistically significant association with contraceptive use. Similarly, the interaction term between religiosity and urban in Model 3 had no statistically significant association with contraceptive use. These statistically non-significant associations indicated that the effect of religiosity on contraceptive use did not vary by modernization, specifically, egalitarian ideology and urban, thus provides partial evidence to support my hypothesis $(\mathrm{H} 2)$.

Surprisingly, Model 4 presents a statistically significant $(\mathrm{p}<0.010)$ and negative association $(\mathrm{OR}=0.606)$ interaction between women's education and urban and any contraceptive use. Specifically, for women living in urban areas, the positive effect of woman's education on the odds of using any contraceptive methods was $39.4 \%$ smaller than for their rural counterparts, holding other factors in the model constant. The interaction plot in Figure 5.2 shows the interaction term between women's education and urban residence on any contraceptive use; the lines as not parallel as they intersect at women's primary education (1). This interaction effect was mostly driven by women's 
primary education and indicated that the association between women's education and any contraceptive use depends on residential area (urban vs. rural).

In supplementary analyses, I ran the same analyses for different age groups and found that among younger women $(\leq$ age 37$)$ the interaction was not statistically significant, but it was statistically significant $(\mathrm{OR}=0.318, \mathrm{p}<0.001)$ among older women (> age 37). I also created interaction terms between each category of women's education and urban. Findings showed only one interaction term, between primary education and urban, was statistically significant $(\mathrm{OR}=528, \mathrm{p}=0.003)$. These results also indicated the significance of this interaction effect as mostly driven by the effect of education of older women (age > 37).

The analysis in Model 5 revealed the effect of egalitarian ideology on any contraceptive use did not vary by area of residence (urban vs. rural). The first three-way interaction term, between religiosity, woman's education, and urban residence, in Model 6 was statistically significant $(\mathrm{p}<0.050)$ and negatively associated $(\mathrm{OR}=0.747)$ with contraceptive use.

The interaction plot in Figure 5.3 presents the interaction term between religiosity, woman's education, and urban residence on any contraceptive use; the lines as not parallel. Thus, we see the negative effect of religiosity on the association between women's education and any contraceptive use - observed in no, primary, and secondary education lines in rural areas, but largely in no education and slightly in primary education lines in urban areas - was larger in rural than in urban areas. This interaction effect indicated that the association between religiosity and any contraceptive use depends on women's education and residential area (urban vs. rural). As women's 
education increases, the negative effect of religiosity on any contraceptive use decreases and there are larger variations in rural areas. In supplementary analyses stratified by urban/rural, I tested whether the interaction term between women's education and religiosity was significantly different by area. I found that the interaction term was statistically significant $(\mathrm{p}<0.001)$ for only rural areas. These findings indicate that religiosity and modernization have individual effects on contraceptive use in urban areas, and this partly supports my hypothesis (H2).

In Model 7, the second three-way interaction term, between religiosity, egalitarian ideology, and urban residence, provided no statistically significant association. This finding indicated that the effect of religiosity on contraceptive use does not depend on modernization factors, egalitarian ideology, and urban.

\subsubsection{Summary}

Overall, the results from the first part of the analysis showed women's education and egalitarian ideology were highly significant and positively associated with contraceptive use. Urban, however, was not statistically significant, because of its spurious relationship with wealth. These findings supported the first part of my second hypothesis (H2).

However, contrary to my expectations, religiosity was negatively associated with contraceptive use, and the effect of religiosity on contraceptive use was mediated by the modernization factors in the analysis. In other words, the negative association between religiosity and contraceptive use disappeared when I included modernization factors. As the Pew Research Center (2010) found that educated people were more likely to have more religious knowledge, the reason for this mediation might be related to educated 
individuals' desire to find religious justifications for their behaviors and their access to more sources than their counterparts. These results showed that the second part of my second hypothesis (H2) - there would be no association between religious behaviors and contraception use because contraceptive use in Islamic teachings is generally permissible —was partly supported; religiosity had a non-significant relationship with contraceptive use when I controlled for modernization factors in the analysis.

In addition, some interaction terms also provided unexpected results. For instance, the effect of religiosity on any contraceptive use depended on a woman's education. As argued in the previous paragraph, this is possibly due to Islam's perspective on contraceptive use. Because of this significant association between the interaction term between religiosity and women's education, and contraceptive use, the last part of my second hypothesis $(\mathrm{H} 2)$ - the interaction terms between religiosity and modernization (education, egalitarianism, and urbanization) would also demonstrate no significant association with contraception use - was partly supported because the effect of religiosity on contraceptive use did not depend on only egalitarian ideology. These analyses provide some evidence that contradict the general literature (positing that modernization and secularization co-occur and have no independent effects), which claims both of these as hand-in-hand processes that negatively influence individual's fertility behaviors (Lesthaeghe 2010, 2014).

Moreover, the interaction terms between women's education and urban, and between religiosity, women's education and urban, in Models 4 and 6 (Table 5.3), had statistically significant and negative associations with contraceptive use. In supplementary analyses, I tested these analyses for different age groups and found that 
the statistically significant and negative associations of these interaction terms with contraceptive use were due to the older age of women (age > 37). As a conclusion of this section, my hypothesis (H2) was partly supported due to the strong association between women's education and contraceptive use.

\subsection{Types of Contraceptive Methods}

The findings of the first part of this section necessitated further examination of currently used contraceptive methods, to understand if the significant and positive association between contraceptive use and the interaction term between religiosity and women's education in Model 1 (Table 5.3) was caused by modernization or secularization. Since contraceptive use is generally permissible in Islam (except permanent contraceptive methods), this continued investigation of currently used contraceptive methods allowed me to demonstrate the detailed individual effects of both religiosity and modernization factors, and interaction effects between religiosity and modernization factors, on types of contraceptive methods, including categories of "no method," "traditional method" (e.g., coitus interruptus, rhythm method), "modern reversible methods" (e.g., male condom, IUD) and "permanent methods" (e.g., tubal ligation).

\subsubsection{Bivariate Results}

Table 5.4 presents the OR of bivariate logistic analyses between all contraceptive methods (no method, traditional method, modern reversible methods, and permanent methods), and all other variables included in the analyses. The first column shows the results of bivariate analyses between no contraceptive method and all variables in the analyses. Religiosity and using no method were statistically significant $(\mathrm{p}<0.010)$ and 
positively associated $(\mathrm{OR}=1.066)$. Specifically, for a one-unit increase in religiosity, the odds of using no contraceptive method were multiplied by 1.066. All modernization factors, women's education, egalitarian ideology, and urban, were statistically significant (all $\mathrm{p}<0.001)$ and negatively associated $(\mathrm{OR}=0.864, \mathrm{OR}=0.830$, and $\mathrm{OR}=0.762)$ with using no method. Women's education specifically indicated that for a one-unit increase in women's education, the odds of using no methods were multiplied by 0.864 . Egalitarian ideology showed that for a one-unit increase in egalitarian ideology, the odds of using no method were multiplied by 0.830 . Lastly, for women living in urban areas the odds of using no method were $33.8 \%$ smaller than for women living in rural areas.

The control variables showed several interesting findings. Age at first marriage was statistically significant $(\mathrm{p}<0.001)$ and positively associated $(\mathrm{OR}=1.034)$ with using no method. Abortion use and parity were statistically significant (both $\mathrm{p}<0.001$ ) and negatively associated $(\mathrm{OR}=0.760, \mathrm{OR}=0.921$, and $\mathrm{OR}=0.770)$ with using no method. Variables controlling for women's individual and household characteristics (women's employment, women's age, husband's education, wealth, and Turkish ethnicity) were statistically significant (all $\mathrm{p}<0.001)$ and negatively associated $(\mathrm{OR}=0.791, \mathrm{OR}=$ $0.988, \mathrm{OR}=0.877, \mathrm{OR}=0.853$, and $\mathrm{OR}=0.500)$ with using no method. All region variables were statistically significant, and their directions correspond to the fertility rates in those regions. West, south, and north regions were negatively associated $(\mathrm{OR}=0.778$, $\mathrm{OR}=0.777$, and $\mathrm{OR}=0.864$ ) with using no method, but central and east regions were positively associated $(\mathrm{OR}=1.156$ and $\mathrm{OR}=1.916)$ with using no methods. Finally, the survey year was not associated with using no method. Overall, control variables in all the 
bivariate analyses provided the anticipated findings for Turkey; thus, I will interpret only focal independent variables for the bivariate comparisons of other contraceptive methods.

The second column in Table 5.4 shows the bivariate analyses between traditional contraceptive methods and all variables included in the analyses. A one-unit increase in religiosity multiplied the odds of using traditional methods by 1.079. Modernization factors were negative associated with traditional contraceptive use, but only women's education and urban were statistically significant. More specifically, for a one-unit increase in women's education, the odds of using traditional method were multiplied by 1.129. For women living in urban areas the odds of using traditional contraceptive methods were $13.4 \%$ smaller than for women living in rural areas. These results indicated religiosity had a statistically significant and positive association with traditional method use, while modernization factors (specifically, women's education and urban) has a statistically significant and negative association with traditional method use.

The third column provides the results of bivariate analyses between modern reversible methods and all variables in the analyses. These analyses provided consistent findings with the general literature, but not consistent with my expectations. For example, religiosity showed a statistically significant and negative association with modern reversible method use. Specifically, for a one-unit increase in religiosity, the odds of using modern reversible methods were multiplied by 0.860 . Contraceptive use is generally accepted as permissible in the popular interpretation of Islam (al-Bukhari 1999: v7: b62:h9, h11, h12, h135); thus, I was expecting to find that religiosity was not significantly associated with modern reversible methods. The findings, however, suggest 
that religious women are reluctant to use contraceptive methods (especially the modern methods).

On the other hand, modernization factors showed quite large and statistically significant positive associations with modern reversible method use. For example, for a one-unit increase in women's education, the odds of using modern reversible methods were multiplied by 1.447 . Similarly, the odds of using modern reversible contraceptive methods were multiplied by 1.274 with each unit increase in egalitarian ideology. Urban residence was positively associated and had a large effect size, indicating the odds of urban women's modern reversible contraceptive use were $48.7 \%$ larger than for their rural counterparts.

The last column shows the results of bivariate analyses between permanent methods and all variables in analyses. Unexpectedly, religiosity showed a statistically significant positive bivariate association with permanent contraceptive method use. This result indicated that for a one-unit increase in religiosity, the odds of using permanent methods were multiplied by 1.121 . This is surprising, because permanent methods are the only forbidden contraceptive methods in Islamic teachings. Furthermore, women's education and egalitarian ideology were statistically significant and negatively associated with permanent contraceptive method use (urban was not statistically significant), which is surprising because prior literature would suggest the opposite (positive association).

In supplementary analysis, I explored whether these surprising association might reflect the influence of a third variable. These findings showed that number of children was acting as a distorter variable. When I controlled for woman's parity, the direction of associations reversed (from positive to negative for religiosity and from negative to 
positive for the modernization factors) This indicated that women with high religiosity were more likely to have more children than their counterparts, and more likely to use permanent methods (possibly because of high C-section use in Turkey ${ }^{1}$ ) to avoid future pregnancies; but when controlled for number of children religious women were actually less likely to use permanent contraceptive methods.

On the other hand, women with higher levels of education had fewer children than their counterparts and less likely to use permanent contraceptive methods to limit their pregnancies. When I controlled for number of children, however, I found that women with higher education were actaully more likely to use permanent contraceptive methods than their counterparts.

\subsubsection{Multivariate Results}

Table 5.5 presents the results of Multinomial Logistic regressions (I assigned "using no contraceptive method" as the baseline category in the analyses) in Relative Risk Ratio (RRR, exponentiated coefficients $[\exp (b)])$ for all analyses. Since the model that I used was Multinomial Logistic regression, the analyses have a series of comparisons and they are defined as: Panel A: Traditional methods vs No methods; Panel B: Modern Reversible vs No methods; and Panel C: Permanent methods vs No methods. From Model 1, across panels, we see that religiosity was not significant association with traditional contraceptive methods, but had statistically significant and negative associations with modern and permanent contraceptive methods. For example, in Panel B

\footnotetext{
${ }^{1}$ This positive association may be related to the high rates of Caesarean sections (C-section) in Turkey (Koc 2003). After the third C-section doctors discuss complications for both women and the child in case of a fourth pregnancy, and recommend women avoid becoming pregnant again or ask them to consider sterilization. In most cases, women choose sterilization because of these complications after C-section operations. Even while they are still in the C-section surgery, they may undergo sterilization.
} 
(Table 5.5), for a one-unit increase in religiosity, the relative risk of using modern reversible methods vs. no methods was multiplied by 0.888 , holding all other variables in the model constant. In other words, the expected risk of using modern contraceptive methods vs. no methods decreased with each unit increase in religiosity of married women. This finding suggests that some religious people are reluctant to use modern reversible contraceptive methods, though many popular Islamic teachings, based on hadiths, allow these contraceptive methods (Al-Ghazali 1939; al-Bukhari 1999:v7:b62:h9, h11, h12, h135).

Similarly, in Panel C (Table 5.5), for a one-unit increase in married women's religiosity, the relative risk of using permanent contraceptive methods rather than using no methods was multiplied by 0.821 , after controlling for all other variables in the model. In supplementary analyses, to test the other contraceptive methods as a baseline category, I used traditional contraceptive use and modern reversible contraceptive use as baseline categories. These analyses provided statistically significant and negative associations.

More specifically, the supplementary analyses with traditional contraceptive use as the baseline category showed that, for a one-unit increase in religiosity, the relative risks of using modern reversible and permanent contraceptive methods - rather than the traditional method - were multiplied by $0.893(\mathrm{p}<0.001)$ and $0.817(\mathrm{p}<0.001)$, respectively, net of all other factors. Moreover, the supplementary analysis with modern reversible contraceptive methods as the baseline category showed that, for a one-unit increase in religiosity, the relative risk of using permanent contraceptive methods (rather than modern reversible methods) was multiplied by $0.914(\mathrm{p}<0.050)$, all else being equal. Again, these findings suggest that married women who are religious are reluctant 
to use modern contraceptive methods, including both reversible and permanent ones, than using traditional methods. Further analyses also showed that married women are more likely to use permanent methods than modern reversible contraceptive methods.

I ran all analyses with a series of control variables for all three categories. In Panel A of Model 1 (Table 5.5), the number of children born was the only PDF indicator that was associated (positively) with using traditional contraceptive rather than no method, all else being equal. From variables measuring women's and household characteristics, women's employment, wealth, and Turkish ethnicity were statistically significant and positively associated with using traditional method vs. no method, holding all other factors constant. Women's age was statistically significant and negatively associated with traditional methods of contraception. The south, central, and east regions were statistically significant and negatively associated with using a traditional contraceptive method rather than no method (relative to the west), all else being equal.

In Panel B of Model 1 (Table 5.5), in addition to the variables discussed in the previous paragraph, among the variables measuring women's individual and household characteristics, only husband's education was statistically significant and positively associated with using modern reversible contraceptive methods vs. no method, after holding all other factors in the analysis constant. Among the variables measuring region, south and central were not statistically significant, but north was statistically significant and negative association with using modern reversible contraceptive methods vs. no methods, all else being equal.

In Panel C of Model 1 (Table 5.5), among the variables measuring women's individual and household characteristics, women's employment, age, and husband's 
education were not statically significant. Among variables measuring region, north was significantly and positively associated with using permanent contraceptive methods rather than no method, all else being equal. Finally, survey year was statistically significant and positively associated with using permanent contraceptive methods vs. using no method, net of all other factors.

Across panels, Model 2 (Table 5.5) shows the results of main independent variables including religiosity, women's education, egalitarian ideology, and urban on the currently used contraceptive method. The analysis (in Panel A) for traditional vs. no methods showed only egalitarian gender ideology had a statistically significant and positive association with the use of traditional methods. This finding indicated that for a one-unit increase in egalitarian gender ideology, the relative risk of using the traditional method vs. using no methods was multiplied by 1.153 , holding all other factors in the model constant.

Moreover, the analysis (in Panel B in Model 2 [Table 5.5]) for modern reversible vs. no methods showed religiosity had a statistically significant association. More specifically, this result indicated that for a one-unit increase in religiosity of married women, the relative risk of using the modern contraceptive methods vs. no methods was multiplied by 0.914 , holding all other variables in the model constant.

As expected, all modernization factors had positive associations with modern reversible contraceptive methods vs. no methods. For example, for a one-unit increase in women's education, the relative risk of using modern contraceptive methods vs. no methods was multiplied by 1.187 , net of other factors. Similarly, for a one-unit increase in egalitarian ideology, the relative risk of using modern contraceptive methods vs. no 
methods was multiplied by 1.208 , holding other factors constant. Finally, for married women living in urban areas, the relative risk of using modern contraceptive methods rather than using no method was $16.0 \%$ larger than for their counterparts living in rural areas, controlling for all other variables in the model.

In Panel C of Model 2 (Table 5.5), the analysis for permanent contraceptive methods vs. no methods showed religiosity, egalitarian ideology, and urban residence were statistically significant (respectively, $\mathrm{p}<0.001, \mathrm{p}<0.010$, and $\mathrm{p}<0.050$ ). More specifically, for a one-unit increase in religiosity, the relative risk of using permanent contraceptive methods rather than no methods was multiplied by 0.819 , holding all other factors constant. Egalitarian ideology, however, showed a positive association with a oneunit increase in the egalitarian ideology multiplying the relative risk of using permanent contraceptive methods rather than no methods by 1.184 , net of other factors. Similarly, urban residence also showed a positive association with women who live in urban areas, having a relative risk of using permanent contraceptive methods rather than no methods that was $23.6 \%$ larger than their rural counterparts, all else being equal.

\subsubsection{Interaction Results}

Table 5.6 presents the results of multinomial logistic regression for interaction terms between religiosity and modernization factors, including women's education, egalitarian ideology and urban on currently used contraceptive methods (the baseline category was no methods) in RRR. I used no method as the baseline category; thus, to better investigate the effect of religiosity on different contraceptive methods. In Model 1 (Table 5.6), the interaction term between religiosity and women's education was statistically significant associations in all comparisons (traditional vs. no methods, 
modern reversible vs. no methods, and permanent vs. no methods). For example, in Panel A, a one-unit increase in religiosity, multiplied the negative effect of women's education on the relative risk of using traditional method rather than using no method by 1.096 , holding all other factors constant.

The interaction plot in Figure 5.4 shows the interaction term between religiosity and woman's education on using traditional contraceptive method. This show that women with higher education were less likely to use traditional contraceptive methods than women with other education categories. At the high level of religiosity, for women with secondary school education, the odds of using traditional method was as likely as women with no education. Except for women with no education, the relative risk of using traditional contraceptive method increased for women with highest, secondary, and primary education for each unit increased in religiosity. These results indicated that women's education decreased the relative risk of using traditional contraceptive method, but also that the negative effect of women's education on the relative risk of using traditional contraceptive method reduced with each unit increase in religiosity for women with primary, secondary, and highest education. Overall, these results showed that the effect of women's education on using traditional contraceptive method depends on religiosity.

In Panel B (modern reversible vs. no method) of Model 1 (Table 5.6), the interaction term between religiosity and women's education was statistically significant and positive. Specifically, for each unit increase in women's education, the negative effect of religiosity on the relative risk of using modern reversible contraceptive methods, rather than no methods, was multiplied by 1.072 , all else being equal. Figure 5.5 presents 
the interaction between religiosity and woman's education on using modern reversible contraceptive methods. The lines for primary, secondary, and higher education show that highly religious women are less likely to use modern contraceptive methods than women in other religious categories. The relative risk of using modern reversible methods for women with no education increased with religiosity, but also decreased slightly at the high level of religiosity. Nonetheless, the relative risk of using modern reversible contraceptive methods rose with each unit increase in women's education. This interaction effect indicated that the effect of women's education on using modern reversible contraceptive methods, rather than no methods, depends on religiosity. Thus, with each unit increase in a woman's education the effect of women's education on using modern reversible contraceptive methods decreases.

In supplementary analyses, I tested the traditional contraceptive use (instead of no methods) as the baseline category. Supplementary results showed that the interaction term lost was not statistically significant with traditional contraceptive use as the baseline category. This finding showed that the effect of religiosity on using modern reversible methods rather than traditional method did not depend on women's education. This finding may also indicate that married women using modern reversible methods are also using traditional methods.

In Panel C (permanent methods vs. no method) of Model 1 (Table 5.6), the examination of the interaction between religiosity and women's education on permanent contraceptive method, interestingly, provided a statistically significant and positive association. More specifically, for each unit increase in religiosity, the negative effect of women's education on the relative risk of using permanent contraceptive methods, rather 
than using no method, was multiplied by 1.254 , all else being equal. Figure 5.6 shows the interaction between religiosity and woman's education on using permanent contraceptive methods. For women with higher education the relative risk of using permanent methods increased as religiosity increases. However, for women with no education, the relative risk of using permanent methods declines more steeply compared to women with a primary education as religiosity increased. Women with a secondary education showed a smaller decline than those with a primary education as religiosity increased. More specifically, at a high level of religiosity, the relative risk of using permanent contraceptive methods was highest for women with primary education. Overall, this interaction effect indicated that the effect of religiosity on using permanent contraceptive methods decreased depending on level of women's education.

In supplementary analyses, I tested all other categories: traditional and modern reversible contraceptive methods (one by one), as the baseline category. The results showed the interaction term between religiosity and women's education as statistically significant and positively associated with using permanent contraceptive methods rather than traditional or modern reversible methods. These results indicated that the risk of using permanent contraceptive methods for married women who are religious and highly educated was higher than for married women who are less religious and less educated.

The interaction term between religiosity and egalitarian ideology in Models 2 was only statistically significant in (Panel C) the comparison between using permanent methods vs no method. Specifically, for each one-unit increase in religiosity, the positive effect of egalitarian ideology on the relative risks of using permanent contraceptive methods rather than no methods multiplied the relative risks by 1.140 , net of other factors 
in the model. Figure 5.7 presents the interaction between religiosity and egalitarian ideology on using permanent contraceptive methods; the lines are not parallel. This indicates that the effect of religiosity on permanent contraceptive use depends on egalitarian ideology. The egalitarian ideology lines showed that the effect of egalitarian ideology on permanent contraceptive use decreases as one-unit increase in religiosity. However, at high level of religiosity the effect size of egalitarian ideology on the relative risk of permanent contraceptive use increased for each increase in egalitarian ideology. Interestingly, the risk of using permanent methods for women with traditional ideology and with high religiosity is quite similar with the risk for women with egalitarian ideology and with high religiosity.

In supplementary analyses, I also tested all other contraceptive methods as a baseline category for permanent contraceptive methods and found that the interaction term between religiosity and egalitarian ideology is statistically significant in analyses using no methods and traditional methods as baseline categories (but not statistically significant for modern reversible methods).

In Model 3 the interaction between religiosity and urban was not statistically significant in all three comparisons. Thus, the effect of religiosity on using traditional, modern reversible, and permanent methods, compared to no methods did not depend on residential area (urban vs. rural). Overall the results in Models 1, 2 and 3 provided evidence that partially support my second hypothesis (H2), where I claimed that the interaction terms between religiosity and modernization factors would not provide statistically significant associations with contraceptive use. The results of Model 1 (Table 5.6) did not support my hypothesis (H2), because of the strong effect of women's 
education on their contraceptive use, regardless of methods; thus, the effect of religion on using any methods, including permanent methods not allowed in Islam, depended on women's education.

The interaction term between women's education and urban in Model 4 (Table 5.5) showed a statistically significant and negative association with using traditional, modern reversible, and permanent methods, rather than no methods. In Panel A (traditional method vs. no method), for women living in urban areas, the positive effect of women's education on the relative risks of using traditional method rather than no methods, multiplied the relative risks by 0.758 , all else being equal.

The interaction plot in Figure 5.8 shows the interaction between woman's education and urban residence on using traditional contraceptive method; the lines are not parallel. Specifically, the effect of woman's education on the probability of using traditional contraceptive method was higher for rural women with primary education than for their urban counterparts, and the effect of woman's education decreased faster for rural women. This interaction effect indicated that the association between women's education and traditional contraceptive method use was lower for women living in urban areas than for their rural counterparts.

Panel B (modern reversible vs. no methods) of Model 4 (Table 5.5) shows that for women living in urban areas, the positive effect of women's education on the relative risk of using modern reversible contraceptive method, rather than no methods, multiplied the relative risks by 0.706 , all else being equal. Figure 5.9 presents the interaction between woman's education and urban residence on modern reversible contraceptive use; the lines are crossed after secondary education. Specifically, the figure shows that, at a high level 
of education, the effect woman's education on the relative risk of using modern reversible contraceptive methods, rather than no methods, was larger for women living in rural areas than their urban counterparts. However, the relative risk of using modern reversible methods was larger for urban women in all other education categories. This interaction effect shows that the association between women's education and using modern reversible contraceptive methods depends on their residency area (urban vs. rural).

Panel C (permanent methods vs. no method) of Model 4 (Table 5.5), unexpectedly shows that, for women living in urban areas, the positive effect of women's education on the relative risks of using permanent method, rather than no methods, was $42.8 \%$ smaller than their rural counterparts, all else being equal. Figure 5.10 presents the interaction between woman's education and urban residence on using permanent contraceptive methods; the lines are crossed after primary education. The interaction effect indicated that the association between women's education and using permanent contraceptive methods depends on women's residency (urban vs. rural). This difference might reflect government efforts to provide free and easier access to contraceptive methods in rural areas. In rural areas where no hospital or health clinics are available, a nurse, generally female, provides health care for people or guides them in obtaining necessary services, including all modern contraceptive methods (reversible and permanent). Female nurses commonly advise female patients on possible contraceptive methods.

The interaction term between egalitarian ideology and urban in Model 5 (Table 5.5) was not associated with traditional, modern reversible, or permanent contraceptive 
methods vs. no method. This indicated that the effect of egalitarian ideology on contraceptive methods did not depend on residential areas (urban vs. rural).

Model 6, however, shows the three-way interaction term between women's education, religiosity, and urban residence in Panel A (traditional method vs. no method) as statistically significant and negatively associated with using traditional contraceptive methods, rather than using no methods. Figure 5.11 graphically displays the interaction between women's education, religiosity, and urban residence on traditional contraceptive method. This three-way interaction effect indicates that the association between religiosity and using traditional contraceptive methods depends on women's education and residential area (urban vs. rural). More specifically, the effect of religiosity on using traditional contraceptive methods was smaller for women with higher education who live in urban areas. The other categories of education also showed that the effect of religiosity on the probability of using traditional contraceptive methods had smaller effects in urban areas. Overall these findings indicated that the effect of religion on using traditional contraceptive methods varies by a woman's education and residential area (urban vs. rural). In supplementary analyses, I tested whether these interactions were significant in stratified samples for urban and rural residence and found that the interaction term between women's education and religiosity on traditional method use was statistically significant $(\mathrm{p}<0.001)$ in only rural areas.

The other three-way interaction term, between religiosity, egalitarian ideology and urban, in Model 7 (Table 5.5), however, showed no statistically significant association in all three comparisons. This indicates that the effect of religiosity on using traditional, modern reversible, and permanent did not depend on modernization factors, 
egalitarian ideology, and residential area (urban vs. rural). This finding, a non-significant association of the three-way interaction term, supports my second hypothesis.

\subsubsection{Summary}

To summarize the findings, the main independent variables presented interesting results: In Model 1 (Table 5.2), religiosity was significantly and negatively associated with using modern contraceptive methods, including both reversible and permanent ones. In Model 2 (Table 5.2), among the modernization factors in Panel A, only egalitarian ideology was statistically significant with using traditional methods. In Panel 2, women's education, egalitarian ideology, and urban, were statistically significant and positively associated with modern reversible contraceptive methods, but in Panel C, only egalitarian ideology and urban residence were significant and positively associated with using permanent methods. These results (from Model 1) do not support the first partreligiosity would not be significantly associated with all contraceptive methods - of my second hypothesis (H2), but they (from Model 2) partially support the second part of H2 - all modernization factors would be positively associated with all contraceptive methods.

Furthermore, analyses including interaction terms in Table 5.6 provided quite unexpected findings. Women's education had a strong positive effect on contraceptive use; therefore, in the interaction terms in Panels A, B, and C in Model 1 (Table 5.6), the effects of religiosity on contraceptive methods depended on women's education. The findings in Panel C in Model 1, indicated that highly religious and educated women use permanent contraceptive methods without considering religious prohibitions for this type of contraceptive use. In addition, the finding in Panel C in Model 2 also shows an 
interdependency between religiosity and egalitarian ideology on permanent contraceptive use. These findings do not support the last part of my second hypothesis (H2), where I expected to find no statistically significant association between contraceptive use and interaction terms between religiosity and modernization factors (women's education, egalitarian ideology, and urban). Since the effect of religiosity on any contraceptive method use depended on women's education and the effect of religiosity on permanent contraceptive method use depended on egalitarian ideology, findings of this section only partially supported the last part of $\mathrm{H} 2$.

Finally, interaction terms between women's education and urban residency in Panels A, B, and C in Model 4, provided unexpected findings, showing negative associations with all contraceptive methods. As I argued above, in the analyses of any contraceptive use (dichotomous variable), these negative associations were related to older age and might also relate with the free and easier access to contraceptive methods in rural areas. In addition, three-way interaction term, in Panel A in Model 6, between women's education, religiosity and urban residency showed a statistically significant and negative association with traditional method use. 


\section{CHAPTER 6: ANALYSES OF ANY ABORTION USE AND FREQUENCY}

This chapter presents the results of bivariate and multivariate analyses of religiosity, women's education, egalitarian ideology, and urban residency on abortion use and abortion frequency variables. I hypothesized (H3) that modernization positively associates with abortion, and that religious behaviors negatively associate with abortion, given Islamic regulations for the practice, but that the interaction terms between modernization (women's education, egalitarian ideology, and urban) and religiosity would demonstrate no significant association with abortion use (see Table 2.1).

For this chapter, I used Binary Logistic and Negative Binomial Regression Models (NBRM) to examine the effects of interaction terms between women's education, egalitarian ideology, urban, and religiosity on abortion use (dichotomous variable) and frequency (count variable). I used NBRM because descriptive statistics for abortion frequency in chapter 3 show greater variance than the mean, and the dependent variable has excessive zeroes. In addition, in rare count events, researchers generally use the Poisson Regression Model (PRM) or NBRM. The "countfit" test (in Stata), which compares fit of alternative count models, also suggests that NBRM fit better than PRM for abortion frequency (Long and Freese 2014).

\subsection{Any Abortion Use}

\subsubsection{Bivariate Results}

Table 6.1 shows the regression coefficients of bivariate analyses between the dependent variable, any abortion use, and all other variables in analyses, in Odds Ratios (OR). All categories in ordinal variables in the analyses were dummy-coded, so there is no omitted variable in the bivariate analyses on categorical measures (e.g., region). 
Religiosity was, as expected, statistically significant $(\mathrm{p}<0.001)$ and negatively associated $(\mathrm{OR}=0.823)$ with abortion use. Specifically, for a one-unit increase in women's education, the odds of using induced abortion decreased by $17.7 \%$. Even though overall abortion use in Islam is generally restricted, some Islamic scholars argue its permissibility depending on health conditions of the mother and the stage of pregnancy (Asman 2004; Hessini 2007).

Even though I expected to find positive effects of modernization (including women's education, egalitarian ideology, and urban) on abortion use, they were not consistently associated with any abortion use at the bivariate level. Only women's education was statistically significant $(\mathrm{p}<0.010)$ but this was negatively associated (OR $=0.889$ ) with married women's abortion use. This result indicated that for a one-unit increase in women's education, the odds of ending a pregnancy with induced abortion decreased by $11.1 \%$. In supplemental analyses, I checked primary statistics and found women's parity as a distorter variable "reveals that the correct interpretation is precisely the reverse of that suggested by the original data" (Rosenberg 1968:94). Thus, when controlling parity — and no other variables, the direction of the association between woman's education and any abortion use turned positive $(\mathrm{p}<0.001)$. This indicates that women with high education are actually more likely to end their pregnancy with induced abortion, as expected.

Variables used to control for the behavioral aspects of the Proximate Determinants of Fertility (PDF) had interesting associations with abortion use. Age at first marriage was statistically significant $(\mathrm{p}<0.001)$ and negatively associated $(\mathrm{OR}=$ 0.952) with abortion use. This indicated that for a year increase in age at first marriage, 
the odds of using induced abortion reduced by $4.8 \%$. Any contraceptive use had a statistically significant $(\mathrm{p}<0.001)$ and positive association $(\mathrm{OR}=4.488)$ with abortion use. Specifically, for women who ever used a contraceptive method, the odds of using induced abortion was 4.5 times higher than women who never used any contraceptive methods.

Types of contraceptive methods showed using no method had a negative association and permanent contraceptive use had a positive association with any abortion use. More specifically, for women not using any method, the odds of using induced abortion was $24.0 \%$ lower than for women using any contraceptive methods $(\mathrm{p}<0.001)$. Both traditional and modern reversible contraceptive methods were not association with abortion use. However, for women who use permanent contraceptive methods, the odds of having had an induced abortion was $42.0 \%$ higher than for women not using permanent contraceptive methods $(\mathrm{p}<0.001)$. This is perhaps not surprising given that women who've undergone permanent contraceptive procedures have completed their family sizes and thus may have had an abortion prior to tubal ligation reflecting this completion. Lastly, the number of children born to married women was also statistically significant $(\mathrm{p}<0.001)$ and positively associated $(\mathrm{OR}=1.239)$ with abortion use.

The variables measuring women's individual and household characteristics showed women's employment was statistically significant $(\mathrm{p}<0.001)$ and positively associated $(\mathrm{OR}=1.332)$ with abortion use. Women's age was statistically significant $(\mathrm{p}<$ $0.001)$ and positively associated $(\mathrm{OR}=1.098)$ with abortion use. This indicated that, for each year increase in a woman's age, the odds of using induced abortion multiplied by an additional 1.098. Similar to women's education, the husband's education was statistically 
significant $(\mathrm{p}<0.050)$ and negatively associated $(\mathrm{OR}=0.932)$ with abortion use. Again, when I controlled for parity, the direction of the association between husband's education and abortion use reversed and became positive, because parity was a distorter variable for both women's and husband's education. Wealth and Turkish ethnicity had statistically significant $(\mathrm{p}<0.001)$ and positive associations (1.140 and 1.521 , respectively) with abortion use.

For these bivariate analyses each region $(=1)$ was compared to all other regions $(=0)$. West was statistically significant $(\mathrm{p}<0.001)$ and positively associated $(\mathrm{OR}=$ 1.416) with abortion use, possibly because the western parts of Turkey are the most developed and Europeanized. On the other hand, south and east were statistically significant (respectively at $\mathrm{p}<0.010$ and $\mathrm{p}<0.001$ ) and negatively associated (respectively, $\mathrm{OR}=0.803$ and $\mathrm{OR}=0.611$ ) with abortion use.

Finally, the survey year unexpectedly showed as statistically significant, at $\mathrm{p}<$ 0.001 , and negatively associated $(\mathrm{OR}=0.544)$ with abortion use. This result indicated that, for women interviewed in 2013, the odds of using induced abortion was $45.6 \%$ lower than women interviewed in 2008. The main reason for this enormous difference in abortion use from 2008 to 2013 may lie in the Turkish government's agenda in 2012, set on changing abortion policy. The Ministry of Health discussed changing the abortion policy, which allows women to use state hospitals to end their pregnancies before 10 weeks, because abortion rates were rising very fast after having declines since the1980s (Senlet et al. 2001) and because of complaints from doctors who found giving induced abortion as a contraceptive method unethical. Today the abortion policy has not changed, 
but when a woman wants to use induced abortion, hospitals ask for her husband's consent and if possible, immediately inform the husband about the situation.

\subsubsection{Multivariate Results}

Table 6.2 presents Binary Logistic regressions of the main independent variables: religiosity, women's education, egalitarian ideology, and urban on abortion use. Odds Ratios (OR) are presented for all analyses in this table. Model 1 showed religiosity as statistically significant $(\mathrm{p}<0.001)$ and negatively associated $(\mathrm{OR}=.709)$ with abortion use. More specifically, for a one-unit increase in religiosity, reduced the odds of ending a pregnancy with induced abortion for a married woman by $29.1 \%$, net of all other factors in the analysis.

I computed all analyses with a series of control variables in Table 6.2. The results of all control variables were quite similar with the interpretations of the control variables in Table 6.1, but some variables lost their significance or became statistically significant in multivariate analyses. For example, permanent contraceptive use lost its significance, but modern reversible contraceptive method use in multivariate analysis was statistically significant $(\mathrm{p}<0.001)$ and positively associated $(\mathrm{OR}=1.321)$ with any abortion use. Women's age was statistically significant $(\mathrm{p}<0.001)$ and all other variables in women's individual and household characteristics category lost their significance. Lastly, only south and east region variables remained statistically significant $(\mathrm{p}<0.001$, and $\mathrm{p}<$ 0.010 , respectively) and had negative associations $(\mathrm{OR}=0.735$ and $\mathrm{OR}=0.766)$ with abortion use.

Model 2 includes both religiosity and modernization factors (women's education, egalitarian ideology, and urban), showing religiosity as still statistically significant ( $\mathrm{p}$ 
$0.001)$ and negatively associated $(\mathrm{OR}=0.710)$ with abortion use. This highly significant and negative association remained almost the same — most likely because of the strong argument of Islam against abortion use — even after controlling for main independent variables, modernization factors. Among modernization factors, only egalitarian ideology showed a statistically significant $(\mathrm{OR}=1.113)$ association with abortion use. This finding indicated that, for a one-unit increase in egalitarian ideology, the odds of any abortion use for a married woman multiplied by an additional $11.3 \%$, holding all other factors in the analysis constant. The results of control variables (except wealth) in Model 1 were consistent across Models 1 and 2.

\subsubsection{Interaction Results}

Table 6.3 presents the results of interaction terms between religiosity and modernization factors, including women's education, egalitarian ideology, urban, on abortion use in Odds Ratios (OR). Models 1, 2, and 3 show that two-way interaction terms between religiosity and modernization factors (women's education, egalitarian ideology, and urban); none of these had statistically significant associations with abortion use. This indicates that the effect of religiosity on abortion did not vary by women's education, egalitarian ideology, or residential area (urban vs. rural). These findings supported the argument in the latter part of my final hypothesis (H3), stating that interaction terms between modernization factors (women's education, egalitarian ideology, and urban) and religiosity would demonstrate no significant association with abortion use.

In Model 4, the interaction term between women's education and urban, however, was statistically significant $(\mathrm{p}<0.001)$ and negatively associated $(\mathrm{OR}=0.728)$ with 
abortion use. This result indicated that the positive effect of women's education on the odds of any abortion use decreased by $27.2 \%$ in urban areas, holding all other variables in the model constant. In other words, the positive effect of women's education on abortion use in urban areas was weaker than the positive effect of women's education in rural areas. This unexpected difference may relate to women's contraceptive use prior to abortion use (Westoff et al. 1998). Since my data were cross-sectional, it was not possible to discover women's contraceptive use prior to their abortion use. Figure 6.1 shows the interaction between women's education and urban residence for any abortion use; the lines are not parallel. Specifically, the positive effect of women's education on any abortion use for women living in rural areas increased directly after their primary education. Overall, this finding indicated that the effect of women's education on any abortion use depended on residential areas (urban vs. rural).

Model 5 shows the interaction term between egalitarian ideology and urban was not statistically significant. Furthermore, two three-way interaction terms (between religiosity, women's education, and urban, and between religiosity, egalitarian ideology, and urban) in Models 6 and 7 also were not statistically significant. These results revealed that the effect of religiosity on abortion use did not depend on women's education, egalitarian ideology, and residential area (urban vs. rural).

\subsubsection{Summary}

To summarize the findings, the main independent variables in Table 6.2 showed two main variables were statistically significant and associated with abortion use. First, religiosity, as expected, was statistically significant and negatively associated with abortion use. Second, only egalitarian ideology was statistically significant $(\mathrm{p}<0.050)$ 
and positively associated with abortion use. However, women's education and urban variables were jointly associated with any abortion use. The results for religiosity support the first part of H3 (religiosity would be negatively associated with abortion, given Islamic regulations for the practice), but the results of modernization factors only partly support the second part of H3 (modernization would be positively associated with abortion use).

Moreover, in Table 6.3, which shows the results of interaction variables, only one interaction term (between women's education and urban) was statistically significant. The other two-way and three-way interaction terms were not statistically significant. These statistically non-significant associations indicated that, in all analyses for abortion use, the effect of religiosity did not depend on women's education, egalitarian ideology, or residency (urban vs. rural) factors. Thus, modernization did not affect the association between religiosity and abortion use.

Overall, findings supported my general argument stating that both modernization and religiosity have independent effects on determinants of fertility (in this case abortion use), and modernization and religiosity can coexist in a Muslim-majority nation such as Turkey.

\subsection{Abortion Frequency}

\subsubsection{Bivariate Results}

I also estimated bivariate analyses between the abortion frequency $(0,1$, and $2+)$ and each of the independent variables. Since the results of bivariate analyses between all variables and abortion frequency were consistent with the previous bivariate analyses 
between all variables and any abortion use, I refrain here from discussing these findings but they are presented in Table 6.4.

\subsubsection{Multivariate Results}

Table 6.5 shows the results of Negative Binomial regressions for the main independent variables, religiosity, women's education, egalitarian ideology, and urban. The results are presented in Incidence Rate Ratios (IRR, exponentiated coefficients $[\exp (b)])$ in all analyses. Model 1 shows religiosity was statistically significant, at $\mathrm{p}<$ 0.001, and negatively associated with abortion frequency. This result indicated that for a one-unit increase in religiosity, the incidence rate of abortion frequency was reduced by $27.2 \%$, after controlling for all other variables in the analysis.

Results including the control variables showed relatively consistent across the models. Variables used for the PDF showed age at first marriage as statistically significant $(\mathrm{p}<0.001)$ and negatively associated $(\mathrm{IRR}=0.937)$ with abortion frequency. Variables for contraceptive methods revealed only modern reversible contraceptive methods was statistically significant $(\mathrm{p}<0.050)$ and positively associated $(\mathrm{IRR}=1.180)$ with abortion frequency. Lastly, the number of children was also statistically significant $(\mathrm{p}<0.001)$, but positively associated $(\mathrm{IRR}=1.108)$ with abortion frequency. This indicated that, all else being equal, for each additional child a married woman had the incidence rate of using induced abortion was 1.109 times larger. Although the TDHS does not ask about the motivation for abortion received, this result suggests that women who believed they had completed their family size were more likely to use induced abortion. 
Variables that measured women's individual and household characteristics showed women's age, wealth and Turkish ethnicity were statistically significant and positively associated with abortion frequency. For each a one-year increase in women's age, the incidence rate of using induced abortion multiplied by an additional $9.2 \%$, holding all other variables constant. For each one-unit increase in household wealth, the incidence rate of using induced abortion multiplied by an additional 5.9\%, holding all other variables in the model constant. Lastly, women of Turkish ethnicity had an incidence rate of using induced abortion $21.0 \%$ higher than women from other ethnic groups, net of all other factors in the model.

Among the region variables, only the south and east regions were statistically $(\mathrm{p}<$ 0.050) significant and negatively associated with abortion frequency. These results indicate that for women living in the south or east areas of Turkey, the incidence rate of using induced abortion again was $19.1 \%$ and $18.2 \%$, respectively, lower than for women living in the west region. Lastly, the survey year showed statistically significant $(\mathrm{p}<$ 0.001) and negative association with abortion frequency.

In Model 2, I included modernization factors (women's education egalitarian ideology, and urban), none of these were statistically significant. Religiosity (IRR = $0.726, \mathrm{p}<0.001)$ retained its statistically significant and negative association with abortion frequency. Thus, these findings show that modernization had no statistically significant effect on abortion frequency, whereas religiosity had a quite strong association with abortion use. Control variables in Model 2 were had similar effects as those discussed in Model 1, except for wealth, which was no longer statistically significant (Table 6.5). 


\subsubsection{Interaction Results}

Table 6.6 presents the results of interaction terms between religiosity and each of the modernization factors, including women's education, egalitarian ideology, urban, on abortion frequency in IRR. Model 1 shows the interaction term between religiosity and women's education was not statistically significant for abortion frequency. Model 2 shows the interaction term between religiosity and egalitarian ideology was statistically significant $(\mathrm{p}<0.050)$ and positively associated with abortion frequency. Specifically, for each one-unit increase in religiosity, the positive effect of egalitarian ideology on the incidence rate of using induced abortion was multiplied by an additional 1.075, all else being equal. This indicates that the effect of religiosity on induced abortion use depended on egalitarian ideology, contrary to my expectation.

Figure 6.2 presents the interaction between religiosity and egalitarian ideology on the frequency of abortion use. The egalitarian ideology lines show that for both women supporting traditional ideology and egalitarian ideology (1), religiosity is associated with a steeper decline in induced abortion use, from practicing no religious behavior to only one religious behavior, compared to other categories of egalitarian ideology. The lines for women who supported two egalitarian ideology statements (2) and all egalitarian ideology statements (3) showed a weaker effect at low levels of religiosity; however, at high levels of religiosity, the predicted frequency of abortion use for women supporting one egalitarian ideology statement was quite similar to women supporting two egalitarian ideology statements. At high levels of religiosity, the findings also showed that women with egalitarian ideology had the highest predicted frequency of abortion use. Overall, 
these results indicated the effect of religiosity on abortion use substantially varies by women's egalitarian ideology.

In Model 3 the interaction term between religiosity and urban was not statistically significant. The results of Models 1 and 3 indicated that the effect of religiosity on abortion frequency did not depend on women's education and residential areas (urban vs. rural), but the result of the interaction term in Model 2, unexpectedly, showed that the effect of religiosity on induced abortion use depended on egalitarian ideology. Overall, these results partly support the last part of my third hypothesis (H3).

The interaction term between women's education and urban in Model 4 was statistically significant $(\mathrm{p}<0.001)$ and negatively associated $(\mathrm{IRR}=0.758)$ with abortion frequency. This result indicated that, for women living in urban areas, the incidence rate of using induced abortion was reduced by $24.2 \%$ compared to women living in rural areas, holding all other factors in the analysis constant. This indicates that the association between women's education and abortion frequency varied by residential areas (urban vs. rural). As I argued after Table 6.3, this unexpected association may be related to women's contraceptive use prior to abortion practice (Westoff et al. 1998). Figure 6.3 presents the interaction between women's education and urban residence on abortion frequency; the lines as not parallel. Specifically, the effect of women's education on abortion frequency increased right after primary education in rural areas. This indicated that women's education had a stronger positive effect on abortion use in rural areas.

Model 5 shows there was no statistically significant association between egalitarian ideology and urban residence an abortion frequency. Finally, the three-way interaction terms showed the interaction terms between religiosity women's education 
and urban, and between religiosity, egalitarian ideology, and urban, was not statistically significant. Overall, these findings reveal that the effects of religiosity on abortion frequency do not depended on modernization factors, women's education, and urban but only depends on egalitarian ideology. These non-significant interaction terms supported the last part of my $\mathrm{H} 3$.

\subsubsection{Summary}

To summarize, religiosity had a strong negative association with abortion frequency. The magnitude and significance of religiosity remained the same across models after including the modernization factors (women's education, egalitarian ideology, and urban). This indicated that the effect of religiosity on abortion frequency was not mediated by modernization measures.

The non-significant interaction terms between religiosity and modernization factors (except egalitarian ideology) show that the association between religiosity and abortion frequency did not depend on modernization factors. However, religiosity and egalitarian ideology did statistically interact such that egalitarian ideology was associated with more frequent abortion use regardless of women's religiosity. In addition, the statistically significant and negative association between women's education and urban also indicate that the effect of women's education on abortion frequency depends on urban residency. The findings of chapter 6 did not fully (but mostly) support my last hypothesis (H3), stating the interaction terms between modernization (women's education, egalitarian ideology, and urban) and religiosity would demonstrate no significant association with abortion use. 


\section{CHAPTER 7: DISCUSSION}

This study analyzed nationally representative data on married women from the 2008 and 2013 Demographic and Health Survey Turkey (TDHS) to assess whether modernization and secularization were separately or jointly associated with several indicators of fertility. The study addressed three focal aims. First, I tested the independent and joint effects of modernization factors (education, egalitarianism, and urban residency) and religiosity on the number of children ever born to married women (parity) in Chapter 4. Second, I tested the independent and joint effects of modernization factors (education, egalitarianism, and urban residency) and religiosity on contraception use in Chapter 5. Third, I tested both independent and joint effects of modernization factors (education, egalitarianism, and urban residency) and religiosity on abortion. The results of this dissertation make several contributions to the literature on the importance of examining modernization and secularization processes separately in a different social context than on which most studies of Second Demographic Transition theory have been tested - the Muslim-majority country Turkey. In the sections that follow I summarize the overall findings for each of my dependent variables - parity, contraception use, and abortion. The general direction and significance of the findings for each measure of religiosity, modernization, and their interactions are also presented in Table 7.1.

\subsection{The Effects of Modernization and Secularization on Married Women's Parity}

The findings reveal that both modernization factors (except urban residency) and religiosity have independent effects on married women's parity. Contrary to SDT theory arguments (Lesthaeghe 2010; Lesthaeghe and Van de Kaa 1986) where modernization and secularization co-occur and have joint effects on fertility behaviors, my analyses 
revealed that there is independence between the effect of modernization factors (woman's education and egalitarianism) and religiosity on married women's parity. This indicates that contrary to findings of prior studies largely of modern Christian nations, modernization and religiosity can coexist and have independent effects on married women's parity in a Muslim majority nation, Turkey.

However, I also found a statistically significant and positive interaction between urban residency (one of the modernization indicators) and religiosity on married women's party. This is contrary to the expected negative association derived from SDT theory (see Table 2.1), whereby modernization should undermine the effect of religiosity. This finding also demonstrates that both modernization (at least, urban residency) and religiosity can also coexist because contrary to SDT theory, urbanization does not reduce the positive effect of religiosity on married women's parity in Turkey. Overall, the findings of Chapter 4 suggest that the components of modernization factors have strong and negative associations with married women's parity, though the positive effect of religiosity does not depend on components of modernization (except urban residence, which is in the opposite direction expected by SDT theory and thus suggests that modernization and religiosity are compatible in Turkey).

\subsection{The Effects of Modernization and Secularization on Contraception Use}

\subsubsection{Any Contraception Use}

Overall, I find mixed evidence concerning the effects of modernization and religiosity on contraceptive use. Religiosity had a negative association with any contraceptive use, whereas modernization factors were positively associated with any contraceptive use. These effects are consistent with the prior literature are not consistent 
with my expectations (of non-significant association) because the primary interpretation of Islamic teachings (Al-Ghazali 1939) generally allow reversible contraceptive use. This negative association might reflect women's limited knowledge on the perspective of Islamic teachings about contraceptive use and their hesitancy to ask for information on these kinds of private topics from a male religious leader.

In addition, I found that the interaction between religiosity and women's education was positive. This indicates that effect of religiosity on contraceptive use vary by women's education. Even though I did not expect this significant association, this association is consistent with the increased opportunity cost for women with higher education (Becker 1981), and the perspective of the primary teachings of Islam on contraceptive use (Al-Ghazali 1939). For women's education and urban residency, I found a negative association indicating the effect of women's education on any contraceptive use in rural areas was larger than its effect in urban areas. The reason for this difference is unclear. It may be that the weaker effect of education in urban areas may reflect the fact that contractive use is more prevalent and normative in urban areas. However, supplemental analyses by age showed that this negative interaction between education and urban residency was only significant for women over age 37 . Thus, this unexpected finding might reflect urban women's postponement of marriage and parenthood (Kulu 2013; White et al. 2008). Older urban women may be less likely to use any contraceptive method than their rural counterparts at older ages because they are not trying to avoided pregnancy, whereas rural women at the same age have already achieved their ideal number of children. 
Finally, the statistically significant and negative association of the three-way interaction term (between religiosity, women's education and urban residency) indicates that the effect of religiosity on contraceptive use depends on modernization factors (women's education and urban residency). Both of these findings are not consistent with my expectation of separate and independent effects of modernization and religiosity on any contraceptive use. On the other hand, the only non-significant interaction between religiosity and egalitarianism shows the individual effects of modernization and religiosity partly supports my expectations.

\subsubsection{Types of Contraceptive Methods}

The interdependency between religiosity and women's education on any contraception use is not consistent with my expectations. Findings examining types of contraceptive methods (traditional, modern reversible, and permanent) also showed a statistically significant and positive interaction between women's education and religiosity. These findings - most surprisingly for permanent contraception use - indicate that educated married women are willing to use all types of contraception methods regardless of their religiosity. This unexpected finding demonstrates that the effect of religiosity on contraception use (specifically permanent method) depends on women's education.

Analyses examining types of contraceptive methods also show that there is a statistically significant and negatively associated interaction effect between women's education and urban residency on all types of contraceptive methods. As I argued above in section 7.2.1 in any contraceptive use, this unexpected statistically significant and negative association may be explained by age groups, because of the urban women's 
postponement of marriage and parenthood (Kulu 2013; White et al. 2008). In addition, the three-way interaction term between women's education, religiosity, and urban residency show that the effect of religiosity on using traditional contraceptive methods rather than using nothing also depends on the modernization factors (Lesthaeghe 2010; Lesthaeghe and Van de Kaa 1986).

Overall, the results of the Chapter 5 suggest that there is a strong interdependency between women's education and religiosity and both any contraceptive use and each types of contraceptive method. The strong positive effect of women's education on contraceptive use regardless of religiosity is in line with the propositions of SDT theory (Lesthaeghe 2010).

\subsection{The Effects of Modernization and Secularization on Abortion Use}

The findings of Chapter 6 reveal that modernization factors and religiosity have independent effects on any abortion use and that they do not significantly interact as expected. The negative association between religiosity and any abortion use is consistent with prior literature (Erfani and McQuillan 2008). Contrary to expectation and prior literature, however, modernization factors (except egalitarian ideology) were nonsignificantly associated with abortion use.

The analyses of abortion frequency indicated interdependency between religiosity and egalitarian ideology, contrary to my expectation. This indicates that the effect of religiosity on the frequency of abortion use depends on women's egalitarian ideology. Married women with more egalitarian ideologies appear more likely to have had an abortion regardless of their level of religiosity. Even though the other interaction terms are consistent with my argument of modernization and religiosity having independent 
effects on abortion use, this significant and positive finding is consistent with the propositions of SDT theory (Lesthaeghe 2010; Lesthaeghe and Van de Kaa 1986).

\subsection{Limitations}

The results presented in this dissertation should be considered with the study's limitations. First, due to the fact that the TDHS are cross-sectional studies collected every five years, the data does not allow observation of individual change. Thus, it is not possible to determine whether married women's religiosity and characteristics signifying modernization have effects on their subsequent fertility behavior. Cross-sectional studies provide no evidence that religiosity and modernization are in any way causally related to women's behavior.

Second, this study is also limited because the TDHS does not collect information on the motivation behind fertility behaviors. For example, it is not possible to know why women are using certain contraceptive methods (e.g., hormonal methods to regulate menstruation, or permanent methods due to having previously received too many $\mathrm{C}$ sections [see footnote 1 in Chapter 5]). Likewise, I am unable to ascertain why women use induced abortion to end their pregnancies (e.g., did not want any (more) children, or felt that having another child was not possible given income). Relatedly, the TDHS lacks detailed measures on fertility intentions. ${ }^{2}$ Information on women's motivation for fertility

\footnotetext{
${ }^{2}$ The TDHS contains a single item that asks women what their "ideal" number of children is. As (Philipov 2009) argues, though, the ideal number of children is a problematic measure because - outside of the United States - it is often interpreted to mean the number of children desired under "ideal" conditions. This problematic nature may be even greater in a Muslim-majority country like Turkey given that Islam encourages adherents to marry and have children without worry because Allah (God) will always provide for children and their parents (Quran 6:151, 17:31). Nevertheless, future studies with the TDHS should explore the utility of this single measure.
} 
behaviors and their intentions would help to understand how modernization and secularization might exert their effects through such individual level processes.

Third, the TDHS collects data only on women. Yet, fertility decisions in married couples represent joint decision-making processes with a spouse. According to Thomson (1997) a man or woman's intention to have a child highly depends on the desire of their spouses. Specifically, this study of U.S. couples showed that respondents' odds of having a child were reduced by more than half the couple's fertility intentions were incongruent (one wanted a(nother) child, one did not). In developing countries, men typically express a desire for more children than do their wives and across countries men's preferences appear to hold slightly more sway in couple level fertility behavior (Bankole and Singh 1998). Although I included indicators of husband's education and the household socioeconomic status in my analyses, these do not capture the full extent of husbands' influence on fertility. Additional information, ideally self-reported, on husbands' fertility intentions and religiosity, for example, would be useful.

\subsection{Contributions}

Using nationally representative data from a sample of married women, I examined the separate and joint effects of modernization and secularization on indicators of fertility in Turkey. The findings of this study are important for two reasons. First, the study provides evidence that the secularization argument of the SDT theory is not necessarily directly applicable to Muslim-majority countries in general and to Turkey specifically. The results of interaction analyses generally emphasize that, contrary to the existing theory and literature (Lesthaeghe 2010; Lesthaeghe and Van de Kaa 1986), both modernization and secularization mostly have independent effects on indicators of 
fertility behaviors — with some exceptions primarily surrounding married women's contraceptive use and methods. Thus, these findings reveal that low fertility in Turkey is largely related to modernization and not to secularization. Indeed, the continued positive effects of religiosity indicates that religion somewhat balances out the negative effect of modernization factors in Turkey and if this were not the case Turkish fertility would be even lower.

Second, this dissertation provides empirical evidence that is important for government policies on fertility, contraception use, and abortion. There are several ways that these findings have policy relevance. First, the results suggest that policies should provide opportunities for women to balance family and career demands (Chesnais 1996). For example, since education has a very negative effect on women's parity, the government could support couples who are planning to marry and have children during their college years by providing free family dorm rooms and childcare services at campuses. This kind of policy might be quite costly, but it might deter couples from postponing marriage and parenthood, and therefore would ease the higher cost of shrinking working age people in the country. Advanced countries that have policies that reduce the opportunity costs of childbearing for women are more likely to maintain a TFR closer to replacement-level than those countries that do not have such policies (Rindfuss, Choe, and Brauner-Otto 2016).

Second, contraceptive use among married women in Turkey is quite high (above $95 \%$ ) and indicates that married women are trying to limit or space their births. This is generally socially acceptable (Koc 2000) and is associated with better maternal and child health outcomes (Ahmed et al. 2012). However, religiosity is, surprisingly, positively 
associated with permanent contraception use. This unexpected association

unquestionably requires further investigation because permanent contraceptive methods are the only contraceptive methods that are prohibited by the primary interpretation of Islamic teachings (Al-Bukhari 1999). As noted previously, permanent contraception might be related with the high $\mathrm{C}$-section delivery rate because, after the third or fourth $\mathrm{C}$ section, obstetricians may suggest women undergo tubal ligation given the increased complication risk of future pregnancies.

Therefore, the government may wish to develop policies that reduce the use of Csections. An ethnographic study of Iranian women, for example, suggests that some women may use $\mathrm{C}$-section based on the belief that it reduces the pain associated with delivery (Zakerihamidi, Latifnejad Roudsari, and Merghati Khoei 2015). A government sponsored information campaign could be developed to inform women about the health consequences of elective $\mathrm{C}$-section use, including the potential to limit future fertility. Policies aimed at physicians to discourage the routine use of C-section out of convenience may also be warranted.

Third, my findings show that women with more egalitarian attitudes are more likely to have received abortion services regardless of their religiosity. This suggests that any policy response should look to those that have been implemented by other countries undergoing the SDT. In general, abortion use is rather high in Turkey with $16 \%$ of women in the pooled 2008-2013 TDHS indicating that they had received an abortion previously. This rate is lower than it was in the 1990s (Senlet et al. 2001). The government could simply outlaw abortion, although this would likely be politically unfeasible and would contradict the secular nature of the Republic of Turkey. Previous 
studies (e.g., Senlet et al. 2001) suggested that abortion use was higher among Turkish women who used traditional contraceptive methods, owing to their high failure rate. My findings indicate that this unlikely to be the explanation for the higher abortion use among egalitarian women given that they are less likely to use traditional contraceptive methods. Although my data cannot speak to the motivation for abortion receipt as noted above, it may be that more egalitarian women are more concerned with their ability to provide adequate time and resources to children and thus to want to limit family size. If this were the case, government policies that provided more generous family allowances, longer maternity leave, and greater employment protections for women (Chesnais 1996) may be effective as modernized countries that have reduced opportunity costs for childbearing have fertility rates closer to replacement level (Rindfuss et al. 2016).

\subsection{Conclusion}

Overall, my findings add to the growing body of literature challenging the general proposition of SDT theory that very low fertility is the outcome of the co-occurring processes of modernization and secularization. My study is among the first to do this in a majority-Muslim country. I show that modernization and secularization do not co-occur in Turkey as these processes have separate effects on fertility behaviors, although the findings vary depending on the modernization factors and outcomes examined. It is possible for modernization to proceed without secularization in a Muslim-majority country, where there are high rates of religiosity, because of the dominant interpretation of Islam placing value in both secular and sacred knowledge. The co-occurrence of modernization and secularization — and their joint effects on family behaviors - appears to be a uniquely Northern, Western European and Christian one. 


\section{REFERENCES}

Abbasi-Shavazi, Mohammad Jalal and Fatemeh Torabi. 2012. "Women's Education and Fertility in Islamic Countries." Pp. 43-62 in Population Dynamics in Muslim Countries. Berlin Heidelberg: Springer.

Abbasi-Shavazi, Mohammad Jalal, Peter McDonald, and Meimanat Hosseini-Chavoshi. 2009. "The Fertility Transition in Iran: Revelution and Reproduction." Canadian Studies in Population 38(1-2):203-5.

Abduh, Muhammad. 1966. The Theology of Unity. London.

Abouchedid, Kamal and Ramzi Nasser. 2007. "Effects of Gender and Religiosity among Christians and Muslims on 'Gendered' Role Attitudes towards Ability and Equality: The Case of Lebanon.” Electronic Journal of Sociology 7(January):1-18.

Acemoglu, Daron, Simon Johnson, and James A. Robinson. 2002. "Reversal of Fortune: Geography and Institutions in the Making of the Modern World Income Distribution." The Quarterly Journal of Economics 117(4):1231-94.

Ahmed, Saifuddin, Qingfeng Li, Li Liu, and Amy Tsui. 2012. "Maternal Deaths Averted by Contraceptive Use: An Analysis of 172 Countries." The Lancet 380(9837):11125.

Al-attas, Muhammad Naquib. 1980. The Concept of Education in Islam. Muslim Youth Movement of Malaysia.

Al-Bukhari. 1976. Sahịh Al-Bukhārī: The Translation of the Meanings of Sahih AlBukhari. Vol. 7, Bo. edited by M. ibn I. Bukhārī and M. M. Khan. Saudi Arabia: Al Nabawi'ya.

Al-Bukhari. 1999. Sahih Al Bukhari.

Al-Ghazali, A. H. M. 1939. Ihya' 'ulum-Ud-Din [The Revival of the Religious Sciences]. Vol. 2. Cairo, Egypt: Mustafa Al-Babi.

Al-islam.org. 2018. "The Five Schools of Islamic Thought." The Islamic Educational Center of Orange County. Retrieved (https://www.al-islam.org/inquiries-about-shiaislam-sayyid-moustafa-al-qazwini/five-schools-islamic-thought).

Aramesh, Kiarash. 2006. "A Shiite Perspective toward Abortion.” Journal of Medical Ethics and History of Medicine Suppl (1):2-4.

Aries, Philippe. 1980. "Two Successive Motivations for the Declining Birth Rate in the West.” Source: Population and Development Review 6(4):645-50.

Asman, Oren. 2004. "Abortion in Islamic Countries - Legal and Religious Aspects." Med Law 23(1):73-89.

Atighetchi, Dariusch. 1994. "The Position of Islamic Tradition on Contraception." Med Law 13(1):717-25.

Bankole, Akinrinola and Susheela Singh. 1998. "Couples' Fertility and Contraceptive Decision-Making in Developing Countries: Hearing the Man's Voice." International Family Planning Perspectives 24(1):15.

Basu, A. M. 2002. "Why Does Education Lead to Lower Fertlity? A Critical Review of Some of the Possibilities." World Development 30(5):1779-90.

Becker, Gary S. 1981. "Altruism in the Family and Selfishness in the Market Place." Economica 48(189):1-15.

Becker, Gary S. and H.Gregg Lewis. 1973. "On the Interaction between the Quantity and Quality of Children.” Journal of Political Economy 81(2):S279-88.

Berger, Peter L. 1967. "A Sociological View of the Secularization of Theology." Journal 
for the Scientific Study of Religion 6(1):3-16.

Berger, Peter L. 2012. "Further Thoughts on Religion and Modernity." Society 49(4):313-16.

Berger, Peter L. 1992. “Sociology: A Disinvitation?” Society 30(1):12-18.

Berger, Peter L. 1999. The Desecularization of the World: Resurgent Religion and World Politics. edited by P. L. Berger. Wm. B. Eerdmans Publishing.

Berger, Peter L. 2014. The Many Altars of Modernity: Toward a Paradigm for Religion in a Pluralist Age. Walter de Gruyter GmbH \&Co KG.

Berger, Peter L. 2011. The Sacred Canopy: Elements of a Sociological Theory of Religion. New York: Open Road Media.

Berger, Peter L., Brigitte Berger, and Hansfried Kellner. 1973. The Homeless Mind: Modernization and Consciousness.

Berger, Peter L., Grace Davie, and Effie Fokas. 2008. Religious America, Secular Europe? A Theme and Variations. Aldershot, England; Burlington, VT: Ashgate.

Bickel, Robert. 2017. Peter Berger on Modernization and Modernity: An Unvarnished Overview. Routledge.

Black, Cyril E., ed. 1976. Comparative Modernization. New York: The Free Press. Bongaarts, John. 1978. "A Framework for Analyzing the Proximate Determinants of Fertility." Population and Development Review 4(1):105-32.

Bongaarts, John. 2011. "Can Family Planning Programs Reduce High Desired Family Size in Sub-Saharan Africa?" International Perspectives on Sexual and Reproductive Health 37(4):209-16.

Bongaarts, John. 1993. "The Supply-Demand Framework for the Determinants of Fertility." Population Studies 47(3):437-56.

Bongaarts, John and Rodolfo A. Bulatao, eds. 2000. "Beyond Six Billion: Forecasting the World's Population. Panel on Population Projections." Committee on Population, Commission on Behavioral and Social Sciences and Education.

Bongaarts, Ohn and Rodolfo A. Bulatao. 1999. "Completing the Demographic Transition." Population and Development Review 25(3):515-29.

Bruce, Steve. 2011. "A Sociology Classic Revisited: Religion in Banbury." Sociological Review 59(2):201-22.

Bruce, Steve. 2002. God Is Dead: Secularization in the West. Vol. 3. Oxford: Blackwell. Caldwell, John C. 1980. "Mass Education as a Determinant of the Timing of Fertility Decline." Population and Development Review 6(2):225-55.

Casanova, José. 2011. Public Religions in the Modern World. Chicago: University of Chicago Press.

Chaves, Mark. 1994. "Secularization as Declining Religious Authority." Social Forces 72(3):749-74.

Chesnais, J. C. 1996. "Fertility, Family, and Social Policy in Contemporary Western Europe." Population and Development Review 22(4):729-.

Choe, Ehn-Hyun, Han-Gon Kim, and Sang-Young Lee. 1993. "Consequences of Rapid Fertility Decline in the Republic of Korea."

Çinar, Alev. 2005. Modernity, Islam, and Secularism in Turkey: Bodies, Places, and Time. $\mathrm{U}$ of Minnesota Press.

Cleland, John and German Rodriguez. 1988. "The Effect of Parental Education on Marital Fertility in Developing Countries." Population Studies 42(3):419-42. 
Coale, Ansley J. and Susan Cotts Watkins. 1986. The Decline of Fertility in Europe. Princeton, NJ, NJ: Princeton University Press.

Coale, Ansley Johnson and Edgar M. Hoover. 1958. Population Growth and Economic Development. Princeton University Press.

Cohen, Joel. 2008. "Make Secondary Education Universal." Nature 456(December 2008):572-73.

Colclough, Christopher. 1982. "The Impact of Primary Schooling on Economic Development: A Review of the Evidence." World Development 10(3):167-85.

Colonna, Fanny and David Macey. 1995. "Islam in the French Sociology of Religion." Economy and Society 24(2):225-44.

Cox, Harvey G. and Jan Swyngedouw. 2000. "The Myth of the Twentieth Century: The Rise and Fall of Secularization." Japanese Journal of Religious Studies 27(1/2):113.

Cromer, Evelyn Baring. 1908. Modern Egypt. Vol. 1. Macmillan.

Cunningham, Mick, Ann M. Beutel, Jennifer S. Barber, and Arland Thornton. 2005. "Reciprocal Relationships between Attitudes about Gender and Social Contexts during Young Adulthood." Social Science Research 34(4):862-92.

Davie, Grace. 2002. Europe: The Exceptional Case: Parameters of Faith in the Modern World. London: Darton: Longman and Todd.

Davie, Grace. 2000. Religion in Modern Europe: A Memory Mutates. Oxford: Oxford University Press.

Dayioglu, Meltem and Murat G. Kirdar. 2010. "Determinants of and Trends in Labor Force Participation of Women in Turkey." State Plannign Organization of the Republic of Turkey and World Bank (Working Paper No. 5):1-80.

Dobbelaere, Karel. 1985. "Secularization Theories and Sociological Paradigms : A Reformulation of the Private-Public Dichotomy and the Problem of Societal Integration." Sociological Analysis 46(4):377-87.

Dobbelaere, Karel. 1987. "Some Trends in European Sociology of Religion : The Secularization." Sociological Analysis 48(2):107-37.

Dobbelaere, Karel. 1981. "Trend Report: Secularization: A Multi-Dimensional Concept." Current Sociology 29(2):3-153.

Doepke, M. 2004. "Accounting for Fertility Decline during the Transition to Growth." Journal of Economic Growth 9(3):347-83.

Durkheim, Emile. 1902. "Review of Freidrich Prinzing, 'Die Eheliche Fruchtbarkeit in Deutschland,' Zeitschrift Für Socialwissenschaft 1901, Issue 1:336-338; Issue 2:290-311; Issue 3:188-90.” Année sociologiqueV 436-37.

Durkheim, Emile, H. L. Sutcliffe, and J. Simons. 1992. "Suicide and Fertility: A Study of Moral Statistics." European Journal of Population 8(3):175-97.

Erfani, Amir and Kevin McQuillan. 2008. "Rapid Fertility Decline in Iran: Analysis of Intermediate Variables." Journal of Biosocial Science 40(3):459-78.

Esposito, John L. 1999. "Islam and the State: Dynamics of the Resurgence." Pp. 74-127 in The Islamic threat: Myth or reality? New York: Oxford University Press.

Faust, Kimberly, Rebecca Bach, and Saad G. A. D. Alla. 1991. "Mass Education, Islamic Revival , and the Population Problem in Egypt." Journal of Comparative Family Studies 22(3):329-41.

Finke, Roger, Avery M. Guest, and Rodney Stark. 1996. "Mobilizing Local Religious 
Markets : Religious Pluralism in the Empire State , 1855 to 1865." American Sociological Review 61(2):203-18.

Finke, Roger and Rodney Stark. 1989. "Evaluating the Evidence : Religious Economies and Sacred Canopies." American Sociological Review 54(6):1054-56.

Finke, Roger and Rodney Stark. 1998. "Religious Choice and Competition." American Sociological Review 63(5):761-66.

Frejka, T. and C. F. Westoff. 2008. "Religion, Religiousness and Fertility in the US and in Europe." European Journal of Population-Revue Europeenne De Demographie 24(1):5-31.

Gallup-Korea. 1998. "Hangukinuijonggyowajonggyosaengwhal (Religion and Religious Life of Koreans)."

Gerland, Patrick et al. 2014. "World Population Stabilization Unlikely This Century." Science 346(6206):234-37.

Goldscheider, Frances and Gayle Kaufman. 2006. "Willingness to Stepparent: Attitudes About Partners Who Already Have Children." Journal of Family Issues 27(10):1415-36.

Göle, Nilüfer. 1997. "Secularism and Islamism in Turkey: The Making of Elites and Counter-Elites." Middle East Institute 51(1):46-58.

Gönder, Hasan. 2017. "An Overlook Over The Declining Fertility Rate In Turkey." International Journal of Society Researches 7(12).

Gould, Stephen Jay. 1999. Rocks of Ages: Science and Religion in the Fullness of Life. New York: The Ballantine Publishing Group.

Gries, Thomas and Rainer Grundmann. 2015. "Fertility and Modernization: The Role of Urbanization in Developing Countries." Journal of International Development n/an/a.

Gwatkin, D. R., S. Rutstein, K. Johnson, R. P. Pande, and A. \& Wagstaff. 2000. SocioEconomic Differences in Health, Nutrition and Poverty. Washington D.C.: World Bank: HNP/Poverty Thematic Group, World Bank.

Halman, Loek and Veerle Draulans. 2006. "How Secular Is Europe?" British Journal of Sociology 57(2):263-88.

Hay, D.Alastair. 2014. "An Investigation into the Swiftness and Intensity of Recent Secularization in Canada: Was Berger Right?" Sociology of Religion: A Quarterly Review 75(1):136-62.

Hayford, Sarah R. and Philip S. Morgan. 2008. "Religiosity and Fertility in the United States: The Role of Fertility Intentions." Social Forces 86(3):1163-88.

Heaton, Tim B. 2011. "Does Religion Influence Fertility in Developing Countries." Population Research and Policy Review 30(3):449-65.

Heaton, Tim B., Daniel T. Lichter, and Acheampong Amoateng. 1989. "The Timing of Family Formation: Rural-Urban Differentials in First Intercourse, Childbirth, and Marriage." Rural Sociology 54(1).

Hertel, Bradley R. and Michael Hughes. 1987. "Religious Affiliation, Attendence, and Support for Pro-Family Issues in the United States." Social Forces 65(1):858.

Hessini, Leila. 2007. "Abortion and Islam: Policies and Practice in the Middle East and North Africa." Reproductive Health Matters 15(29):75-84.

Hirschman, Charles and Stewart E. Tolnay. 2005. "Social Demography." Handbook of Population 419-49. 
Hoebink, Michel. 1999. "Thinking about Renewal in Islam: Towards a History of Islamic Ideas on Modernization andSecularization." Arabica 46(1):29-62.

Iannaccone, Laurence R., Rodney Stark, and Roger Finke. 1998. "Rationality and The "Religious Mind"." Economic Inquiry 36(3):373-89.

Ibn-Khaldūn. 1969. The Muqaddimah: An Introduction to History. Princeton University Press.

Ibn-Khaldun, A. R. 1974. The Muqaddimah (The Introduction). Princeton, NJ, (translated by Franz Rosenthal): Princeton University Press.

Ince, Meltem. 2010. "How the Education Affects Female Labor Force? Empirical Evidence from Turkey." Procedia - Social and Behavioral Sciences 2(2):634-39.

Inglehart, Ronald. 1997. Modernization and Postmodernization. Cultural,Economic, and Political Change in 43 Societies. Princeton University Press.

Inglehart, Ronald and Wayne E. Baker. 2000. "Modernization, Cultural Change, and the Persistence of Traditional Values." American Sociological Review 65(1):19-51.

Iyer, Sriya. 2002. "Religion and the Decision to Use Contraception in India." 4:711-22.

Johnson, Todd Michael and Kenneth R. Ross, eds. 2009. Atlas of Global Christianity. Edinburgh University Press.

Van de Kaa, Dirk J. 1987. "Europe's Second Demographic Transition." Population Bulletin 42(1):1-57.

Van de Kaa, Dirk J. 2002. "The Idea of a Second Demographic Transition in Industrialized Countries." Paper Presented at the Sixth Welfare Policy Seminar of the National Institute of Population and Social Security, Tokyo, Japan, 29 January 2002 (January):1-34.

Kane, Jennifer B. 2013. "A Closer Look at the Second Demographic Transition in the US: Evidence of Bidirectionality from a Cohort Perspective (1982-2006)." Population Research and Policy Review 32(1):47-80.

Kaplan, Hillard. 1996. "A Theory of Fertility and Parental Investment in Traditional and Modern Human Societies." American Journal of Physical Anthropology 101(S23):91-135.

Kaplan, Hillard S., Jane B. Lancaster, John A. Bock, and Sara E. Johnson. 1995. "Fertility and Fitness among Albuquerque Men: A Competitive Labour Market Theory." Pp. 96-136 in InHuman reproductive decisions. Palgrave, London.

Karaman, Hayrettin. 2018. "Doğum Kontrolü." Retrieved (http://www.hayrettinkaraman.net/kitap/helalharam/0102.htm).

Kaufman, G. 2000. “Do Gender Role Attitudes Matter?” Journal of Family Issues 21(1):128-44.

Kaufmann, Eric. 2009. "Islamism, Religiosity and Fertility in the Muslim World." Pp. 144 in Islamism, religiosity and fertility in the muslim world, edited by V. 15. New York City: annual meeting of the ISA's 50th annual convention "Exploring the past, anticipating the future", New York Marriott Marquis.

Kazembe, Lawrence N. 2009. "Modelling Individual Fertility Levels in Malawian Women: A Spatial Semiparametric Regression Model." Statistical Methods and Applications 18(2):237-55.

Kim, Andrew Eungi. 2002. "Characteristics of Religious Life in South Korea: A Sociological Survey." Review of Religious Research 43(4):291-310.

Kirk, Dudley. 1996. "Demographic Transition Theory." Population Studies 50(3):361- 
87.

Kuhn, R. 2012. "On the Role of Human Development in the Arab Spring." Population and Development Review 38(4):649-83.

Kulu, Hill. 2006. "Fertility of Internal Migrants: Comparison between Austria and Poland." Population, Space and Place 12(3):147-70.

Kulu, Hill. 2005. "Migration and Fertility: Competing Hypotheses Re-Examined." European Journal of Population 21(1):51-87.

Kulu, Hill. 2013. "Why Do Fertility Levels Vary between Urban and Rural Areas?" Regional Studies 47(6):895-912.

Kuru, Ahmet. 2009. Secularism and State Policies toward Religion : The United States, France, and Turkey. Cambridge University Press.

Ladhari, Riadh. 2010. "Developing E-Service Quality Scales: A Literature Review." Journal of Retailing and Consumer Services 17(6):464-77.

Lamanna, Mary Ann. 2002. Emile Durkheim on the Family. Sage Publications.

Lerner, Daniel. 1958. The Passing of Traditional Society: Modernizing the Middle East. New York: Free Press.

Lesthaeghe, R. and K. Neels. 2002. "From the First to the Second Demographic Transition: An Interpretation of the Spatial Continuity of Demographic Innovation in France, Belgium and Switzerland.” European Journal of Population-Revue Europeenne De Demographie 18(4):325-60.

Lesthaeghe, Ron J. 1983. "A Century of Demographic and Cultural-Change in WesternEurope - An Exploration of Underlying Dimensions." Population and Development Review 9(3):411-35.

Lesthaeghe, Ron J. 2014. "The Second Demographic Transition: A Concise Overview of Its Development." Proceedings of the National Academy of Sciences 111(51):18112-15.

Lesthaeghe, Ron J. 2010. "The Unfolding Story of the Second Demographic Transition." Population and Development Review 36(2):211-+.

Lesthaeghe, Ron J. and Dirk J. Van de Kaa. 1986. Twee Demografische Transities? [Two Demographic Transitions?]. Bevolking-Groei En Krimp, Mens En Maatschappij. edited by R. J. Lesthaeghe and D. J. Van de Kaa. Deventer, The Netherlands: Van Loghum Slaterus.

Lesthaeghe, Ron J. and Johan Surkyn. 1988. "Cultural Dynamics and Economic Theories of Fertility Change." Population and Development Review 14(1):1-45.

Lesthaeghe, Ron and Karel Neels. 2002. "From the First to the Second Demographic Transition : An Interpretation of the Spatial Continuity of Demographic Innovation in France, Belgium and Switzerland.” European Journal of Population 18(2):32560.

Lesthaeghe, Ron and Chris Wilson. 1986. "Modes of Production, Secularization, and the Pace of Fertility Decline in Western Europe, 1870-1930." Pp. 261-92 in The decline of fertility in Europe, edited by A. j. Coale and S. C. Watkins. Princeton Univ, Princeton, NJ 08544 USA. Westoff, CF (reprint author), Princeton Univ, Princeton, NJ 08544 USA.: Princeton University Press.

Long, J.Scott and Jeremy Freese. 2014. Regression Models for Categorical Dependent Variables Using Stata. Third Edit. Stata Press.

Lutz, Wolfgang and Samir Kc. 2011. "Global Human Capital : Integrating Education and 
Population." American Association for the Advancement of Science 333(6042):58792.

Macunovich, Diane J. 2007. "Effects of Changing Age Structure and Intergenerational Transfers on Patterns of Consumption and Saving." Pp. 243-77 in Allocating Public and Private Resources across Generations, edited by G. A.H., C. C.Y.C., and T. S. Dordrecht: Springer.

Mardin, Serif. 1983. "Religion and Secularism, in Turkey." P. 195 in Atatürk: founder of a modern state, edited by A. Kazancigil and and E. Ozbudun. London: C. Hurst.

Mardin, Şerif. 2006. Religion, Society, and Modernity in Turkey. Syracuse University Press.

Martin, David. 1978. A General Theory of Secularization. Harper \& Row.

Martin, David. 1991. "The Secularization Issue: Prospect and Retrospect." The British Journal of Sociology 42(3):465-74.

Martin, David. 1990. Tongues of Fire: The Explosion of Protestantism in Latin America. Wiley.

Martin, Teresa Castro. 1995. "Women's Education and Fertility: Results from 26 Demographic and Health Surveys." Studies in Family Planning 26(4):187.

Mcdonald, Peter. 2006. "Low Fertility and the State :" Population and Development Review 32(September):485-510.

McDonald, Peter F. 1992. "Convergence or Compromise in Historical Family Change?" Pp. 15-30 in Family Systems and Cultural Change, edited by E. Berquo and P. Xenos. Oxford: Clarendon Press.

McDonald, Peter F. 1994. "Families in Developing Countries: Idealized Morality and Theories of Family Change." Pp. 19-28 in Tradition and Change in the Asian Family, edited by L.-J. Cho and M. Yada. Honolulu: East-West Center.

McLeod, Hugh and Werner Ustorf, eds. 2003. The Decline of Christendom in Western Europe, 1750-2000. Cambridge University Press.

McQuillan, Kevin. 2004. "When Does Religion Influence Fertility?” Population and Development Review 30(1):25-56.

Melchert, Christopher. 1997. The Formation of the Sunni Schools of Law: 9th-10th Centuries CE. Vol. 4. Brill.

Moav, Omer. 2005. "Cheap Children and the Persistence of Poverty." Economic Journal 115(500):88-110.

Moksony, Ferenc and Rita Hegedüs. 2014. "The Use of Poisson Regression in the Sociological Study of Suicide." Corvinus Journal of Sociology and Social Policy 5(2):97-114.

Moors, Guy. 2008. "The Valued Child. In Search of a Latent Attitude Profile That Influences the Transition to Motherhood." European Journal of Population-Revue Europeenne De Demographie 24(1):33-57.

Morgan, Philip and Kellie j. Hagewen. 2005. "Fertility." Pp. 229-49 in Handbook of Population, edited by D. Poston and M. Micklin. New York: Springer.

Morgan, S.Philip. 2003. "Is Low Fertility a Twenty-First-Century Demographic Crisis?" Demography 40(3):589-603.

Mosher, William D., Linda B. Williams, and David P. Johnson. 1992. "Religion and Fertility in the United States : New Patterns." Demography 29(2):199-214.

Moss, SC et al. 1998. "Reliability and Validity of the PAS-ADD Checklist for Detecting 
Psychiatric Disorders in Adults with Intellectual Disability." Journal of Intellectual Disability Research 42(April 1998):173-83.

Munir, LZ. 2003. "Islam, Modernity and Justice for Women." A Paper Presented at the Islam and Human Rights ... 2:1-6.

Musallam, Basim. 1983. Sex and Society in Islam: Birth Control before the Nineteenth Century. Cambridge, UK: Cambridge University Press.

Nitzan, Peri-Rotem. 2016. Religion and Fertility in Western Europe: Trends Across Cohorts in Britain, France and the Netherlands. Springer Netherlands.

Norris, Pippa and Ronald Inglehart. 2004. Sacred and Secular: Religion and Politics Worldwide. Cambridge, UK: Cambridge University Press.

Notestein, Frank W. 1945. "Population - the Long View." Pp. 37-57 in Food for the World, edited by W. Schultz. Chicago: Chicago University Press.

Notestein, Frank Wallace. 1953. "Economic Problems of Population Change." Pp. 13-31 in The Eight International Conference of Agricultural Economics. London, England: Oxford University Press.

Obermeyer, Carla Makhlouf. 1992. "Islam, Women, and Politics : The Demography of Arab Countries." Population and Development Review 18(1):33-60.

Ogden, P. E. and R. Hall. 2004. "The Second Demographic Transition, New Household Forms and the Urban Population of France during the 1990s." Transactions of the Institute of British Geographers 29(1):88-105.

Okumus, Ejder. 2008. "Turkey-Religiosity and the PRA (Presidency of Religious Affairs)." Muslim World 98(2-3):345-62.

Okumuş, Ejder. 2005. Dinin Meşrulaştırma Gücü. Istanbul: Ark Kitaplari Yay.

Okumuş, Ejder. 2008. "Turkey-Religiosity and the PRA." The Muslim World 98(23):345-62.

Olson, Daniel V. .. A. .. 1998. "Religious Pluralism in Contemporary U . S . Counties." American Sociological Association 63(5):759-61.

Patrick, James. 2007. Renaissance and Reformation. New York: Marshall Cavendish.

Peek, Charles W., George D. Lowe, and L.Susan Williams. 1991. "Another Look at Religious." Social Forces 69(1):1205.

Philipov, Dimiter. 2009. "Fertility Intentions and Outcomes: The Role of Policies to Close the Gap.” European Journal of Population 25(4):355-61.

Quinn, Bernard, Hermann Anderson, Martin Bradley, Paul Goetting, and Peggy Shriver. 1982. Churches and Church Membership in the United States, 1980: An

Enumeration by Re-Gion, State, and County, Based on Data Re-Ported by 111 Church Bodies. Atlanta, GA: Glenmary Reseach Center.

Reed, Steven R. 2007. “Analyzing Secularization and Religiosity in Asia.” Japanese Journal of Political Science 8(3):327-39.

Rendall, Michael S. and Raisa A. Bahchieva. 1998. "An Old-Age Security Motive for Fertility in the United States ?" Population and Development Review 24(2):293-307.

Rindfuss, Ronald R., Minja Kim Choe, and Sarah R. Brauner-Otto. 2016. "The Emergence of Two Distinct Fertility Regimes in Economically Advanced Countries." Population Research and Policy Review 35(3):287-304.

Rodney Stark and Laurence R. Iannaccone. 1994. "A Supply-Side Reinterpretation of the 'Secularization' of Europe." Journal for the Scientific Study of Religion 33(3):23052. 
Rosenberg, Morris. 1968. The Logic of Survey Analysis. New York: Basic Books. Ruiter, Stijn and Frank van Tubergen. 2009. "Religious Attendance in Cross-National Perspective: A Multilevel Analysis of 60 Countries.” American Journal of Sociology 115(3):863-95.

Saeed, Javaid. 1994. Islam and Modernization: A Comparative Analysis of Pakistan, Egypt and Turkey. Westport, Conn. and London: Praeger Press.

Sarah R. Hayford and S.Philip Morgan. 2008. "Religiosity and Fertility in the United States: The Role of Fertility Intentions." Social Forces 86(3):1163-88.

Sasaki, Masamichi and Tatsuzo Suzuki. 1987. "Changes in Religious Commitment in the United States, Holland, and Japan." American Journal of Sociology 92(5):1055-76.

Senlet, Pinar, Sian L. Curtis, Jill Mathis, and Han Raggers. 2001. "The Role of Changes in Contraceptive Use in the Decline of Induced Abortion in Turkey." Studies in Family Planning 32(1):41-52. Retrieved (http://www.jstor.org/stable/2696295).

Sherkat, Darren E. .. 1998. "Counterculture or Continuity? Competing Influences on Baby Boomers â $€^{\mathrm{TM}}$ Religious Orientations and Participation." Social Forces 76(3):1087-1114.

Sonn, Tamara. 2005. "Islam and Modernity: Are They Compatible?" Pp. 65-81 in Modernization, democracy, and Islam, edited by S. Hunter and H. Malik. Greenwood Publishing Group.

Stark, Rodney. 1999. "Secularization, R.I.P.” Sociology of Religion 60(3):249-73.

Stark, Rodney and Roger Finke. 2000. Acts of Faith: Explaining the Human Side of Religion. Univ of California Press.

Stark, Rodney, Laurence R. .. Iannaccone, and Roger Finke. 1996. "Religion, Science , and Rationality." The American Economic Review 86(2):433-37.

Steinhoff, Anthony. 2011. "Nineteenth-Century Urbanization as Sacred Process: Insights from German Strasbourg." Journal of Urban History 37(6):828-41.

Stewart, Jennifer. 2003. "The Mommy Track: The Consequences of Gender Ideology and Aspirations on Age at First Motherhood." Journal of Sociology and Social Welfare 102(2):3-30.

Stover, John. 1998. "Revising the Proximate Determinants of Fertility Framework: What Have We Learned in the Past 20 Years?” Studies in Family Planning 29(3):255.

Strauss, John and Duncan Thomas. 1995. "Human Resources: Empirical Modeling of Household and Family Decisions.” Pp. 1883-2023 in Handbook of development economics 3.

Surkyn, Johan and Ron Lesthaeghe. 2004. "Value Orientation and the Second Demographic Transition (SDT) in Northern, Western and Southern Europe: An Update." Demographic Research 10(SUPPL. 3):45-86.

Teitelbaum, Michael S. and Jay M. Winter. 1985. The Fear of Population Decline. Orlando: Acadamic Press, INC.

The-Pew-Reserch-Center. 2010. U.S. Religious Knowledge Survey.

Thompson, Warren S. 1929. "Population." American Journal of Sociology 34(1):959-75. Thomson, E. 1997. "Couple Childbearing Desires, Intentions, and Births." Demography 34(3):343-54.

Tromans, Nicola, Eva Natamba, and Julie Jefferie. 2009. "Have Women Born Outside the U.K. Driven the Rise in U.K. Births since 2001?" Population Trends (136):2842. 
Tschannent, Olivier. 1991. "The Secularization Paradigm : A Systematization.” Journal for the Scientific Study of Religion 30(4):395-415.

Turkstat. 2016. "Turkish Statistical Institude." Turkstat. Retrieved (http://www.turkstat.gov.tr/Start.do).

United Nations, Department of Economic and Social Affairs. 2011. World Fertility Report 2009. New York.

United Nations, Department of Economic and Social Affairs. 2013. World Population Prospects, The 2012 Revision. Population Division. New York: United Nations.

United Nations, Department of Economic and Social Affairs. 2003. World Population Prospects: The 2002 Revision. Population Division. New York: United Nations.

Wallace, Anthony. 1966. Religion: An Anthropological View. Random House.

Wallwork, Ernest. 1985. "Durkheim's Early Sociology of Religion.” Sociological Analysis 46(3):201-17.

Weber, Max. 1973. "Die „Objektivität" Sozialwissenschaftlicher Und Sozialpolitischer Erkenntnis.” Gesammelte Aufsätze Zur Wissenschaftslehre 180-214.

Westoff, Charles F., Almaz T. Sharmanov, Jeremiah M. Sullivan, and Trevor Croft. 1998. Replacement of Abortion by Contraception in Three Central Asian Republics. Calverton, Maryland: The Policy Project and Macro International Inc.

Whimster, Sam and Scott Lash. 2014. Rationality and Modernity. edited by M. Weber. Routledge.

White, Michael J. et al. 2008. "A Urbanization and Fertility: An Event-History Analysis of Coastal Ghana." Demography 45(4):803-16.

Wilson, Brayn R. 1966. Religion in Secular Society. London: Watts.

Wilson, Bryan. 2003. "Secularisation.” Key Ideas in Sociology. Nelson Thornes Ltd.

Wilson, Bryan. 1998. "The Secularization Thesis: Criticisms and Rebuttals." P. 45 in Secularization and Social integration, edited by B. R. Laermans and W. Billiet. Leuven: Leuven University Press.

Wilson, Bryan R. 2016. Religion in Secular Society: Fifty Yers on. edited by S. Bruce. London: C.A. Watts.

Wilson, Bryan R. 1985. "Secularization: The Inherited Model." Pp. 9-20 in The sacred in a secular age: Toward revision in the scientific study of religion, edited by $\mathrm{P}$. E. Hammond. Univ of California Press.

Wohlrab-Sahr, Monika and Marian Burchardt. 2012. "Multiple Secularities: Toward a Cultural Sociology of Secular Modernities.” Comparative Sociology 11(6):875-909.

World-Bank. 2015. "Fertility."

Yardumian, Aram and Theodore G. Schurr. 2011. "Who Are the Anatolian Turks?" Anthropology \& Archeology of Eurasia 50(1):6-42.

Yavuz, Sutay. 2008. "Fertility Decline in Turkey From the 1980s Onwards: Patterns by Main Language Groups.” Hacettepe University.

Yusuf, Jibrail Bin. 2014. "Contraception and Sexual and Reproductive Awareness among Ghanaian Muslim Youth: Issues, Challenges, and Prospects for Positive Development." SAGE Open 4(3):1-12.

Zakerihamidi, Maryam, Robab Latifnejad Roudsari, and Effat Merghati Khoei. 2015. "Vaginal Delivery vs. Cesarean Section: A Focused Ethnographic Study of Women's Perceptions in The North of Iran." International Journal of Community Based Nursing and Midwifery 3(1):39-50. 
Zhang, L. 2008. "Religious Affiliation, Religiosity, and Male and Female Fertility." Demographic Research 18:233-61. 


\section{FIGURES AND TABLES}

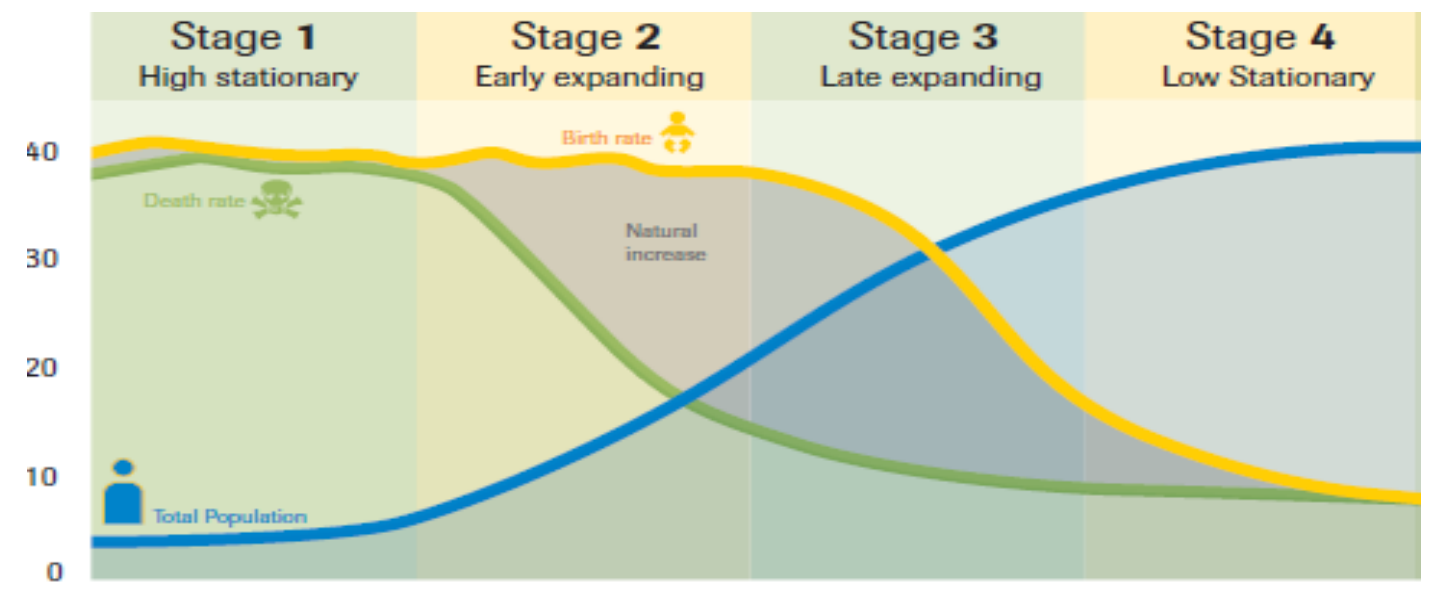

Source: www.populationeducation.org

Figure 2.1. The Stages of Demographic Transition 


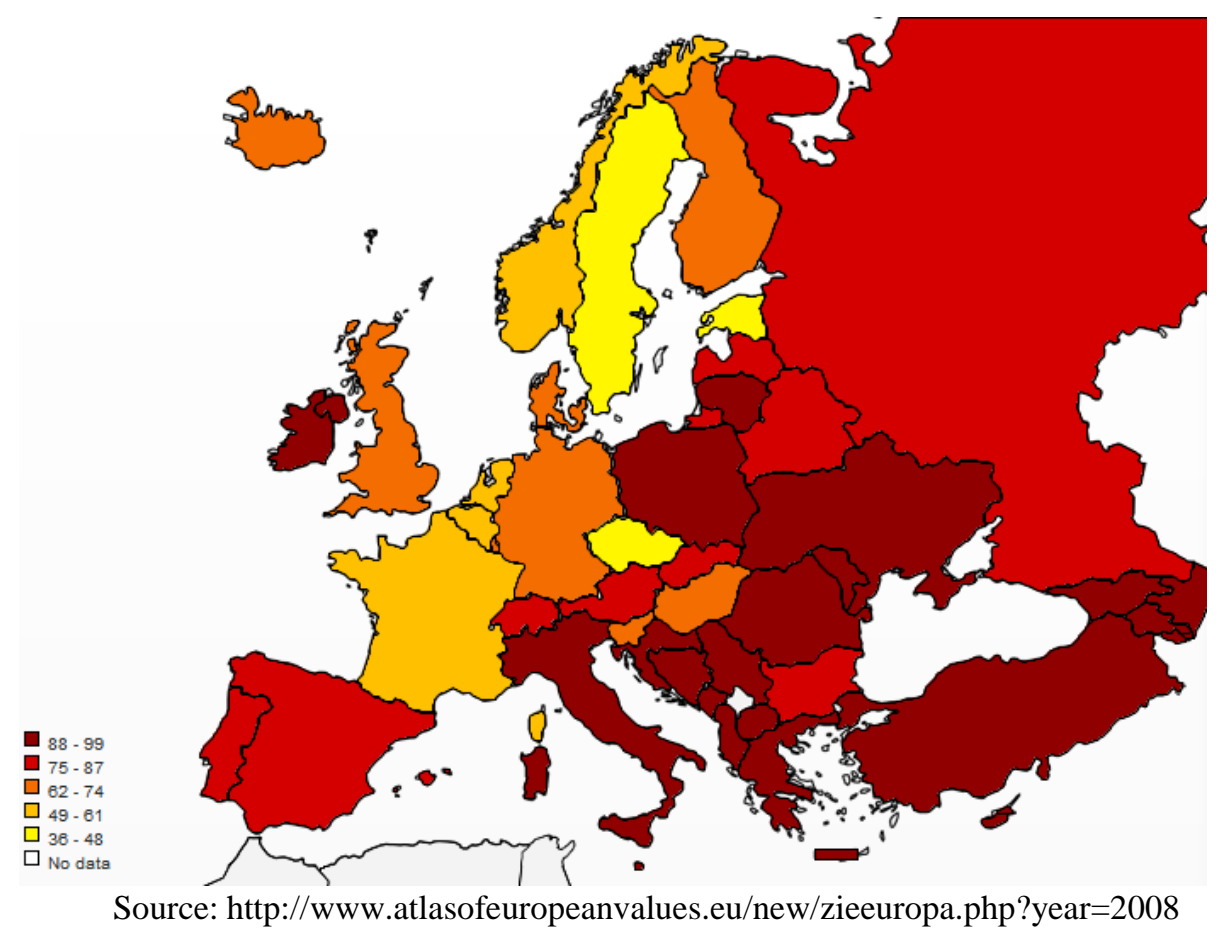

Figure 2.2. Percentage of Europeans Expressing a Belief in God, by Country. Results from the 2008 European Value Survey 


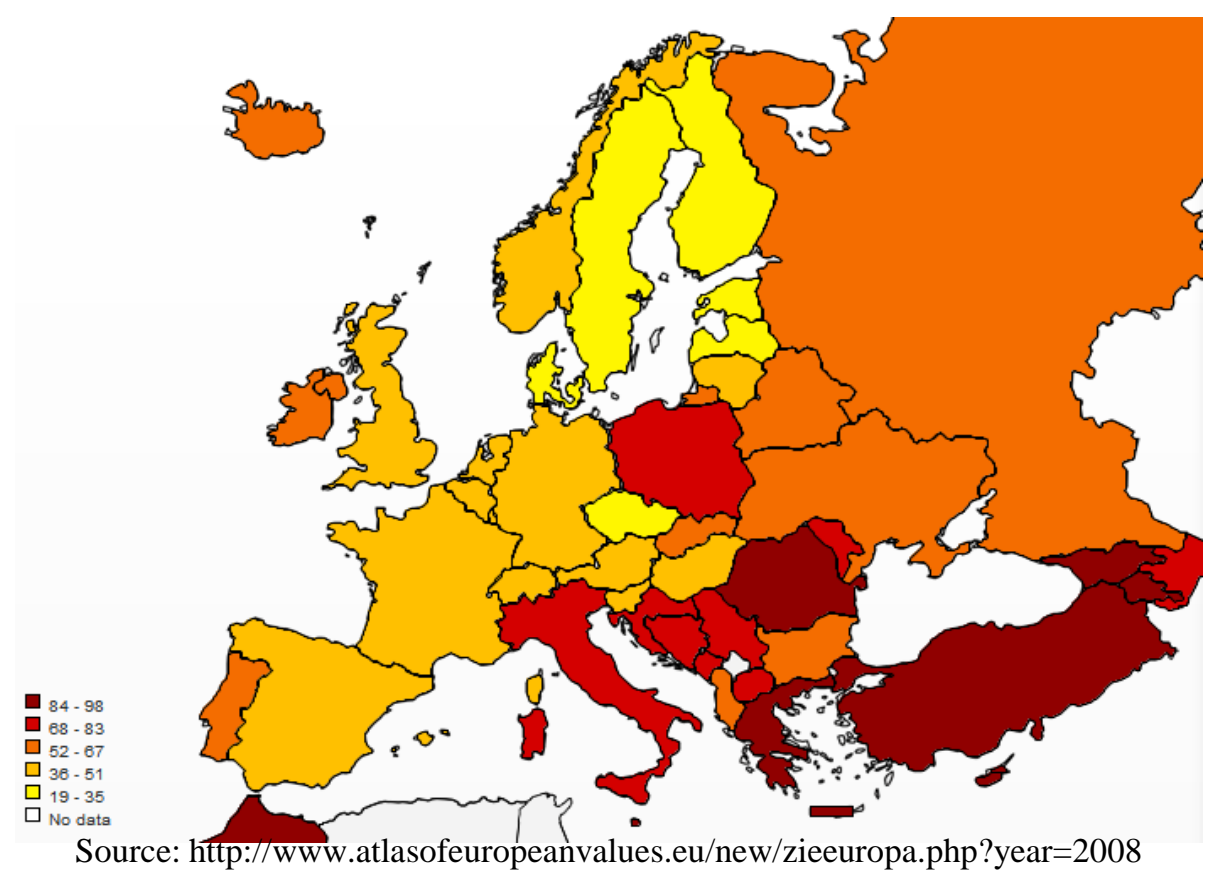

Figure 2.3. Percentage of Europeans Indicating that Relgion is Important in their Lives, by Country. Results from the 2008. European Value Survey 


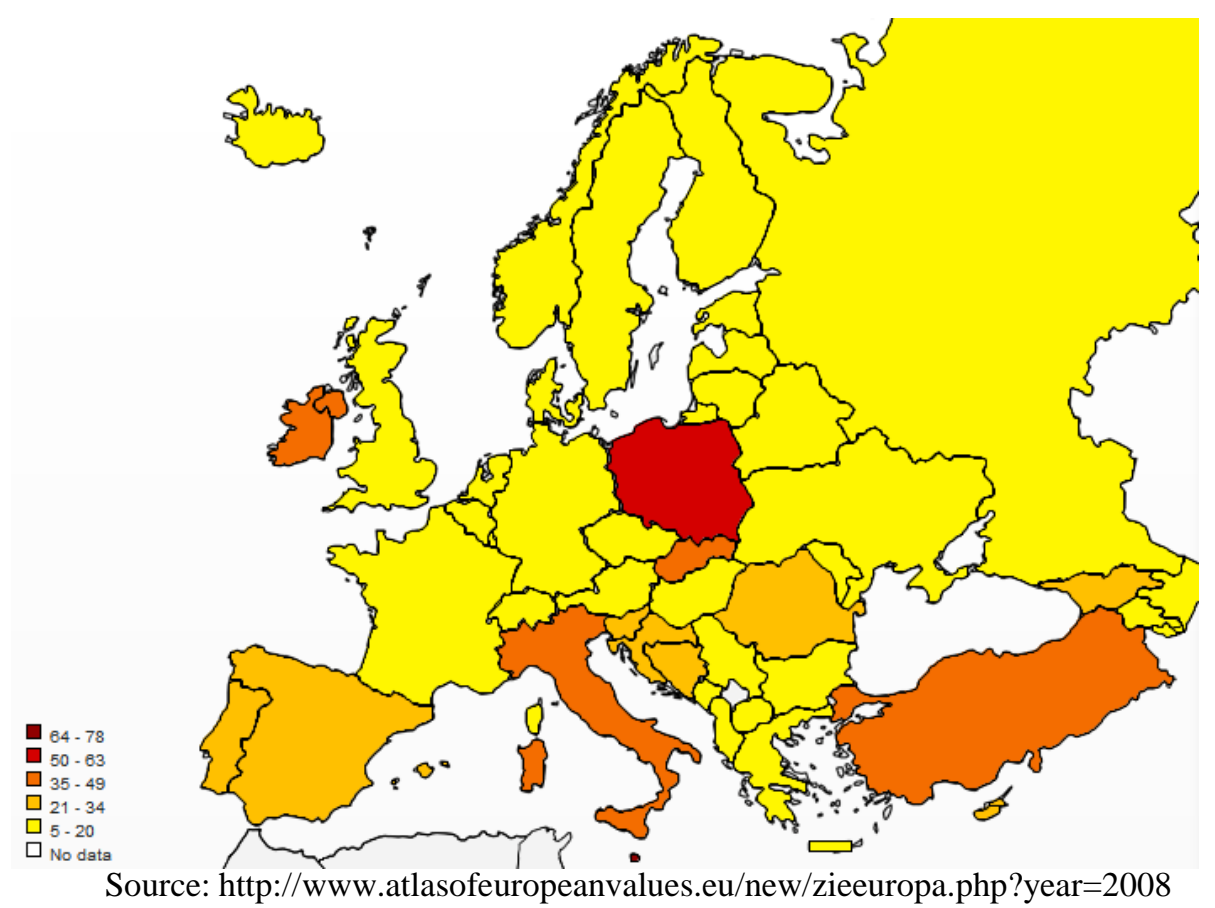

Figure 2.4. Percentage of Europeans AttendinG Religious Services at Least Once per Week, by Country. Results from the 2008 European Value Survey 


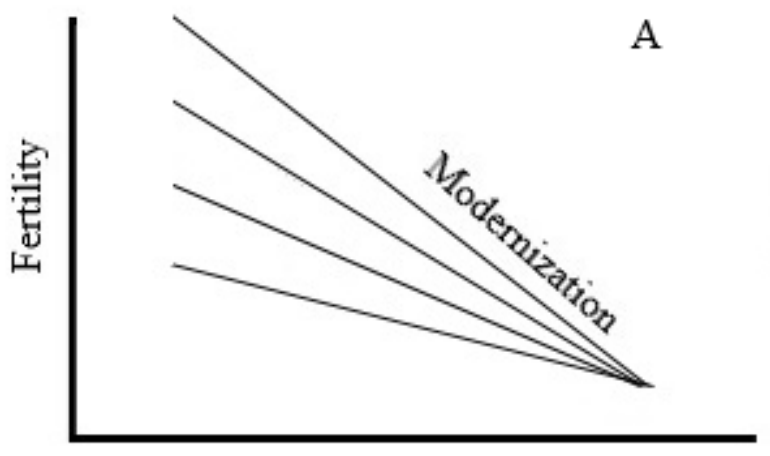

Secularization

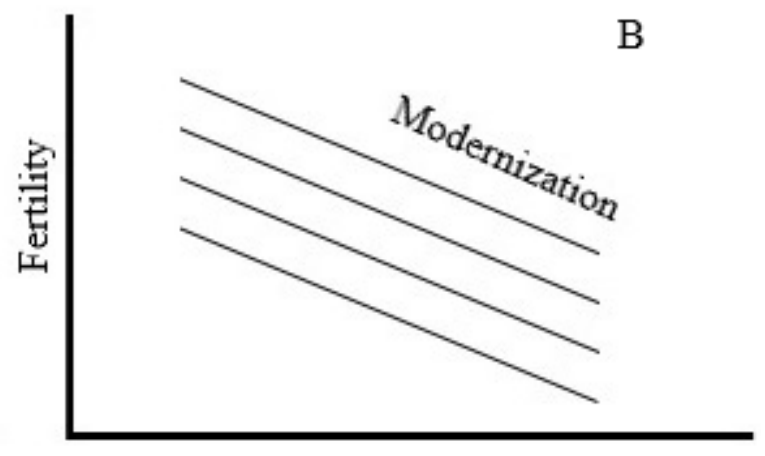

Secularization

Figure 2.5. Modernization and Secularization as Joint Processes according to SDT theory (Panel A) and as Separate Processes as Hypothesized Here (Panel B) 


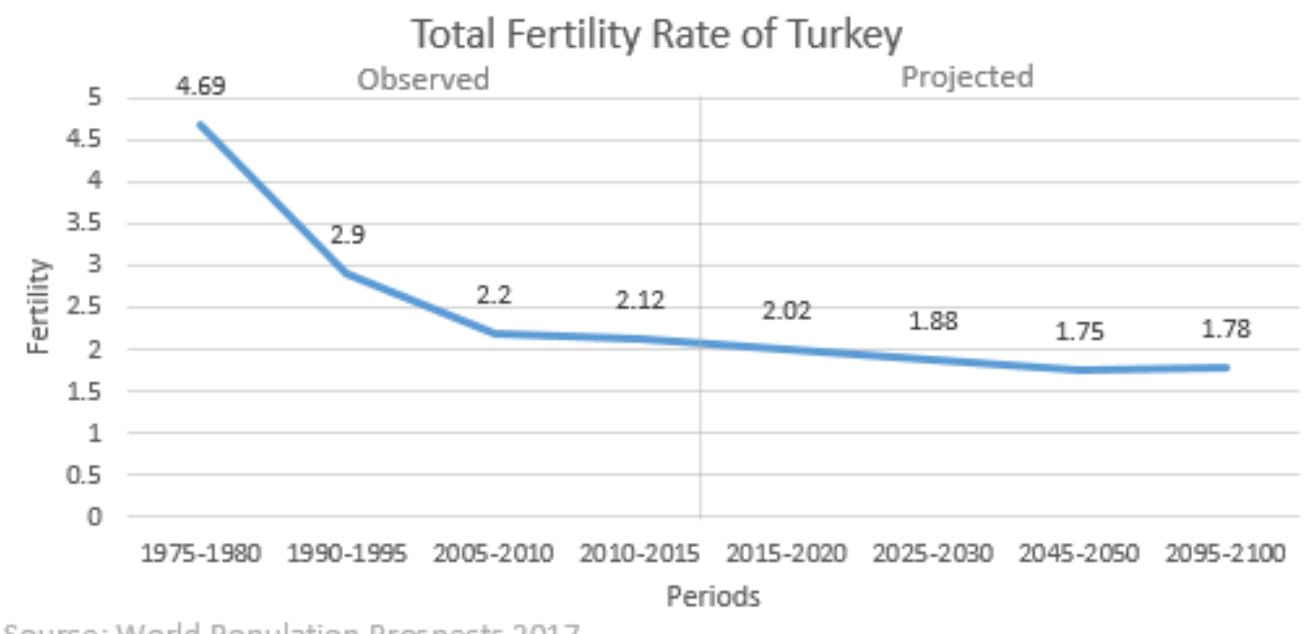

Source: World Population Pros pects 2017

Figure 2.6. Observed and Projected Total Fertility Rate for Turkey 
Table 2.1. Hypotheses Table Comparing the Expected Association Derived from SDT Theory and those Hypothesized in this Study

\begin{tabular}{|c|c|c|}
\hline Hypotheses & SDT Theory Expectation & Hypothesized \\
\hline $\begin{array}{l}\text { The interaction effects of } \\
\text { modernization (education, } \\
\text { egalitarianism, and urban } \\
\text { residence) and religiosity } \\
\text { variables would provide a } \\
\text { non-significant association } \\
\text { with the number of } \\
\text { children. }\end{array}$ & $\begin{array}{c}\text { Negative and Significant } \\
\text { Association }\end{array}$ & $\begin{array}{c}\text { Non-significant } \\
\text { Association }\end{array}$ \\
\hline $\begin{array}{l}\text { The interaction effects of } \\
\text { modernization (education, } \\
\text { egalitarianism, and urban } \\
\text { residence) and religiosity } \\
\text { would provide a non- } \\
\text { significant association with } \\
\text { contraceptive use. }\end{array}$ & $\begin{array}{l}\text { Positive and Significant } \\
\text { Association }\end{array}$ & $\begin{array}{c}\text { Non-significant } \\
\text { Association }\end{array}$ \\
\hline $\begin{array}{l}\text { The interaction effects of } \\
\text { modernization (education, } \\
\text { egalitarianism, and urban } \\
\text { residence) and religiosity } \\
\text { would provide a non- } \\
\text { significant association with } \\
\text { abortion use. }\end{array}$ & $\begin{array}{c}\text { Positive and Significant } \\
\text { Association }\end{array}$ & $\begin{array}{c}\text { Non-significant } \\
\text { Association }\end{array}$ \\
\hline
\end{tabular}




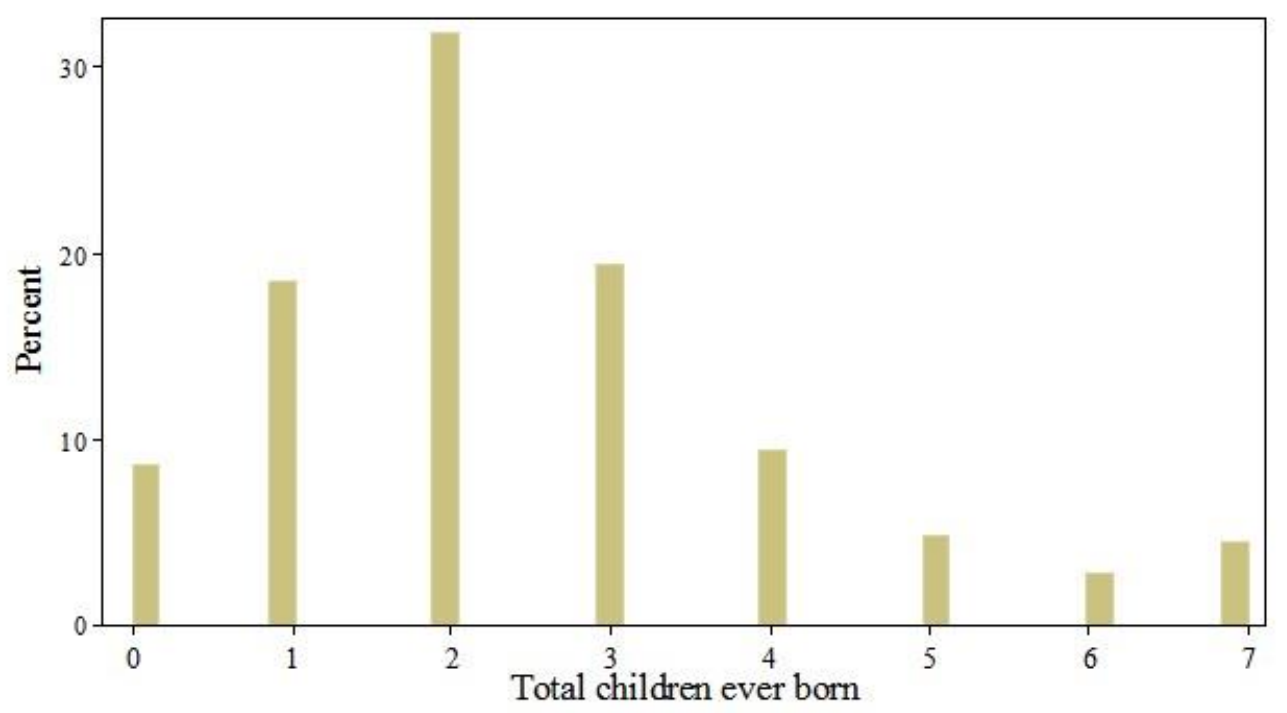

Figure 3.1. Distribution of the Number of Children Ever Born 
Table 3.1. Descriptive Statistics of Analytic Sample (N=13578)

\begin{tabular}{|c|c|c|c|c|}
\hline \multirow{2}{*}{ Variables } & \multicolumn{4}{|c|}{ Descriptive Statistics } \\
\hline & Mean & S.D. & Min & Max \\
\hline \multicolumn{5}{|l|}{ Secularization } \\
\hline Religiosity & 2.154 & 0.964 & 0 & 3 \\
\hline \multicolumn{5}{|l|}{ Modernization } \\
\hline Woman Education & 1.203 & 0.828 & 0 & 3 \\
\hline No education & 0.151 & 0.358 & & \\
\hline Primary Education & 0.604 & 0.488 & & \\
\hline Secondary Education & 0.134 & 0.341 & & \\
\hline Higher Education & 0.109 & 0.312 & & \\
\hline Egalitarian Ideology & 2.384 & 0.813 & 0 & 3 \\
\hline Urban & 0.731 & 0.443 & 0 & 1 \\
\hline \multicolumn{5}{|c|}{ The Proximate Determinants of Fertility } \\
\hline Age at First Sex & 20.087 & 4.221 & 10 & 48 \\
\hline Contraception Use & 0.903 & 0.297 & 0 & 1 \\
\hline Contraception None & 0.284 & 0.451 & 0 & 1 \\
\hline Contraception Traditional & 0.263 & 0.441 & 0 & 1 \\
\hline Contraception Modern & 0.361 & 0.480 & 0 & 1 \\
\hline Contraception Irreversible & 0.091 & 0.288 & 0 & 1 \\
\hline Induced Abortion & 0.160 & 0.366 & 0 & 1 \\
\hline Abortion Frequency & 0.227 & 0.588 & 0 & 3 \\
\hline 0 & 0.840 & 0.365 & & \\
\hline 1 & 0.108 & 0.310 & & \\
\hline 2 & 0.033 & 0.179 & & \\
\hline $3+$ & 0.017 & 0.033 & & \\
\hline The Number of Children & 2.513 & 1.694 & 0 & 7 \\
\hline 0 & 0.860 & 0.280 & & \\
\hline 1 & 0.184 & 0.388 & & \\
\hline 2 & 0.318 & 0.465 & & \\
\hline 3 & 0.193 & 0.395 & & \\
\hline 4 & 0.095 & 0.293 & & \\
\hline 5 & 0.048 & 0.215 & & \\
\hline 6 & 0.028 & 0.166 & & \\
\hline $7+$ & 0.044 & 0.207 & & \\
\hline \multicolumn{5}{|c|}{ Women's and Household Characteristics } \\
\hline Woman Employment & 0.301 & 0.459 & 0 & 1 \\
\hline Woman Age & 34.189 & 8.194 & 15 & 49 \\
\hline Husband Education & 1.747 & 0.860 & 0 & 3 \\
\hline No education & 0.033 & 0.180 & & \\
\hline Primary Education & 0.427 & 0.495 & & \\
\hline Secondary Education & 0.299 & 0.458 & & \\
\hline Higher Education & 0.239 & 0.426 & & \\
\hline
\end{tabular}


Wealth

Turkish

Region

West

South

Central

North

East
$2.909 \quad 1.395$

$0.771 \quad 0.420$

$\begin{array}{lll}0.252 & 0.434 & 0\end{array}$

$0.137 \quad 0.344 \quad 0$

$\begin{array}{lll}0.198 & 0.398 & 0\end{array}$

$0.132 \quad 0.338 \quad 0$

$\begin{array}{lll}0.281 & 0.450 \quad 0\end{array}$

$\begin{array}{lll}0.488 & 0.500 & 0\end{array}$
5

1

1

1

1

1

1

1

Source: Demographic and Health Surveys, Turkey 2008 and 2013

${ }^{*} p<0.05,{ }^{* *} p<0.01,{ }^{* * *} p<0.001$ (two-tailed tests). 
Table 3.2. Descriptive Statistics and Mean Differences Between 2008 and 2013

\begin{tabular}{|c|c|c|c|}
\hline \multirow[b]{2}{*}{ Variables } & \multicolumn{2}{|c|}{ Descriptive Statistics } & \multirow[b]{2}{*}{$\begin{array}{l}\text { Significan } \\
\text { Difference }\end{array}$} \\
\hline & $\begin{array}{c}2008 \text { Mean } \\
(\mathrm{N}=6888)\end{array}$ & $\begin{array}{c}2013 \text { Mean } \\
(\mathrm{N}=6687)\end{array}$ & \\
\hline \multicolumn{4}{|l|}{ Secularization } \\
\hline Religiosity Scale & 2.158 & 2.149 & NS \\
\hline \multicolumn{4}{|l|}{ Modernization } \\
\hline Woman Education & 1.167 & 1.241 & **** \\
\hline Egalitarian Ideology & 2.318 & 2.453 & *** \\
\hline Urban & 0.734 & 0.728 & NS \\
\hline \multicolumn{4}{|c|}{ The Proximate Determinants of Fertility } \\
\hline Age at First Sex & 19.901 & 20.284 & $* * *$ \\
\hline Contraception Use & 0.898 & 0.908 & NS \\
\hline Contraception None & 0.286 & 0.282 & NS \\
\hline Contraception Traditional & 0.264 & 0.262 & NS \\
\hline Contraception Modern & 0.364 & 0.359 & NS \\
\hline Contraception Irreversible & 0.085 & 0.097 & $*$ \\
\hline Induced Abortion & 0.190 & 0.128 & $* * *$ \\
\hline Abortion Frequency & 0.274 & 0.178 & $* * *$ \\
\hline The Number of Children & 2.577 & 2.447 & $* * *$ \\
\hline \multicolumn{4}{|l|}{ Women's and Household } \\
\hline \multicolumn{4}{|l|}{ Characteristics } \\
\hline Woman Employment & 0.292 & 0.574 & $* * *$ \\
\hline Woman Age & 33.830 & 34.566 & $* * *$ \\
\hline Husband Education & 1.791 & 1.700 & $* * *$ \\
\hline Wealth Index & 2.934 & 2.884 & * \\
\hline Turkish & 0.772 & 0.769 & NS \\
\hline \multicolumn{4}{|l|}{ Region } \\
\hline West & 0.253 & 0.252 & NS \\
\hline South & 0.135 & 0.139 & NS \\
\hline Central & 0.199 & 0.197 & NS \\
\hline North & 0.118 & 0.146 & $* * *$ \\
\hline East & 0.296 & 0.267 & $* * *$ \\
\hline
\end{tabular}

Source: Demographic and Health Surveys, Turkey 2008 and 2013

${ }^{*} p<0.05,{ }^{* *} p<0.01,{ }^{* * *} p<0.001$ (two-tailed tests). 
Table 4.1. Bivariate Poisson Regression Analyses between Number of Children and All Other Variables, IRR ${ }^{1}(\mathrm{~N}=13575)$

\begin{tabular}{|c|c|}
\hline Variables & Number of Children \\
\hline \multicolumn{2}{|l|}{ Secularization } \\
\hline Religiosity & $1.237^{* * *}$ \\
\hline \multicolumn{2}{|l|}{ Modernization } \\
\hline Woman's Education & $0.658^{* * *}$ \\
\hline Egalitarian Ideology & $0.840^{* * *}$ \\
\hline Urban & $0.794^{* * *}$ \\
\hline \multicolumn{2}{|c|}{ The Proximate Determinants of Fertility } \\
\hline Age at First Marriage & $0.933^{* * *}$ \\
\hline Any Contraception Use & $1.712^{* * *}$ \\
\hline Contraception None & $0.768^{* * *}$ \\
\hline Contraception Traditional & 1.026 \\
\hline Contraception Modern & 0.976 \\
\hline Contraception Irreversible & $1.638^{* * *}$ \\
\hline Induced Abortion & $1.261^{* * *}$ \\
\hline Abortion Frequency & $1.153^{* * *}$ \\
\hline \multicolumn{2}{|c|}{ Women's Individual and Household } \\
\hline \multicolumn{2}{|l|}{ Characteristics } \\
\hline Woman's Employment & $0.888^{* * *}$ \\
\hline Woman's Age & $1.039^{* * *}$ \\
\hline Husband Education & $0.750^{* * * *}$ \\
\hline Wealth & $0.863^{* * *}$ \\
\hline Turkish & $0.627^{* * *}$ \\
\hline \multicolumn{2}{|l|}{ Region } \\
\hline West & $0.793^{* * *}$ \\
\hline South & $1.069^{* * *}$ \\
\hline Central & $0.927^{* * *}$ \\
\hline North & 0.976 \\
\hline East & $1.504^{* * *}$ \\
\hline Survey Year (2013) & $0.944^{* * *}$ \\
\hline
\end{tabular}

Source: Demographic and Health Surveys, Turkey 2008 and 2013

${ }^{1}$ Incidence Rate Ratio (IRR) $=\exp (\mathrm{b}) ; \mathrm{b}=$ Poisson coefficient ${ }^{*} \mathrm{p}<0.05,{ }^{* *} \mathrm{p}<0.01,{ }^{* * *} \mathrm{p}<0.001$ 
Table 4.2. Poisson Regression Results for Effect of Secularization and Modernization on Number of Children, $\operatorname{IRR}^{1}(\mathrm{~N}=13575)$

\begin{tabular}{|c|c|c|}
\hline Variables & $\begin{array}{c}\text { Model } 1 \\
\text { Exp(b)/(se) }\end{array}$ & $\begin{array}{c}\text { Model } 2 \\
\operatorname{Exp}(\mathrm{b}) /(\mathrm{se})\end{array}$ \\
\hline \multicolumn{3}{|l|}{ Secularization } \\
\hline Religiosity & $\begin{array}{l}1.069^{* * *} \\
(0.006)\end{array}$ & $\begin{array}{l}1.057^{* * *} \\
(0.006)\end{array}$ \\
\hline \multicolumn{3}{|l|}{ Modernization } \\
\hline Woman's Education & & $\begin{array}{l}0.921^{* * *} \\
(0.008)\end{array}$ \\
\hline Egalitarian Ideology & & $\begin{array}{l}0.971^{* * *} \\
(0.006)\end{array}$ \\
\hline Urban & & $\begin{array}{c}1.022^{*} \\
(0.011)\end{array}$ \\
\hline \multicolumn{3}{|l|}{$\begin{array}{l}\text { Proximate Determinants of } \\
\text { Fertility }\end{array}$} \\
\hline Age at First Marriage ${ }^{a}$ & $\begin{array}{l}0.954^{* * *} \\
(0.001)\end{array}$ & $\begin{array}{l}0.957^{* * * *} \\
(0.001)\end{array}$ \\
\hline Contraception Traditional $^{\mathrm{b}}$ & $\begin{array}{l}1.310^{* * *} \\
(0.019)\end{array}$ & $\begin{array}{l}1.310^{* * * *} \\
(0.019)\end{array}$ \\
\hline Contraception Modern & $\begin{array}{l}1.394^{* * *} \\
(0.019)\end{array}$ & $\begin{array}{l}1.403^{* * *} \\
(0.019)\end{array}$ \\
\hline Contraception Irreversible & $\begin{array}{l}1.596^{* * * *} \\
(0.027)\end{array}$ & $\begin{array}{l}1.591^{* * *} \\
(0.027)\end{array}$ \\
\hline Abortion Frequency & $\begin{array}{l}1.021^{* *} \\
(0.008)\end{array}$ & $\begin{array}{l}1.021^{* *} \\
(0.008)\end{array}$ \\
\hline \multicolumn{3}{|c|}{ Women's Individual and Household } \\
\hline Woman's Employment & $\begin{array}{l}0.952^{* * *} \\
(0.009)\end{array}$ & $\begin{array}{l}0.967^{* * *} \\
(0.009)\end{array}$ \\
\hline Woman's Age $^{c}$ & $\begin{array}{l}1.040^{* * *} \\
(0.001)\end{array}$ & $\begin{array}{l}1.039^{* * *} \\
(0.001)\end{array}$ \\
\hline Husband Education & $\begin{array}{l}0.929^{* * *} \\
(0.006)\end{array}$ & $\begin{array}{l}0.949^{* * *} \\
(0.006)\end{array}$ \\
\hline Wealth & $\begin{array}{l}0.937^{* * *} \\
(0.004)\end{array}$ & $\begin{array}{l}0.948^{* * *} \\
(0.005)\end{array}$ \\
\hline Turkish & $\begin{array}{l}0.768^{* * *} \\
(0.010)\end{array}$ & $\begin{array}{l}0.790^{* * * *} \\
(0.011)\end{array}$ \\
\hline Region $^{d}$ & & \\
\hline South & $\begin{array}{l}1.091^{* * *} \\
(0.016)\end{array}$ & $\begin{array}{l}1.099^{* * * *} \\
(0.016)\end{array}$ \\
\hline Central & $\begin{array}{l}1.047^{* * *} \\
(0.014)\end{array}$ & $\begin{array}{l}1.054^{* * * *} \\
(0.014)\end{array}$ \\
\hline North & $\begin{array}{l}1.062^{* * *} \\
(0.017)\end{array}$ & $\begin{array}{l}1.066^{* * *} \\
(0.016)\end{array}$ \\
\hline East & $1.240^{* * * *}$ & $1.240^{* * * *}$ \\
\hline
\end{tabular}


(0.019)

$0.947^{* * * *}$

(0.009)
(0.019)

$0.953^{* * * *}$

(0.009)

Source: Demographic and Health Surveys, Turkey 2008 and 2013

${ }^{1}$ Incidence Rate Ratio $(I R R)=\exp (b) ; b=$ Poisson coefficient. Note: se = standard errors; se are $\exp ($ se $)$

${ }^{\mathrm{a} C e n t e r e d}$ at age $10,{ }^{\mathrm{b}}$ Using no method is the reference, ${ }^{\mathrm{c}}$ Centered at age $15,{ }^{\mathrm{d}} \mathrm{West}$ is the reference

${ }^{*} \mathrm{p}<0.05,{ }^{* *} \mathrm{p}<0.01,{ }^{* * *} \mathrm{p}<0.001$ (two-tailed tests). 


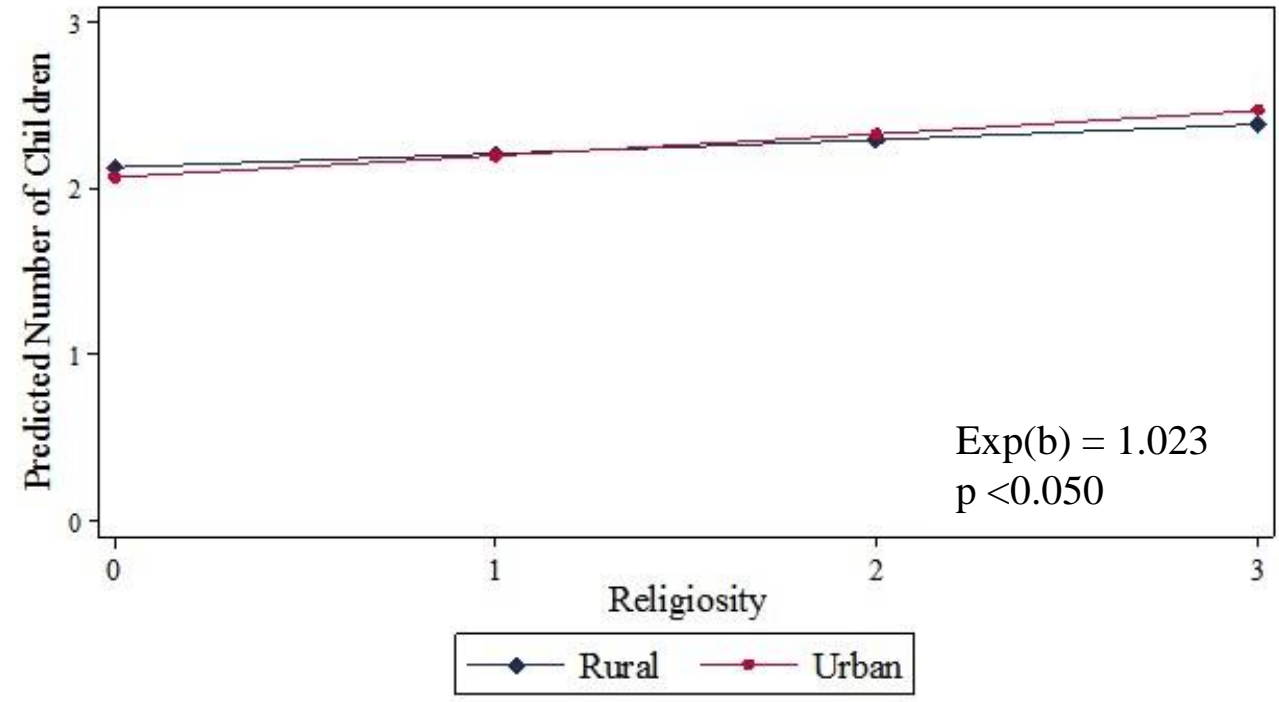

Figure 4.1. The Effect of The Interaction Term between Religiosity and Urban on the Number of Children Born to A Married Woman. 


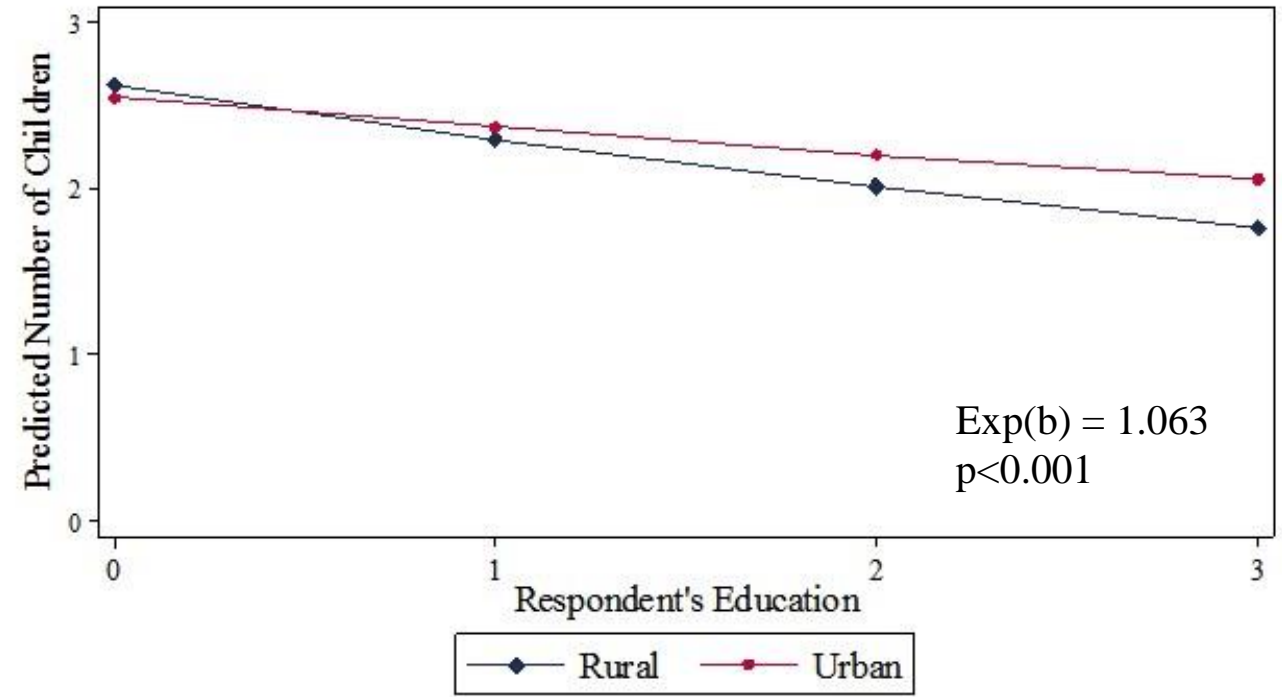

Figure 4.2. The Effect of the Interaction Term between Respondent's Education and Urban on the Number of Children Born to A Married Woman 
Table 4.3. Poisson Regression Results for the Interactions between Secularization and Modernization on Number of Children, IRR (N =13575)

\begin{tabular}{|c|c|c|c|c|c|c|c|}
\hline Variables & $\begin{array}{c}\text { Model } 1 \\
\operatorname{Exp}(\mathrm{b}) /(\mathrm{se})\end{array}$ & $\begin{array}{c}\text { Model } 2 \\
\text { Exp(b)/(se) }\end{array}$ & $\begin{array}{c}\text { Model } 3 \\
\operatorname{Exp}(\mathrm{b}) /(\mathrm{se})\end{array}$ & $\begin{array}{c}\text { Model } 4 \\
\operatorname{Exp}(\mathrm{b}) /(\mathrm{se})\end{array}$ & $\begin{array}{c}\text { Model } 5 \\
\text { Exp(b)/(se) }\end{array}$ & $\begin{array}{c}\text { Model } 6 \\
\operatorname{Exp}(\mathrm{b}) /(\mathrm{se})\end{array}$ & $\begin{array}{c}\text { Model } 7 \\
\text { Exp(b)/(se) }\end{array}$ \\
\hline \multicolumn{8}{|l|}{ Secularization } \\
\hline Religiosity & $\begin{array}{l}1.056^{* * *} \\
(0.006)\end{array}$ & $\begin{array}{l}1.056^{* * *} \\
(0.006)\end{array}$ & $\begin{array}{l}1.038^{* * * *} \\
(0.010)\end{array}$ & $\begin{array}{l}1.058^{* * *} \\
(0.006)\end{array}$ & $\begin{array}{l}1.057^{* * *} \\
(0.006)\end{array}$ & $\begin{array}{l}1.027^{*} \\
(0.011)\end{array}$ & $\begin{array}{l}1.035^{\text {**** }} \\
(0.010)\end{array}$ \\
\hline \multicolumn{8}{|l|}{ Modernization } \\
\hline Woman's Education & $\begin{array}{l}0.922^{* * * *} \\
(0.008)\end{array}$ & $\begin{array}{l}0.921^{* * *} \\
(0.008)\end{array}$ & $\begin{array}{l}0.921^{* * * *} \\
(0.008)\end{array}$ & $\begin{array}{l}0.875^{* * *} \\
(0.013)\end{array}$ & $\begin{array}{l}0.920^{* * * *} \\
(0.008)\end{array}$ & $\begin{array}{l}0.867^{* * * *} \\
(0.013)\end{array}$ & $\begin{array}{l}0.921^{* * * *} \\
(0.008)\end{array}$ \\
\hline Egalitarian Ideology & $\begin{array}{l}0.971^{* * *} \\
(0.006)\end{array}$ & $\begin{array}{l}0.971^{* * *} \\
(0.006)\end{array}$ & $\begin{array}{l}0.971^{* * * *} \\
(0.006)\end{array}$ & $\begin{array}{l}0.972^{* * *} \\
(0.006)\end{array}$ & $\begin{array}{l}0.952^{* * *} \\
(0.008)\end{array}$ & $\begin{array}{l}0.972^{* * * *} \\
(0.006)\end{array}$ & $\begin{array}{l}0.950^{* * * *} \\
(0.009)\end{array}$ \\
\hline Urban & $\begin{array}{r}1.022^{*} \\
(0.011)\end{array}$ & $\begin{array}{r}1.022^{*} \\
(0.011)\end{array}$ & $\begin{array}{c}1.017 \\
(0.012)\end{array}$ & $\begin{array}{l}1.046^{* * * *} \\
(0.013)\end{array}$ & $\begin{array}{c}1.029^{*} \\
(0.012)\end{array}$ & $\begin{array}{l}1.044^{* * * *} \\
(0.013)\end{array}$ & $\begin{array}{c}1.024^{*} \\
(0.012)\end{array}$ \\
\hline \multicolumn{8}{|l|}{ Interactions } \\
\hline Religiosity * Woman's Education & $\begin{array}{r}1.006^{\mathrm{e}} \\
(0.006)\end{array}$ & & & & & $\begin{array}{l}1.002 \\
(0.015)\end{array}$ & \\
\hline Religiosity * Egalitarian Ideology & & $\begin{array}{r}1.001^{\mathrm{f}} \\
(0.007)\end{array}$ & & & & & $\begin{array}{c}1.002 \\
(0.012)\end{array}$ \\
\hline Religiosity * Urban & & & $\begin{array}{l}1.023^{* g} \\
(0.011)\end{array}$ & & & $\begin{array}{l}1.037^{* *} \\
(0.013)\end{array}$ & $\begin{array}{c}1.027^{*} \\
(0.012)\end{array}$ \\
\hline Woman's Education * Urban & & & & $\begin{array}{l}1.063^{* * * * h} \\
(0.016)\end{array}$ & & $\begin{array}{l}1.078^{* * * *} \\
(0.017)\end{array}$ & \\
\hline Egalitarian Ideology * Urban & & & & & $\begin{array}{l}1.031^{* * \mathrm{i}} \\
(0.011)\end{array}$ & & $\begin{array}{l}1.035^{* *} \\
(0.013)\end{array}$ \\
\hline $\begin{array}{l}\text { Religiosity * Woman's Education } \\
\text { * Urban }\end{array}$ & & & & & & $\begin{array}{r}1.003^{\mathrm{j}} \\
(0.017)\end{array}$ & \\
\hline $\begin{array}{l}\text { Religiosity * Egalitarian Ideology } \\
* \text { Urban }\end{array}$ & & & & & & & $\begin{array}{r}0.997^{\mathrm{k}} \\
(0.014)\end{array}$ \\
\hline
\end{tabular}


Proximate Determinants of Fertility Age at First Marriage ${ }^{\mathrm{a}}$

Contraception Traditional $^{\mathrm{b}}$

Contraception Modern

Contraception Irreversible

Abortion Frequency

Women's Individual and Household

Characteristics

Woman's Employment

Woman's Age

Husband Education

Wealth

Turkish

Region $^{\mathrm{d}}$

South

Central

North

East

\begin{tabular}{|c|c|c|c|c|c|c|}
\hline $0.957^{* * * *}$ & $0.957^{* * *}$ & $0.957^{* * * *}$ & $0.957^{* * *}$ & $0.957^{* * * *}$ & $0.957^{* * * *}$ & $\begin{array}{c}0.957^{* * *} \\
(0.001)\end{array}$ \\
\hline$(0.001)$ & $(0.001)$ & $(0.001)$ & $(0.001)$ & $(0.001)^{* * * *}$ & $(0.001)^{* * *}$ & $(0.001)$ \\
\hline $1.310^{* * * *}$ & $1.310^{* * *}$ & $1.310^{* * * *}$ & $1.312^{* * * *}$ & $1.310^{* * * *}$ & $1.312^{* * * *}$ & $1.310^{* * * *}$ \\
\hline$(0.019)$ & $(0.019)$ & $(0.019)$ & $(0.019)$ & $(0.0$ & (0.019) & $(0.019)$ \\
\hline $1.403^{* * *}$ & $1.403^{* * * *}$ & 1.4 & $1.404^{* * *}$ & **** & $1.405^{* * * *}$ & $1.403^{* * *}$ \\
\hline$(0.019)$ & $(0.0$ & $(0.0$ & $(0.019)$ & $(0.0$ & $(0.019)$ & $(0.019)$ \\
\hline $1.591^{* * * *}$ & $1.591^{* * * *}$ & $1.591^{* * * *}$ & $1.593^{* * *}$ & $1.591^{* * * *}$ & $1.592^{* * *}$ & $1.590^{* * * *}$ \\
\hline$(0.027)$ & $(0.027)$ & $(0.027)$ & $(0.027)$ & $(0.02$ & $(0.027)$ & $(0.027)$ \\
\hline $1.021^{* *}$ & $1.021^{* *}$ & $1.021^{*}$ & $1.022^{* *}$ & 1.02 & $1.022^{* * *}$ & $1.021^{* *}$ \\
\hline$(0.008)$ & $(0.008)$ & $(0.008)$ & $(0.008)$ & $(0.008)$ & $(0.008)$ & $(0.008)$ \\
\hline
\end{tabular}

\begin{tabular}{|c|c|c|c|c|c|c|}
\hline $0.967^{* * *}$ & $0.967^{* * * *}$ & $0.968^{* * * *}$ & $0.965^{* * * *}$ & $0.966^{* * * *}$ & $0.967^{* * * *}$ & $0.967^{* * * *}$ \\
\hline (0.009) & $(0.009)$ & $(0.009)$ & $(0.009)$ & $(0.009)$ & (0.009) & $(0.009)$ \\
\hline $1.039^{* * *}$ & $1.039^{* * *}$ & $1.039^{* * * *}$ & $1.039^{* * * *}$ & $1.039^{* * * *}$ & $1.039^{* * * *}$ & $1.039^{* * * *}$ \\
\hline$(0.001)$ & $(0.001)$ & $(0.001)$ & $(0.001)$ & $(0.001)$ & (0.001) & $(0.001)$ \\
\hline $0.950^{* * * *}$ & $0.949^{* * * *}$ & $0.949^{* * * *}$ & $0.949^{* * * *}$ & $0.949^{* * * *}$ & $0.949^{* * * *}$ & $0.949^{* * * *}$ \\
\hline$(0.006)$ & $(0.006)$ & $(0.006)$ & $(0.006)$ & $(0.006)$ & (0.006) & $(0.006)$ \\
\hline $0.948^{* * *}$ & $0.948^{* * * *}$ & $0.949^{* * * *}$ & $0.947^{* * * *}$ & $0.948^{* * * *}$ & $0.948^{* * *}$ & $0.948^{* * * *}$ \\
\hline (0.005) & $(0.005)$ & $(0.005)$ & $(0.005)$ & $(0.005)$ & (0.005) & $(0.005)$ \\
\hline $0.788^{* * * *}$ & $0.790^{* * * *}$ & $0.790^{* * * *}$ & $0.791^{* * * *}$ & $0.789^{* * * *}$ & $0.791^{\text {**** }}$ & $0.790^{* * * *}$ \\
\hline$(0.011)$ & $(0.011)$ & $(0.011)$ & $(0.011)$ & $(0.011)$ & (0.011) & (0.011) \\
\hline $1.099^{* * * *}$ & $1.099^{* * * *}$ & $1.099^{* * *}$ & $1.099^{*}$ & 1.099 & $1.099^{* * * *}$ & $1.098^{* * * *}$ \\
\hline$(0.016)$ & $(0.016)$ & $(0.016)$ & $(0.016)$ & $(0.016)$ & (0.016) & (0.016) \\
\hline $1.054^{* * * *}$ & $1.054^{* * * *}$ & $1.054^{* * * *}$ & $1.053^{* * *}$ & $1.053^{* * * *}$ & $1.053^{* * *}$ & $1.053^{* * * *}$ \\
\hline (0.014) & $(0.014)$ & $(0.014)$ & $(0.014)$ & $(0.014)$ & (0.014) & (0.014) \\
\hline $1.066^{*}$ & $1.066^{* * * *}$ & $1.067^{* * * *}$ & $1.065^{* * *}$ & $1.064^{* * * *}$ & $1.067^{* * * *}$ & $1.065^{* * * *}$ \\
\hline$(0.016)$ & $(0.016)$ & $(0.016)$ & $(0.017)$ & $(0.017)$ & $(0.016)$ & $(0.016)$ \\
\hline $1.241^{\prime \prime}$ & $1.240^{* * * *}$ & $1.242^{* * * *}$ & $1.232^{* * * *}$ & $1.238^{* * * *}$ & $1.233^{* * *}$ & $1.239^{* * * *}$ \\
\hline
\end{tabular}




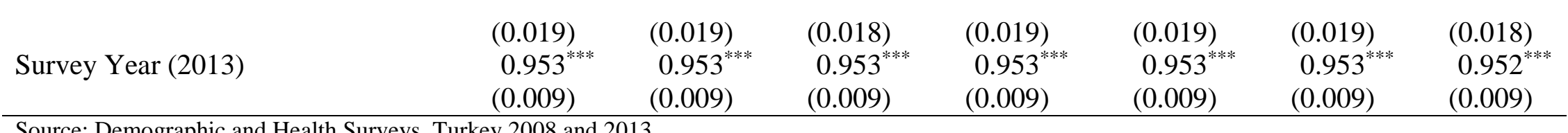

Source: Demographic and Health Surveys, Turkey 2008 and 2013

Note: $\mathrm{b}=$ Poisson coefficient; incidence rate ratio $(\mathrm{IRR})=\exp (\mathrm{b}) ; \mathrm{se}=$ standard error;

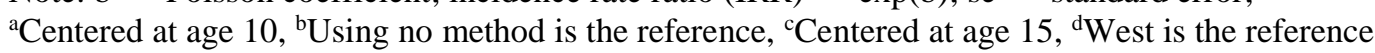

'Joint effects of religiosity, women's education, and religiosity x women's education are statistically significant (Wald $\left.c h i^{2}(3)=244.8, p=.0000\right)$.

${ }^{\mathrm{f} J o i n t}$ effects of religiosity, egalitarian ideology, and religiosity $\mathrm{x}$ egalitarian ideology are statistically significant (Wald $\operatorname{chi}^{2}(3)=144.5, \mathrm{p}=.0000$ ).

${ }^{g}$ Joint effects of religiosity, urban, and religiosity $\mathrm{x}$ urban are statistically significant (Wald $c h i^{2}(3)=114.5, \mathrm{p}=.0000$ ).

hJoint effects of women's education, urban, and women's education x urban are statistically significant $\left(\right.$ Wald chi $\left.^{2}(3)=122.7, \mathrm{p}=.0000\right)$

${ }^{\mathrm{i} J o i n t}$ effects of egalitarian ideology, urban, and egalitarian ideology $\mathrm{x}$ urban are statistically significant (Wald $\left.c h i^{2}(3)=38.4, \mathrm{p}=.0000\right)$.

jJoint effects of religiosity, women's education, urban, religiosity $\mathrm{x}$ women's education, religiosity $\mathrm{x}$ urban, women's education $\mathrm{x}$ urban, and religiosity $\mathrm{x}$ women's education $\mathrm{x}$ urban are statistically significant (Wald $\mathrm{chi}^{2}(8)=332.5, \mathrm{p}=.0000$ ).

${ }^{\mathrm{k} J o i n t}$ effects of religiosity, egalitarian ideology, urban, religiosity x egalitarian ideology, religiosity $\mathrm{x}$ urban, egalitarian ideology $\mathrm{x}$ urban, and religiosity $\mathrm{x}$ egalitarian ideology $\mathrm{x}$ urban are statistically significant (Wald $c h i^{2}(8)=317.2, \mathrm{p}=.0000$ ).

${ }^{*} \mathrm{p}<0.05,{ }^{* *} \mathrm{p}<0.01,{ }^{* * *} \mathrm{p}<0.001$ (two-tailed tests). 


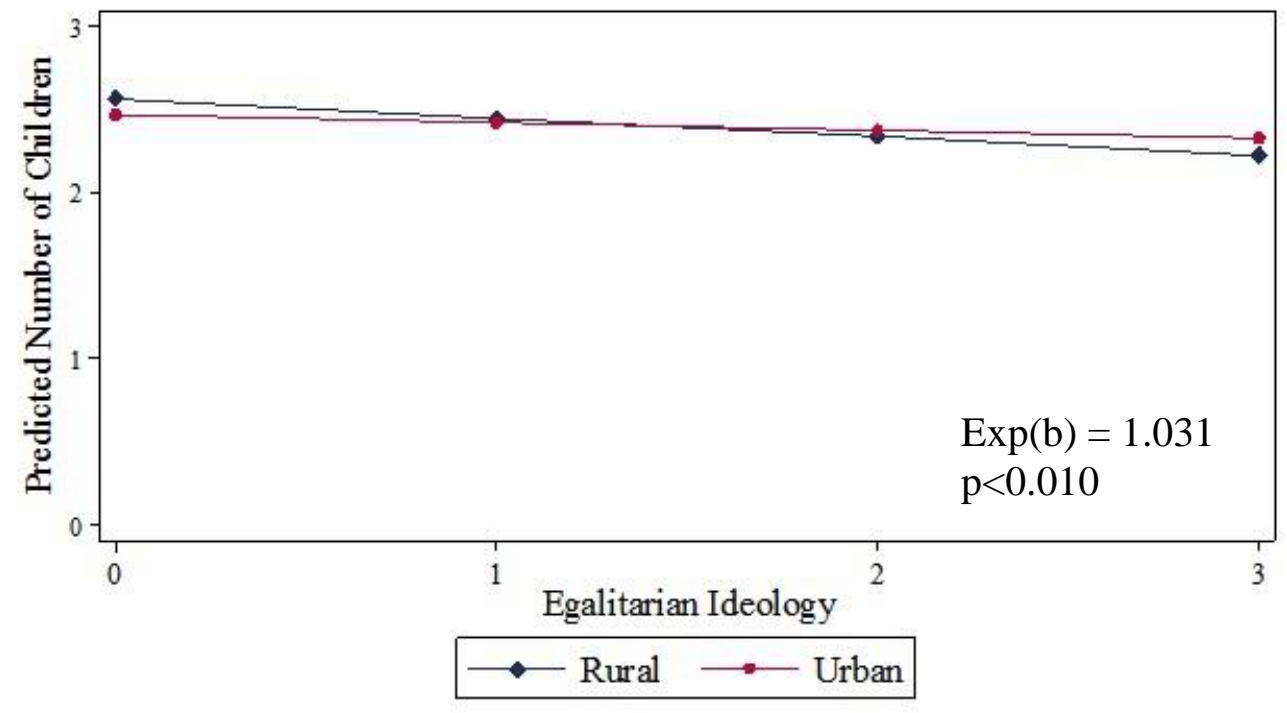

Figure 4.3. The Effect of the Interaction Term between Egalitarian Ideology and Urban on the Number of Children Born to A Married Woman. 
Table 5.1. Bivariate Logistic Regression Analyses between Contraceptive Use and All Other Variables, $\mathrm{OR}^{1}(\mathrm{~N}=13575)$

\begin{tabular}{|c|c|}
\hline Variables & Any Contraception Use \\
\hline \multicolumn{2}{|l|}{ Secularization } \\
\hline Religiosity & $0.852^{* * *}$ \\
\hline \multicolumn{2}{|l|}{ Modernization } \\
\hline Woman's Education & $1.506^{* * *}$ \\
\hline Egalitarian Ideology & $1.479^{* * * *}$ \\
\hline Urban & $1.706^{* * *}$ \\
\hline \multicolumn{2}{|c|}{ The Proximate Determinants of Fertility } \\
\hline Age at First Marriage & $0.952^{* * *}$ \\
\hline Induced Abortion & $4.488^{* * *}$ \\
\hline Abortion Frequency & $2.588^{* * * *}$ \\
\hline The Number of Children & $1.775^{* * *}$ \\
\hline \multicolumn{2}{|l|}{ Women's and Household } \\
\hline \multicolumn{2}{|l|}{ Characteristics } \\
\hline Woman's Employment & $1.433^{* * *}$ \\
\hline Woman's Age & $1.050^{* * *}$ \\
\hline Husband Education & $1.375^{* * *}$ \\
\hline Wealth & $1.423^{* * *}$ \\
\hline Turkish & $2.772^{* * *}$ \\
\hline \multicolumn{2}{|l|}{ Region } \\
\hline West & $1.802^{* * *}$ \\
\hline South & $0.757^{* *}$ \\
\hline Central & $1.479^{* * *}$ \\
\hline North & 1.236 \\
\hline East & $0.358^{* * *}$ \\
\hline Survey Year (2013) & 1.056 \\
\hline
\end{tabular}

Source: Demographic and Health Surveys, Turkey 2008 and 2013

${ }^{1}$ Odds Ratios $=\exp (\mathrm{b}) ; \mathrm{b}=$ Logistic coefficient

${ }^{*} p<0.05,{ }^{* *} p<0.01,{ }^{* * *} p<0.001$ 
Table 5.2. Logistic Regression Results for the Effect of Secularization and Modernization on the Contraceptive Use, $\mathrm{OR}^{1}(\mathrm{~N}=13575)$

\begin{tabular}{|c|c|c|}
\hline Variables & $\begin{array}{c}\text { Model 1 } \\
\operatorname{Exp}(\mathrm{b}) /(\mathrm{se})\end{array}$ & $\begin{array}{c}\text { Model } 2 \\
\operatorname{Exp}(\mathrm{b}) /(\mathrm{se})\end{array}$ \\
\hline \multicolumn{3}{|l|}{ Secularization } \\
\hline Religiosity & $\begin{array}{l}0.880^{* *} \\
(0.039)\end{array}$ & $\begin{array}{c}0.931 \\
(0.041)\end{array}$ \\
\hline \multicolumn{3}{|l|}{ Modernization } \\
\hline Woman's Education & & $\begin{array}{l}1.403^{* * *} \\
(0.107)\end{array}$ \\
\hline Egalitarian Ideology & & $\begin{array}{l}1.358^{* * *} \\
(0.062)\end{array}$ \\
\hline Urban & & $\begin{array}{c}1.148 \\
(0.099)\end{array}$ \\
\hline \multicolumn{3}{|c|}{ The Proximate Determinants of Fertility } \\
\hline Age at First Marriage ${ }^{a}$ & $\begin{array}{c}0.995 \\
(0.011)\end{array}$ & $\begin{array}{c}0.988 \\
(0.011)\end{array}$ \\
\hline Abortion Frequency & $\begin{array}{l}1.836^{* * *} \\
(0.295)\end{array}$ & $\begin{array}{l}1.844^{* * * *} \\
(0.298)\end{array}$ \\
\hline The Number of Children & $\begin{array}{l}2.386^{* * *} \\
(0.141)\end{array}$ & $\begin{array}{l}2.445^{* * *} \\
(0.147)\end{array}$ \\
\hline \multicolumn{3}{|c|}{ Women's and Household Characteristics } \\
\hline Woman's Employment & $\begin{array}{l}1.260^{* *} \\
(0.107)\end{array}$ & $\begin{array}{c}1.172 \\
(0.101)\end{array}$ \\
\hline Woman's Age & $\begin{array}{l}0.960^{* * * *} \\
(0.006)\end{array}$ & $\begin{array}{l}0.965^{\text {*** }} \\
(0.007)\end{array}$ \\
\hline Husband Education & $\begin{array}{l}1.401^{* * *} \\
(0.078)\end{array}$ & $\begin{array}{l}1.253^{* * *} \\
(0.071)\end{array}$ \\
\hline Wealth & $\begin{array}{l}1.308^{* * *} \\
(0.051)\end{array}$ & $\begin{array}{l}1.193^{* * *} \\
(0.049)\end{array}$ \\
\hline Turkish & $\begin{array}{l}2.216^{* * * *} \\
(0.208)\end{array}$ & $\begin{array}{l}1.990^{\text {**** }} \\
(0.191)\end{array}$ \\
\hline \multicolumn{3}{|l|}{ Region $^{c}$} \\
\hline South & $\begin{array}{l}0.637^{* * *} \\
(0.074)\end{array}$ & $\begin{array}{l}0.596^{* * * *} \\
(0.069)\end{array}$ \\
\hline Central & $\begin{array}{c}0.872 \\
(0.109)\end{array}$ & $\begin{array}{c}0.840 \\
(0.106)\end{array}$ \\
\hline North & $\begin{array}{c}0.828 \\
(0.110)\end{array}$ & $\begin{array}{c}0.833 \\
(0.112)\end{array}$ \\
\hline East & $\begin{array}{l}0.361^{* * *} \\
(0.040)\end{array}$ & $\begin{array}{l}0.352^{* * * *} \\
(0.039)\end{array}$ \\
\hline Survey Year (2013) & $\begin{array}{c}1.180^{*} \\
(0.093)\end{array}$ & $\begin{array}{c}1.127 \\
(0.090)\end{array}$ \\
\hline
\end{tabular}

Source: Demographic and Health Surveys, Turkey 2008 and 2013

${ }^{1}$ Odds Ratios $=\exp (b) ; b=$ Logistic coefficient, Note: se = standard error; $\exp (\mathrm{se})$ is exponentiated.

${ }^{\mathrm{a}}$ Centered at age $10,{ }^{\mathrm{b}}$ Centered at age $15,{ }^{\mathrm{c}} \mathrm{West}$ is the reference

${ }^{*} p<0.05,{ }^{* *} p<0.01,{ }^{* * *} p<0.001$ (two-tailed tests). 


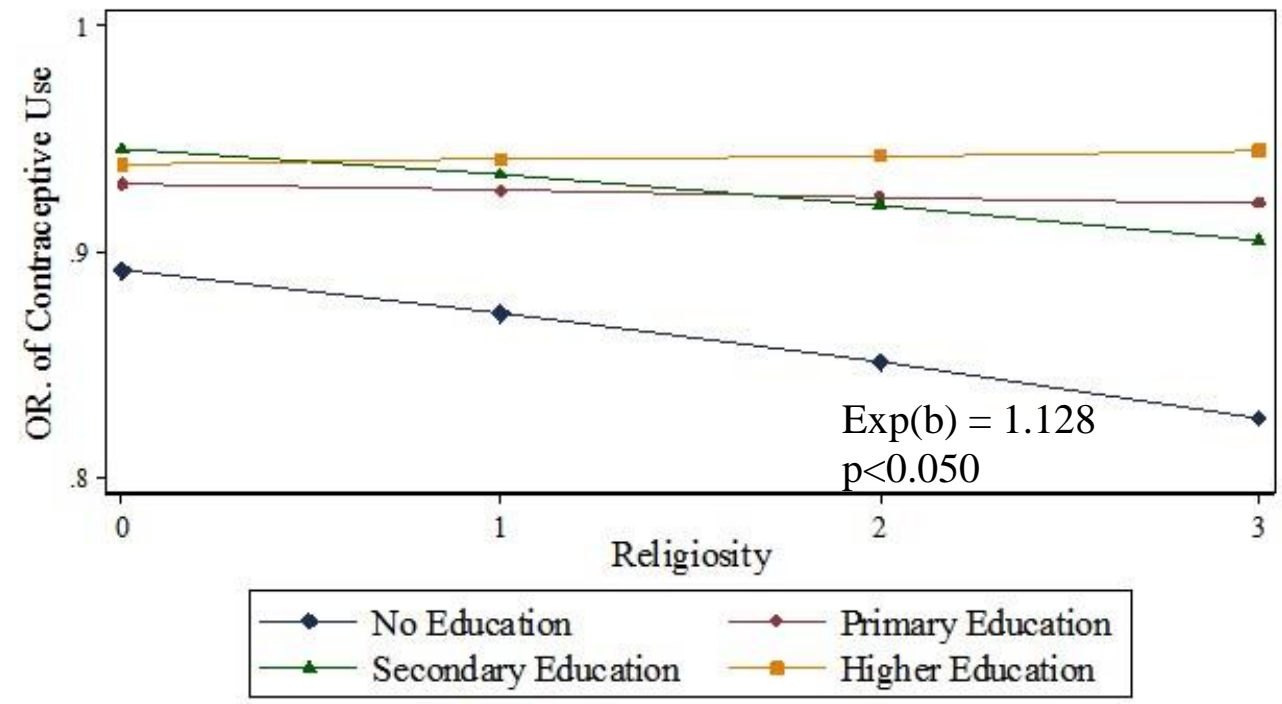

Figure 5.1. The Effect of the Interaction Term between Religiosity and Women's Education on Contraceptive Use 


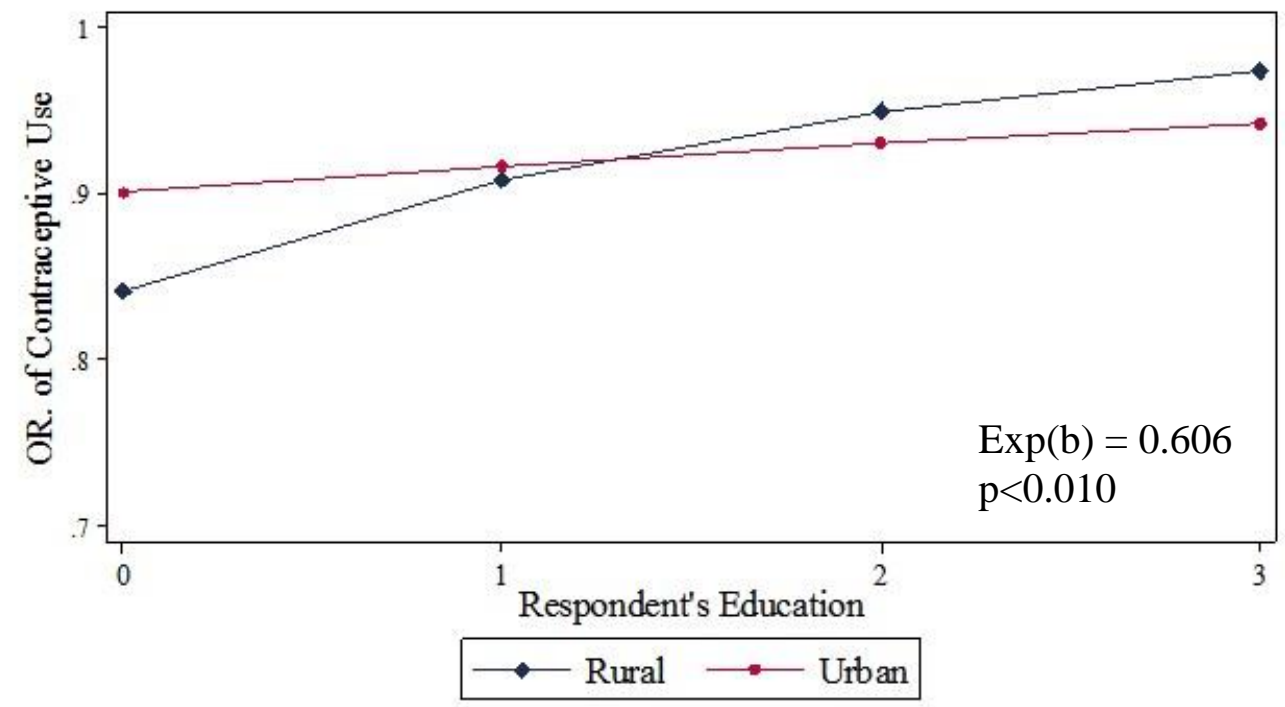

Figure 5.2. The Effect of the Interaction Term between Women's Education and Urban on Contraceptive Use 


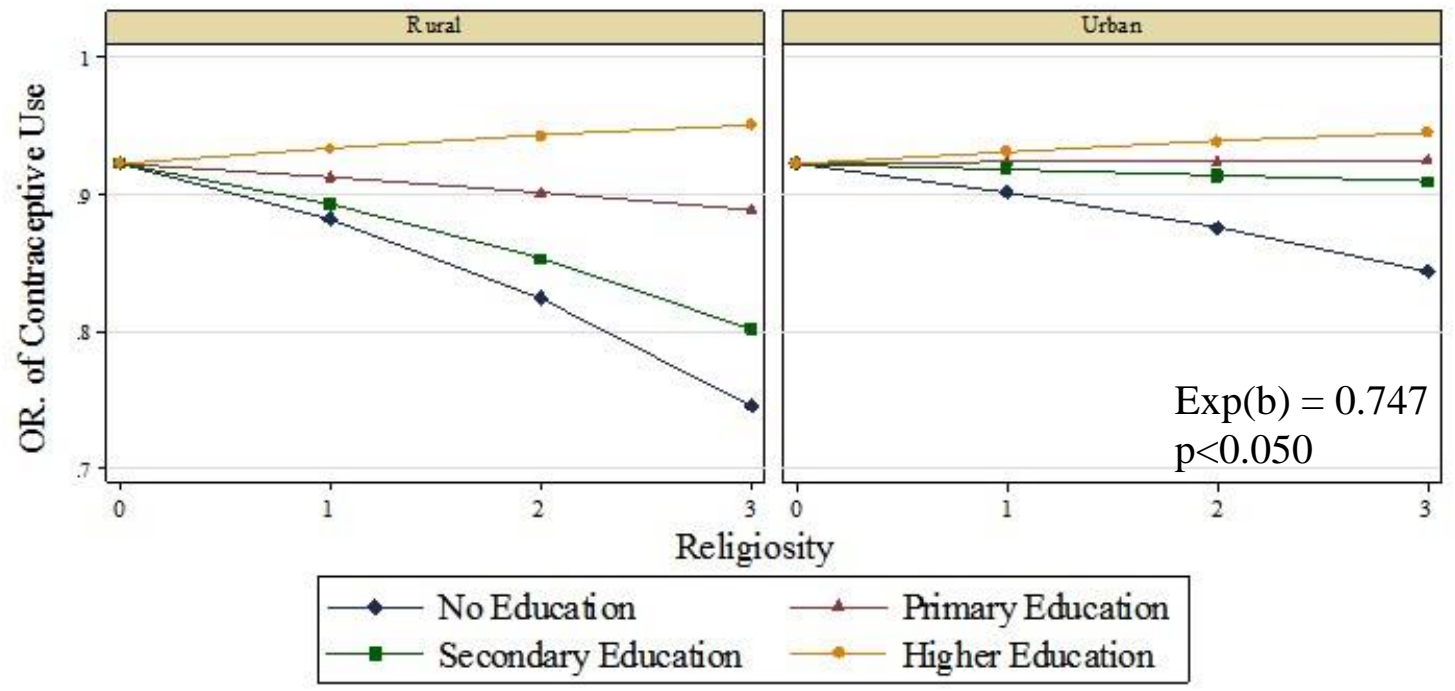

Figure 5.3. The Effect of the Three-Way Interaction Term between Religiosity, Women's Education, and Urban on Contraceptive Use 
Table 5.3. Logistic Regression Results for the Interactions between Secularization and Modernization on the Contraceptive Use, OR ${ }^{1}$ $(\mathrm{N}=13575)$

\begin{tabular}{|c|c|c|c|c|c|c|c|}
\hline Variables & $\begin{array}{c}\text { Model } 1 \\
\operatorname{Exp}(\mathrm{b}) /(\mathrm{se})\end{array}$ & $\begin{array}{c}\text { Model } 2 \\
\operatorname{Exp}(\mathrm{b}) /(\mathrm{se})\end{array}$ & $\begin{array}{c}\text { Model } 3 \\
\text { Exp(b)/(se) }\end{array}$ & $\begin{array}{c}\text { Model } 4 \\
\operatorname{Exp}(\mathrm{b}) /(\mathrm{se})\end{array}$ & $\begin{array}{c}\text { Model } 5 \\
\operatorname{Exp}(\mathrm{b}) /(\mathrm{se})\end{array}$ & $\begin{array}{c}\text { Model } 6 \\
\text { Exp(b)/(se) }\end{array}$ & $\begin{array}{c}\text { Model } 7 \\
\text { Exp(b)/(se) }\end{array}$ \\
\hline \multicolumn{8}{|l|}{ Secularization } \\
\hline Religiosity Scale & $\begin{array}{c}0.919 \\
(0.042)\end{array}$ & $\begin{array}{c}0.930 \\
(0.041)\end{array}$ & $\begin{array}{c}0.880 \\
(0.065)\end{array}$ & $\begin{array}{c}0.924 \\
(0.041)\end{array}$ & $\begin{array}{c}0.930 \\
(0.041)\end{array}$ & $\begin{array}{c}0.998 \\
(0.078)\end{array}$ & $\begin{array}{c}0.890 \\
(0.067)\end{array}$ \\
\hline \multicolumn{8}{|l|}{ Modernization } \\
\hline Woman's Education & $\begin{array}{l}1.454^{* * *} \\
(0.112)\end{array}$ & $\begin{array}{l}1.407^{* * * *} \\
(0.106)\end{array}$ & $\begin{array}{l}1.405^{* * * *} \\
(0.107)\end{array}$ & $\begin{array}{l}2.102^{* * *} \\
(0.309)\end{array}$ & $\begin{array}{l}1.405^{* * * *} \\
(0.107)\end{array}$ & $\begin{array}{l}2.203^{* * * *} \\
(0.298)\end{array}$ & $\begin{array}{l}1.409^{* * * *} \\
(0.107)\end{array}$ \\
\hline Egalitarian Ideology & $\begin{array}{l}1.357^{* * * *} \\
(0.063)\end{array}$ & $\begin{array}{l}1.353^{* * *} \\
(0.063)\end{array}$ & $\begin{array}{l}1.357^{* * * *} \\
(0.062)\end{array}$ & $\begin{array}{l}1.352^{* * * *} \\
(0.063)\end{array}$ & $\begin{array}{l}1.398^{* * * *} \\
(0.095)\end{array}$ & $\begin{array}{l}1.352^{* * *} \\
(0.063)\end{array}$ & $\begin{array}{l}1.377^{* * * *} \\
(0.096)\end{array}$ \\
\hline Urban & $\begin{array}{c}1.145 \\
(0.099)\end{array}$ & $\begin{array}{c}1.147 \\
(0.099)\end{array}$ & $\begin{array}{c}1.140 \\
(0.100)\end{array}$ & $\begin{array}{c}1.001 \\
(0.105)\end{array}$ & $\begin{array}{l}1.136 \\
(0.100)\end{array}$ & $\begin{array}{c}0.942 \\
(0.096)\end{array}$ & $\begin{array}{c}1.127 \\
(0.100)\end{array}$ \\
\hline \multicolumn{8}{|l|}{ Interactions } \\
\hline Religiosity * Woman's Education & $\begin{array}{l}1.128^{* d} \\
(0.062)\end{array}$ & & & & & $\begin{array}{l}1.417^{* *} \\
(0.164)\end{array}$ & \\
\hline Religiosity * Egalitarian Ideology & & $\begin{array}{r}1.032^{\mathrm{e}} \\
(0.055)\end{array}$ & & & & & $\begin{array}{c}1.060 \\
(0.088)\end{array}$ \\
\hline Religiosity * Urban & & & $\begin{array}{r}1.077^{\mathrm{f}} \\
(0.096)\end{array}$ & & & $\begin{array}{c}0.912 \\
(0.087)\end{array}$ & $\begin{array}{c}1.062 \\
(0.096)\end{array}$ \\
\hline Woman's Education * Urban & & & & $\begin{array}{l}0.606^{* * \mathrm{~g}} \\
(0.096)\end{array}$ & & $\begin{array}{l}0.588^{* * * *} \\
(0.087)\end{array}$ & \\
\hline Egalitarian Ideology * Urban & & & & & $\begin{array}{r}0.956^{\mathrm{h}} \\
(0.086)\end{array}$ & & $\begin{array}{c}0.971 \\
(0.089)\end{array}$ \\
\hline $\begin{array}{l}\text { Religiosity * Woman's Education } \\
* \text { Urban }\end{array}$ & & & & & & $\begin{array}{c}0.747^{* \mathrm{i}} \\
(0.099)\end{array}$ & \\
\hline $\begin{array}{l}\text { Religiosity * Egalitarian Ideology } \\
* \text { Urban }\end{array}$ & & & & & & & $\begin{array}{r}0.956^{\mathrm{j}} \\
(0.102)\end{array}$ \\
\hline
\end{tabular}


The Proximate Determinants of Fertility

Age at First Marriage ${ }^{a}$

Abortion Frequency

The Number of Children

Women's and Household

Characteristics

Woman's Employment

Woman's Age ${ }^{\mathrm{b}}$

Husband Education

Wealth

Turkish

\section{Region $^{\mathrm{c}}$}

South

Central

North

East

Survey Year (2013)

$\begin{array}{ccccccc}0.989 & 0.988 & 0.988 & 0.989 & 0.988 & 0.990 & 0.988 \\ (0.011) & (0.011) & (0.011) & (0.011) & (0.011) & (0.011) & (0.011)^{* * * * * *} \\ 1.838^{* * *} & 1.843^{* * * *} & 1.847^{* * *} & 1.836^{* * *} & 1.843^{* * *} & 1.833^{* * *} & 1.845^{* * * *} \\ (0.297) & (0.298) & (0.299) & (0.297) & (0.298) & (0.298) & \left.(0.299)^{* * * * *}\right) \\ 2.462^{* * *} & 2.448^{* * *} & 2.447^{* * *} & 2.468^{* * *} & 2.447^{* * *} & 2.493^{* * *} & 2.451^{* * *} \\ (0.147) & (0.147) & (0.146) & (0.147) & (0.147) & (0.149) & (0.147)\end{array}$

\begin{tabular}{|c|c|c|c|c|c|c|}
\hline $\begin{array}{c}1.188^{*} \\
(0.104)\end{array}$ & $\begin{array}{c}1.175 \\
(0.102)\end{array}$ & $\begin{array}{c}1.178 \\
(0.102)\end{array}$ & $\begin{array}{c}1.199^{*} \\
(0.104)\end{array}$ & $\begin{array}{c}1.175 \\
(0.102)\end{array}$ & $\begin{array}{c}1.204^{*} \\
(0.106)\end{array}$ & $\begin{array}{c}1.182 \\
(0.102)\end{array}$ \\
\hline $0.965^{* * * *}$ & $0.965^{\text {**** }}$ & $0.965^{\text {**** }}$ & $0.965^{* * *}$ & $0.965^{\text {*** }}$ & $0.965^{\text {**** }}$ & $0.965^{\text {**** }}$ \\
\hline$(0.007)$ & $(0.007)$ & $(0.007)$ & $(0.007)$ & $(0.007)$ & $(0.007)$ & $(0.007)$ \\
\hline $1.258^{* * *}$ & $1.253^{\text {**** }}$ & $1.252^{\text {**** }}$ & $1.261^{* * *}$ & $1.253^{* * *}$ & $1.263^{* * * *}$ & $1.252^{* * * *}$ \\
\hline$(0.071)$ & $(0.071)$ & $(0.071)$ & $(0.072)$ & $(0.071)$ & $(0.072)$ & $(0.071)$ \\
\hline $1.201^{* * *}$ & $1.195^{\text {*** }}$ & $1.195^{\text {**** }}$ & $1.207^{\text {*** }}$ & $1.194^{* * *}$ & $1.217^{* * * *}$ & $1.197^{\text {**** }}$ \\
\hline$(0.050)$ & $(0.049)$ & $(0.049)$ & $(0.051)$ & $(0.049)$ & $(0.051)$ & $(0.049)$ \\
\hline $1.922^{* * *}$ & $1.984^{\text {**** }}$ & $1.995^{\text {*** }}$ & $1.976^{* * * *}$ & $1.991^{* * *}$ & $1.918^{* * * *}$ & $1.990^{\text {***** }}$ \\
\hline$(0.186)$ & $(0.191)$ & $(0.192)$ & $(0.193)$ & $(0.192)$ & $(0.188)$ & $(0.192)$ \\
\hline $0.593^{* * *}$ & $0.595^{* * *}$ & $0.596^{* * * *}$ & $0.594^{* * *}$ & $0.596^{* * *}$ & $0.590^{* * * *}$ & $0.596^{* * *}$ \\
\hline$(0.069)$ & $(0.069)$ & $(0.069)$ & (0.069) & $(0.069)$ & $(0.068)$ & $(0.069)$ \\
\hline 0.839 & 0.840 & 0.841 & 0.852 & 0.841 & 0.843 & 0.841 \\
\hline$(0.106)$ & $(0.106)$ & $(0.106)$ & $(0.107)$ & $(0.106)$ & $(0.106)$ & $(0.106)$ \\
\hline 0.835 & 0.835 & 0.835 & 0.837 & 0.835 & 0.836 & 0.838 \\
\hline$(0.113)$ & $(0.113)$ & $(0.113)$ & $(0.114)$ & $(0.113)$ & $(0.114)$ & $(0.113)$ \\
\hline $0.355^{* * *}$ & $0.352^{* * *}$ & $0.353^{\text {*** }}$ & $0.370^{* * *}$ & $0.353^{* * *}$ & $0.372^{* * * *}$ & $0.353^{\text {**** }}$ \\
\hline$(0.040)$ & $(0.039)$ & (0.039) & $(0.042)$ & $(0.039)$ & $(0.042)$ & $(0.039)$ \\
\hline 1.121 & 1.126 & 1.126 & 1.126 & 1.128 & 1.123 & 1.126 \\
\hline
\end{tabular}




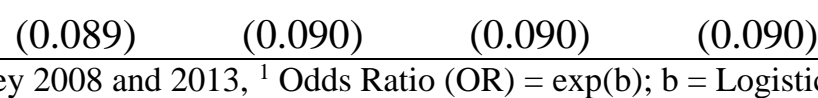

Source: Demographic and Health Surveys, Turkey 2008 and $2013,{ }^{1}$ Odds Ratio $(\mathrm{OR})=\exp (\mathrm{b}) ; \mathrm{b}=$ Logis
Note: se $=$ standard errors; se are exp $(\mathrm{se}),{ }^{\mathrm{a}}$ Centered at age $10,{ }^{\mathrm{b}}$ Centered at age $15,{ }^{\mathrm{c}}$ West is the reference

dJoint effects of religiosity, women's education, and religiosity $\mathrm{x}$ women's education are statistically significant (Wald $c h i^{2}(3)=33.5, \mathrm{p}=.0000$ ).

e Joint effects of religiosity, egalitarian ideology, and religiosity x egalitarian ideology are statistically significant (Wald $\left.c h i^{2}(3)=48.5, p=.0000\right)$.

${ }^{\mathrm{f} J o i n t}$ effects of religiosity, urban, and religiosity $\mathrm{x}$ urban are statistically significant (Wald $c h i^{2}(3)=7.9, \mathrm{p}=.0478$ ).

gJoint effects of women's education, urban, and women's education $\mathrm{x}$ urban are statistically significant (Wald $\left.\operatorname{chi}^{2}(3)=35.1, \mathrm{p}=.0000\right)$.

hJoint effects of egalitarian ideology, urban, and egalitarian ideology $\mathrm{x}$ urban are statistically significant (Wald $\operatorname{chi}^{2}(3)=38.4, \mathrm{p}=.0000$ ).

'Joint effects of religiosity, women's education, urban, religiosity $\mathrm{x}$ women's education, religiosity $\mathrm{x}$ urban, women's education $\mathrm{x}$ urban, and religiosity $\mathrm{x}$ women's education $\mathrm{x}$ urban are statistically significant (Wald $\left.\operatorname{chi}^{2}(8)=53.9, \mathrm{p}=.0000\right)$.

${ }^{\mathrm{j} J o i n t}$ effects of religiosity, egalitarian ideology, urban, religiosity $\mathrm{x}$ egalitarian ideology, religiosity $\mathrm{x}$ urban, egalitarian ideology $\mathrm{x}$ urban, and religiosity $\mathrm{x}$ egalitarian ideology $\mathrm{x}$ urban are statistically significant (Wald $c h i^{2}(8)=58.1, \mathrm{p}=.0000$ ).

${ }^{*} p<0.05,{ }^{* *} p<0.01,{ }^{* * *} p<0.001$ (two-tailed tests) 
Table 5.4. Bivariate Logistic Regression Analyses between Contraceptive Method Type and All Other Variables, $\mathrm{OR}^{1}(\mathrm{~N}=13575)$

\begin{tabular}{|c|c|c|c|c|}
\hline Variables & No Method & $\begin{array}{l}\text { Traditional } \\
\text { Method }\end{array}$ & $\begin{array}{l}\text { Modern } \\
\text { Reversible } \\
\text { Methods }\end{array}$ & $\begin{array}{l}\text { Permanent } \\
\text { Methods }\end{array}$ \\
\hline \multicolumn{5}{|l|}{ Secularization } \\
\hline Religiosity & $1.066^{* *}$ & $1.079^{* *}$ & $0.860^{* * *}$ & $1.121^{* *}$ \\
\hline \multicolumn{5}{|l|}{ Modernization } \\
\hline Woman's Education & $0.864^{* * *}$ & $0.871^{* * *}$ & $1.447^{* * *}$ & $0.620^{* * *}$ \\
\hline Egalitarian Ideology & $0.830^{* * *}$ & 0.987 & $1.274^{* * *}$ & $0.844^{* * *}$ \\
\hline Urban & $0.762^{* * * *}$ & $0.866^{* *}$ & $1.487^{* * *}$ & 0.915 \\
\hline \multicolumn{5}{|l|}{$\begin{array}{l}\text { The Proximate Determinants } \\
\text { of Fertility }\end{array}$} \\
\hline Age at First Marriage & $1.034^{* * *}$ & $0.988^{*}$ & 1.001 & $0.942^{* * *}$ \\
\hline Induced Abortion & $0.760^{* * *}$ & 0.991 & 1.096 & $1.420^{* * *}$ \\
\hline Abortion Frequency & 0.921 & 0.989 & 0.999 & $1.213^{* * *}$ \\
\hline The Number of Children & $0.770^{* * * *}$ & 1.024 & 0.977 & $1.583^{* * *}$ \\
\hline \multicolumn{5}{|l|}{ Women's and Household } \\
\hline \multicolumn{5}{|l|}{ Characteristics } \\
\hline Woman's Employment & $0.791^{* * * *}$ & 1.017 & $1.183^{* * *}$ & 1.017 \\
\hline Woman's Age & $0.988^{* * *}$ & 1.001 & $0.983^{* * *}$ & $1.087^{* * *}$ \\
\hline Husband Education & $0.877^{* * *}$ & $0.919^{* *}$ & $1.329^{* * *}$ & $0.725^{* * *}$ \\
\hline Wealth & $0.853^{* * *}$ & $0.955^{* *}$ & $1.219^{* * *}$ & $0.926^{* *}$ \\
\hline Turkish & $0.500^{* * *}$ & 1.022 & $1.934^{* * *}$ & 0.963 \\
\hline \multicolumn{5}{|l|}{ Region } \\
\hline West & $0.778^{* * *}$ & $1.165^{* *}$ & $1.100^{*}$ & 0.954 \\
\hline South & $1.156^{*}$ & $0.868^{*}$ & 0.908 & $1.265^{* *}$ \\
\hline Central & $0.777^{* * *}$ & $0.888^{*}$ & $1.464^{* * *}$ & $0.752^{* *}$ \\
\hline North & $0.864^{*}$ & $1.450^{* * *}$ & $0.635^{* * *}$ & $1.694^{* * *}$ \\
\hline East & $1.916^{* * *}$ & $0.810^{* * *}$ & $0.665^{* * *}$ & 0.927 \\
\hline Survey Year (2013) & 0.986 & 0.952 & 1.011 & 1.127 \\
\hline
\end{tabular}

Source: Demographic and Health Surveys, Turkey 2008 and 2013

${ }^{1}$ Odds Ratios $=\exp (\mathrm{b}) ; \mathrm{b}=$ Logistic coefficient

${ }^{*} p<0.05,{ }^{* *} p<0.01,{ }^{* * *} p<0.001$ 
Table 5.5. Multinomial Logistic Regression Results for the Effect of Secularization and Modernization on Currently Used Contraceptive Method Types, RRR ${ }^{1}(\mathrm{~N}=13575)$

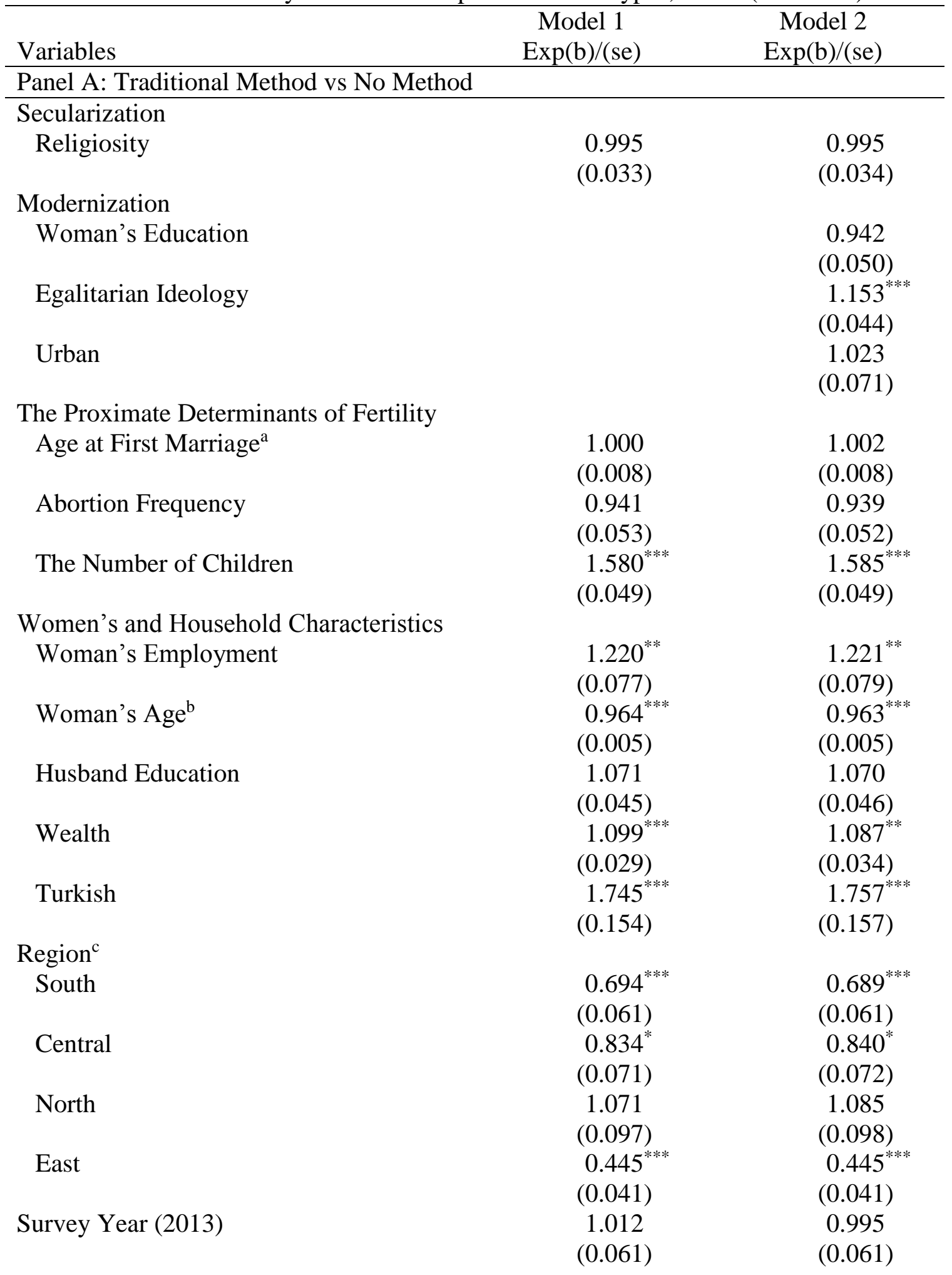


Panel B: Modern Reversible vs No Methods

Secularization

Religiosity

$0.888^{* * *}$

$0.914^{* *}$

(0.027)

(0.029)

Modernization

Woman's Education

$1.187^{* * *}$

(0.058)

Egalitarian Ideology

$1.208^{* * *}$

(0.045)

Urban

$1.160^{*}$

(0.080)

The Proximate Determinants of Fertility

Age at First Marriage ${ }^{a}$

1.008

1.001

$(0.008)$

(0.008)

Abortion Frequency

0.967

0.966

The Number of Children

(0.050)

(0.050)

$1.826^{* * *}$

$1.852^{* * *}$

(0.056)

(0.057)

Women's and Household Characteristics

Woman's Employment

$1.206^{* *}$

$1.176^{* *}$

(0.073)

Woman's Age

$0.940^{* * *}$

$(0.073)$

(0.004)

Husband Education

$1.211^{* * *}$

$0.943^{* * *}$

(0.004)

$(0.048)$

Wealth

$1.264^{* * * *}$

$1.141^{* *}$

(0.047)

(0.032)

Turkish

$2.732^{* * *}$

$1.174^{* * * *}$

(0.034)

$2.613^{* * *}$

(0.226)

(0.220)

Region $^{c}$

South

0.856

$0.830^{*}$

(0.071)

(0.069)

Central

1.105

1.097

(0.088)

North

$0.702^{* * *}$

(0.087)

$(0.064)$

East

$0.549^{* * *}$

$0.719^{* * * *}$

$(0.065)$

$0.546^{* * * *}$

(0.047)

(0.047)

Survey Year (2013)

1.119

1.078

(0.064)

(0.062)

Panel C: Permanent Methods vs No Methods

Secularization

Religiosity

$0.821^{* * * *}$

$0.819^{* * *}$

Modernization

(0.040)

(0.041)

Woman's Education

0.913 
(0.069)

Egalitarian Ideology $1.184^{* *}$

(0.073)

Urban

The Proximate Determinants of Fertility

Age at First Marriage ${ }^{a}$

Abortion Frequency

The Number of Children

Women's and Household Characteristics

Woman's Employment

Woman's Age

Husband Education

Wealth

Turkish

Region $^{c}$

South

Central

North

East

Survey Year (2013)
1.011
(0.012)
0.868
$(0.065)$
$2.686^{* * * *}$
(0.117)

0.986

(0.093)

0.999

(0.007)

1.094

(0.071)

$1.215^{* * * *}$

(0.051)

$3.601^{\text {**** }}$

(0.544)

0.870

(0.116)

$0.735^{*}$

(0.096)

$1.412^{* * *}$

(0.187)

$0.344^{* * *}$

(0.052)

$1.396^{* * * *}$

(0.127)
1.013

(0.012)

0.865

(0.065)

$2.699^{\text {**** }}$

(0.119)

1.012

(0.098)

0.999

(0.007)

1.101

(0.074)

$1.165^{\text {** }}$

(0.057)

$3.687^{\text {**** }}$

(0.563)

0.864

(0.115)

$0.753^{*}$

(0.099)

$1.484^{* * *}$

(0.194)

$0.346^{* * * *}$

(0.052)

$1.355^{* * *}$

(0.124)

Source: Demographic and Health Surveys, Turkey 2008 and 2013

${ }^{1}$ Relative Risk Ratios $=\exp (b) ; b=$ Multinomial Logistic coefficient, Note: $s e=$ standard error; $\exp (\mathrm{se})$ is exponentiated. ${ }^{\mathrm{a} C e n t e r e d ~ a t ~ a g e ~} 10,{ }^{\mathrm{b}}$ Centered at age $15,{ }^{\mathrm{c}} \mathrm{West}$ is the reference ${ }^{*} p<0.05,{ }^{* *} p<0.01,{ }^{* * *} p<0.001$ (two-tailed tests). 


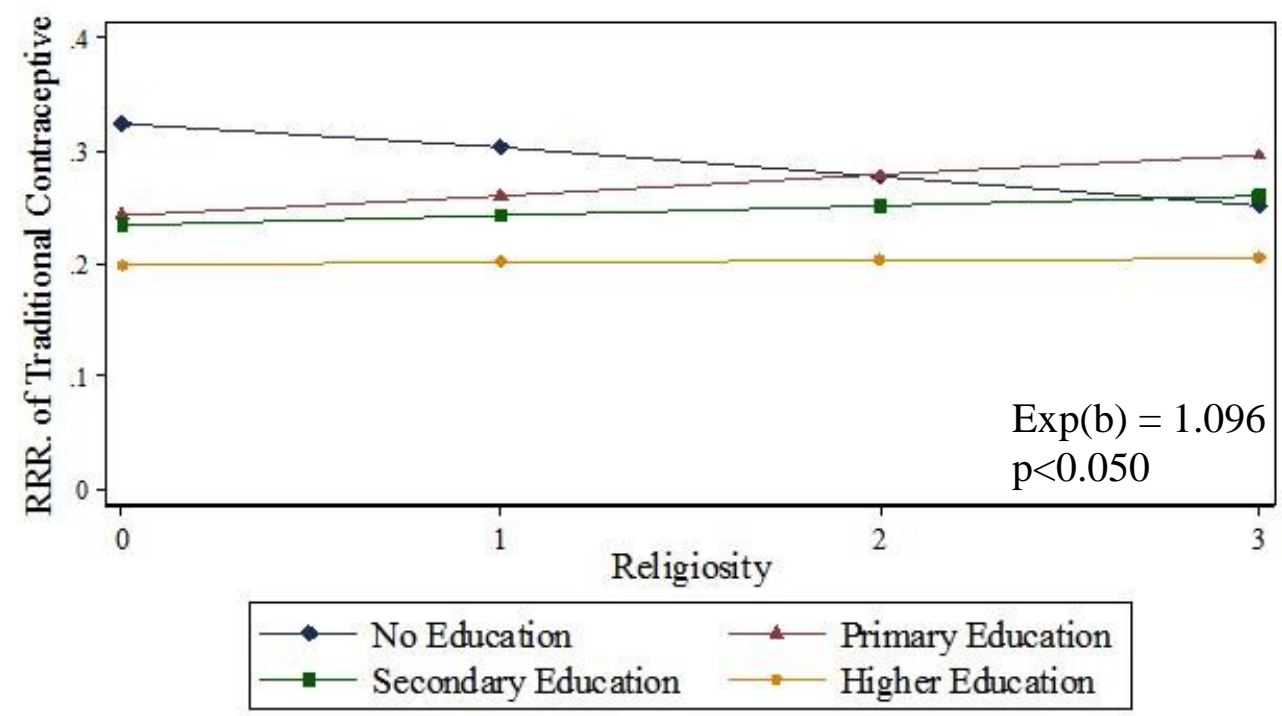

Figure 5.4. The Effect of the Interaction Term between Religiosity and Women's Education on Traditional Contraceptive Methods 


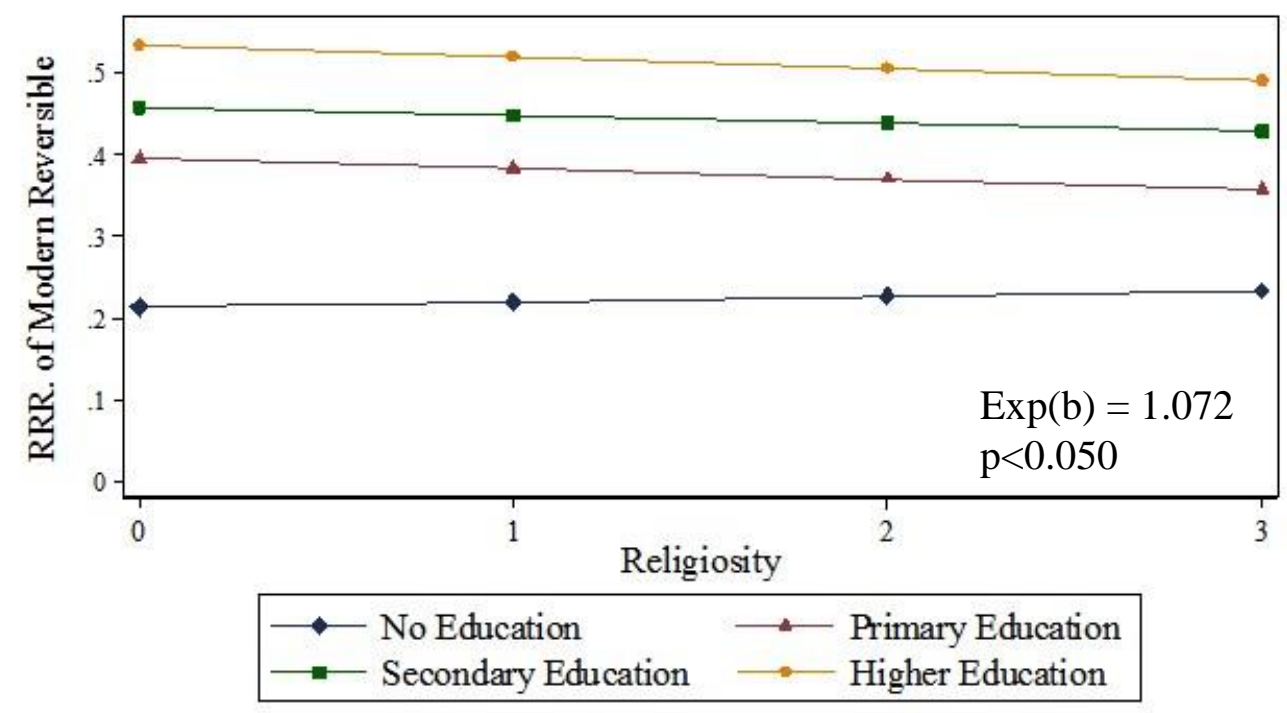

Figure 5.5. The Effect of the Interaction Term between Religiosity and Women's Education on Modern Reversible Contraceptive Methods 


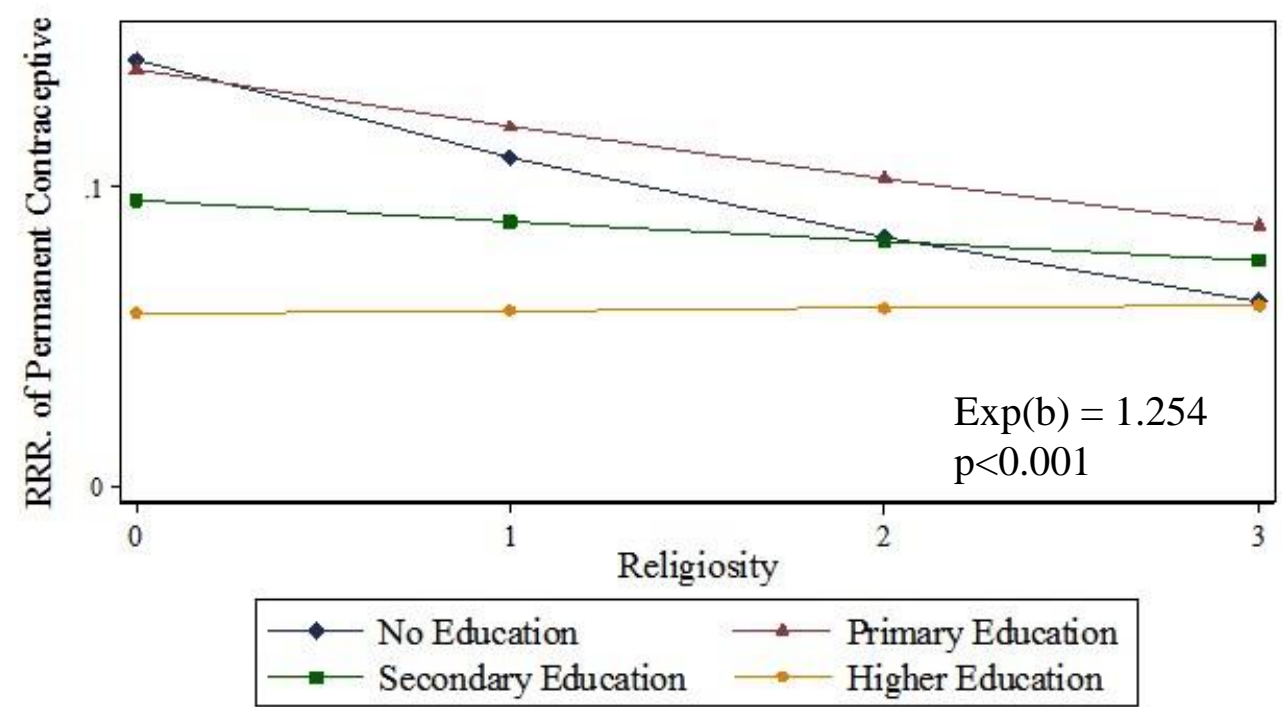

Figure 5.6. The Effect of the Interaction Term between Religiosity and Women's Education on Permanent Contraceptive Methods 


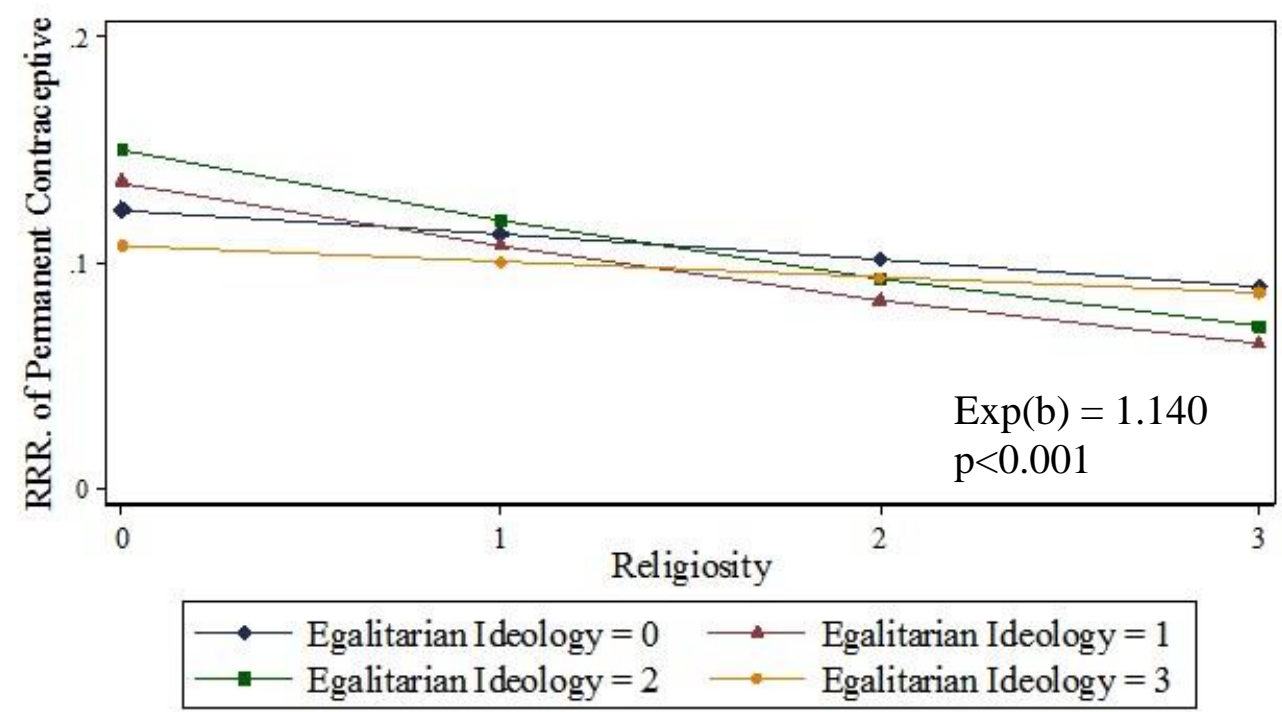

Figure 5.7. The Effect of the Interaction Term between Religiosity and Egalitarian Ideology on Permanent Contraceptive Methods 
Table 5.6. Multinomial Logistic Regression Results for the Interactions between Secularization and Modernization on Currently Used Contraceptive Method Types, RRR (N=13575)

\begin{tabular}{|c|c|c|c|c|c|c|c|}
\hline Variables & $\begin{array}{c}\text { Model } 1 \\
\operatorname{Exp}(\mathrm{b}) /(\mathrm{se}) \\
\end{array}$ & $\begin{array}{c}\text { Model } 2 \\
\operatorname{Exp}(\mathrm{b}) /(\mathrm{se})\end{array}$ & $\begin{array}{c}\text { Model } 3 \\
\operatorname{Exp}(\mathrm{b}) /(\mathrm{se})\end{array}$ & $\begin{array}{c}\text { Model } 4 \\
\operatorname{Exp}(\mathrm{b}) /(\mathrm{se}) \\
\end{array}$ & $\begin{array}{c}\text { Model } 5 \\
\operatorname{Exp}(\mathrm{b}) /(\mathrm{se})\end{array}$ & $\begin{array}{c}\text { Model } 6 \\
\text { Exp(b)/(se) }\end{array}$ & $\begin{array}{c}\text { Model } 7 \\
\operatorname{Exp}(\mathrm{b}) /(\mathrm{se})\end{array}$ \\
\hline \multicolumn{8}{|c|}{ Panel A: Traditional Method vs No Method } \\
\hline \multicolumn{8}{|l|}{ Secularization } \\
\hline Religiosity & $\begin{array}{c}0.975 \\
(0.034)\end{array}$ & $\begin{array}{c}1.000 \\
(0.035)\end{array}$ & $\begin{array}{c}0.983 \\
(0.060)\end{array}$ & $\begin{array}{c}0.992 \\
(0.034)\end{array}$ & $\begin{array}{c}0.995 \\
(0.034)\end{array}$ & $\begin{array}{c}1.060 \\
(0.069)\end{array}$ & $\begin{array}{c}0.984 \\
(0.060)\end{array}$ \\
\hline \multicolumn{8}{|l|}{ Modernization } \\
\hline Woman's Education & $\begin{array}{c}0.975 \\
(0.053)\end{array}$ & $\begin{array}{c}0.940 \\
(0.050)\end{array}$ & $\begin{array}{c}0.942 \\
(0.050)\end{array}$ & $\begin{array}{c}1.191 \\
(0.113)\end{array}$ & $\begin{array}{c}0.942 \\
(0.050)\end{array}$ & $\begin{array}{c}1.251^{*} \\
(0.126)\end{array}$ & $\begin{array}{c}0.940 \\
(0.050)\end{array}$ \\
\hline Egalitarian Ideology & $\begin{array}{l}1.151^{* * * *} \\
(0.044)\end{array}$ & $\begin{array}{l}1.160^{* * * *} \\
(0.045)\end{array}$ & $\begin{array}{l}1.153^{\text {**** }} \\
(0.044)\end{array}$ & $\begin{array}{l}1.149^{* * * *} \\
(0.044)\end{array}$ & $\begin{array}{l}1.152^{*} \\
(0.064)\end{array}$ & $\begin{array}{l}1.148^{* * * *} \\
(0.044)\end{array}$ & $\begin{array}{l}1.138^{*} \\
(0.067)\end{array}$ \\
\hline Urban & $\begin{array}{l}1.020 \\
(0.071)\end{array}$ & $\begin{array}{l}1.023 \\
(0.071)\end{array}$ & $\begin{array}{c}1.023 \\
(0.072)\end{array}$ & $\begin{array}{c}0.968 \\
(0.073)\end{array}$ & $\begin{array}{c}1.022 \\
(0.072)\end{array}$ & $\begin{array}{c}0.930 \\
(0.073)\end{array}$ & $\begin{array}{c}1.011 \\
(0.072)\end{array}$ \\
\hline \multicolumn{8}{|l|}{$\begin{array}{l}\text { Interactions } \\
\text { Religiosity }\end{array}$} \\
\hline Education & $\begin{array}{l}1.096^{*} \mathrm{~d} 1 \\
(0.043)\end{array}$ & & & & & $\begin{array}{l}1.314^{* *} \\
(0.114)\end{array}$ & \\
\hline \multicolumn{8}{|l|}{ Religiosity * Egalitarian } \\
\hline Ideology & & $\begin{array}{c}0.982^{\mathrm{e} 1} \\
(0.042)\end{array}$ & & & & & $\begin{array}{c}1.059 \\
(0.075)\end{array}$ \\
\hline Religiosity * Urban & & & $\begin{array}{l}1.015^{\mathrm{f} 1} \\
(0.070)\end{array}$ & & & $\begin{array}{c}0.910 \\
(0.069)\end{array}$ & $\begin{array}{c}1.027 \\
(0.073)\end{array}$ \\
\hline Woman's Education * Urban & & & & $\begin{array}{l}0.758^{* * \mathrm{~g} 1} \\
(0.075)\end{array}$ & & $\begin{array}{l}0.737^{* * *} \\
(0.078)\end{array}$ & \\
\hline Egalitarian Ideology * Urban & & & & & $\begin{array}{l}1.002^{\mathrm{h} 1} \\
(0.072)\end{array}$ & & $\begin{array}{c}1.022 \\
(0.077)\end{array}$ \\
\hline $\begin{array}{l}\text { Religiosity * Woman's } \\
\text { Education * Urban }\end{array}$ & & & & & & $\begin{array}{l}0.808^{* \mathrm{i} 1} \\
(0.078)\end{array}$ & \\
\hline
\end{tabular}


Religiosity * Egalitarian

Ideology * Urban

$0.901^{\mathrm{j} 1}$

(0.079)

The Proximate Determinants of Fertility

Age at First Marriage ${ }^{a}$

Abortion Frequency

The Number of Children

Women's and Household

Characteristics

Woman's Employment

Woman's Age ${ }^{\text {b }}$

Husband Education

Wealth

Turkish

Region $^{c}$

South

Central

North

East

$\begin{array}{ccccccc}1.003 & 1.002 & 1.002 & 1.003 & 1.002 & 1.004 & 1.002 \\ (0.008) & (0.008) & (0.008) & (0.008) & (0.008) & (0.009) & (0.008) \\ 0.936 & 0.939 & 0.939 & 0.936 & 0.939 & 0.932 & 0.940 \\ (0.052) & (0.052) & (0.052) & (0.052) & (0.052) & (0.052) & (0.052) \\ 1.594^{* * *} & 1.585^{* * *} & 1.586^{* * *} & 1.595^{* * *} & 1.585^{* * *} & 1.606^{* * *} & 1.586^{* * *} \\ (0.050) & (0.049) & (0.049) & (0.050) & (0.049) & (0.051) & (0.049)\end{array}$

\begin{tabular}{|c|c|c|c|c|c|c|}
\hline $1.233^{* *}$ & $1.220^{* *}$ & $1.222^{* *}$ & $1.236^{* *}$ & $1.221^{* *}$ & $1.239^{* * *}$ & $1.221^{* *}$ \\
\hline$(0.080)$ & $(0.079)$ & $(0.079)$ & $(0.080)$ & $(0.079)$ & $(0.080)$ & $(0.079)$ \\
\hline $0.964^{* * *}$ & $0.963^{\text {**** }}$ & $0.963^{\text {**** }}$ & $0.963^{* * * *}$ & $0.963^{* * * *}$ & $0.963^{* * *}$ & $0.963^{\text {**** }}$ \\
\hline$(0.005)$ & $(0.005)$ & $(0.005)$ & $(0.005)$ & $(0.005)$ & $(0.005)$ & $(0.005)$ \\
\hline 1.073 & 1.070 & 1.070 & 1.073 & 1.070 & 1.075 & 1.070 \\
\hline (0.047) & $(0.046)$ & $(0.046)$ & $(0.047)$ & $(0.046)$ & $(0.047)$ & $(0.046)$ \\
\hline $1.091^{* *}$ & $1.087^{* *}$ & $1.087^{* *}$ & $1.091^{* * *}$ & $1.087^{* *}$ & $1.096^{* *}$ & $1.087^{* *}$ \\
\hline$(0.034)$ & $(0.034)$ & $(0.034)$ & $(0.034)$ & $(0.034)$ & $(0.035)$ & $(0.034)$ \\
\hline $1.706^{* * *}$ & $1.761^{* * * *}$ & $1.757^{* * *}$ & $1.747^{* * * *}$ & $1.756^{* * * *}$ & $1.700^{* * * *}$ & $1.763^{* * *}$ \\
\hline (0.154) & $(0.158)$ & $(0.157)$ & $(0.157)$ & $(0.157)$ & $(0.154)$ & $(0.158)$ \\
\hline $0.687^{* * *}$ & $0.688^{* * *}$ & $0.688^{* * * *}$ & $0.686^{\text {**** }}$ & $0.689^{* * *}$ & $0.683^{* * *}$ & $0.689^{\text {**** }}$ \\
\hline$(0.061)$ & $(0.061)$ & $(0.061)$ & $(0.061)$ & $(0.061)$ & $(0.060)$ & $(0.061)$ \\
\hline $0.841^{*}$ & $0.840^{*}$ & $0.840^{*}$ & $0.845^{*}$ & $0.840^{*}$ & $0.840^{*}$ & $0.840^{*}$ \\
\hline$(0.072)$ & $(0.072)$ & $(0.072)$ & $(0.072)$ & $(0.072)$ & $(0.072)$ & $(0.072)$ \\
\hline 1.087 & 1.085 & 1.085 & 1.083 & 1.084 & 1.080 & 1.087 \\
\hline (0.099) & $(0.099)$ & $(0.099)$ & (0.099) & (0.099) & $(0.098)$ & $(0.099)$ \\
\hline $0.451^{* * *}$ & $0.445^{* * *}$ & $0.445^{\text {**** }}$ & $0.456^{\text {**** }}$ & $0.445^{\text {*** }}$ & $0.463^{* * *}$ & $0.445^{\text {*** }}$ \\
\hline
\end{tabular}




\begin{tabular}{|c|c|c|c|c|c|c|c|}
\hline Survey Year (2013) & $\begin{array}{c}(0.041) \\
0.989 \\
(0.060)\end{array}$ & $\begin{array}{c}(0.041) \\
0.996 \\
(0.061)\end{array}$ & $\begin{array}{c}(0.041) \\
0.995 \\
(0.061)\end{array}$ & $\begin{array}{c}(0.042) \\
0.994 \\
(0.060)\end{array}$ & $\begin{array}{c}(0.041) \\
0.995 \\
(0.061)\end{array}$ & $\begin{array}{c}(0.043) \\
0.990 \\
(0.060)\end{array}$ & $\begin{array}{c}(0.041) \\
0.996 \\
(0.061)\end{array}$ \\
\hline \multicolumn{8}{|c|}{ Panel B: Modern Reversible Methods vs No Method } \\
\hline \multicolumn{8}{|l|}{ Secularization } \\
\hline Religiosity & $\begin{array}{c}0.899^{* *} \\
(0.029)\end{array}$ & $\begin{array}{c}0.903^{* *} \\
(0.029)\end{array}$ & $\begin{array}{c}0.863^{*} \\
(0.050)\end{array}$ & $\begin{array}{c}0.910^{* *} \\
(0.029)\end{array}$ & $\begin{array}{c}0.913^{* *} \\
(0.029)\end{array}$ & $\begin{array}{c}0.930 \\
(0.057)\end{array}$ & $\begin{array}{c}0.864^{*} \\
(0.050)\end{array}$ \\
\hline \multicolumn{8}{|l|}{ Modernization } \\
\hline Woman's Education & $\begin{array}{l}1.220^{* * *} \\
(0.063)\end{array}$ & $\begin{array}{l}1.193^{* * *} \\
(0.059)\end{array}$ & $\begin{array}{l}1.188^{* * * *} \\
(0.058)\end{array}$ & $\begin{array}{l}1.600^{* * * *} \\
(0.152)\end{array}$ & $\begin{array}{l}1.188^{* * *} \\
(0.058)\end{array}$ & $\begin{array}{l}1.628^{* * *} \\
(0.163)\end{array}$ & $\begin{array}{l}1.194^{* * *} \\
(0.059)\end{array}$ \\
\hline Egalitarian Ideology & $\begin{array}{l}1.206^{* * * *} \\
(0.045)\end{array}$ & $\begin{array}{l}1.202^{* * * *} \\
(0.045)\end{array}$ & $\begin{array}{l}1.207^{* * * *} \\
(0.045)\end{array}$ & $\begin{array}{l}1.202^{* * * *} \\
(0.045)\end{array}$ & $\begin{array}{l}1.246^{* * * *} \\
(0.072)\end{array}$ & $\begin{array}{l}1.202^{* * * *} \\
(0.045)\end{array}$ & $\begin{array}{l}1.212^{* *} \\
(0.072)\end{array}$ \\
\hline Urban & $\begin{array}{c}1.157^{*} \\
(0.080)\end{array}$ & $\begin{array}{c}1.157^{*} \\
(0.080)\end{array}$ & $\begin{array}{c}1.158^{*} \\
(0.080)\end{array}$ & $\begin{array}{c}1.098 \\
(0.080)\end{array}$ & $\begin{array}{c}1.156^{*} \\
(0.080)\end{array}$ & $\begin{array}{c}1.093 \\
(0.084)\end{array}$ & $\begin{array}{c}1.145 \\
(0.080)\end{array}$ \\
\hline \multicolumn{8}{|l|}{ Interactions } \\
\hline Education & $\begin{array}{l}1.072^{*} \mathrm{~d} 2 \\
(0.037)\end{array}$ & & & & & $\begin{array}{c}1.090 \\
(0.085)\end{array}$ & \\
\hline \multicolumn{8}{|l|}{ Religiosity * Egalitarian } \\
\hline Ideology & & $\begin{array}{c}1.059^{\mathrm{e} 2} \\
(0.042)\end{array}$ & & & & & $\begin{array}{c}1.116 \\
(0.076)\end{array}$ \\
\hline Religiosity * Urban & & & $\begin{array}{c}1.071^{\mathrm{f} 2} \\
(0.070)\end{array}$ & & & $\begin{array}{c}0.959 \\
(0.068)\end{array}$ & $\begin{array}{c}1.060 \\
(0.070)\end{array}$ \\
\hline Woman's Education * Urban & & & & $\begin{array}{l}0.706^{* * * \mathrm{~g} 2} \\
(0.069)\end{array}$ & & $\begin{array}{l}0.710^{* * * *} \\
(0.074)\end{array}$ & \\
\hline Egalitarian Ideology * Urban & & & & & $\begin{array}{c}0.957^{\mathrm{h} 2} \\
(0.069)\end{array}$ & & $\begin{array}{c}0.985 \\
(0.073)\end{array}$ \\
\hline Religiosity * Woman's & & & & & & & \\
\hline Education * Urban & & & & & & $\begin{array}{c}0.973^{\mathrm{i} 2} \\
(0.084)\end{array}$ & \\
\hline Religiosity $*$ Egalitarian & & & & & & & $0.927^{\mathrm{j} 2}$ \\
\hline
\end{tabular}


Ideology * Urban

The Proximate Determinants of Fertility

Age at First Marriage ${ }^{a}$

Abortion Frequency

The Number of Children

Women's and Household

Characteristics

Woman's Employment

Woman's Age ${ }^{\text {b }}$

Husband Education

Wealth

Turkish

Region $^{\mathrm{c}}$

South

Central

North

East

$\begin{array}{ccccccc}1.002 & 1.001 & 1.001 & 1.002 & 1.001 & 1.003 & 1.001 \\ (0.008) & (0.008) & (0.008) & (0.008) & (0.008) & (0.008) & (0.008) \\ 0.963 & 0.964 & 0.967 & 0.962 & 0.966 & 0.959 & 0.965 \\ (0.050) & (0.050) & (0.050) & (0.050) & (0.050) & (0.050) & (0.050) \\ 1.861^{* * * *} & 1.856^{* * *} & 1.853^{* * *} & 1.868^{* * *} & 1.853^{* * *} & 1.876^{* * *} & 1.858^{* * *} \\ (0.058) & (0.058) & (0.057) & (0.058) & (0.057) & (0.059) & (0.058)\end{array}$

$\begin{array}{ccccccc}1.185^{* *} & 1.179^{* *} & 1.181^{* *} & 1.195^{* *} & 1.177^{* *} & 1.200^{* *} & 1.183^{* *} \\ (0.073) & (0.073) & (0.073) & (0.074) & (0.073) & (0.075) & (0.073) \\ 0.943^{* * *} & 0.943^{* * *} & 0.943^{* * *} & 0.943^{* * *} & 0.943^{* * *} & 0.943^{* * *} & 0.943^{* * *} \\ (0.004) & (0.004) & (0.004) & (0.004) & (0.004) & (0.004) & \left.(0.004)^{*}\right) \\ 1.144^{* *} & 1.141^{* *} & 1.141^{* *} & 1.145^{* *} & 1.141^{* *} & 1.147^{* * *} & 1.140^{* *} \\ (0.047) & (0.047) & (0.047) & (0.048) & (0.047) & (0.048) & \left.(0.047)^{* * * * *}\right) \\ 1.177^{* * *} & 1.176^{* * *} & 1.175^{* * *} & 1.177^{* * *} & 1.174^{* * *} & 1.179^{* * *} & 1.177^{* * *} \\ (0.034) & (0.034) & (0.034) & (0.035) & (0.034) & (0.035) & (0.034) \\ 2.55)^{* * *} & 2.602^{* * *} & 2.614^{* * *} & 2.594^{* * *} & 2.613^{* * *} & 2.546^{* * *} & 2.605^{* * *} \\ (0.218) & (0.219) & (0.220) & (0.219) & (0.220) & (0.217) & (0.219) \\ & & & & & \\ 0.828^{*} & 0.829^{*} & 0.829^{*} & 0.826^{*} & 0.830^{*} & 0.825^{*} & 0.830^{*} \\ (0.069) & (0.069) & (0.069) & (0.069) & (0.069) & (0.068) & (0.069) \\ 1.098 & 1.097 & 1.098 & 1.105 & 1.098 & 1.106 & 1.098 \\ (0.088) & (0.088) & (0.088) & (0.088) & (0.088) & (0.088) & (0.088) \\ 0.721^{* * * *} & 0.720^{* * *} & 0.721^{* * *} & 0.718^{* * *} & 0.720^{* * *} & 0.719^{* * *} & 0.723^{* * *} \\ (0.066) & (0.065) & (0.066) & (0.065) & (0.066) & (0.066) & (0.066) \\ 0.550^{* * *} & 0.546^{* * *} & 0.548^{* * *} & 0.560^{* * *} & 0.546^{* * *} & 0.564^{* * *} & 0.548^{* * *} \\ (0.047) & (0.047) & (0.047) & (0.048) & (0.047) & (0.048) & (0.047)\end{array}$




\begin{tabular}{|c|c|c|c|c|c|c|c|}
\hline Survey Year (2013) & $\begin{array}{c}1.072 \\
(0.062)\end{array}$ & $\begin{array}{l}1.075 \\
(0.062)\end{array}$ & $\begin{array}{c}1.076 \\
(0.062)\end{array}$ & $\begin{array}{l}1.075 \\
(0.062)\end{array}$ & $\begin{array}{c}1.078 \\
(0.062)\end{array}$ & $\begin{array}{c}1.071 \\
(0.062)\end{array}$ & $\begin{array}{l}1.075 \\
(0.062)\end{array}$ \\
\hline \multicolumn{8}{|c|}{ Panel C: Permanent Methods vs No Method } \\
\hline \multicolumn{8}{|l|}{ Secularization } \\
\hline Religiosity & $\begin{array}{l}0.799^{* * *} \\
(0.040)\end{array}$ & $\begin{array}{l}0.802^{* * *} \\
(0.041)\end{array}$ & $\begin{array}{l}0.738^{* * * *} \\
(0.066)\end{array}$ & $\begin{array}{l}0.813^{* * *} \\
(0.041)\end{array}$ & $\begin{array}{l}0.818^{* * * *} \\
(0.041)\end{array}$ & $\begin{array}{c}0.821^{*} \\
(0.076)\end{array}$ & $\begin{array}{l}0.748^{* * *} \\
(0.068)\end{array}$ \\
\hline \multicolumn{8}{|l|}{ Modernization } \\
\hline Woman's Education & $\begin{array}{c}0.985 \\
(0.076)\end{array}$ & $\begin{array}{c}0.929 \\
(0.071)\end{array}$ & $\begin{array}{c}0.916 \\
(0.070)\end{array}$ & $\begin{array}{l}1.469^{* *} \\
(0.214)\end{array}$ & $\begin{array}{c}0.914 \\
(0.070)\end{array}$ & $\begin{array}{l}1.548^{* *} \\
(0.233)\end{array}$ & $\begin{array}{c}0.928 \\
(0.071)\end{array}$ \\
\hline Egalitarian Ideology & $\begin{array}{l}1.180^{* *} \\
(0.072)\end{array}$ & $\begin{array}{r}1.158^{*} \\
(0.071)\end{array}$ & $\begin{array}{l}1.182^{* *} \\
(0.073)\end{array}$ & $\begin{array}{l}1.176^{* *} \\
(0.072)\end{array}$ & $\begin{array}{r}1.203^{*} \\
(0.106)\end{array}$ & $\begin{array}{l}1.174^{* *} \\
(0.072)\end{array}$ & $\begin{array}{c}1.128 \\
(0.103)\end{array}$ \\
\hline Urban & $\begin{array}{c}1.228 \\
(0.140)\end{array}$ & $\begin{array}{c}1.227 \\
(0.140)\end{array}$ & $\begin{array}{c}1.221 \\
(0.140)\end{array}$ & $\begin{array}{c}1.062 \\
(0.128)\end{array}$ & $\begin{array}{c}1.232 \\
(0.142)\end{array}$ & $\begin{array}{c}1.083 \\
(0.134)\end{array}$ & $\begin{array}{l}1.203 \\
(0.139)\end{array}$ \\
\hline \multicolumn{8}{|l|}{$\begin{array}{l}\text { Interactions } \\
\quad \text { Religiosity * Woman's }\end{array}$} \\
\hline Education & $\begin{array}{l}1.254^{* * * \mathrm{~d} 3} \\
(0.068)\end{array}$ & & & & & $\begin{array}{c}1.173 \\
(0.147)\end{array}$ & \\
\hline \multicolumn{8}{|l|}{ Religiosity $*$ Egalitarian } \\
\hline Ideology & & $\begin{array}{l}1.140^{*} \mathrm{e} 3 \\
(0.073)\end{array}$ & & & & & $\begin{array}{c}1.274^{*} \\
(0.131)\end{array}$ \\
\hline Religiosity * Urban & & & $\begin{array}{c}1.135^{\mathrm{f} 3} \\
(0.114)\end{array}$ & & & $\begin{array}{c}0.960 \\
(0.102)\end{array}$ & $\begin{array}{c}1.099 \\
(0.115)\end{array}$ \\
\hline Woman's Education * Urban & & & & $\begin{array}{l}0.572^{* * * * \mathrm{~g} 3} \\
(0.083)\end{array}$ & & $\begin{array}{l}0.587^{* * * *} \\
(0.089)\end{array}$ & \\
\hline Egalitarian Ideology * Urban & & & & & $\begin{array}{l}0.977^{\mathrm{h} 3} \\
(0.110)\end{array}$ & & $\begin{array}{c}1.031 \\
(0.120)\end{array}$ \\
\hline $\begin{array}{l}\text { Religiosity * Woman's } \\
\text { Education * Urban }\end{array}$ & & & & & & $\begin{array}{c}1.068^{\mathrm{i} 3} \\
(0.148)\end{array}$ & \\
\hline $\begin{array}{l}\text { Religiosity * Egalitarian } \\
\text { Ideology * Urban }\end{array}$ & & & & & & & $0.858^{\mathrm{j} 3}$ \\
\hline
\end{tabular}


The Proximate Determinants of Fertility

Age at First Marriage ${ }^{a}$

Abortion Frequency

The Number of Children

Women's and Household

Characteristics

Woman's Employment

Woman's Age ${ }^{\mathrm{b}}$

Husband Education

Wealth

Turkish

\section{Region $^{\mathrm{c}}$}

South

Central

North

East

Survey Year (2013)

$\begin{array}{ccccccc}1.017 & 1.013 & 1.013 & 1.015 & 1.013 & 1.018 & 1.013 \\ (0.013) & (0.012) & (0.012) & (0.013) & (0.012) & (0.013) & (0.012) \\ 0.858^{*} & 0.860^{*} & 0.866 & 0.859^{*} & 0.865 & 0.853^{*} & 0.863^{*} \\ (0.065) & (0.065) & (0.065) & (0.065) & (0.065) & (0.065) & (0.065) \\ 2.734^{* * *} & 2.708^{* * *} & 2.699^{* * *} & 2.729^{* * *} & 2.700^{* * *} & 2.764^{* * *} & 2.708^{* * *} \\ (0.121) & (0.120) & (0.119) & (0.121) & (0.119) & (0.124) & (0.120)\end{array}$

$\begin{array}{ccccccc}1.034 & 1.016 & 1.019 & 1.034 & 1.013 & 1.052 & 1.019 \\ (0.100) & (0.099) & (0.099) & (0.100) & (0.098) & (0.102) & (0.099) \\ 1.000 & 0.999 & 0.999 & 0.999 & 0.999 & 1.000 & 0.999 \\ (0.007) & (0.007) & (0.007) & (0.007) & (0.007) & (0.007) & (0.007) \\ 1.110 & 1.100 & 1.101 & 1.109 & 1.101 & 1.117 & 1.099 \\ (0.074) & (0.074) & (0.074) & (0.074) & (0.074) & (0.075) & (0.074) \\ 1.174^{* * *} & 1.171^{* *} & 1.166^{* *} & 1.172^{* *} & 1.165^{* *} & 1.179^{* * *} & 1.172^{* *} \\ (0.057) & (0.057) & (0.057) & (0.057) & (0.057) & (0.057) & (0.057) \\ 3.402^{* * * *} & 3.644^{* * *} & 3.694^{* * *} & 3.648^{* * *} & 3.687^{* * *} & 3.372^{* * *} & 3.657^{* * *} \\ (0.515) & (0.554) & (0.563) & (0.555) & (0.563) & (0.509) & (0.557) \\ & & & & & & \\ 0.864 & 0.864 & 0.863 & 0.859 & 0.864 & 0.860 & 0.865 \\ (0.115) & (0.115) & (0.115) & (0.115) & (0.115) & (0.115) & (0.115) \\ 0.751^{*} & 0.750^{*} & 0.753^{*} & 0.761^{*} & 0.753^{*} & 0.760^{*} & 0.749^{*} \\ (0.098) & (0.098) & (0.099) & (0.100) & (0.099) & (0.100) & (0.098) \\ 1.490^{* *} & 1.487^{* *} & 1.492^{* *} & 1.483^{* *} & 1.486^{* *} & 1.486^{* *} & 1.497^{* *} \\ (0.196) & (0.195) & (0.195) & (0.194) & (0.194) & (0.195) & (0.195) \\ 0.358^{* * *} & 0.348^{* * *} & 0.350^{* * *} & 0.364^{* * *} & 0.347^{* * *} & 0.372^{* * *} & 0.350^{* * *} \\ (0.054) & (0.052) & (0.052) & (0.054) & (0.052) & (0.055) & (0.052) \\ 1.340^{* *} & 1.347^{* *} & 1.351^{* * *} & 1.351^{* * *} & 1.355^{* * *} & 1.337^{* *} & 1.347^{* *}\end{array}$


(0.122)

(0.123)

(0.123)

(0.123)

(0.124)

(0.122)

Source: Demographic and Health Surveys, Turkey 2008 and 2013, ${ }^{1}$ Relative Risks Ratio $(\mathrm{RRR})=\exp (\mathrm{b})$; b = Multinomial Logistic coefficient Note: se $=$ standard errors; se are $\exp (\mathrm{se}),{ }^{\mathrm{a} C e n t e r e d}$ at age $10,{ }^{\mathrm{b}}$ Centered at age $15,{ }^{\mathrm{c}} \mathrm{West}$ is the reference

${ }^{\mathrm{d} 1}$ Joint effects of religiosity, women's education, and religiosity $\mathrm{x}$ women's education are not statistically significant $\left(\mathrm{Wald} c h i^{2}(3)=6.6, \mathrm{p}=.0855\right)$.

$\mathrm{d} 2$ Joint effects of religiosity, women's education, and religiosity $\mathrm{x}$ women's education are statistically significant $\left(\mathrm{Wald} c h i^{2}(3)=27.9\right.$, $\left.\mathrm{p}=.0000\right)$.

${ }^{\mathrm{d} 3}$ Joint effects of religiosity, women's education, and religiosity $\mathrm{x}$ women's education are statistically significant $\left(\mathrm{Wald} c h i^{2}(3)=35.5, \mathrm{p}=.0000\right)$.

${ }^{\mathrm{e} 1}$ Joint effects of religiosity, egalitarian ideology, and religiosity $\mathrm{x}$ egalitarian ideology are not statistically significant $\left(\mathrm{Wald} c h i^{2}(3)=11.7, \mathrm{p}=.0113\right)$.

e2 Joint effects of religiosity, egalitarian ideology, and religiosity x egalitarian ideology are statistically significant $\left(\mathrm{Wald} c h i^{2}(3)=18.4, \mathrm{p}=.0004\right)$.

e3 Joint effects of religiosity, egalitarian ideology, and religiosity x egalitarian ideology are not statistically significant $\left(\right.$ Wald $\left.c h i^{2}(3)=4.9, p=.1831\right)$.

${ }^{\mathrm{f} 1}$ Joint effects of religiosity, urban, and religiosity $\mathrm{x}$ urban are not statistically significant (Wald $\left.c h i^{2}(3)=0.1, \mathrm{p}=.9937\right)$.

f2 Joint effects of religiosity, urban, and religiosity $x$ urban are statistically significant (Wald $\left.c h i^{2}(3)=16.7, \mathrm{p}=.0008\right)$.

${ }^{\mathrm{f} 3}$ Joint effects of religiosity, urban, and religiosity $\mathrm{x}$ urban are statistically significant (Wald $\left.\operatorname{chi}^{2}(3)=24.3, \mathrm{p}=.0000\right)$.

${ }^{\mathrm{g} 1}$ Joint effects of women's education, urban, and women's education $\mathrm{x}$ urban are not statistically significant $\left(\mathrm{Wald}_{\mathrm{chi}}{ }^{2}(3)=8.1, \mathrm{p}=.0433\right)$.

g2 Joint effects of women's education, urban, and women's education $\mathrm{x}$ urban are statistically significant $\left(\mathrm{Wald} \mathrm{chi}^{2}(3)=34.2, \mathrm{p}=.0000\right)$.

g3 Joint effects of women's education, urban, and women's education x urban are statistically significant $\left(\mathrm{Wald}\right.$ chi $\left.{ }^{2}(3)=22.4, \mathrm{p}=.0001\right)$.

${ }^{\mathrm{h} 1}$ Joint effects of egalitarian ideology, urban, and egalitarian ideology $\mathrm{x}$ urban are statistically significant $\left(\mathrm{Wald} c h i^{2}(3)=15.7, \mathrm{p}=.0013\right)$.

h2 Joint effects of egalitarian ideology, urban, and egalitarian ideology x urban are statistically significant $\left(\mathrm{Wald} c h i^{2}(3)=38.2, \mathrm{p}=.0000\right)$.

${ }^{\mathrm{h} 3}$ Joint effects of egalitarian ideology, urban, and egalitarian ideology $\mathrm{x}$ urban are statistically significant $\left(\mathrm{Wald} c h i^{2}(3)=13.2, \mathrm{p}=.0043\right)$.

i1 Joint effects of religiosity, women's education, urban, religiosity $\mathrm{x}$ women's education, religiosity $\mathrm{x}$ urban, women's education $\mathrm{x}$ urban, and religiosity $\mathrm{x}$ women's education $\mathrm{x}$ urban are statistically significant $\left(\right.$ Wald $\left.\mathrm{chi}^{2}(8)=19.5, \mathrm{p}=.0068\right)$.

i2 Joint effects of religiosity, women's education, urban, religiosity $\mathrm{x}$ women's education, religiosity $\mathrm{x}$ urban, women's education $\mathrm{x}$ urban, and religiosity $\mathrm{x}$ women's education $\mathrm{x}$ urban are statistically significant $\left(\right.$ Wald $\left.\mathrm{chi}^{2}(8)=47.3, \mathrm{p}=.0000\right)$.

i3 Joint effects of religiosity, women's education, urban, religiosity $\mathrm{x}$ women's education, religiosity $\mathrm{x}$ urban, women's education $\mathrm{x}$ urban, and religiosity $\mathrm{x}$ women's education $\mathrm{x}$ urban are statistically significant $\left(\right.$ Wald $\left.\mathrm{chi}^{2}(8)=53.3, \mathrm{p}=.0000\right)$.

j1 Joint effects of religiosity, egalitarian ideology, urban, religiosity $\mathrm{x}$ egalitarian ideology, religiosity $\mathrm{x}$ urban, egalitarian ideology $\mathrm{x}$ urban, and religiosity $\mathrm{x}$ egalitarian ideology $\mathrm{x}$ urban are statistically significant (Wald $c h i^{2}(8)=17.5, \mathrm{p}=.0145$ ).

j2 Joint effects of religiosity, egalitarian ideology, urban, religiosity x egalitarian ideology, religiosity x urban, egalitarian ideology x urban, and religiosity $\mathrm{x}$ egalitarian ideology $\mathrm{x}$ urban are statistically significant (Wald $\left.c h i^{2}(8)=54.2, \mathrm{p}=.0000\right)$.

j3 Joint effects of religiosity, egalitarian ideology, urban, religiosity x egalitarian ideology, religiosity $\mathrm{x}$ urban, egalitarian ideology $\mathrm{x}$ urban, and religiosity $\mathrm{x}$ egalitarian ideology $\mathrm{x}$ urban are statistically significant (Wald $\left.c h i^{2}(8)=38.8, \mathrm{p}=.0000\right)$.

${ }^{*} p<0.05,{ }^{* *} p<0.01,{ }^{* * *} p<0.001$ (two-tailed tests). 


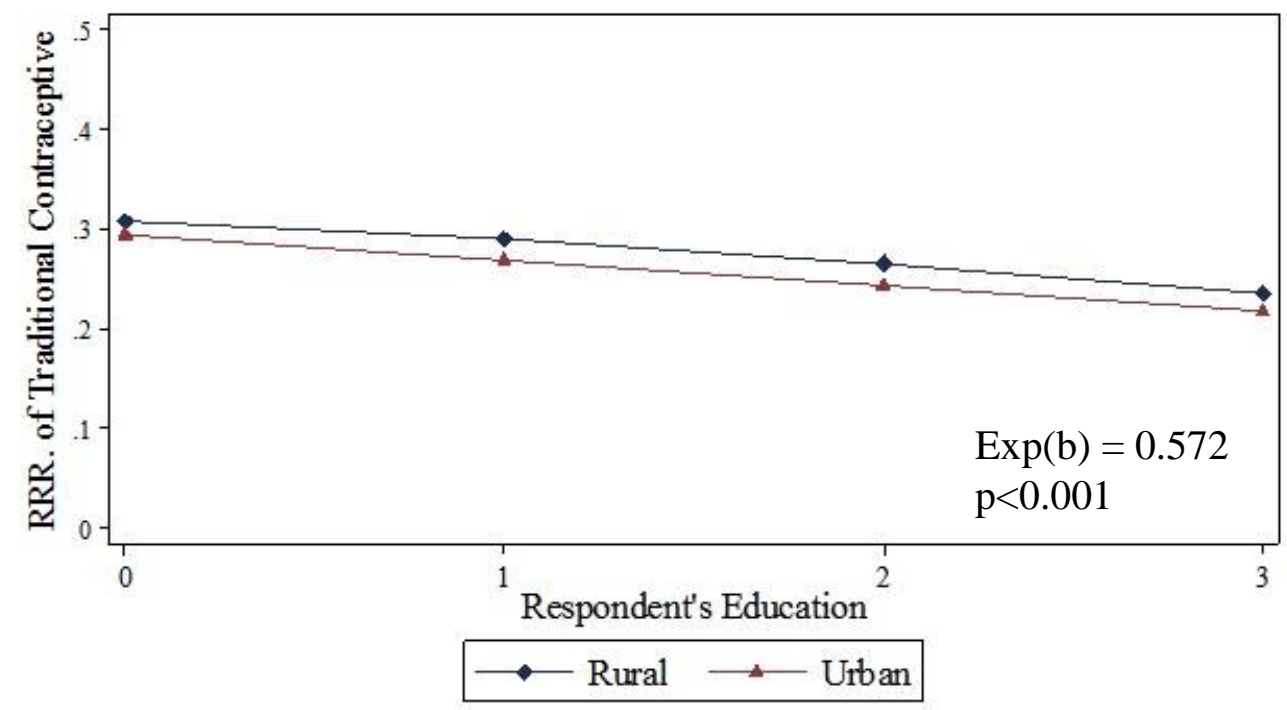

Figure 5.8. The Effect of the Interaction Term between Women's Education and Urban on Traditional Contraceptive Methods 


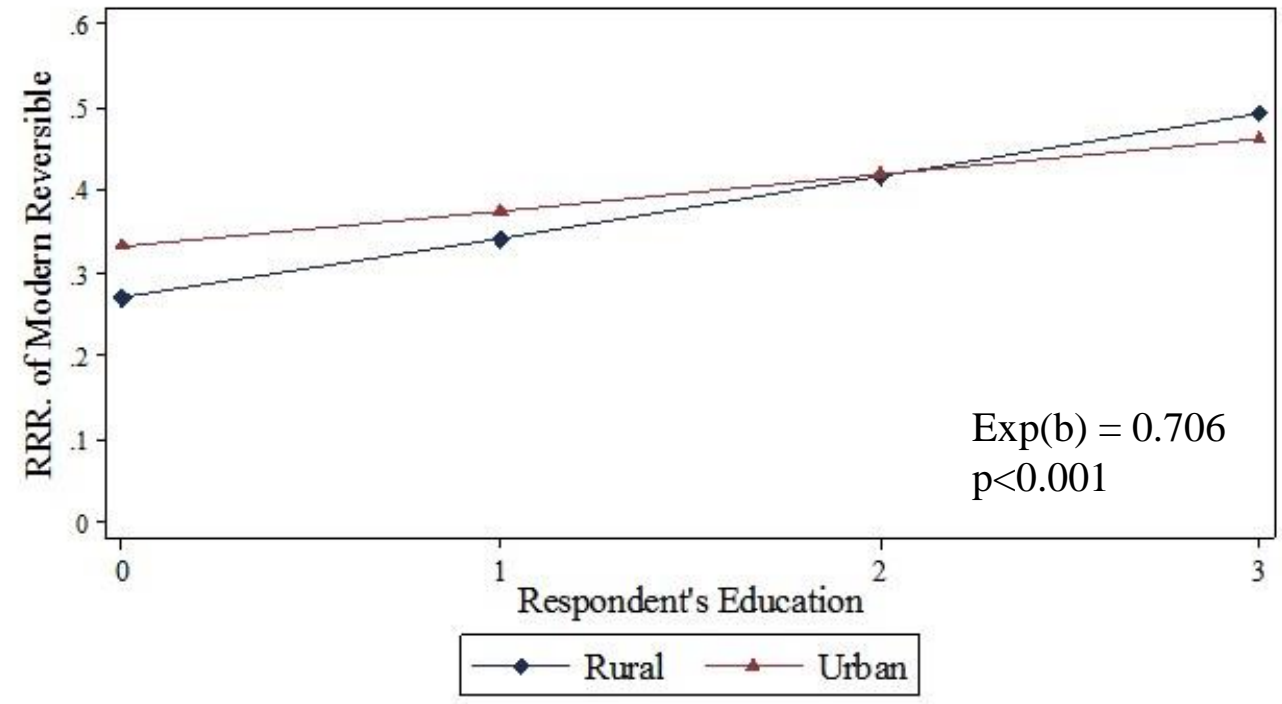

Figure 5.9. The Effect of the Interaction Term between Women's Education and Urban on Modern Reversible Contraceptive Methods 


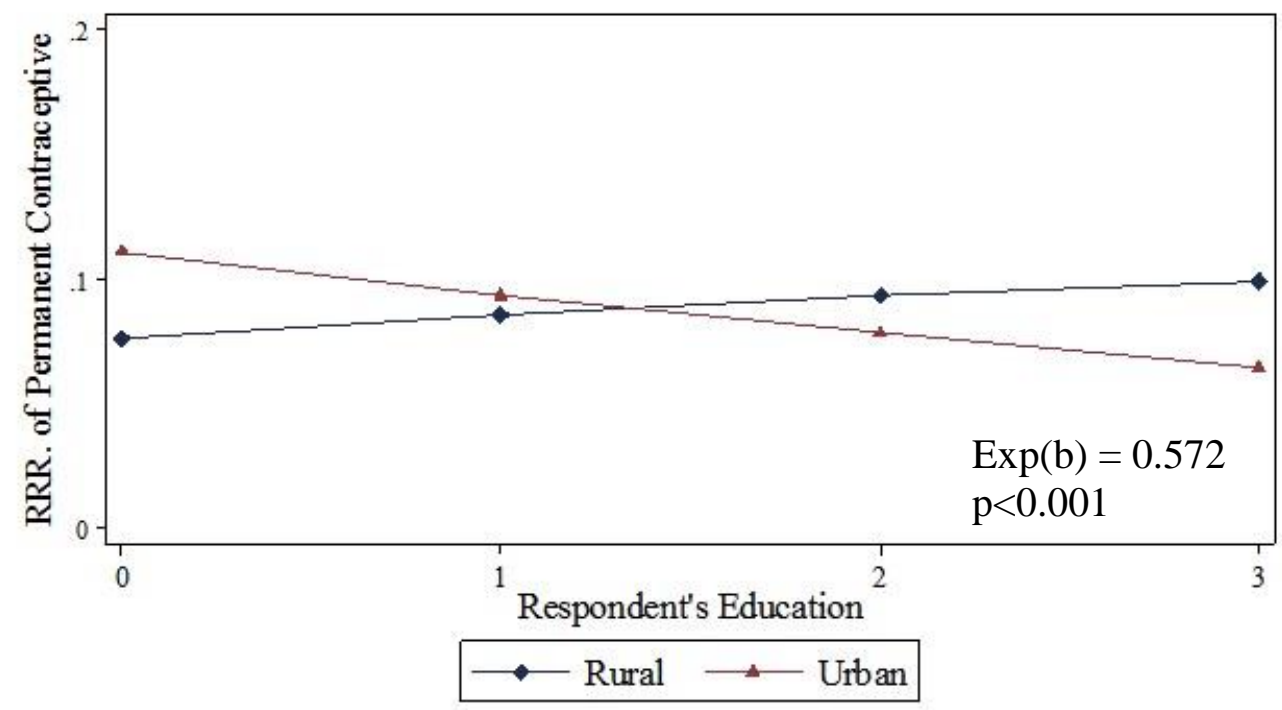

Figure 5.10. The Effect of the Interaction Term between Women's Education and Urban on Permanent Contraceptive Methods 


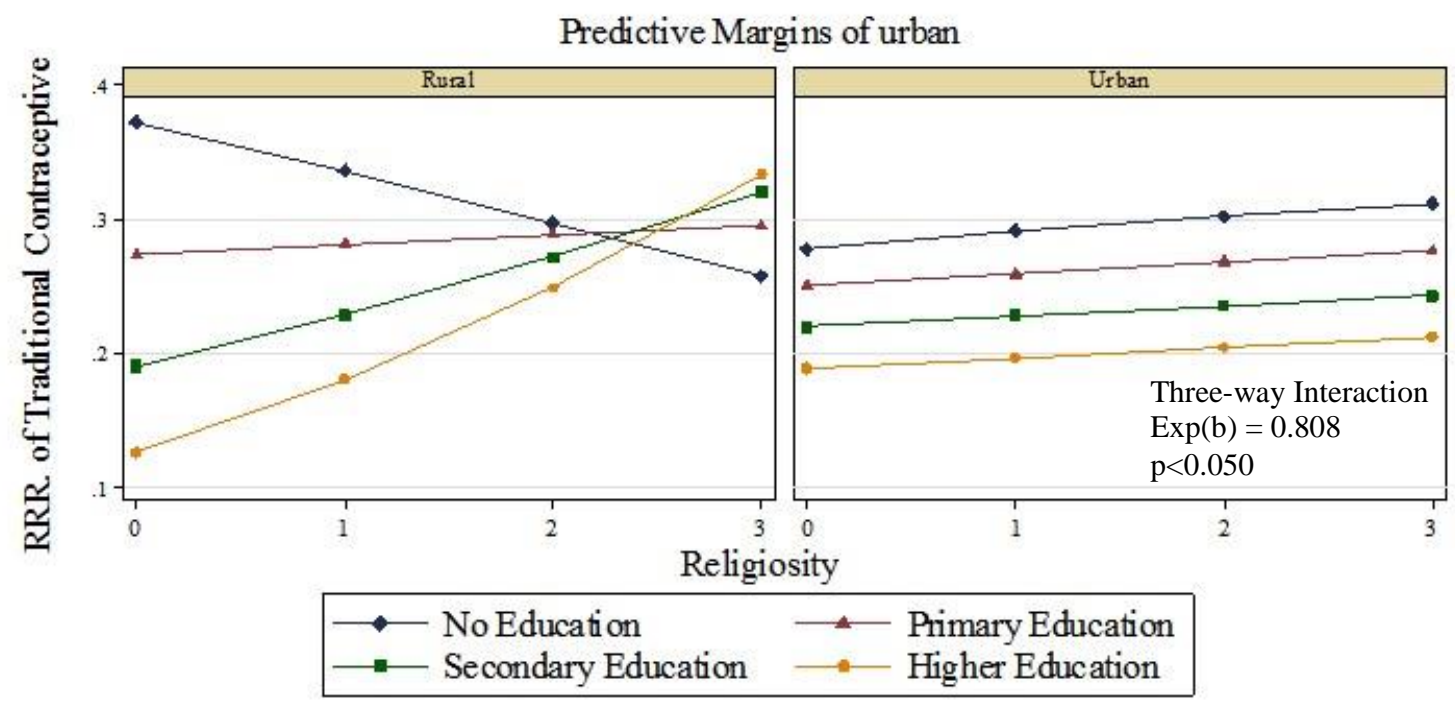

Figure 5.11. The Effect of the Three-Way Interaction Term between Religiosity, Women's Education, and Urban on Traditional Contraceptive Methods 


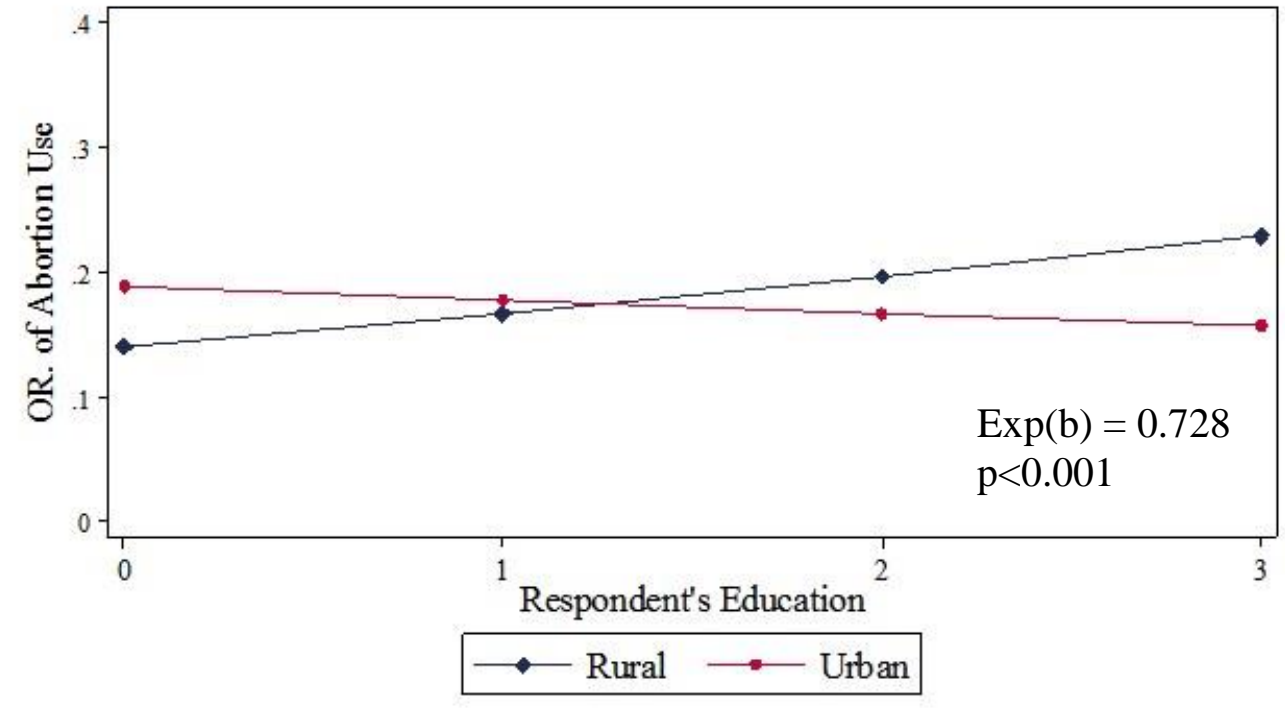

Figure 6.1.The Effect of the Interaction Term between Woman's Education and Urban on Any Abortion Use 


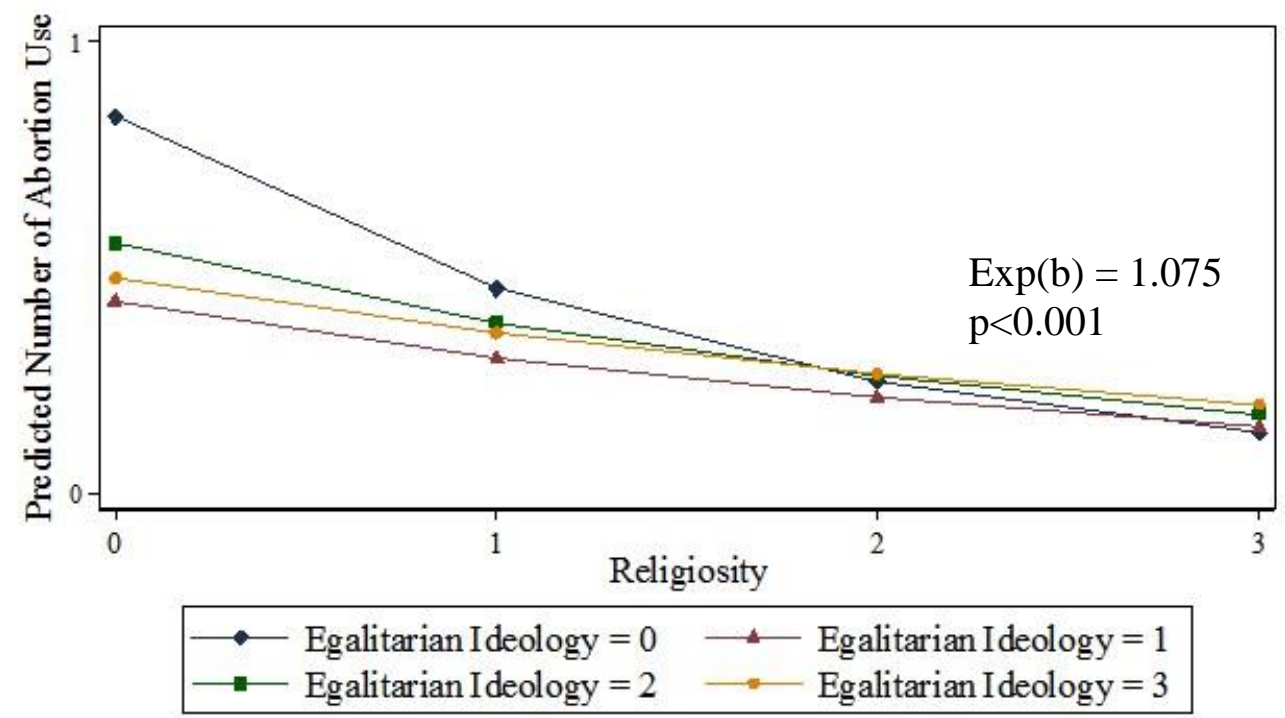

Figure 6.2. The Effect of the Interaction Term between Religiosity and Egalitarian Ideology on Abortion Frequency 


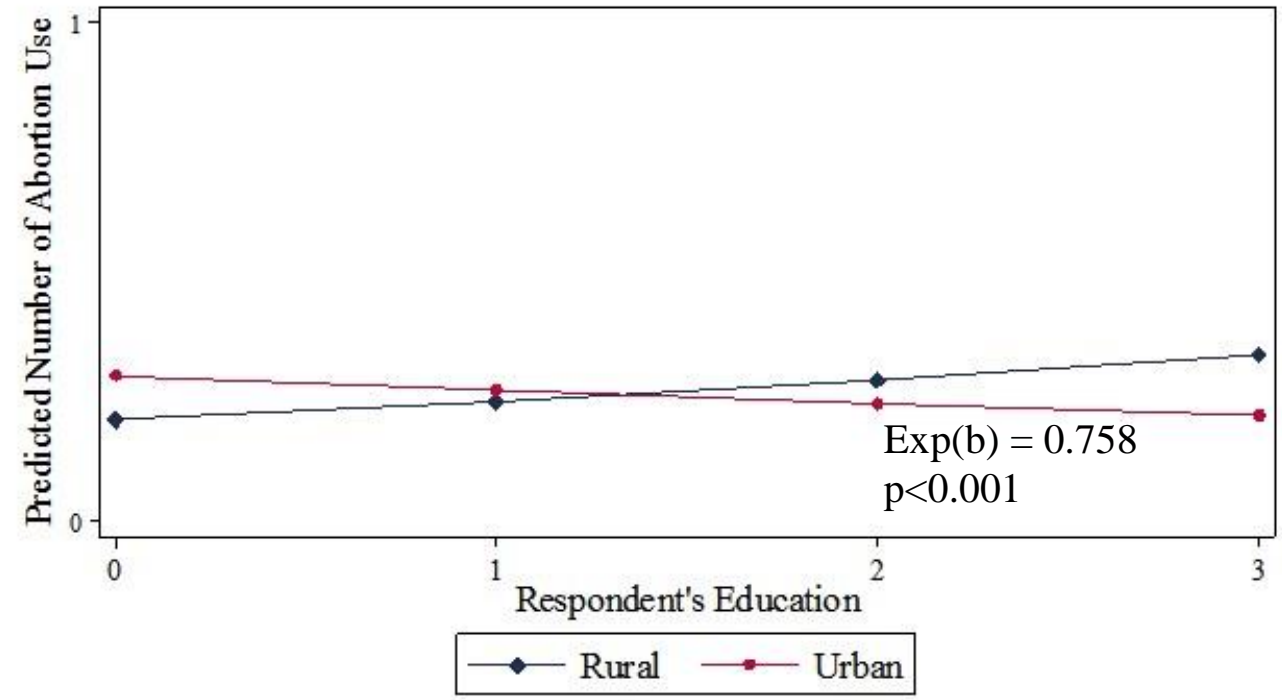

Figure 6.3. The Effect of the Interaction Term between Woman's Education and Urban on Abortion Frequency 
Table 6.1. Bivariate Logistic Regression Analyses between Abortion Use and all Other Variables, $\mathrm{OR}^{1}(\mathrm{~N}=13575)$

\begin{tabular}{|c|c|}
\hline Variables & Induced Abortion \\
\hline \multicolumn{2}{|l|}{ Secularization } \\
\hline Religiosity & $0.823^{* * *}$ \\
\hline \multicolumn{2}{|l|}{ Modernization } \\
\hline Woman's Education & $0.889^{* *}$ \\
\hline Egalitarian Ideology & 1.065 \\
\hline Urban & 1.097 \\
\hline \multicolumn{2}{|c|}{ The Proximate Determinants of Fertility } \\
\hline Age at First Marriage & $0.952^{* * *}$ \\
\hline Contraception Use & $4.488^{* * *}$ \\
\hline Contraception None & $0.760^{* * *}$ \\
\hline Contraception Traditional & 0.991 \\
\hline Contraception Modern & 1.096 \\
\hline Contraception Irreversible & $1.420^{* * *}$ \\
\hline The Number of Children & $1.239^{* * *}$ \\
\hline \multicolumn{2}{|c|}{ Women's Individual and Household } \\
\hline \multicolumn{2}{|l|}{ Characteristics } \\
\hline Woman's Employment & $1.332^{* * *}$ \\
\hline Woman's Age & $1.098^{* * *}$ \\
\hline Husband Education & $0.932^{*}$ \\
\hline Wealth & $1.140^{* * *}$ \\
\hline Turkish & $1.521^{* * *}$ \\
\hline \multicolumn{2}{|l|}{ Region } \\
\hline West & $1.416^{* * *}$ \\
\hline South & $0.803^{* *}$ \\
\hline Central & 0.982 \\
\hline North & 0.970 \\
\hline East & $0.611^{* * *}$ \\
\hline Survey Year (2013) & $0.544^{* * *}$ \\
\hline
\end{tabular}

Source: Demographic and Health Surveys, Turkey 2008 and 2013

${ }^{1}$ Odds Ratios $=\exp (\mathrm{b}) ; \mathrm{b}=$ Logistic coefficient

${ }^{*} p<0.05,{ }^{* *} p<0.01,{ }^{* * *} p<0.001$ (two-tailed tests). 
Table 6.2. Logistic Regression Results for the Effect of Secularization and Modernization on Abortion Use, $\mathrm{OR}^{1}(\mathrm{~N}=13575)$

\begin{tabular}{|c|c|c|}
\hline Variables & $\begin{array}{c}\text { Model } 1 \\
\operatorname{Exp}(\mathrm{b}) /(\mathrm{se})\end{array}$ & $\begin{array}{c}\text { Model } 2 \\
\operatorname{Exp}(\mathrm{b}) /(\mathrm{se})\end{array}$ \\
\hline \multicolumn{3}{|l|}{ Secularization } \\
\hline Religiosity & $\begin{array}{l}0.709^{* * *} \\
(0.024)\end{array}$ & $\begin{array}{l}0.710^{\text {*** }} \\
(0.024)\end{array}$ \\
\hline \multicolumn{3}{|l|}{ Modernization } \\
\hline Woman's Education & & $\begin{array}{c}0.960 \\
(0.051)\end{array}$ \\
\hline Egalitarian Ideology & & $\begin{array}{c}1.113^{*} \\
(0.047)\end{array}$ \\
\hline Urban & & $\begin{array}{c}1.102 \\
(0.089)\end{array}$ \\
\hline \multicolumn{3}{|c|}{ The Proximate Determinants of Fertility } \\
\hline Age at First Marriage $^{a}$ & $\begin{array}{l}0.926^{* * *} \\
(0.009)\end{array}$ & $\begin{array}{l}0.928^{* * *} \\
(0.009)\end{array}$ \\
\hline Contraception Traditional & $\begin{array}{c}1.156 \\
(0.102)\end{array}$ & $\begin{array}{c}1.147 \\
(0.101)\end{array}$ \\
\hline Contraception Modern & $\begin{array}{l}1.331^{* * *} \\
(0.111)\end{array}$ & $\begin{array}{l}1.321^{* * * *} \\
(0.111)\end{array}$ \\
\hline Contraception Irreversible & $\begin{array}{c}1.070 \\
(0.126)\end{array}$ & $\begin{array}{c}1.058 \\
(0.125)\end{array}$ \\
\hline The Number of Children & $\begin{array}{l}1.092^{* * *} \\
(0.029)\end{array}$ & $\begin{array}{l}1.097^{* * * *} \\
(0.029)\end{array}$ \\
\hline \multicolumn{3}{|c|}{ Women's and Household Characteristics } \\
\hline Woman's Employment & $\begin{array}{c}1.108 \\
(0.074)\end{array}$ & $\begin{array}{c}1.124 \\
(0.076)\end{array}$ \\
\hline Woman's Age & $\begin{array}{l}1.100^{* * *} \\
(0.005)\end{array}$ & $\begin{array}{l}1.100^{\text {**** }} \\
(0.005)\end{array}$ \\
\hline Husband Education & $\begin{array}{c}0.970 \\
(0.042)\end{array}$ & $\begin{array}{c}0.972 \\
(0.044)\end{array}$ \\
\hline Wealth & $\begin{array}{c}1.075^{*} \\
(0.030)\end{array}$ & $\begin{array}{c}1.052 \\
(0.034)\end{array}$ \\
\hline Turkish & $\begin{array}{c}1.214 \\
(0.127)\end{array}$ & $\begin{array}{c}1.229 \\
(0.130)\end{array}$ \\
\hline \multicolumn{3}{|l|}{ Region $^{c}$} \\
\hline South & $\begin{array}{c}0.738^{* *} \\
(0.069)\end{array}$ & $\begin{array}{l}0.735^{* * *} \\
(0.069)\end{array}$ \\
\hline Central & $\begin{array}{c}0.906 \\
(0.077)\end{array}$ & $\begin{array}{c}0.916 \\
(0.078)\end{array}$ \\
\hline North & $\begin{array}{c}0.929 \\
(0.087)\end{array}$ & $\begin{array}{c}0.949 \\
(0.089)\end{array}$ \\
\hline East & $\begin{array}{l}0.765^{* *} \\
(0.076)\end{array}$ & $\begin{array}{c}0.766^{* *} \\
(0.075)\end{array}$ \\
\hline Survey Year (2013) & $0.494^{* * *}$ & $0.484^{* * *}$ \\
\hline
\end{tabular}


(0.032)

Source: Demographic and Health Surveys, Turkey 2008 and 2013,

${ }^{1}$ Odds Ratios $=\exp (\mathrm{b}) ; \mathrm{b}=$ Logistic coefficient, Note: $\mathrm{se}=$ standard error; exp(se) is exponentiated.

${ }^{\mathrm{a}}$ Centered at age $10,{ }^{\mathrm{b}}$ Centered at age $15,{ }^{\mathrm{c}} \mathrm{West}$ is the reference

${ }^{*} p<0.05,{ }^{* *} p<0.01,{ }^{* * *} p<0.001$ (two-tailed tests). 
Table 6.3. Logistic Regression Results for the Interactions between Secularization and Modernization on Abortion Use, OR ${ }^{1}$ $(\mathrm{N}=13575)$

\begin{tabular}{|c|c|c|c|c|c|c|c|}
\hline Variables & $\begin{array}{c}\text { Model } 1 \\
\operatorname{Exp}(\mathrm{b}) /(\mathrm{se})\end{array}$ & $\begin{array}{c}\text { Model } 2 \\
\text { Exp(b)/(se) }\end{array}$ & $\begin{array}{c}\text { Model } 3 \\
\operatorname{Exp}(\mathrm{b}) /(\mathrm{se})\end{array}$ & $\begin{array}{c}\text { Model } 4 \\
\text { Exp(b)/(se) }\end{array}$ & $\begin{array}{c}\text { Model } 5 \\
\text { Exp(b)/(se) }\end{array}$ & $\begin{array}{c}\text { Model } 6 \\
\operatorname{Exp}(\mathrm{b}) /(\mathrm{se})\end{array}$ & $\begin{array}{c}\text { Model } 7 \\
\operatorname{Exp}(\mathrm{b}) /(\mathrm{se})\end{array}$ \\
\hline \multicolumn{8}{|l|}{ Secularization } \\
\hline Religiosity & $\begin{array}{l}0.708^{* * *} \\
(0.025)\end{array}$ & $\begin{array}{l}0.699^{* * * *} \\
(0.024)\end{array}$ & $\begin{array}{l}0.734^{* * * *} \\
(0.048)\end{array}$ & $\begin{array}{l}0.708^{* * * *} \\
(0.024)\end{array}$ & $\begin{array}{l}0.710^{* * * *} \\
(0.024)\end{array}$ & $\begin{array}{l}0.788^{* * * *} \\
(0.052)\end{array}$ & $\begin{array}{l}0.743^{* * * *} \\
(0.049)\end{array}$ \\
\hline \multicolumn{8}{|l|}{ Modernization } \\
\hline Woman's Education & $\begin{array}{c}0.971 \\
(0.053)\end{array}$ & $\begin{array}{c}0.969 \\
(0.052)\end{array}$ & $\begin{array}{c}0.959 \\
(0.051)\end{array}$ & $\begin{array}{c}1.268^{*} \\
(0.119)\end{array}$ & $\begin{array}{c}0.962 \\
(0.052)\end{array}$ & $\begin{array}{l}1.345^{* *} \\
(0.127)\end{array}$ & $\begin{array}{c}0.970 \\
(0.052)\end{array}$ \\
\hline Egalitarian Ideology & $\begin{array}{r}1.112^{*} \\
(0.047)\end{array}$ & $\begin{array}{c}1.108^{*} \\
(0.047)\end{array}$ & $\begin{array}{c}1.114^{*} \\
(0.047)\end{array}$ & $\begin{array}{r}1.109^{*} \\
(0.047)\end{array}$ & $\begin{array}{c}1.164^{*} \\
(0.076)\end{array}$ & $\begin{array}{r}1.110^{*} \\
(0.047)\end{array}$ & $\begin{array}{r}1.182^{*} \\
(0.081)\end{array}$ \\
\hline Urban & $\begin{array}{c}1.101 \\
(0.089)\end{array}$ & $\begin{array}{c}1.097 \\
(0.089)\end{array}$ & $\begin{array}{c}1.102 \\
(0.089)\end{array}$ & $\begin{array}{c}1.032 \\
(0.084)\end{array}$ & $\begin{array}{c}1.096 \\
(0.089)\end{array}$ & $\begin{array}{c}1.018 \\
(0.086)\end{array}$ & $\begin{array}{c}1.111 \\
(0.091)\end{array}$ \\
\hline \multicolumn{8}{|l|}{ Interactions } \\
\hline Religiosity * Woman's Education & $\begin{array}{c}1.020 \\
(0.036)\end{array}$ & & & & & $\begin{array}{l}1.015 \\
(0.081)\end{array}$ & \\
\hline Religiosity * Egalitarian Ideology & & $\begin{array}{c}1.079 \\
(0.047)\end{array}$ & & & & & $\begin{array}{c}0.959 \\
(0.075)\end{array}$ \\
\hline Religiosity * Urban & & & $\begin{array}{c}0.961 \\
(0.070)\end{array}$ & & & $\begin{array}{c}0.876 \\
(0.066)\end{array}$ & $\begin{array}{c}0.923 \\
(0.068)\end{array}$ \\
\hline Woman's Education * Urban & & & & $\begin{array}{l}0.728^{* * * *} \\
(0.069)\end{array}$ & & $\begin{array}{l}0.686^{* * * *} \\
(0.067)\end{array}$ & \\
\hline Egalitarian Ideology $*$ Urban & & & & & $\begin{array}{c}0.938 \\
(0.075)\end{array}$ & & $\begin{array}{c}0.922 \\
(0.077)\end{array}$ \\
\hline Religiosity * Woman's Education & & & & & & & \\
\hline * Urban & & & & & & $\begin{array}{l}1.005 \\
(0.089)\end{array}$ & \\
\hline $\begin{array}{l}\text { Religiosity * Egalitarian Ideology } \\
\text { * Urban }\end{array}$ & & & & & & & $\begin{array}{c}1.164 \\
(0.109)\end{array}$ \\
\hline
\end{tabular}


The Proximate Determinants of Fertility

Age at First Marriage ${ }^{a}$

Contraception Traditional ${ }^{b}$

Contraception Modern ${ }^{\mathrm{b}}$

Contraception Irreversible ${ }^{\mathrm{b}}$

The Number of Children

Women's and Household

\section{Characteristics}

Woman's Employment

Woman's Age

Husband Education

Wealth

Turkish

Region $^{\mathrm{d}}$

South

Central

North

$\begin{array}{ccccccc}0.928^{* * *} & 0.927^{* * *} & 0.927^{* * *} & 0.929^{* * *} & 0.928^{* * *} & 0.929^{* * *} & 0.928^{* * *} \\ (0.009) & (0.009) & (0.009) & (0.009) & (0.009) & (0.009) & (0.009) \\ 1.145 & 1.148 & 1.147 & 1.141 & 1.147 & 1.138 & 1.150 \\ (0.102) & (0.102) & (0.101) & (0.101) & (0.101) & (0.101) & \left.(0.102)^{* * * *}\right) \\ 1.320^{* * *} & 1.321^{* * *} & 1.321^{* * *} & 1.314^{* *} & 1.321^{* * *} & 1.310^{* *} & 1.322^{* * *} \\ (0.111) & (0.111) & (0.111) & (0.110) & (0.111) & (0.110) & (0.111) \\ 1.055 & 1.053 & 1.058 & 1.047 & 1.058 & 1.042 & 1.055 \\ (0.125) & (0.124) & (0.125) & (0.124) & (0.125) & (0.124) & (0.125) \\ 1.099^{* * *} & 1.100^{* * *} & 1.097^{* * *} & 1.103^{* * *} & 1.098^{* * *} & 1.105^{* * *} & 1.102^{* * *} \\ (0.030) & (0.030) & (0.029) & (0.030) & (0.030) & (0.030) & (0.030) \\ & & & & & \\ 1.126 & 1.127 & 1.120 & 1.139 & 1.126 & 1.133 & 1.127 \\ (0.077) & (0.077) & (0.076) & (0.078) & (0.077) & (0.077) & (0.077) \\ 1.100^{* * *} & 1.100^{* * *} & 1.100^{* * *} & 1.101^{* * *} & 1.100^{* * *} & 1.100^{* * *} & 1.100^{* * *} \\ (0.005) & (0.005) & (0.005) & (0.005) & (0.005) & (0.005) & (0.005) \\ 0.972 & 0.971 & 0.972 & 0.975 & 0.972 & 0.976 & 0.972 \\ (0.044) & (0.044) & (0.044) & (0.044) & (0.044) & (0.044) & (0.044) \\ 1.053 & 1.056 & 1.052 & 1.053 & 1.052 & 1.053 & 1.055 \\ (0.034) & (0.035) & (0.034) & (0.034) & (0.034) & (0.034) & (0.035) \\ 1.220 & 1.223 & 1.228 & 1.219 & 1.231^{*} & 1.206 & 1.222 \\ (0.130) & (0.129) & (0.130) & (0.128) & (0.130) & (0.128) & (0.129) \\ & & & & & \\ 0.735^{* * *} & 0.734^{* * *} & 0.736^{* * *} & 0.735^{* * *} & 0.735^{* * *} & 0.735^{* * *} & 0.732^{* * *} \\ (0.069) & (0.068) & (0.069) & (0.068) & (0.069) & (0.068) & (0.068) \\ 0.916 & 0.915 & 0.915 & 0.924 & 0.918 & 0.923 & 0.917 \\ (0.078) & (0.078) & (0.078) & (0.079) & (0.078) & (0.079) & (0.078) \\ 0.949 & 0.950 & 0.946 & 0.954 & 0.951 & 0.948 & 0.946\end{array}$


East

$\begin{array}{ccccccc}(0.089) & (0.089) & (0.088) & (0.089) & (0.089) & (0.088) & (0.088) \\ 0.769^{* *} & 0.768^{* *} & 0.764^{* *} & 0.785^{*} & 0.768^{* *} & 0.786^{* *} & 0.768^{* *} \\ (0.076) & (0.076) & (0.075) & (0.077) & (0.076) & (0.077) & (0.076) \\ 0.484^{* * *} & 0.482^{* * *} & 0.485^{* * *} & 0.483^{* * *} & 0.485^{* * *} & 0.484^{* * *} & 0.482^{* * *} \\ (0.031) & (0.031) & (0.031) & (0.031) & (0.031) & (0.031) & (0.031)\end{array}$

Survey Year(2013)

$(0.031)$

$(0.031)$

Source: Demographic and Health Surveys, Turkey 2008 and 2013, ${ }^{1}$ Odds Ratio (OR) $=\exp (\mathrm{b}) ; \mathrm{b}=$ Logistic coefficient

Note: $\mathrm{se}=$ standard errors; se are $\exp (\mathrm{se})$

${ }^{\mathrm{a}}$ Centered at age $10,{ }^{\mathrm{b}} \mathrm{U}$ sing no method is the reference, ${ }^{\mathrm{c}}$ Centered at age $15,{ }^{\mathrm{d}} \mathrm{West}$ is the reference

'Joint effects of religiosity, women's education, and religiosity $\mathrm{x}$ women's education are statistically significant (Wald $\left.c h i^{2}(3)=105.0, \mathrm{p}=.0000\right)$.

$\left.{ }^{\mathrm{f} J o i n t ~ e f f e c t s ~ o f ~ r e l i g i o s i t y, ~ e g a l i t a r i a n ~ i d e o l o g y, ~ a n d ~ r e l i g i o s i t y ~ x ~ e g a l i t a r i a n ~ i d e o l o g y ~ a r e ~ s t a t i s t i c a l l y ~ s i g n i f i c a n t ~(W a l d ~} c h i^{2}(3)=115.1, \mathrm{p}=.0000\right)$.

gJoint effects of religiosity, urban, and religiosity $\mathrm{x}$ urban are statistically significant (Wald $\operatorname{chi}^{2}(3)=12.4, \mathrm{p}=.0062$ ).

${ }^{\mathrm{h} J o i n t}$ effects of women's education, urban, and women's education $\mathrm{x}$ urban are statistically significant (Wald $\mathrm{chi}^{2}(3)=12.4, \mathrm{p}=.0062$ ).

iJoint effects of egalitarian ideology, urban, and egalitarian ideology $\mathrm{x}$ urban are statistically significant (Wald $c h i^{2}(3)=9.3, \mathrm{p}=.0252$ ).

jJoint effects of religiosity, women's education, urban, religiosity $\mathrm{x}$ women's education, religiosity $\mathrm{x}$ urban, women's education $\mathrm{x}$ urban, and religiosity $\mathrm{x}$ women's education $\mathrm{x}$ urban are statistically significant (Wald $\left.\mathrm{chi}^{2}(8)=116.8, \mathrm{p}=.0000\right)$.

${ }^{\mathrm{k} J o i n t}$ effects of religiosity, egalitarian ideology, urban, religiosity $\mathrm{x}$ egalitarian ideology, religiosity $\mathrm{x}$ urban, egalitarian ideology $\mathrm{x}$ urban, and religiosity $\mathrm{x}$ egalitarian ideology x urban are statistically significant (Wald $c h i^{2}(8)=120.0, \mathrm{p}=.0000$ ).

${ }^{*} p<0.05,{ }^{* *} p<0.01,{ }^{* * *} p<0.001$ (two-tailed tests). 
Table 6.4. Negative Binominal Regression Results for the Effect of Secularization and Modernization on Abortion Frequency, $\operatorname{IRR}^{1}(\mathrm{~N}=13575)$

\begin{tabular}{|c|c|c|}
\hline Variables & $\begin{array}{c}\text { Model } 1 \\
\operatorname{Exp}(\mathrm{b}) /(\mathrm{se})\end{array}$ & $\begin{array}{c}\text { Model } 2 \\
\operatorname{Exp}(\mathrm{b}) /(\mathrm{se})\end{array}$ \\
\hline \multicolumn{3}{|l|}{ Secularization } \\
\hline Religiosity & $\begin{array}{l}0.728^{* * * *} \\
(0.019)\end{array}$ & $\begin{array}{l}0.726^{* * *} \\
(0.020)\end{array}$ \\
\hline \multicolumn{3}{|l|}{ Modernization } \\
\hline Woman's Education & & $\begin{array}{c}0.936 \\
(0.042)\end{array}$ \\
\hline Egalitarian Ideology & & $\begin{array}{c}1.074 \\
(0.039)\end{array}$ \\
\hline Urban & & $\begin{array}{c}1.112 \\
(0.074)\end{array}$ \\
\hline \multicolumn{3}{|c|}{ The Proximate Determinants of Fertility } \\
\hline Age at First Marriage $^{\mathrm{a}}$ & $\begin{array}{l}0.937^{* * * *} \\
(0.008)\end{array}$ & $\begin{array}{l}0.939^{* * *} \\
(0.008)\end{array}$ \\
\hline Contraception Traditional $^{\mathrm{b}}$ & $\begin{array}{c}1.070 \\
(0.079)\end{array}$ & $\begin{array}{c}1.066 \\
(0.078)\end{array}$ \\
\hline Contraception Modern ${ }^{\mathrm{b}}$ & $\begin{array}{c}1.180^{*} \\
(0.082)\end{array}$ & $\begin{array}{c}1.181^{*} \\
(0.083)\end{array}$ \\
\hline Contraception Irreversible ${ }^{b}$ & $\begin{array}{c}1.005 \\
(0.097)\end{array}$ & $\begin{array}{c}0.998 \\
(0.096)\end{array}$ \\
\hline The Number of Children & $\begin{array}{l}1.108^{* * *} \\
(0.026)\end{array}$ & $\begin{array}{l}1.109^{* * *} \\
(0.026)\end{array}$ \\
\hline \multicolumn{3}{|l|}{ Women's and Household } \\
\hline Woman's Employment & $\begin{array}{c}1.077 \\
(0.061)\end{array}$ & $\begin{array}{c}1.102 \\
(0.063)\end{array}$ \\
\hline Woman's Age ${ }^{c}$ & $\begin{array}{l}1.092^{* * *} \\
(0.004)\end{array}$ & $\begin{array}{l}1.092^{* * *} \\
(0.004)\end{array}$ \\
\hline Husband Education & $\begin{array}{c}0.968 \\
(0.035)\end{array}$ & $\begin{array}{c}0.979 \\
(0.037)\end{array}$ \\
\hline Wealth & $\begin{array}{c}1.059^{*} \\
(0.026)\end{array}$ & $\begin{array}{c}1.044 \\
(0.029)\end{array}$ \\
\hline Turkish & $\begin{array}{c}1.210^{*} \\
(0.111)\end{array}$ & $\begin{array}{c}1.229^{*} \\
(0.113)\end{array}$ \\
\hline \multicolumn{3}{|l|}{ Region $^{\mathrm{d}}$} \\
\hline South & $\begin{array}{c}0.809^{*} \\
(0.067)\end{array}$ & $\begin{array}{c}0.810^{*} \\
(0.067)\end{array}$ \\
\hline Central & $\begin{array}{c}0.989 \\
(0.069)\end{array}$ & $\begin{array}{c}1.007 \\
(0.070)\end{array}$ \\
\hline North & $\begin{array}{c}1.004 \\
(0.083)\end{array}$ & $\begin{array}{c}1.028 \\
(0.084)\end{array}$ \\
\hline East & $\begin{array}{c}0.816^{*} \\
(0.070)\end{array}$ & $\begin{array}{c}0.821^{*} \\
(0.070)\end{array}$ \\
\hline
\end{tabular}


Survey Year (2013)

$0.556^{* * *}$

$0.549^{* * *}$

$(0.030)$

$(0.030)$

Source: Demographic and Health Surveys, Turkey 2008 and 2013

${ }^{1}$ Incidence Rate Ratio (IRR) = exp(b); b = Negative binomial coefficient

Note: se $=$ standard error; $\exp (\mathrm{se})$ is exponentiated.

${ }^{\mathrm{a}}$ Centered at age $10,{ }^{\mathrm{b}} \mathrm{Using}$ no method is the reference ${ }^{\mathrm{c}}$ Centered at age $15,{ }^{\mathrm{d}} \mathrm{West}$ is the reference ${ }^{*} p<0.05,{ }^{* *} p<0.01,{ }^{* * * *} p<0.001$ (two-tailed tests). 
Table 6.5. Negative Binominal Regression Results for the Interactions between Secularization and Modernization on Abortion Frequency, $\operatorname{IRR}^{1}(\mathrm{~N}=13575)$

\begin{tabular}{|c|c|c|c|c|c|c|c|}
\hline & $\begin{array}{c}\text { Model } 1 \\
\operatorname{Exp}(\mathrm{b}) /(\mathrm{se})\end{array}$ & $\begin{array}{c}\text { Model } 2 \\
\operatorname{Exp}(\mathrm{b}) /(\mathrm{se})\end{array}$ & $\begin{array}{c}\text { Model 3 } \\
\text { Exp(b)/(se) }\end{array}$ & $\begin{array}{c}\text { Model } 4 \\
\operatorname{Exp}(\mathrm{b}) /(\mathrm{se})\end{array}$ & $\begin{array}{c}\text { Model } 5 \\
\operatorname{Exp}(\mathrm{b}) /(\mathrm{se}) \\
\end{array}$ & $\begin{array}{c}\text { Model } 6 \\
\operatorname{Exp}(\mathrm{b}) /(\mathrm{se})\end{array}$ & $\begin{array}{c}\text { Model } 7 \\
\text { Exp(b)/(se) }\end{array}$ \\
\hline \multicolumn{8}{|l|}{ Secularization } \\
\hline Religiosity & $\begin{array}{l}0.723^{* * * *} \\
(0.020)\end{array}$ & $\begin{array}{l}0.716^{* * *} \\
(0.020)\end{array}$ & $\begin{array}{l}0.767^{* * *} \\
(0.043)\end{array}$ & $\begin{array}{l}0.724^{* * *} \\
(0.020)\end{array}$ & $\begin{array}{l}0.725^{* * *} \\
(0.020)\end{array}$ & $\begin{array}{l}0.816^{* * *} \\
(0.046)\end{array}$ & $\begin{array}{l}0.775^{* * *} \\
(0.043)\end{array}$ \\
\hline \multicolumn{8}{|l|}{ Modernization } \\
\hline Woman's Education & $\begin{array}{c}0.955 \\
(0.044)\end{array}$ & $\begin{array}{c}0.946 \\
(0.042)\end{array}$ & $\begin{array}{c}0.935 \\
(0.042)\end{array}$ & $\begin{array}{r}1.192^{*} \\
(0.091)\end{array}$ & $\begin{array}{c}0.938 \\
(0.042)\end{array}$ & $\begin{array}{l}1.282^{* *} \\
(0.105)\end{array}$ & $\begin{array}{c}0.947 \\
(0.043)\end{array}$ \\
\hline Egalitarian Ideology & $\begin{array}{c}1.073 \\
(0.039)\end{array}$ & $\begin{array}{c}1.072 \\
(0.039)\end{array}$ & $\begin{array}{r}1.075^{*} \\
(0.039)\end{array}$ & $\begin{array}{c}1.071 \\
(0.039)\end{array}$ & $\begin{array}{r}1.126^{*} \\
(0.063)\end{array}$ & $\begin{array}{c}1.072 \\
(0.039)\end{array}$ & $\begin{array}{r}1.140^{*} \\
(0.066)\end{array}$ \\
\hline Urban & $\begin{array}{c}1.110 \\
(0.074)\end{array}$ & $\begin{array}{c}1.106 \\
(0.074)\end{array}$ & $\begin{array}{c}1.112 \\
(0.075)\end{array}$ & $\begin{array}{l}1.046 \\
(0.070)\end{array}$ & $\begin{array}{c}1.105 \\
(0.074)\end{array}$ & $\begin{array}{c}1.026 \\
(0.073)\end{array}$ & $\begin{array}{c}1.111 \\
(0.075)\end{array}$ \\
\hline \multicolumn{8}{|l|}{ Interactions } \\
\hline Religiosity * Woman's Education & $\begin{array}{c}1.032 \\
(0.031)\end{array}$ & & & & & $\begin{array}{l}1.038 \\
(0.066)\end{array}$ & \\
\hline Religiosity * Egalitarian Ideology & & $\begin{array}{c}1.075^{*} \\
(0.038)\end{array}$ & & & & & $\begin{array}{c}0.996 \\
(0.064)\end{array}$ \\
\hline Religiosity * Urban & & & $\begin{array}{c}0.936 \\
(0.057)\end{array}$ & & & $\begin{array}{l}0.863^{*} \\
(0.055)\end{array}$ & $\begin{array}{c}0.906 \\
(0.056)\end{array}$ \\
\hline Woman's Education * Urban & & & & $\begin{array}{l}0.758^{* * *} \\
(0.058)\end{array}$ & & $\begin{array}{l}0.711^{* * * *} \\
(0.060)\end{array}$ & \\
\hline Egalitarian Ideology * Urban & & & & & $\begin{array}{c}0.935 \\
(0.064)\end{array}$ & & $\begin{array}{c}0.926 \\
(0.065)\end{array}$ \\
\hline Religiosity * Woman's Education & & & & & & & \\
\hline * Urban & & & & & & $\begin{array}{c}0.993 \\
(0.070)\end{array}$ & \\
\hline $\begin{array}{l}\text { Religiosity * Egalitarian Ideology } \\
\text { * Urban }\end{array}$ & & & & & & & $\begin{array}{c}1.100 \\
(0.083)\end{array}$ \\
\hline
\end{tabular}


The Proximate Determinants of Fertility

Age at First Marriage ${ }^{a}$

Contraception Traditional ${ }^{b}$

Contraception Modern ${ }^{\mathrm{b}}$

Contraception Irreversible ${ }^{\mathrm{b}}$

The Number of Children

Women's and Household

\section{Characteristics}

Woman's Employment

Woman's Age

Husband Education

Wealth

Turkish

Region $^{\mathrm{d}}$

South

Central

North

$\begin{array}{ccccccc}0.939^{* * *} & 0.939^{* * *} & 0.938^{* * *} & 0.939^{* * *} & 0.939^{* * *} & 0.940^{* * *} & 0.939^{* * *} \\ (0.008) & (0.008) & (0.008) & (0.008) & (0.008) & (0.008) & (0.008) \\ 1.062 & 1.065 & 1.065 & 1.062 & 1.066 & 1.056 & 1.067 \\ (0.078) & (0.078) & (0.078) & (0.078) & (0.078) & (0.078) & (0.078) \\ 1.180^{*} & 1.180^{*} & 1.181^{*} & 1.176^{*} & 1.181^{*} & 1.173^{*} & 1.180^{*} \\ (0.082) & (0.082) & (0.082) & (0.082) & (0.082) & (0.082) & (0.082) \\ 0.994 & 0.994 & 0.997 & 0.992 & 0.998 & 0.985 & 0.997 \\ (0.096) & (0.096) & (0.096) & (0.096) & (0.097) & (0.096) & (0.097) \\ 1.111^{* * *} & 1.112^{* * *} & 1.109^{* * *} & 1.113^{* * *} & 1.110^{* * *} & 1.116^{* * *} & 1.113^{* * *} \\ (0.026) & (0.026) & (0.026) & (0.026) & (0.026) & (0.026) & (0.026) \\ & & & & & \\ 1.106 & 1.104 & 1.098 & 1.113 & 1.104 & 1.108 & 1.101 \\ (0.063) & (0.063) & (0.062) & (0.063) & (0.063) & (0.063) & (0.062) \\ 1.093^{* * *} & 1.092^{* * *} & 1.092^{* * *} & 1.093^{* * *} & 1.092^{* * *} & 1.093^{* * *} & 1.092^{* * *} \\ (0.004) & (0.004) & (0.004) & (0.004) & (0.004) & (0.004) & (0.004) \\ 0.980 & 0.979 & 0.979 & 0.983 & 0.980 & 0.985 & 0.980 \\ (0.037) & (0.037) & (0.037) & (0.037) & (0.037) & (0.038) & (0.037) \\ 1.045 & 1.046 & 1.044 & 1.044 & 1.044 & 1.045 & 1.046 \\ (0.028) & (0.029) & (0.029) & (0.028) & (0.029) & (0.028) & (0.029) \\ 1.216^{*} & 1.225^{*} & 1.228^{*} & 1.221^{*} & 1.230^{*} & 1.203^{*} & 1.224^{*} \\ (0.113) & (0.113) & (0.113) & (0.112) & (0.113) & (0.111) & (0.113) \\ & & & & & \\ 0.811^{*} & 0.808^{* *} & 0.811^{*} & 0.808^{* *} & 0.811^{*} & 0.810^{*} & 0.809^{*} \\ (0.067) & (0.067) & (0.067) & (0.066) & (0.067) & (0.067) & (0.067) \\ 1.007 & 1.005 & 1.005 & 1.014 & 1.010 & 1.011 & 1.007 \\ (0.070) & (0.070) & (0.070) & (0.071) & (0.070) & (0.071) & (0.070) \\ 1.030 & 1.028 & 1.024 & 1.034 & 1.031 & 1.027 & 1.025\end{array}$


East

$\begin{array}{ccccccc}(0.084) & (0.084) & (0.083) & (0.084) & (0.084) & (0.083) & (0.083) \\ 0.827^{*} & 0.823^{*} & 0.819^{*} & 0.840^{*} & 0.824^{*} & 0.845^{*} & 0.823^{*} \\ (0.070) & (0.070) & (0.070) & (0.071) & (0.070) & (0.071) & (0.070) \\ 0.547^{* * *} & 0.546^{* * *} & 0.550^{* * *} & 0.547^{* * *} & 0.549^{* * *} & 0.548^{* * *} & 0.547^{* * *} \\ (0.030) & (0.030) & (0.030) & (0.030) & (0.030) & (0.030) & (0.030)\end{array}$

Survey Year (2013)

$(0.030)$

$(0.030)$

$(0.030)$ Source: Demographic and Health Surveys, Turkey 2008 and 2013, ${ }^{1}$ Incidence Rate Ratio $($ IRR $)=\exp (\mathrm{b})$; b $=$ Negative Binomial coefficient, Note: se $=$
standard errors; se are $\exp (\mathrm{se})$

${ }^{\mathrm{a}}$ Centered at age $10,{ }^{\mathrm{b}} \mathrm{Using}$ no method is the reference, ${ }^{\mathrm{c}}$ Centered at age $15,{ }^{\mathrm{d}} \mathrm{West}$ is the reference

'Joint effects of religiosity, women's education, and religiosity x women's education are statistically significant (Wald $c h i^{2}(3)=144.4, \mathrm{p}=.0000$ ).

${ }_{\mathrm{f} J o i n t}$ effects of religiosity, egalitarian ideology, and religiosity $\mathrm{x}$ egalitarian ideology are statistically significant (Wald $\left.c h i^{2}(3)=151.5, \mathrm{p}=.0000\right)$.

gJoint effects of religiosity, urban, and religiosity $\mathrm{x}$ urban are statistically significant (Wald $c h i^{2}(3)=142.5, \mathrm{p}=.0000$ ).

hJoint effects of women's education, urban, and women's education $\mathrm{x}$ urban are statistically significant (Wald $\left.\operatorname{chi}^{2}(3)=15.8, \mathrm{p}=.0012\right)$.

${ }^{\mathrm{i} J o i n t}$ effects of egalitarian ideology, urban, and egalitarian ideology $\mathrm{x}$ urban are statistically significant (Wald $\left.c h i^{2}(3)=8.0, \mathrm{p}=.0471\right)$.

jJoint effects of religiosity, women's education, urban, religiosity $\mathrm{x}$ women's education, religiosity $\mathrm{x}$ urban, women's education $\mathrm{x}$ urban, and religiosity $\mathrm{x}$ women's education $\mathrm{x}$ urban are statistically significant $\left({\mathrm{Wald} \mathrm{chi}^{2}}^{2}(8)=158.4, \mathrm{p}=.0000\right)$.

${ }^{\mathrm{k} J o i n t}$ effects of religiosity, egalitarian ideology, urban, religiosity $\mathrm{x}$ egalitarian ideology, religiosity $\mathrm{x}$ urban, egalitarian ideology $\mathrm{x}$ urban, and religiosity $\mathrm{x}$ egalitarian ideology $\mathrm{x}$ urban are statistically significant (Wald $c h i^{2}(8)=157.7, \mathrm{p}=.0000$ ).

${ }^{*} p<0.05,{ }^{* *} p<0.01,{ }^{* * *} p<0.001$ (two-tailed tests). 
Table 7.1. Summary of Findings (Direction of Statistically Significant Effects) ), b $^{\text {b }}$

\begin{tabular}{|c|c|c|c|c|c|c|c|}
\hline \multirow[b]{2}{*}{ Variables } & \multirow[b]{2}{*}{$\begin{array}{l}\text { Number of } \\
\text { Children }\end{array}$} & \multirow[b]{2}{*}{$\begin{array}{l}\text { Any } \\
\text { Contraception } \\
\text { Use }\end{array}$} & \multicolumn{3}{|c|}{ Contraception Methods $^{\mathrm{c}}$} & \multicolumn{2}{|c|}{ Induced Abortion } \\
\hline & & & $\begin{array}{l}\text { Traditional } \\
\text { Method }\end{array}$ & $\begin{array}{l}\text { Modern } \\
\text { Reversible } \\
\text { Methods }\end{array}$ & $\begin{array}{l}\text { Permanent } \\
\text { Methods }\end{array}$ & $\begin{array}{l}\text { Any } \\
\text { Abortion } \\
\text { Use }\end{array}$ & $\begin{array}{l}\text { Abortion } \\
\text { Frequency }\end{array}$ \\
\hline \multicolumn{8}{|l|}{ Secularization } \\
\hline Religiosity & + & - & n.s. & - & - & - & - \\
\hline \multicolumn{8}{|l|}{ Modernization } \\
\hline Woman Education & - & + & n.s. & + & n.s. & n.s. & n.s. \\
\hline Egalitarian Ideology & - & + & + & + & + & + & n.s. \\
\hline Urban & + & n.s. & n.s. & + & + & n.s. & n.s. \\
\hline \multicolumn{8}{|l|}{ Interactions } \\
\hline Religiosity * Woman Education & n.s. & + & + & + & + & n.s. & n.s. \\
\hline Religiosity * Egalitarian Ideology & n.s. & n.s. & n.s. & n.s. & + & n.s. & + \\
\hline Religiosity * Urban & + & n.s. & n.s. & n.s. & n.s. & n.s. & n.s. \\
\hline
\end{tabular}

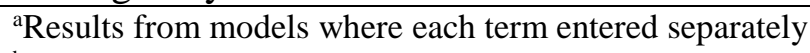

${ }^{b}$ n.s. $=$ not statistically significant

${ }^{\mathrm{c} C o m p a r e d ~ t o ~ n o ~ m e t h o d ~}$ 
APPENDIX A: Supplemental Analyses Using the European Values Surveys

Table A.1. Poisson Regression Analysis for Number of Children, IRR ${ }^{1}$

\begin{tabular}{|c|c|c|c|c|}
\hline Variables & $\begin{array}{c}\text { Model } 1 \\
\text { Exp(b)/(se) }\end{array}$ & $\begin{array}{c}\text { Model } 2 \\
\text { Exp(b)/(se) }\end{array}$ & $\begin{array}{c}\text { Model } 3 \\
\operatorname{Exp}(\mathrm{b}) /(\mathrm{se})\end{array}$ & $\begin{array}{c}\text { Model } 4 \\
\operatorname{Exp}(\mathrm{b}) /(\mathrm{se})\end{array}$ \\
\hline Religiosity & $\begin{array}{l}1.085^{* * *} \\
(0.009)\end{array}$ & & $\begin{array}{l}1.121^{* * * *} \\
(0.027)\end{array}$ & $\begin{array}{l}1.121^{* * * *} \\
(0.027)\end{array}$ \\
\hline Woman's Education & & $\begin{array}{c}0.823^{* * * *} \\
(0.009)\end{array}$ & $\begin{array}{c}0.856^{* * *} \\
(0.016)\end{array}$ & $\begin{array}{c}0.856^{* * *} \\
(0.016)\end{array}$ \\
\hline Religiosity * Woman Education & & & $\begin{array}{l}0.977^{*} \\
(0.011)\end{array}$ & $\begin{array}{c}0.977^{*} \\
(0.011)\end{array}$ \\
\hline Woman's Age & $\begin{array}{l}1.062^{* * * *} \\
(0.001)\end{array}$ & $\begin{array}{l}1.061^{* * * *} \\
(0.001)\end{array}$ & $\begin{array}{l}1.061^{* * * *} \\
(0.001)\end{array}$ & $\begin{array}{l}1.060^{* * * *} \\
(0.001)\end{array}$ \\
\hline Income Level & $\begin{array}{c}1.013 \\
(0.009)\end{array}$ & $\begin{array}{l}1.046^{* * *} \\
(0.010)\end{array}$ & $\begin{array}{c}1.044^{* * * *} \\
(0.010)\end{array}$ & $\begin{array}{c}1.044^{* * * *} \\
(0.010)\end{array}$ \\
\hline Woman's Employment & $\begin{array}{l}0.776^{* * *} \\
(0.012)\end{array}$ & $\begin{array}{c}0.816^{* * * *} \\
(0.013)\end{array}$ & $\begin{array}{l}0.836^{* * *} \\
(0.013)\end{array}$ & $\begin{array}{l}0.835^{* * *} \\
(0.013)\end{array}$ \\
\hline Observations & 15049 & 15049 & 15049 & 14972 \\
\hline
\end{tabular}

Source: Demographic and Health Surveys, Turkey 2008 and 2013

${ }^{1}$ Incidence Rate Ratio (IRR) $=\exp (b) ; b=$ Poisson coefficient

Note: $\mathrm{se}=$ standard errors; se are $\exp (\mathrm{se})$ 


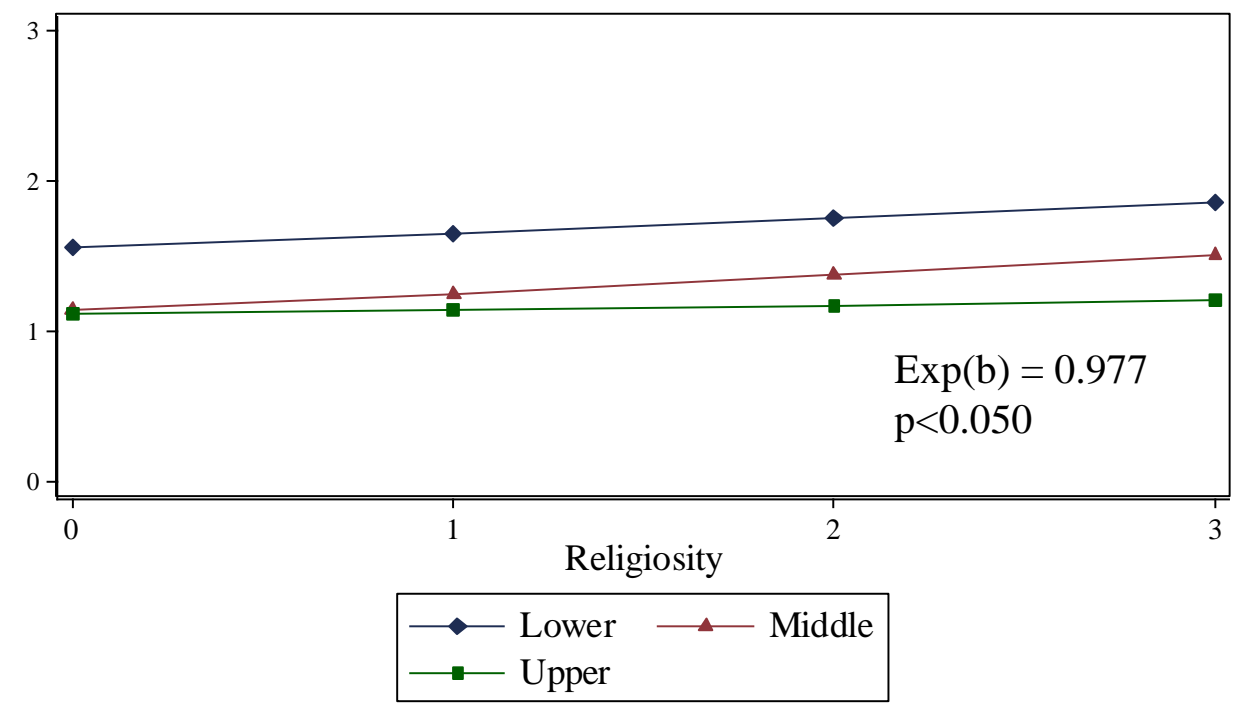

Figure A.1. The Effect of The Interaction Term between woman's education and Religiosity on the Number of Children Born to An Ever Married Woman. 
APPENDIX B: Correlation Matrix for All Study Variables

Table B.1. Correlation Matrix for All Study Variables

\begin{tabular}{|c|c|c|c|c|c|c|c|c|c|}
\hline Variables & Religiosity & $\begin{array}{l}\text { Woman } \\
\text { Education }\end{array}$ & $\begin{array}{c}\text { Egalitarian } \\
\text { Ideology }\end{array}$ & Urban & $\begin{array}{c}\text { Age at First } \\
\text { Sex }\end{array}$ & $\begin{array}{l}\text { Abortion } \\
\text { Frequency }\end{array}$ & $\begin{array}{c}\text { Any } \\
\text { Contraceptive } \\
\text { Use } \\
\end{array}$ & $\begin{array}{c}\text { The } \\
\text { Number of } \\
\text { Children }\end{array}$ & $\begin{array}{c}\text { Woman } \\
\text { Employment }\end{array}$ \\
\hline Religiosity & 1.000 & & & & & & & & \\
\hline Woman Education & $-0.356^{* * *}$ & 1.000 & & & & & & & \\
\hline Egalitarian Ideology & $-0.167^{* * *}$ & $0.307^{* * *}$ & 1.000 & & & & & & \\
\hline Urban & $-0.090^{* * *}$ & $0.235^{* * *}$ & $0.183^{* * *}$ & 1.000 & & & & & \\
\hline Age at First Sex & $-0.205^{* * *}$ & $0.344^{* * *}$ & $0.135^{* * *}$ & $0.116^{* * *}$ & 1.000 & & & & \\
\hline Abortion Frequency & $-0.055^{* * *}$ & $-0.044^{* * *}$ & 0.010 & $0.024^{* *}$ & $-0.081^{* * *}$ & 1.000 & & & \\
\hline Any Contraceptive Use & $-0.042^{* * *}$ & $0.098^{* * *}$ & $0.106^{* * *}$ & $0.086^{* * *}$ & $-0.059^{* * *}$ & $0.089^{* * *}$ & 1.000 & & \\
\hline The Number of Children & $0.288^{* * *}$ & $-0.450^{* * *}$ & $-0.217^{* * *}$ & $-0.167^{* * *}$ & $-0.368^{* * *}$ & $0.142^{* * *}$ & $0.174^{* * *}$ & 1.000 & \\
\hline Woman Employment & $-0.121^{* * *}$ & $0.140^{* * *}$ & $0.051^{* * *}$ & $-0.147^{* * *}$ & $0.075^{* * *}$ & $0.035^{* * *}$ & $0.061^{* * *}$ & $-0.027^{* *}$ & 1.000 \\
\hline Woman Age & $0.098^{* * *}$ & $-0.155^{* * *}$ & $-0.021^{*}$ & -0.003 & $0.115^{* * *}$ & $0.262^{* * *}$ & $0.121^{* * *}$ & $0.458^{* * *}$ & $0.134^{* * *}$ \\
\hline Husband Education & $-0.193^{* * *}$ & $0.534^{* * *}$ & $0.252^{* * *}$ & $0.233^{* * *}$ & $0.220^{* * *}$ & $-0.018^{*}$ & $0.094^{* * *}$ & $-0.348^{* * *}$ & $0.035^{* * *}$ \\
\hline Wealth & $-0.246^{* * *}$ & $0.540^{* * *}$ & $0.308^{* * *}$ & $0.487^{* * *}$ & $0.227^{* * *}$ & $0.065^{* * *}$ & $0.149^{* * *}$ & $-0.308^{* * *}$ & $0.033^{* * *}$ \\
\hline Turkish & $-0.171^{* * *}$ & $0.380^{* * *}$ & $0.177^{* * *}$ & $0.166^{* * *}$ & $0.151^{* * *}$ & $0.048^{* * *}$ & $0.168^{* * *}$ & $-0.318^{* * *}$ & $0.142^{* * *}$ \\
\hline West & $-0.206^{* * *}$ & $0.143^{* * *}$ & $0.108^{* * *}$ & $0.133^{* * *}$ & $0.099^{* * *}$ & $0.044^{* * *}$ & $0.073^{* * *}$ & $-0.178^{* * *}$ & $0.067^{* * *}$ \\
\hline South & $-0.068^{* * *}$ & -0.009 & 0.013 & $-0.038^{* * *}$ & $0.020^{*}$ & $-0.017^{*}$ & -0.011 & 0.002 & $-0.028^{* * *}$ \\
\hline Central & $0.037^{* * *}$ & $0.078^{* * *}$ & -0.000 & 0.005 & $-0.052^{* * *}$ & 0.013 & $0.051^{* * *}$ & $-0.054^{* * *}$ & $-0.035^{* * *}$ \\
\hline North & $0.022^{*}$ & $0.092^{* * *}$ & $0.043^{* * *}$ & 0.006 & $0.086^{* * *}$ & 0.005 & $0.044^{* * *}$ & $-0.068^{* * *}$ & $0.174^{* * *}$ \\
\hline East & $0.203^{* * *}$ & $-0.270^{* * *}$ & $-0.147^{* * *}$ & $-0.107^{* * *}$ & $-0.131^{* * *}$ & $-0.045^{* * *}$ & $-0.141^{* * *}$ & $0.270^{* * * *}$ & $-0.143^{* * *}$ \\
\hline Survey Year (2013) & -0.002 & $0.044^{* * *}$ & $0.082^{* * *}$ & -0.005 & $0.046^{* * *}$ & $-0.081^{* * *}$ & 0.017 & $-0.039^{* * *}$ & $0.020^{*}$ \\
\hline
\end{tabular}

Source: Demographic and Health Surveys, Turkey 2008 and 2013

${ }^{*} p<0.05,{ }^{* *} p<0.01,{ }^{* * *} p<0.001$ 
Table B.1. Continued

\begin{tabular}{|c|c|c|c|c|c|c|c|c|c|c|}
\hline Variables & $\begin{array}{c}\text { Woman } \\
\text { Age }\end{array}$ & $\begin{array}{l}\text { Husband } \\
\text { Education }\end{array}$ & Wealth & Turkish & West & South & Central & North & East & $\begin{array}{c}\text { Survey } \\
\text { Year } \\
(2013)\end{array}$ \\
\hline \multicolumn{11}{|l|}{ Religiosity } \\
\hline \multicolumn{11}{|l|}{ Woman Education } \\
\hline \multicolumn{11}{|l|}{ Egalitarian Ideology } \\
\hline \multicolumn{11}{|l|}{ Urban } \\
\hline \multicolumn{11}{|l|}{ Age at First Sex } \\
\hline \multicolumn{11}{|l|}{ Abortion Frequency } \\
\hline \multicolumn{11}{|l|}{ Any contraceptive use } \\
\hline \multicolumn{11}{|c|}{ The Number of Children } \\
\hline \multicolumn{11}{|c|}{ Woman Employment } \\
\hline Woman Age & 1.000 & & & & & & & & & \\
\hline Husband Education & $-0.129^{* * *}$ & 1.000 & & & & & & & & \\
\hline Wealth & $0.107^{* * *}$ & $0.512^{* * * *}$ & 1.000 & & & & & & & \\
\hline Turkish & $0.095^{* * *}$ & $0.280^{* * *}$ & $0.385^{* * *}$ & 1.000 & & & & & & \\
\hline West & $0.065^{* * * *}$ & $0.058^{* * *}$ & $0.274^{* * *}$ & $0.184^{* * *}$ & 1.000 & & & & & \\
\hline South & $0.026^{* *}$ & $-0.052^{* * *}$ & $-0.090^{* * * *}$ & 0.017 & $-0.231^{* * *}$ & 1.000 & & & & \\
\hline Central & -0.010 & $0.070^{* * *}$ & $0.075^{* * *}$ & $0.213^{* * *}$ & $-0.288^{* * *}$ & $-0.198^{* * *}$ & 1.000 & & & \\
\hline North & $0.049^{* * *}$ & $0.090^{* * *}$ & $0.067^{* * *}$ & $0.191^{* * *}$ & $-0.226^{* * *}$ & $-0.155^{* * *}$ & $-0.194^{* * *}$ & 1.000 & & \\
\hline East & $-0.110^{* * *}$ & $-0.146^{* * *}$ & $-0.313^{* * *}$ & $-0.522^{* * *}$ & $-0.363^{* * *}$ & $-0.249^{* * *}$ & $-0.311^{* * *}$ & $-0.244^{* * *}$ & 1.000 & \\
\hline Survey Year (2013) & $0.045^{* * *}$ & $-0.054^{* * *}$ & $-0.019^{*}$ & -0.004 & -0.001 & 0.006 & -0.004 & $0.042^{* * *}$ & $-0.032^{* * *}$ & 1.000 \\
\hline
\end{tabular}

Source: Demographic and Health Surveys, Turkey 2008 and 2013

${ }^{*} p<0.05,{ }^{* *} p<0.01,{ }^{* * *} p<0.001$ 